DISPLACEMENT-BASED SEISMIC REHABILITATION OF NON-DUCTILE RC FRAMES WITH ADDED SHEAR WALLS

A THESIS SUBMITTED TO

THE GRADUATE SCHOOL OF NATURAL AND APPLIED SCIENCES OF

THE MIDDLE EAST TECHNICAL UNIVERSITY

BY

CAN KARAGEYIKK

IN PARTIAL FULFILLMENT OF THE REQUIREMENTS FOR THE DEGREE OF MASTER OF SCIENCE

IN

THE DEPARTMENT OF CIVIL ENGINEERING

FEBRUARY 2010 


\section{DISPLACEMENT-BASED SEISMIC REHABILITATION OF NON-DUCTILE RC FRAMES WITH ADDED SHEAR WALLS}

Submitted by CAN KARAGEYIK in partial fulfillment of the requirements for the degree of Master of Science in Civil Engineering Department, Middle East Technical University by,

Prof. Dr. Canan Özgen

Dean, Graduate School of Natural and Applied Sciences

Prof. Dr. Güney Özcebe

Head of Department, Civil Engineering

Prof. Dr. Haluk Sucuoğlu

Supervisor, Civil Engineering Dept., METU

\section{Examining Committee Members:}

Assoc. Prof. Dr. Ahmet Yakut

Civil Engineering Dept., METU

Prof. Dr. Haluk Sucuoğlu

Civil Engineering Dept., METU

Assoc. Prof. Dr. Barış Binici

Civil Engineering Dept., METU

Asst.Prof. Dr. Murat Altuğ Erberik

Civil Engineering Dept., METU

M.S. Joseph Kubin

PROTA 
I hereby declare that all information in this document has been obtained and presented in accordance with academic rules and ethical conduct. I also declare that, as required by these rules and conduct, $I$ have fully cited and referenced all material and results that are not original to this work.

Name, Last name: Can KARAGEYIK

Signature: 


\author{
ABSTRACT \\ DISPLACEMENT-BASED SEISMIC REHABILITATION OF \\ NON-DUCTILE RC FRAMES WITH ADDED SHEAR WALLS \\ Karageyik, Can \\ M.S., Department of Civil Engineering \\ Supervisor: Prof. Dr. Haluk Sucuoğlu
}

February 2010, 126 pages

\begin{abstract}
Non-ductile reinforced concrete frame buildings constitute an important part of the vulnerable buildings in seismic regions of the world. Collapse of non-ductile multi story concrete buildings during strong earthquakes in the past resulted in severe casualties and economic losses. Their rehabilitation through retrofitting is a critical issue in reducing seismic risks worldwide.
\end{abstract}

A displacement-based retrofitting approach is presented in this study for seismic retrofitting of medium height non-ductile concrete frames. A minimum amount of shear walls are added for maintaining the deformation levels below the critical level dictated by the existing columns in the critical story, which is usually at the ground story. Detailing of shear walls are based on conforming to the reduced deformation demands of the retrofitted frame/wall system. Member-end rotations are employed as the response parameters for performance evaluation. Initial results obtained from the proposed displacement based approach have revealed that jacketing of columns and confining the end regions of added shear walls are usually unnecessary compared to the conventional force-based approach, where excessive force and deformation capacities are provided regardless of the actual deformation demands.

Keywords: displacement-based design, retrofit, shear walls, reinforced concrete frame 


\title{
ÖZ
}

\section{SÜNEK OLMAYAN BETONARME ÇERÇEVELERIN DEPREME KARŞI PERDE DUVARLARLA DEPLASMAN ESASLI GÜÇLENDIRILIMESI}

\author{
Karageyik, Can \\ Yüksek Lisans, İnşaat Mühendisliği Bölümü \\ Tez Yöneticisi: Prof. Dr. Haluk Sucuoğlu
}

Şubat 2010, 126 sayfa

Dünyanın depremselliği yüksek bölgelerindeki depreme karşı riskli yapıların önemli bir kısmını sünek olmayan betonarme çerçeveli binalar oluşturmaktadır. Sünek olmayan çok katlı betonarme binaların geçmişteki depremlerde yıkılması ağır can ve mal kayıplarına yol açmıştır. Bu tür yapıların depreme karşı güçlendirilmesi deprem riskini azaltmak bakımından tüm dünya için önemli bir meseledir.

$\mathrm{Bu}$ çalışmada, orta yükseklikteki betonarme çerçevelerden oluşan binaların güçlendirilmesine deplasman esaslı bir yaklaşım sunulmuştur. En az miktarda eklenen perde duvarlar şekil değiştirme seviyelerini genellikle kritik olan zemin kattaki mevcut kolonların dikte ettiği seviyeye indirmek için mevcut sisteme eklenir. Perde duvarların donatılandırılması duvar-çerçeve sisteminin azaltılmış şekil değiştirme istemlerini esas alır. Eleman uçlarındaki dönmeler ise performans değerelendirilmesinde kullanılır. Önerilen deplasman esaslı yöntem ile şekil değiştirme istemlerini gözardı ederek aşırı yük taşıma ve şekil değiştirme kapasitelerinin sağlandığı geleneksel kuvvet esaslı yöntemlerin karşılaştırılması, mevcut kolonların betonarme mantolarla sarılmasının ve güçlendirme perdelerinde sarılmış uç bölgesi oluşturulmasının genellikle gereksiz olduğunu göstermiştir.

Anahtar kelimeler: deplasman esaslı tasarım, güçlendirme, perde duvar, betonarme çerçeve 
To my family 


\section{ACKNOWLEDGEMENTS}

I wish to express my sincere appreciation to my supervisor Prof. Dr. Haluk Sucuoğlu for his support, guidance and insights throughout the study.

Mr. Ali Şengöz and Dr. Selim Günay are highly acknowledged for their priceless support and guidance in the thesis study.

I would like to thank my friends Mr. Efe Gökçe Kurt, Mr. Emre Özkök, and Mr. Mehmet Emrah Eryaşar for their sincere friendship and communion.

My family deserves my deepest gratitude for their complimentary devotion, endless love and intimate concern. 


\section{TABLE OF CONTENTS}

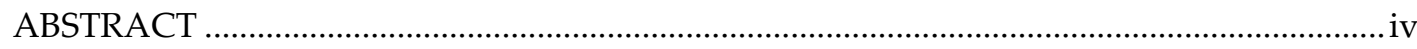

ÖZ

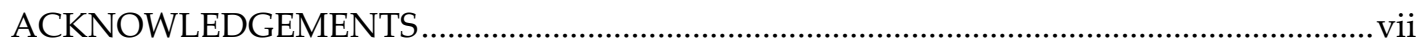

TABLE OF CONTENTS …….....................................................................................................

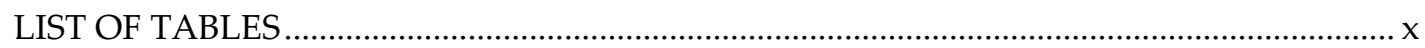

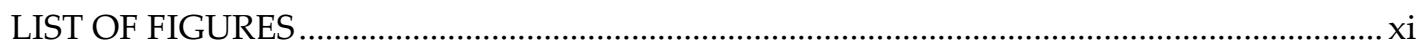

CHAPTER

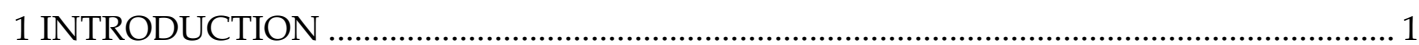

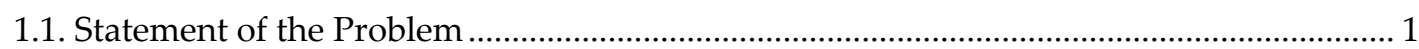

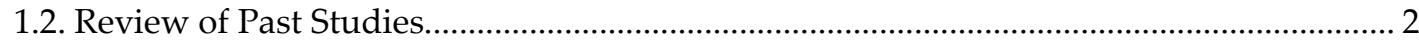

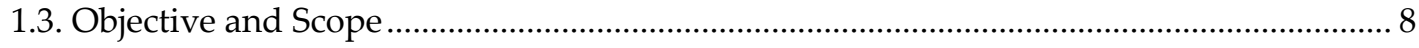

2 A DISPLACEMENT-BASED RETROFIT DESIGN METHODOLOGY FOR SEISMIC

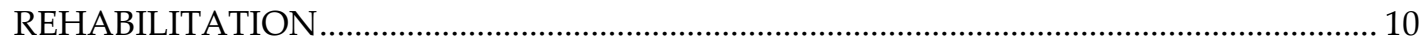

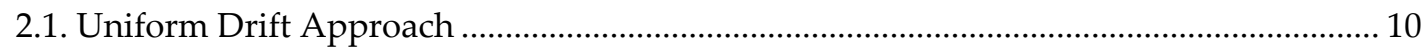

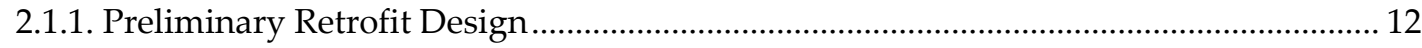

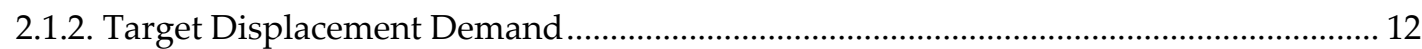

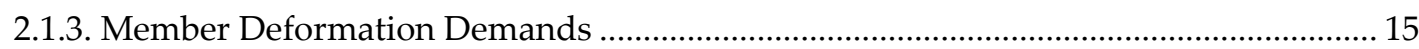

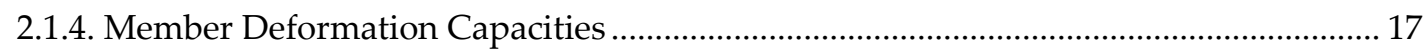

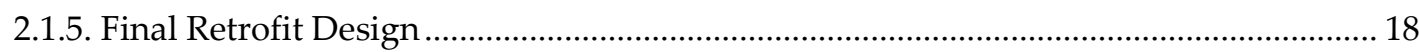

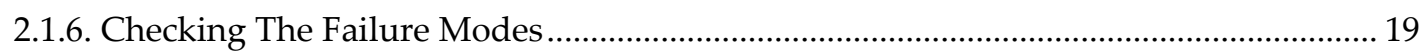

2.2. Implementation of the Proposed Methodology on an Example Frame............................. 19

2.2.1. Displacement-Based Retrofitting of The Existing Frame................................................... 23

3 VERIFICATION OF THE DISPLACEMENT-BASED RETROFIT DESIGN

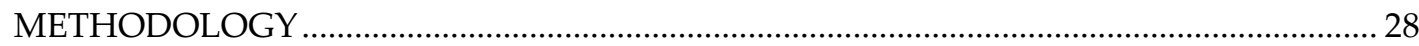

3.1. Verification of Retrofit Design and Uniform Drift Approach.............................................. 29

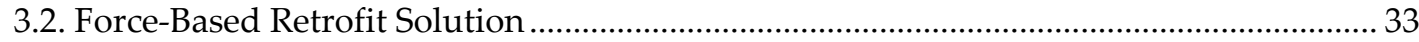

3.3. Comparison of Force-Based and Displacement-Based Retrofit Solutions.......................... 36 


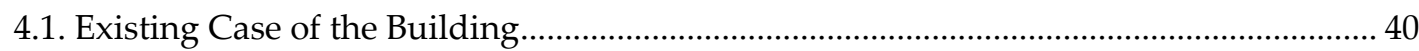

4.2. Implementation of the Retrofit Design Methodology The Verification of Design........... 50

4.3. Verification of the Proposed Retrofit Design Methodology ………………......................... 59

4.4. Force-Based Rehabilitation of the Building ……................................................................ 72

4.5. Comparison of Displacement-Based and Force-Based Retrofit Solutions.......................... 73

5 CASE STUDY II - SEISMIC REHABILITATION OF A FOUR STORY DORMITORY

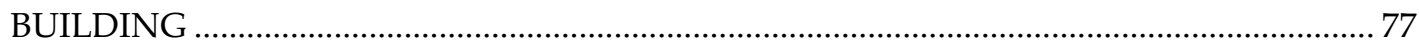

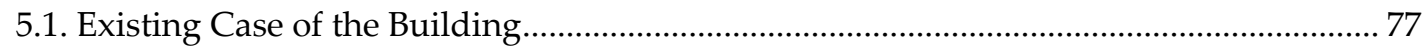

5.2. Implementation of the Retrofit Design Methodology …………………………………..... 87

5.3. Verification of the Proposed Retrofit Design Methodology ………………………............. 96

5.4. Force-Based Rehabilitation of The Building .............................................................. 110

5.5. Comparison of Displacement-Based and Force-Based Retrofit Solutions........................ 111

6 DISCUSSION OF RESULTS AND CONCLUSIONS................................................................. 115

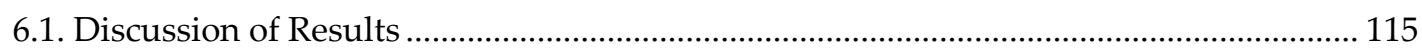

6.1.1. Uniform Drift Analysis vs. Pushover Analysis............................................................. 115

6.1.2. Displacement-Based Retrofit Solutions vs. Force-Based Retrofit Solutions ................. 117

6.1.3. Modeling of the Shear Walls as Fixed-Base and Flexible-Base ...................................... 120

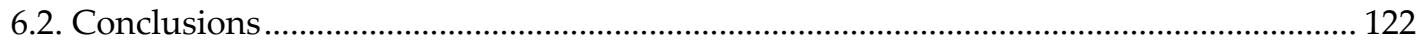

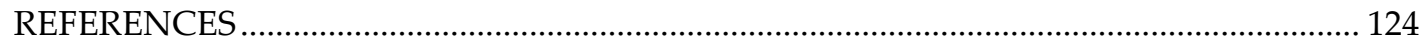




\section{LIST OF TABLES}

\section{TABLES}

Table 2.1 Material strain limits for unconfined member sections used in chord rotation

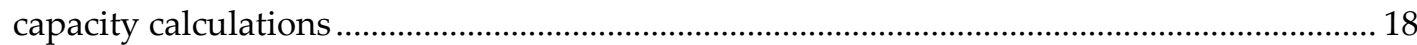

Table 3.1 Global seismic performances of existing and retrofitted cases of the frame ........... 31

Table 3.2 Global seismic performances of the retrofitted frame ................................................. 34

Table 4.1 Global performance of the existing building .............................................................. 50

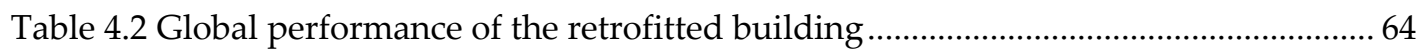

Table 5. 1 Global performance of the existing building ............................................................ 87

Table 5.2 Global performance of the retrofitted building .......................................................... 100

Table 6.1 Comparison of reinforcement ratios according to displacement and force-based

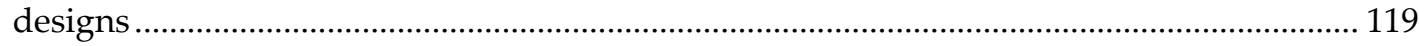

Table 6.2 Comparison of moment capacities of the walls designed according to displacement-based and force-based approaches 


\section{LIST OF FIGURES}

\section{FIGURES}

Figure 2.1 Acceleration displacement response spectrum representation 14

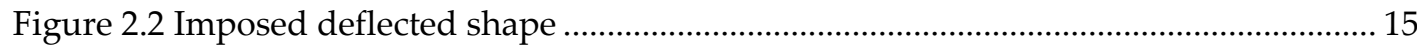

Figure 2.3 Calculation of chord rotations from joint displacements for linear elastic structural members 16

Figure 2.4 Plan view of the example building................................................................... 20

Figure 2.5 2D frame model of the example building ....................................................... 20

Figure 2.6 Section details of a typical column and beam .................................................. 21

Figure 2.7 Damage levels of the columns .......................................................................... 22

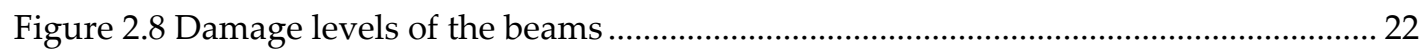

Figure 2.9 Plan view of the retrofitted case of the example building................................. 23

Figure 2.10 2D frame model of the retrofitted case of the example building........................ 23

Figure 2.11 Reinforcement detailing of the retrofit shear wall ........................................... 25

Figure 2.12 Moment-Curvature curve of the retrofit shear wall given in Figure 2.11.......... 25

Figure 2.13 Strain distirbution of composite shear wall section ......................................... 26

Figure 2.14 Chord rotation demands vs. chord rotation capacities of columns ................... 26

Figure 3.1 Capacity curves of the existing and displacement-based retrofitted frames....... 29

Figure 3.2 Plastic hinge distributions along the existing and retrofitted buildings at the

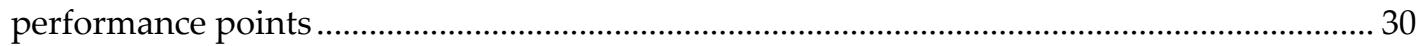

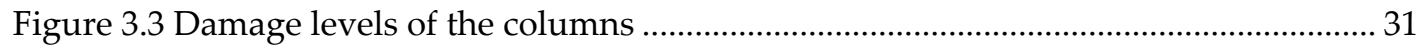

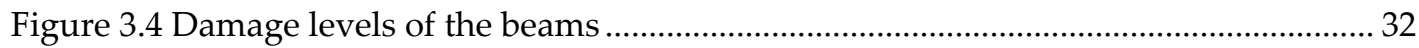

Figure 3.5 a. Displacement, b. interstory drift distributions of the existing and retrofitted frames predicted with uniform drift and pushover analyses ............................................. 32

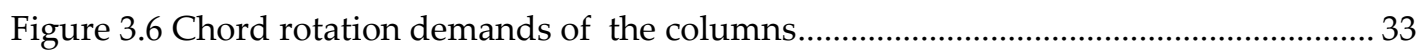

Figure 3.7 Design and code spectra for an earthquake having $2 \%$ probability of exceedance in 50 years. 
Figure 3.8 Moment envelope used in shear wall design. .36

Figure 3.9 Shear wall detailing according to displacement-based and force-based retrofit designs 37

Figure 3.10 Axial force-moment interaction diagrams according to displacement-based and force-based retrofit designs. 38

Figure 3.11 Moment-curvature diagrams of force-based and displacement-based design solutions or the shear wall P1. 38

Figure 3.12 Capacity curves of force-based and displacement-based retrofitted frames...... 39

Figure 4.13D Mathematical model of the four story existing school building . .41

Figure 4.2 Plan view of the four story existing school building 41

Figure 4.3 Capacity curves of the existing building 42

Figure 4.4 Damage levels of the columns in the $\mathrm{X}$ direction loading. 43

Figure 4.5 Damage levels of the beams in the X direction loading ........................................ 45

Figure 4.6 Damage levels of the columns in the $\mathrm{Y}$ direction loading........................................ 46

Figure 4.7 Damage levels of the beams in the $\mathrm{Y}$ direction loading .......................................... 48

Figure 4.8 3D Mathematical model of the retrofitted four story school building .................... 50

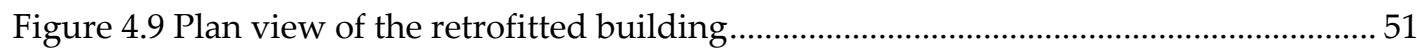

Figure 4.10 i. Story displacements, ii. Interstory drift distributions in X direction.................. 52

Figure 4.11 i. Story displacements, ii. Interstory drift distributions in Y direction.................. 52

Figure 4.12 Comparison of chord rotation demands and capacities for columns in the $\mathrm{X}$

direction for significant damage performance level................................................................... 53

Figure 4.13 Comparison of chord rotation demands and capacities for columns in the $Y$

direction for significant damage performance level.................................................................... 55

Figure 4.14 Moment curvature analysis of shear wall TP01..................................................... 58

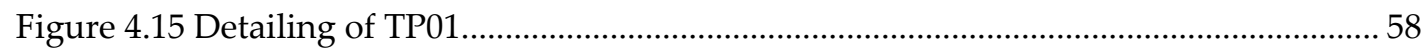

Figure 4.16 Moment curvature analysis of shear wall TP05..................................................... 58

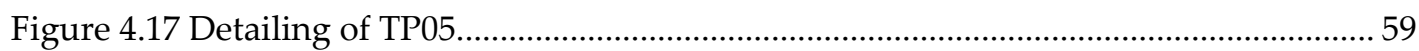

Figure 4.18 Capacity curves of the retrofitted and existing buildings ..................................... 59

Figure 4.19 i. Story displacements, ii. Interstory drift distributions in X direction..................60

Figure 4.20 i. Story displacements, ii. Interstory drift distributions in Y direction.................. 60

Figure 4.21 Chord rotation demands of the columns in the $\mathrm{X}$ direction loading .................... 61 
Figure 4.22 Chord rotation demands of the columns in the $\mathrm{Y}$ direction loading..... 62

Figure 4.23 Damage levels of the columns in the $X$ direction loading................................. 64

Figure 4.24 Damage levels of the beams in the $\mathrm{X}$ direction loading .................................... 66

Figure 4.25 Damage levels of the shear walls in the $\mathrm{X}$ direction loading............................. 68

Figure 4.26 Damage levels of the columns in the Y direction ............................................ 69

Figure 4.27 Damage levels of the beams in the Y direction .................................................. 69

Figure 4.28 Damage levels of the shear walls in the $Y$ direction loading ............................ 71

Figure 4.29 Plan view of the force-based retrofitted building ............................................ 72

Figure 4.30 Detailing of the shear wall TP01 according to the displacement-based and forcebased designs 74

Figure 4.31 P-M Interaction diagrams of the shear wall TP01 according to the displacementbased and forced-based designs 74

Figure 4.32 Detailing of the shear wall TP05 according to the displacement-based and forcebased designs 75

Figure 4.33 P-M Interaction diagrams of the shear wall TP05 according to the displacementbased and forced-based designs 75

Figure 4.34 Capacity curves of the retrofitted building according to displacement-based and

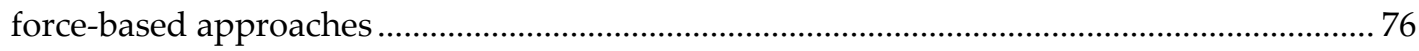

Figure 5.1 3D Mathematical model of the four story existing dormitory building............... 78

Figure 5.2 Plan view of the four story existing dormitory building .................................. 78

Figure 5.3 Capacity curves of the existing building .......................................................... 79

Figure 5.4 Damage levels of the columns in the $\mathrm{X}$ direction loading................................... 80

Figure 5.5 Damage levels of the beams in the $\mathrm{X}$ direction loading ...................................... 82

Figure 5.6 Damage levels of the columns in the $\mathrm{Y}$ direction loading................................... 83

Figure 5.7 Damage levels of the beams in the $\mathrm{Y}$ direction loading ....................................... 85

Figure 5.8 3D Mathematical model of the four story retrofitted dormitory building............ 87

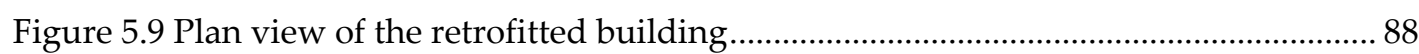

Figure 5.10 i. Story displacements, ii. Interstory drift distributions in X direction............... 89

Figure 5.11 i. Story displacements, ii. Interstory drift distributions in Y direction............... 89

Figure 5.12 Comparison of chord rotation demands and capacities for columns in the $\mathrm{X}$ direction for significant damage performance level. 
Figure 5.13 Comparison of chord rotation demands and capacities for columns in the $Y$ direction for significant damage performance level............................................................... 92

Figure 5.14 Moment curvature analysis of shear wall P4 ........................................................ 95

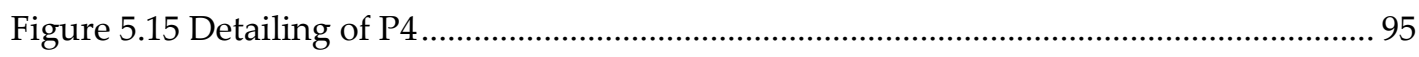

Figure 5.16 Moment curvature analysis of shear wall P1 ....................................................... 95

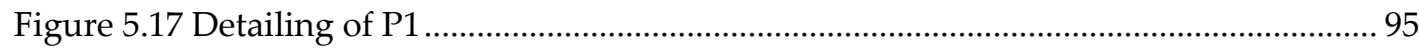

Figure 5.18 Capacity curves of the retrofitted and existing buildings .......................................96

Figure 5.19 i. Story displacements, ii. Interstory drift distributions in X direction.................97

Figure 5.20 i. Story displacements, ii. Interstory drift distributions in Y direction................. 97

Figure 5.21 Chord rotation demands of the columns in the $X$ direction loading ................... 97

Figure 5.22 Chord rotation demands of the columns in the $\mathrm{Y}$ direction loading ................... 99

Figure 5.23 Damage levels of the columns in the X direction loading................................... 101

Figure 5.24 Damage levels of the beams in the $\mathrm{X}$ direction loading ..................................... 103

Figure 5.25 Damage levels of the shear walls in the X direction loading ............................... 105

Figure 5.26 Damage levels of the columns in the $\mathrm{Y}$ direction loading ................................... 105

Figure 5.27 Damage levels of the beams in the Y direction loading ...................................... 107

Figure 5.28 Damage levels of the shear walls in the $Y$ direction loading .............................. 109

Figure 5.29 Plan view of the force-based retrofitted building ……....................................... 110

Figure 5.30 RC jacket detail of the column 1S17 ……............................................................ 111

Figure 5.31 Detailing of the shear wall P4 according to the displacement-based and force-

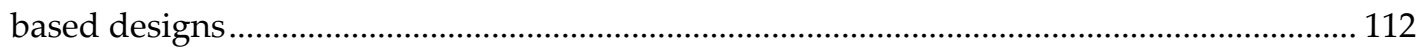

Figure 5.32 P-M Interaction diagrams of shear wall P4 according to displacement-based and forced-based designs

Figure 5.33 Detailing of the shear wall TP05 according to displacement-based and forcebased designs 113

Figure 5.34 P-M Interaction diagrams of the shear wall P1 according to displacement-based and forced-based designs.

Figure 5.35 Capacity curves of the retrofitted building according to displacement-based and force-based approaches

Figure 6.1 Chord rotation demands at the shear wall bases calculated from uniform drift and pushover analyses 116 
Figure 6.2 Footing under the new shear walls in plan...

Figure 6.3 Chord rotation demands calculated from the uniform drift and the pushover analyses for the retrofitted case of the example building with spring... 121

Figure 6.4 Chord rotation demands and capacities calculated from the uniform drift and the pushover analyses for the retrofitted case of the example building with spring..... 122 


\section{CHAPTER 1}

\section{INTRODUCTION}

\subsection{Statement of the Problem}

Non-ductile reinforced concrete frame buildings constitute an important part of the vulnerable buildings in seismic regions of the world. Sub-standard buildings cannot satisfy the basic safety requirements of modern seismic codes because of insufficient material strength, poor detailing and lack of seismic design which eventually lead to brittle response under seismic effects. Collapse of non-ductile multi story concrete buildings during strong earthquakes in the past resulted in severe casualties and economic losses.

The rehabilitation of non-ductile concrete buildings through retrofitting is a critical issue in reducing seismic risks worldwide. Retrofitting of these buildings in the past had been mostly based on adding new reinforced concrete shear walls. New walls improve base shear capacity of existing frame system as well as increasing lateral rigidity. Increase in both lateral load capacity and lateral stiffness results in decreasing the deformation demands. Transition from shear frame behavior into shear wall behavior is another feature that further reduces the demands on existing columns at the lower stories. This is indeed a rational approach because the alternative approach of increasing the deformation capacity of a non-ductile frame system composed of non-ductile structural members is usually unpractical and uneconomical. 
In the conventional force-based retrofitting of non-ductile RC frame buildings in severe seismic regions, a preliminary retrofit design is made first by adding shear walls to the existing frame structure. Then a response reduction factor is assumed for the entire retrofitted building based on the code recommendations, and internal member forces are calculated accordingly under the gravity and seismic design forces reduced by the response reduction factor. The capacity of the existing structural members are checked under these reduced forces, and increased if necessary by proper interventions. New members are designed for the capacities exceeding the internal force demands under reduced seismic forces. Finally, ductility requirements conforming to the employed response reduction factor are implicitly satisfied by providing special seismic detailing. This detailing primarily consists of confining the critical end regions of columns, beams, and shear walls, without considering however whether such deformation capacity is deemed necessary or not.

Utilization of displacement-based seismic design principles is the alternative approach for retrofit design. This approach basically relies on estimation of peak inelastic deformation demands on existing components.

\subsection{Review of Past Studies}

Fundamentals of the displacement based seismic design date back to 1960's with notable studies of Veletsos and Newmark (1960) and Muto, et al. (1960). Although any design recommendation was not stated in these studies, adequacy of structures was examined in terms of displacements and displacement ductility with the help of equal displacement principle. Moehle (1992) compared ductility-based and displacement-based approaches to present a general methodology for displacement based design. In his study it was stated that displacement-based approach is a more effective design tool since it employs displacement or deformation information directly. Furthermore in his study a relation between drift ratio and shear wall detailing was established. It was suggested that if shearwalls are sufficient to limit the drift ratio to a certain value, confined regions at the wall boundaries may be unnecessary. 
Wallace and Thomsen (1995) published a two-part study in which a new code format for seismic design of reinforced concrete structural walls and its applications were presented. A displacement-based approach was developed in order to determine the transverse reinforcement amount at the boundaries of shear walls having rectangular, T-shaped and L-shaped cross sections. Amount of transverse reinforcement required was determined by computing a strain distribution normal to the wall section in which maximum compressive strain at extreme concrete fiber (Wallace, 1994) was estimated. It was concluded that no special transverse reinforcement is required at wall boundaries if the maximum compressive strain at the outermost concrete fiber is less than 0.004. Through the application part of the study, design calculations were accomplished for two different ten story shear wall buildings.

Priestley (1997) studied a displacement-based seismic assessment procedure which employed effective stiffness and effective viscous damping of existing reinforced concrete structures. In his study, flexural capacities of plastic hinges, which are likely to form at member ends, were calculated. In determining flexural capacities, strain-based limit states were suggested.

In addition to displacement-based design and assessment of reinforced concrete structures, effects of shear walls installed to the existing systems were investigated. Kongoli, Minami, and Sakai (1999) examined the effect of structural walls on the elastic-plastic response of frame-wall buildings. Base shear coefficients of frames and walls were introduced together with response ductility factors to express structural damage. Base shear coefficients were defined as the ratio of yield strength to the weight of building. Effects of the number of walls on the elastic-plastic response of frame-wall buildings were additionally stated. It was concluded that as the number of walls increases in a system in which base shear coefficients of frames are relatively small and walls fail in shear, frame may undergo a large plastic deformation. In addition, empirical formulas were suggested to estimate the required base shear coefficients of frames and walls to satisfy predefined displacement responses. 
Panagiotakos and Fardis (1999) attempted to estimate inelastic chord rotation demands from elastic analysis procedures namely equivalent static or multi modal response spectrum analysis in which reinforced concrete members were considered with their secant stiffnesses. Mean and 95 percent characteristic values of chord rotations were calculated from both linear and nonlinear analyses to be compared. It was concluded that conversion factors around one could be introduced for closer estimations of nonlinear chord rotations. Theory of the study lies beneath well known equal-displacement rule and the assumption of fundamental period of cracked elastic mid rise reinforced concrete buildings falling beyond the corner period of response spectrum. Panagiotakos and Fardis (1999) published a further study on the deformation controlled earthquake resistant design of reinforced concrete buildings based on the findings of their former research. Aiming life safety performance, a four story reinforced concrete building was designed to meet peak inelastic member deformation demands which were estimated through elastic procedures. Inelastic deformation demands were defined as chord rotations. Besides, the demand expressions were proposed for chord rotation capacities. Results of monotonic and cyclic tests were employed to introduce these expressions. In design, $5 \%$ characteristic values of expressions were preferred. It was finally stated that employing a displacement design procedure results in economic solutions in terms of significant savings in reinforcement.

Kowalsky (2001) examined force-based seismic provisions of the 1997 UBC from performance based earthquake engineering point of view. His study mainly focused on structural wall design. It was noted that UBC introduces strain and drift based deformation limits in structural wall design. To investigate the force-based design methods of UBC, a number of mid rise reinforced concrete buildings were designed following UBC provisions and analyzed. It was concluded through the analyses that strength and stiffness are dependent on each other, and required base shear capacity for displacement-based design increases as the stiffness decreases. Moreover significance of well predicted peak inelastic deformation demands was emphasized in order to use strain limits as damage limit states.

Seismic response of structural walls defined with bilinear force-displacement relationships was studied by Paulay (2001). In this sense analytical expressions for stiffness and yield 
displacement profile of wall components were established. As an essential aspect of displacement-based seismic design, significance of the reliable estimation of ultimate inelastic deformation demands was emphasized. Ductility capacities both at the component and system levels were examined from the perspective of limiting strains and displacements. It was concluded that displacement ductility demands can be related with displacement ductility capacities with the help of yield displacements of critical components.

A methodology for direct displacement-based design of frame-wall structures was proposed by Sullivan, Priestley, and Calvi (2006). The methodology starts with computation of design displacement profile. In this sense equivalent single degree of freedom system properties were determined to obtain wall inflection height. Then, the substitute structure approach (Gulkan and Sozen, 1974; Shibata and Sozen, 1976) was used to obtain effective period and stiffness. Equivalent viscous damping was determined as another substitute structure characteristic in order to reach design ductility values. It was emphasized that high curvature ductility demands are likely to develop at the joining ends of link beams to shearwalls. Design displacement profile was then computed by making use of equivalent single degree of freedom system properties, wall inflection height and yield deformation capacities of walls and frames. Final step was stated as to compute design base shear and member strength demands.

Tjhin, Aschheim, and Wallace (2006) presented a paper in which a step-by-step performance-based seismic design procedure was proposed. Proposed procedure for ductile reinforced concrete structural wall buildings relies on estimation of the yield displacement through Yield Point Spectra (YPS). YPS was used either for estimation of peak displacement demand of an equivalent single degree of freedom system having a known yield point and ductility demand, or determination of the yield strength required to meet performance objectives. YPS can be constructed for code spectrum representing different performance limits or for particular ground motion records. In this study a design example was also presented, in which a six story reinforced concrete building was designed by employing the proposed method. 
Another study making use of YPS was conducted by Thermou, Pantazopoulou, and Elnashai (2006). This study utilizes YPS together with direct displacement-based design approach for seismic rehabilitation of existing reinforced concrete buildings. Seismic behavior of existing buildings was manipulated in order to have uniform distribution of interstory drift. Proposed methodology was explained in steps. Throughout these steps most remarkable ones can be summarized as the selection of a target response shape and ductility level together with determination of stiffness demand through YPS. To achieve the selected target response shape, computed stiffness demand was distributed along the height of the building. Rehabilitation scenario was then determined in compliance with target response shape and stiffness demand. As verification of the procedure a full scale tested structure was used.

Additionally, seismic design and rehabilitation guidelines are reviewed herein from the perspective of performance-based seismic design. In ATC-40 Seismic Evaluation and Retrofit of Concrete Buildings (1996), determination of inelastic seismic demands being a crucial step of performance-based seismic design was suggested to be calculated through a method known as The Capacity Spectrum method which was originally developed by Freeman et al., (1975). Following The Capacity Spectrum method, displacement demand of the structure is estimated by comparing capacity curve with a demand curve. Capacity curve is basically force-displacement relationship of the structure obtained by conducting a nonlinear static analysis. On the other hand the demand curve is computed by reducing the elastic spectrum in view of the expected hysteretic nonlinear behavior.

An alternative approach known as The Coefficient Method for determination of inelastic seismic demands is presented in FEMA 356 Prestandard and Commentary for the Seismic Rehabilitation of Buildings (2000). The Coefficient Method simply employs coefficients in order to convert maximum elastic displacement demand of an equivalent single degree of freedom system representing a multi degree of freedom system into the maximum inelastic displacement demand. Coefficients simply stand for modal participation, nonlinearity, hysteretic behavior, and P- $\Delta$ effects. FEMA 356 additionally covers linear and nonlinear procedures for rehabilitation of existing reinforced concrete structures. Under the scope of 
nonlinear procedures, performance levels of members are determined in terms of plastic rotations which are assumed to be lumped at member ends.

Limit states representing damage levels are presented for ductile and brittle members also in terms of plastic rotation.

Through the coverage of Eurocode 8 Part 3 Assessment and Retrofitting of Buildings (2005), linear and nonlinear procedures are presented to carry out seismic performance assessment of existing reinforced concrete buildings. In these guidelines nonlinear procedures employ chord rotation as measure of damage in order to determine performances of ductile members. Expressions are proposed to determine ultimate chord rotation capacities. Moreover limit states corresponding to performance levels are defined in terms of ultimate chord rotations and chord rotations at yielding. Chord rotation demands are compared with chord rotation capacities calculated in accordance with damage states.

The recently added Chapter 7 of the Turkish Earthquake Code (2007) involves seismic performance assessment and intervention methods for existing reinforced concrete buildings. Similar to the abovementioned guidelines, Turkish Earthquake Code suggests linear and nonlinear methods. Following nonlinear methods, inelastic displacement demand of a multi degree of freedom system is computed by modifying the elastic displacement demand of equivalent single degree of freedom system through an iterative graphical procedure. Nonlinear procedures define performance limits of ductile members in terms of strains. Predefined strain limits corresponding to damage states are compared with the strain demands of yielded sections of ductile members. Strain limits depend on presence of transverse reinforcement which provides confinement action at critical sections of members.

Calvi and Sullivan (2009), as editors, developed a Model Code for the Displacement-Based Seismic Design of Structures. The essence of the draft code relies on the book on direct displacement-based design by Priestley et al. (2007). Additionally Eurocode 8 serves as a reference provision. The Code covers particular types of structures and buildings including moment resisting frame buildings, reinforced concrete wall buildings, and reinforced 
concrete dual frame-wall buildings. Through the coverage of the Model Code two types of seismic zones are considered together with three levels of design performance. Maximum and residual drifts and maximum strains that occur at a performance level are expressed as performance criteria. To compute maximum inelastic deformation demands design displacement profiles are proposed for various types of buildings which are vertically regular. Together with the design displacement profile and other characteristics belonging to the equivalent single degree of freedom structure (i.e. the substitute structure) are defined in order to determine required base shear force. The design base shear force is simply calculated by multiplying the effective stiffness by the design displacement. Floor masses and design displacements are used to distribute the base shear force along the building. The Model Code finalizes the displacement-based design as satisfying the capacity design requirements to avoid unintended inelastic mechanisms.

\subsection{Objective and Scope}

As an alternative approach to force-based retrofit design, a simple displacement-based procedure is proposed for medium rise concrete buildings. The proposed displacementbased and the conventional force-based retrofit designs are applied on a hypothetical five story building, a four story school building, and a four story dormitory building. Retrofit design solutions are comparatively evaluated for each building.

Member deformation demands were expressed in terms of chord rotations in this study which are determined from an elastic analysis in which uniform drift distribution is assumed along the building height. Different retrofit schemes can be achieved from displacement-based and force-based approaches. Comparison of achieved retrofit schemes was presented for each case study building. The objective is studying the simplicity of displacement-based seismic design principles in the rehabilitation of existing buildings aiming to satisfy seismic performance level objectives together with investigating deficiencies of force-based approaches which usually offer less economical results due to courage in formation of confined boundaries at shear wall ends and employment of reduced elastic forces in design. 
This thesis is composed of six main chapters. Brief contents are given as follows:

Chapter 1 Statement of the problem and literature survey on the displacement-based seismic design and rehabilitation of reinforced concrete buildings together with seismic response of shear wall buildings. Objectives and scope.

Chapter 2 Explanation and implementation of the proposed procedure in detail on a hypothetical five story reinforced concrete building.

Chapter 2 Verification of the methodology

Chapter $4 \quad$ Case study I: Four story school building, nonlinear seismic assessment of the existing building, retrofit design with the proposed procedure as well as with the force-based procedure, comparison of retrofit solutions.

Chapter 5 Case study II: Four story dormitory building, nonlinear seismic assessment of the existing building, retrofit design with the proposed procedure and the force-based procedure, comparison of retrofit solutions.

Chapter 6 A brief summary and conclusions. 


\section{CHAPTER 2}

\section{A DISPLACEMENT-BASED RETROFIT DESIGN METHODOLOGY FOR SEISMIC REHABILITATION}

A simplified displacement-based procedure for retrofit design of medium rise reinforced concrete buildings is proposed in this chapter. The proposed methodology relies on estimating the nonlinear deformation demands of existing and new members through a linear elastic analysis in which a pre-assumed displacement response is imposed to retrofitted system. Basic steps and implementation of the methodology on an example building are presented throughout subsections of this chapter.

\subsection{Uniform Drift Approach}

Uniform Drift approach is a displacement-based methodology for retrofit design of medium rise RC buildings. Basic steps of the proposed methodology can be listed as

- preliminary retrofit design,

- computation of target displacement demand,

- member deformation demands, compared with capacities

- final retrofit design.

In the uniform drift approach, preliminary retrofit design only involves decision on the location and size of the shear walls to be added to the existing frame system. Target displacement demand is calculated by employing the coefficient method of FEMA-356 
(3.3.1.3.1) (ASCE, 2000) where an R factor is not directly required. Fundamental period is estimated by employing cracked section stiffnesses of reinforced concrete members.

Member deformation demands are expressed in terms of chord rotations at the member ends. Chord rotation demands are computed by imposing a uniform drift distribution compatible with the target displacement demand. They represent maximum nonlinear deformation demands.

Chord rotation capacities are calculated by employing moment-curvature analysis and moment area theorem. Axial load demands of columns are obtained from gravity analysis whereas shear span lengths are taken from linear elastic analysis under imposed uniform drift distribution. Strain limits stated in Chapter 7 of the Turkish Earthquake Code 2007 (TEC 2007) are used in chord rotation limit state calculations.

At the final retrofit design stage, reinforcement detailing of the new shear walls are finalized in order to satisfy deformation demands. Seismic detailing of confined regions may or may not be required.

To control failure modes of reinforce concrete members for preventing brittle failure, shear capacities are compared with the lesser of demands compatible with moment capacities and demands at performance point.

A displacement based approach is developed by employing a deformation controlled linear elastic analysis procedure to estimate the inelastic deformation demands in terms of chord rotations. The Uniform Drift approach relies on imposing a uniform drift distribution with an inverse triangular displaced shape to the retrofitted wall-frame system where roof displacement is equal to the target roof displacement demand computed for the desired performance level. A uniform drift distribution is a well fitting approximation to estimate the inelastic deformation behavior of mid-rise reinforced concrete wall-frame systems. Assuming the shear wall yields at its base, drift response of the wall-frame system converges to uniform drift distribution as the wall dominates the behavior as well. Cracked stiffnesses of reinforced concrete members are used in the proposed linear elastic analysis 
procedure. Details of retrofit design procedure utilizing the uniform drift approach are explained in detail in the following sub-sections.

\subsubsection{Preliminary Retrofit Design}

Preliminary retrofit design stage involves only locating and sizing the new shear walls to be installed. Since fundamental mode behavior is utilized to represent seismic response based on the assumption of medium rise concrete buildings symmetric in plan and having a mass participation ratio more than $70 \%$ in the fundamental mode are more likely to have fundamental mode shape dominant behavior, it is not only essential but also preferable to locate new shear walls not to disturb symmetry and regularity of the structure. On the other hand architectural considerations are taken into account not to disrupt serviceability of the building.

Size of shear walls gains importance as it affects global lateral stiffness of the retrofitted structure. Increase in stiffness results in decrease in displacement demand of mid-rise reinforced concrete buildings. Thus, size and number of shear walls to be added can be accounted as the control parameters of retrofit design. For preliminary design, chord rotation capacities at the bottom ends of columns are compared with chord rotation demand at the target performance objective calculated after addition of the shear walls which is indeed equal to the interstory drift ratio of the first story. Usually, the cross section area of shear walls in the earthquake direction should not exceed one percent of the total floor area in medium rise concrete buildings.

\subsubsection{Target Displacement Demand}

Preliminary design is followed by computation of the target displacement demand corresponding to the maximum expected displacement response for a desired performance level. Seismic performance levels are defined as follows; Immediate Occupancy (IO), Life Safety (LS) and Collapse Prevention (CP). Each performance level has its own acceptability criteria which are defined in the Turkish Earthquake Code, 2007. For example a school 
building should satisfy LS performance level for an earthquake having a return period of 2475 years that corresponds to the linear elastic design spectrum with a return period of 475 years factored by 1.5 .

Target displacement demand for a selected performance level is calculated by employing the coefficient method i.e. Equation 2.1. Coefficients to convert maximum elastic displacement demand to maximum inelastic demand are defined in FEMA 356 (ASCE, 2000) as stated below.

$$
\delta_{t}=C_{0} \cdot C_{1} \cdot C_{2} \cdot C_{3} \cdot S_{a} \cdot \frac{T_{e}^{2}}{4 \cdot \pi^{2}} \cdot g
$$

$\delta_{t} \quad$ : Target displacement demand computed at the roof level.

Co : The first modal participation factor computed at the roof level $\left(\phi_{1, \text { roof }} \cdot \Gamma_{1}\right)$

$C_{1} \quad$ : Modification factor to relate expected maximum inelastic displacements to displacements calculated for linear elastic response.

$C_{2} \quad$ : Modification factor to represent the effect of pinched hysteretic shape, stiffness degradation and strength deterioration on maximum displacement response.

$C_{3} \quad$ : Modification factor to represent increased displacements due to dynamic P- $\Delta$ effects.

$S_{a} \quad$ : Spectral acceleration, at the effective fundamental period and damping ratio of the building in the direction under consideration.

$T_{e} \quad$ : Effective fundamental period of the building in the direction under consideration, sec.

Ts : Characteristic period of the response spectrum, defined as the period associated with the transition from the constant acceleration region of the spectrum to the constant velocity region of the spectrum.

Effective period $T_{e}$ is taken as elastic fundamental period of the building computed through eigenvalue analysis using cracked stiffnesses of reinforced concrete members. Cracked section stiffnesses of reinforced concrete members can be calculated by employing paragraph 7.4.13 of the Turkish Earthquake Code, 2007. 
According to this paragraph effective flexural stiffnesses of beams are taken as $40 \%$ of uncracked flexural stiffnesses. In case of columns and shear walls, the relation given in Equation 2.2 is used where $N_{D}$ is axial load effect under gravity loading, i.e. dead and factored live loads, $A_{c}$ is the cross sectional area of column, and $f_{c m}$ is compressive strength of existing concrete.

If $\mathrm{ND}_{\mathrm{D}} /\left(\mathrm{Acfcm}_{\mathrm{c}}\right) \leq 0.10:(\mathrm{EI})_{\mathrm{e}}=0.40(\mathrm{EI})_{\text {o }}$

If $\mathrm{ND}_{\mathrm{D}} /\left(\mathrm{Acf}_{\mathrm{cm}}\right) \geq 0.40:(\mathrm{EI})_{\mathrm{e}}=0.80(\mathrm{EI})$ 。

Linear interpolation is permitted for the intermediate values of $N_{D} /\left(A_{c} f_{c m}\right)$.

Since capacity curve is not available in the uniform drift approach, coefficient $C_{1}$ given in Equation 2.1 is taken from paragraph 3.3.1.3.1 of FEMA 356 (ASCE, 2000) in which $R$ factor is not required. If the fundamental period of structure is longer than the corner period $T_{s}$ of the response spectrum, equal displacement rule is applicable and maximum elastic and inelastic displacement demands are equal to each other (Figure 2.1). If the fundamental period falls on constant acceleration plateau of the response spectrum, then $C_{1}$ is calculated through Equation 2.3 by linear interpolation between the values of 1 to 1.5 .

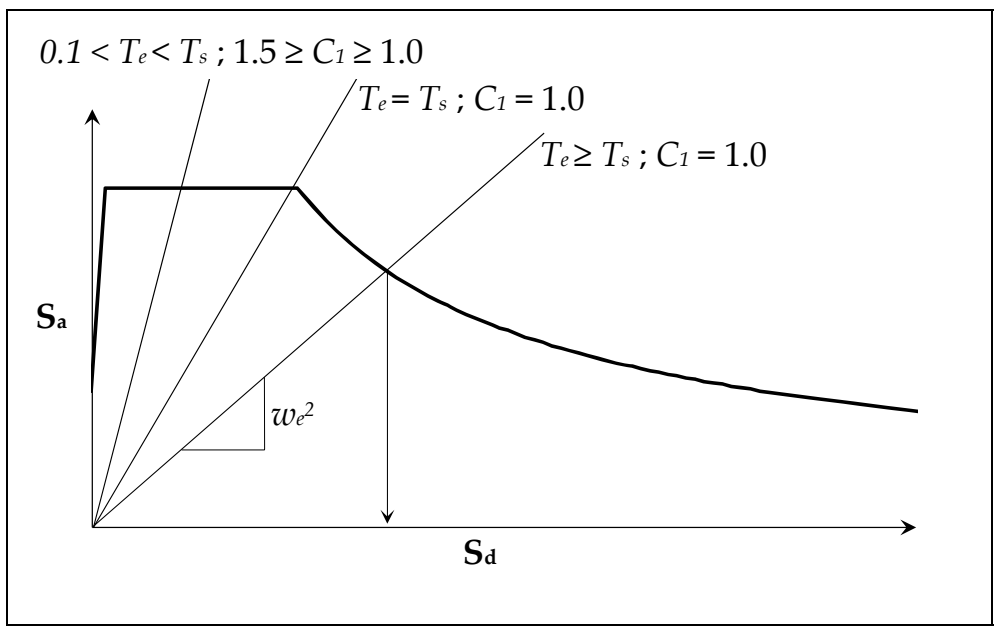

Figure 2.1 Acceleration displacement response spectrum representation 
$C_{1}=1.5$ for $T_{e}<0.10$ second

$C_{1}=1.0$ for $T_{e} \geq T_{S}$

After obtaining the maximum expected inelastic roof displacement demand of MDOF system, an assumed deformed shape pattern, which represents the displacement response of the wall-frame system when the roof reaches target displacement, is computed for the selected performance objective. Displacement demand of each story is calculated from Equation 2.4.

$\delta_{i}=\delta_{t} \cdot \frac{h_{i}}{h_{t}}$

Elastically imposed deflected shape which corresponds to uniform interstory drift distribution is illustrated in Figure 2.2.

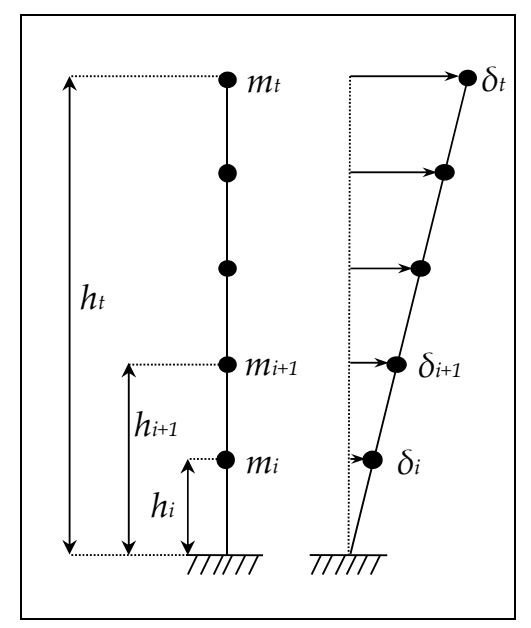

Figure 2.2 Imposed deflected shape

\subsubsection{Member Deformation Demands}

Member deformation demands are defined in terms of chord rotations at the member ends. In this sense, chord rotation demands are calculated at each end of columns by employing the proposed deformation-controlled linear elastic analysis by using cracked flexural stiffnesses of reinforced concrete members. Chord rotations are measured from the chord 
connecting the two ends of a member, to the tangent of deformed shape at the concerned member end. If chord rotation and joint rotation are in the same direction, joint rotation is subtracted from drift ratio. Calculation of chord rotation is given analytically in Equation 2.5;

where

$C R_{i} \quad$ : Chord rotation demand at $i$ end of the member.

$C R_{j} \quad$ : Chord rotation demand at $j$ end of the member.

$\Delta \quad$ : Sway displacement between two ends of the member at the deformed pattern.

lc : Clear length of the member.

$\theta_{i} \quad$ : Joint rotation demand at $i$ end of the member.

$\theta_{j} \quad: \quad$ Joint rotation demand at $j$ end of the member.

$C R_{i}=\frac{\Delta}{l_{c}} \pm \theta_{i}, C R_{j}=\frac{\Delta}{l_{c}} \pm \theta_{j}$

Chord rotations at the ends of linear elastic frame members are shown in Figure 2.3.

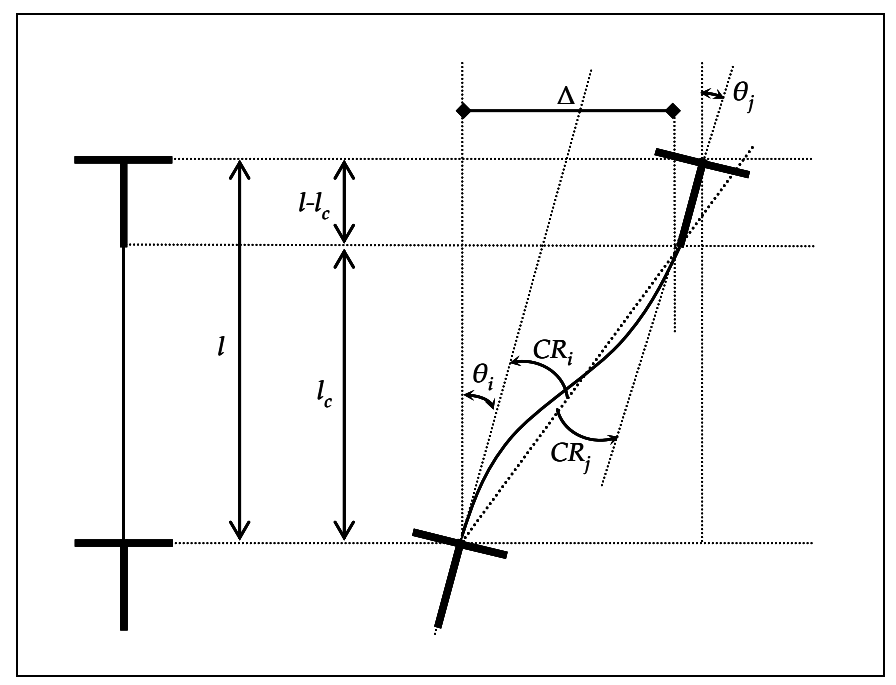

Figure 2.3 Calculation of chord rotations from joint displacements for linear elastic structural members 


\subsubsection{Member Deformation Capacities}

The chord rotation capacity of a structural member depends on the strain capacity of its extreme fibers and its deflection shape. The relationship between chord rotation capacity and limit state strains can be established through the curvature at the end section (Priestley et al, 2007):

$$
\begin{array}{lcc}
C R_{i, c a p}=\theta_{y i}+\theta_{p i} & \theta_{y i}=\phi_{y} \cdot \frac{l_{v}}{3} & \theta_{p i}=\left(\phi_{u}-\phi_{y}\right) \cdot L_{p} \\
C R_{j, c a p}=\theta_{y j}+\theta_{p j} & \theta_{y j}=\phi_{y} \cdot \frac{\left(l_{c}-l_{v}\right)}{3} & \theta_{p j}=\left(\phi_{u}-\phi_{y}\right) \cdot L_{p}
\end{array}
$$

In the above expressions (Equation 2.6), $\theta_{y}$ and $\theta_{p}$ are the yield rotation and plastic rotation capacities, and $\phi_{y}$ and $\phi_{u}$ are the yield curvature and ultimate curvature capacities at a member end, respectively. $L_{p}$ is the plastic hinge length, $l_{c}$ is the clear span length and $l_{v}$ is the shear span length for the associated member end. Plastic hinge length $L_{p}$ is taken as half of the section dimension parallel to the loading direction as stated in Chapter 7 of TEC 2007. $l_{v}$ for a column member in the inelastic state can be estimated from its end moments $M_{i}$ and $M_{j}$ obtained from linear elastic analysis through Equation 2.7.

$$
l_{v}=l_{c} \cdot\left(\frac{M_{i}}{M_{i}+M_{j}}\right)
$$

Finally, the relation between curvature capacity and strain capacity is determined from the moment-curvature analysis of the associated member-end section. Keeping effect of axial load level on ductility in mind, axial load level calculated under gravity loading i.e. dead and factored live loads is used in ultimate rotation capacity calculations. In case of earthquake loading axial load level on columns changes. Due to earthquake loading axial load levels on the exterior columns can increase or decrease. However, in the uniform drift approach the variation in axial load levels due to earthquake loading is neglected.

Another significant parameter on which chord rotation performance depends is strain performance limits defined in accordance with the desired performance objective and 
damage levels. Strain limits used in capacity calculations are taken from paragraph 7.6.9 of the Turkish Earthquake Code, 2007. In case of minimum damage, ultimate compressive strain at the outermost concrete fiber should not exceed 0.0035 whether any confinement reinforcement is present or not. If the rotation capacity corresponding to significant damage level is investigated, then the ultimate compressive strain at the level of stirrups enclosing the section should not exceed 0.0035 . However, this limit is modified with the amount of confinement reinforcement present in the section. The upper strain limit for significant damage level is 0.0135 . For severe damage level, ultimate compressive strain limit for unconfined sections is 0.004 . This limit is modified with the amount of confinement reinforcement present in the section as well. Ultimate strain limits for reinforcement steel are $0.01,0.04$, and 0.06 corresponding to minimum, significant, and severe damage levels, respectively. Strain limits for reinforced concrete materials with and without confinement are tabulated in Table 2.1 in accordance with the damage levels defined in the Turkish Earthquake Code (2007).

Table 2.1 Material strain limits for unconfined member sections used in chord rotation capacity calculations

\begin{tabular}{|c|c|c|}
\hline Damage Level & $\varepsilon_{\mathrm{c}}$ & $\varepsilon_{\mathrm{s}}$ \\
\hline \hline Minimum & 0.0035 (outermost fiber) & 0.01 \\
\hline Significant & $0.0035+0.01\left(\rho_{s} / \rho_{s m}\right) \leq 0.0135$ (stirrup level) & 0.04 \\
\hline Severe & $0.004+0.014\left(\rho_{s} / \rho_{s m}\right) \leq 0.018$ (stirrup level) & 0.06 \\
\hline
\end{tabular}

\subsubsection{Final Retrofit Design}

At the final retrofit design stage, chord rotation demands computed from uniform drift analysis are compared with the chord rotations corresponding to performance limit states for the existing columns. According to the obtained results, interventions to increase ductility, or strength and stiffness, or all may be applied to deficient existing columns. 
Chord rotation demands at the $i$ ends (lower end) of the first story columns and shear walls are equal to the interstory drift ratio since joint rotation is zero at the fixed base. Moreover for shear walls it is assumed that all plastic action occurs at the base which is the most likely case for medium rise reinforced concrete wall-frame systems. Thus, interstory drift ratio demand of the first story computed from the imposed uniform drift pattern is the design parameter for shear walls to be added to the existing system. Initial gravity loading on the columns forming boundary elements of the new shear walls is considered as well. If damage level objective is not satisfied with the existing unconfined column section, then boundary columns are confined by either FRP wrapping or reinforced concrete jacketing. Another option is to form confined boundaries at the inner edges of the shear wall ends by ignoring existing columns. However the consequences of this practical choice have to be examined well.

\subsubsection{Checking The Failure Modes}

To complete retrofit design, failure modes of structural members are determined in order to prevent brittle behavior. Capacity shears or internal shear force demands at the performance point can be compared with member shear strengths in order to determine failure modes. In capacity shear method, maximum shear force demand is calculated in compliance with end moment capacities. For example maximum shear force demand of a beam is developed when its both ends reach their moment capacities. If shear strength of a member is greater than lesser of calculated capacity shear force or shear demands calculated at the performance point, member is classified as ductile. Members determined as brittle, in other words members having shear dominated failure mode has to be retrofitted in order to prevent brittle behavior during seismic response.

\subsection{Implementation of the Proposed Methodology on an Example Frame}

A reinforced concrete structure comprised of five story fames was used to demonstrate the application of the proposed methodology. 2D modeling was employed and only $+X$ direction was considered in calculations. Plan view is shown in Figures 2.4 and 2.5 together 
with the equivalent 2D frame. The building was intentionally designed to represent poor quality and seismic deficiency of existing substandard buildings. Characteristic compressive strength of concrete was chosen as $12 \mathrm{MPa}$. Yield strength of longitudinal and transverse reinforcement steel was taken as $420 \mathrm{MPa}$ ignoring strain hardening.

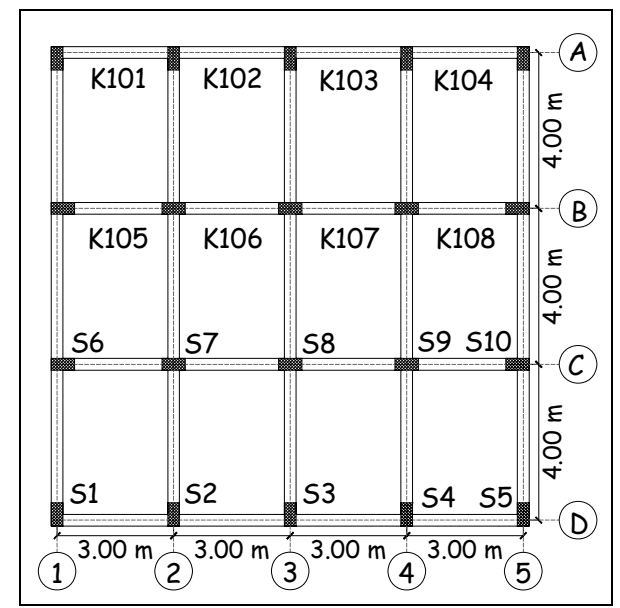

Figure 2.4 Plan view of the example building

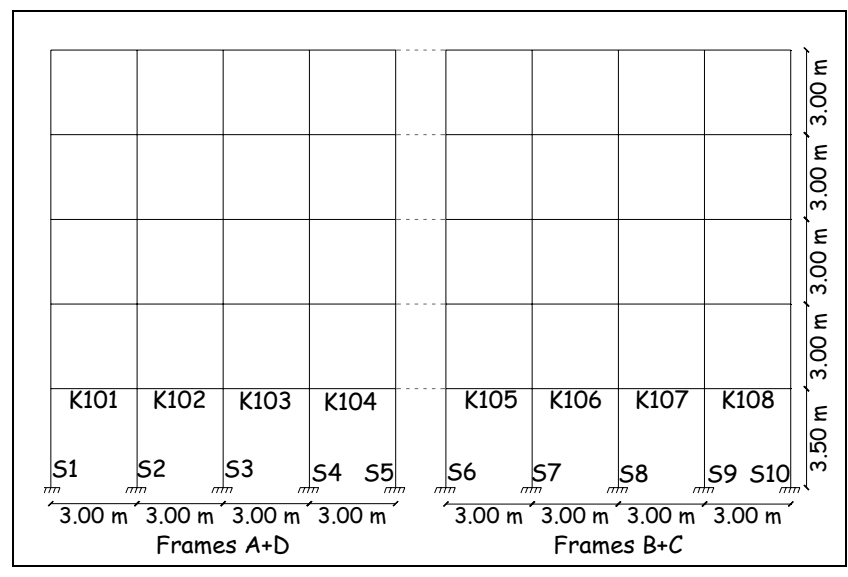

Figure 2.5 2D frame model of the example building

All columns were designed with cross section dimensions of $300 \times 600 \mathrm{~mm}$ having a longitudinal reinforcement ratio of $\rho_{s}$ equal to 0.009 . Additionally all beams were designed as $300 \times 500 \mathrm{~mm}$ having tension reinforcement ratio of $\rho_{s^{\prime}}$ equal to 0.007 and compression reinforcement of $\rho_{\text {s }}$ equal to 0.005 at the supports. No confined zones were formed at critical sections of members. $\Phi 10 / 200 \mathrm{~mm}$ stirrups with hook angle of $135^{\circ}$ were used as transverse 
reinforcement in all members and considered as confinement reinforcement. Thus $\rho_{s} / \rho_{s m}$ ratio was calculated as 0.17 which yields a strain limit at stirrup level corresponding to the significant damage limit state of 0.0052 . Detailing of columns and beams are illustrated in Figure 2.6.

Seismic performance of the existing building was evaluated through the inelastic procedure of the Turkish Earthquake Code 2007. Life Safety performance level for school buildings was selected as the performance objective. According to the specifications stated within the scope of Life Safety objective, a response spectrum represents an earthquake intensity which has $2 \%$ / 50 years probability of exceedance or a return period of 2475 years. A target roof displacement demand of $170 \mathrm{~mm}$ was calculated for the existing building under the $2 \%$ / 50 years earthquake response spectrum for Z2 soil type by employing the coefficient method.

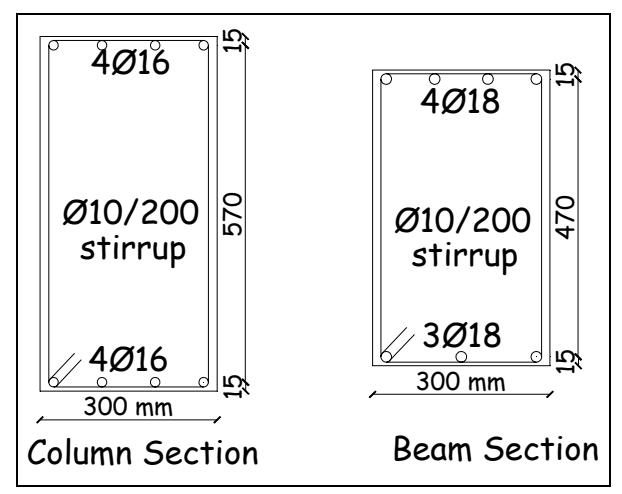

Figure 2.6 Section details of a typical column and beam

Seismic performance of columns and beams were evaluated separately by following the nonlinear assessment procedures of TEC'07 in the $+\mathrm{X}$ direction and summarized in Figures 2.7 and 2.8. All of the columns at the first story exceed severe damage limit state. In other words all story shear is carried by deficient columns. Moreover $37.5 \%$ of beams at the first story exceed significant damage limit state. At the second story $42 \%$ of the story shear is carried by columns exceeding significant damage limit. Columns of the upper three stories satisfy minimum damage limit state. 
According to the Turkish Earthquake Code 2007 not more than $20 \%$ of story shear shall be carried by columns exceeding significant damage limit at any story. Additionally deficient beams exceeding significant damage limit shall not be more than $30 \%$ of beams at any story. Thus it can be concluded that existing building does not satisfy Life Safety performance.

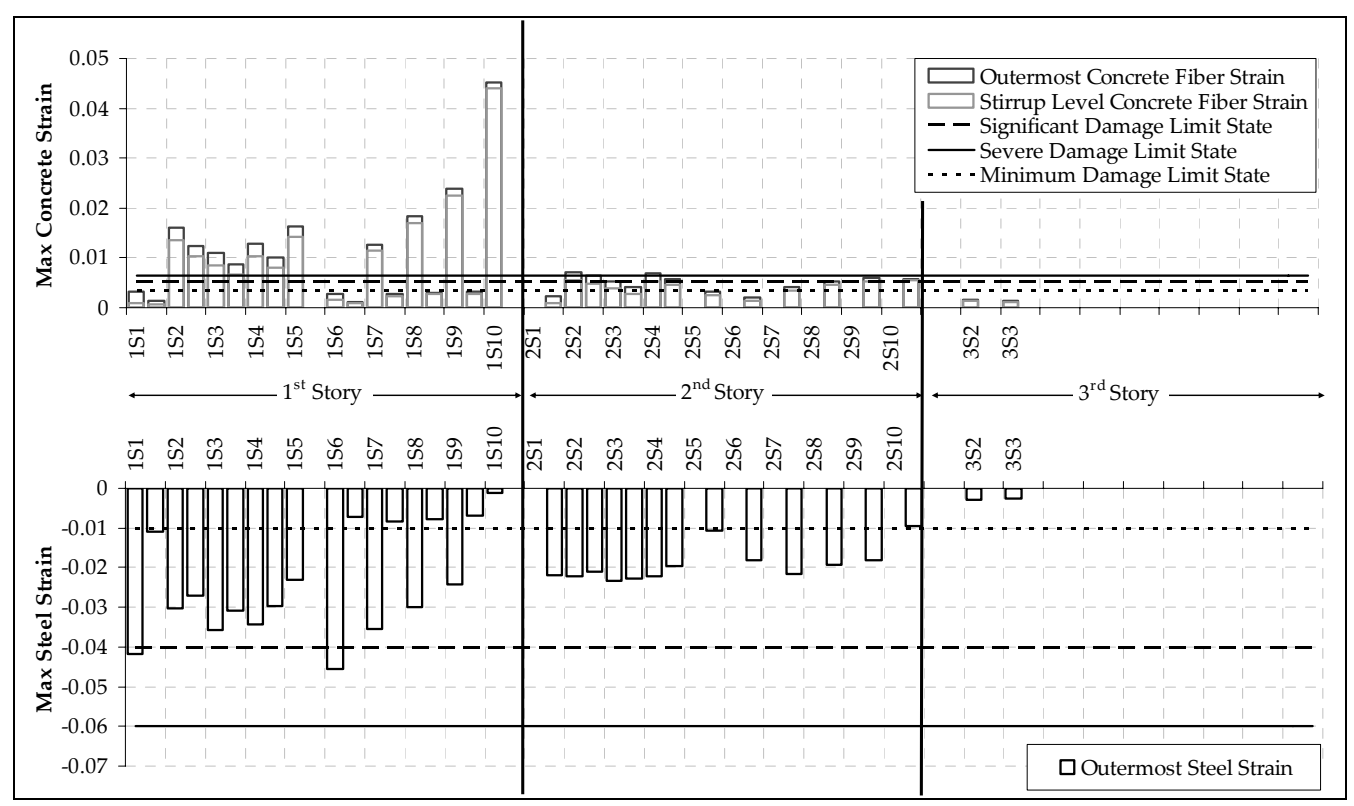

Figure 2.7 Damage levels of the columns

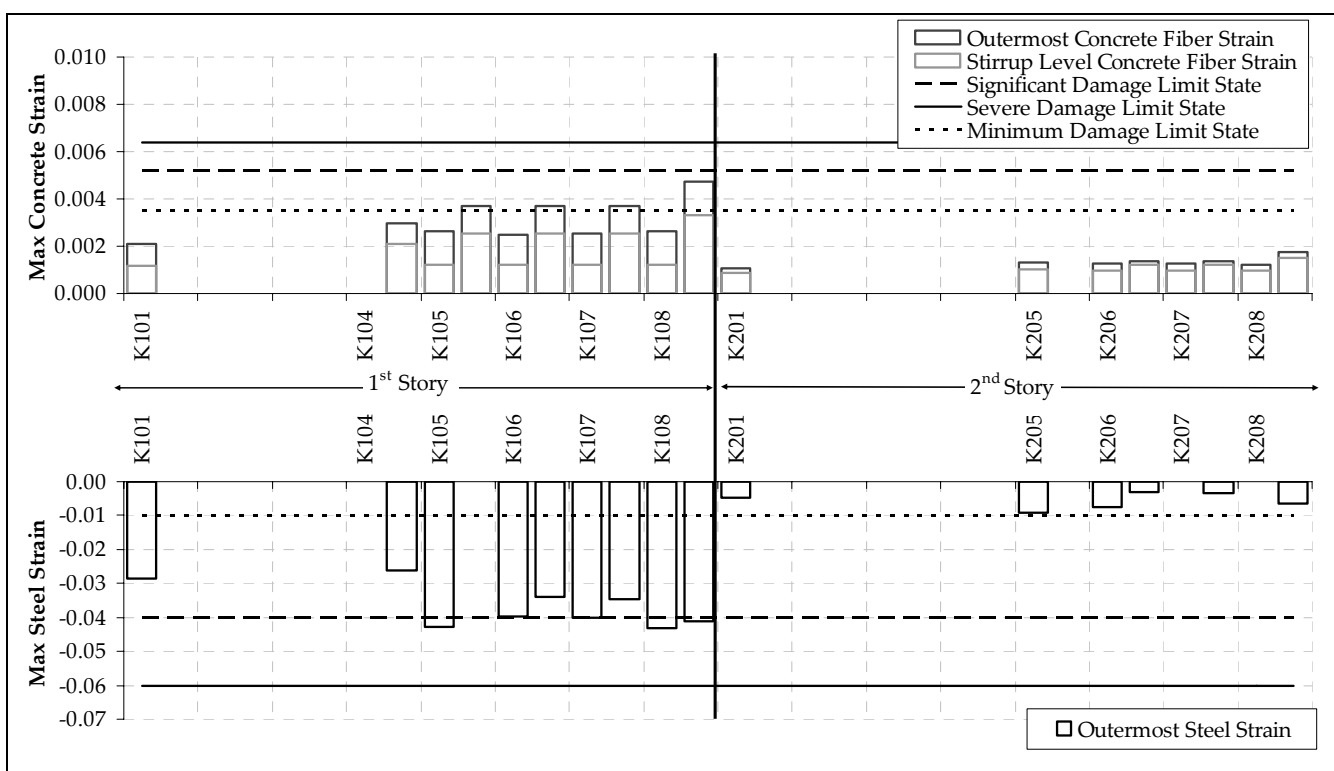

Figure 2.8 Damage levels of the beams 


\subsubsection{Displacement-Based Retrofitting of The Existing Frame}

Existing frame system was retrofitted by employing the uniform drift approach. Implementation of the procedure is explained in following paragraphs.

Two shear walls having dimensions of $300 \times 2400 \mathrm{~mm}$ were installed into interior frames symmetrically. Characteristic concrete strength of retrofitting members was chosen as 20 MPa. Only X direction was considered in calculations, hence the added shear walls were installed only in the $\mathrm{X}$ direction. Shear wall area to total floor area was calculated as 0.015 . Plan and frame views of the retrofitted building are shown in Figures 2.9 and 2.10.

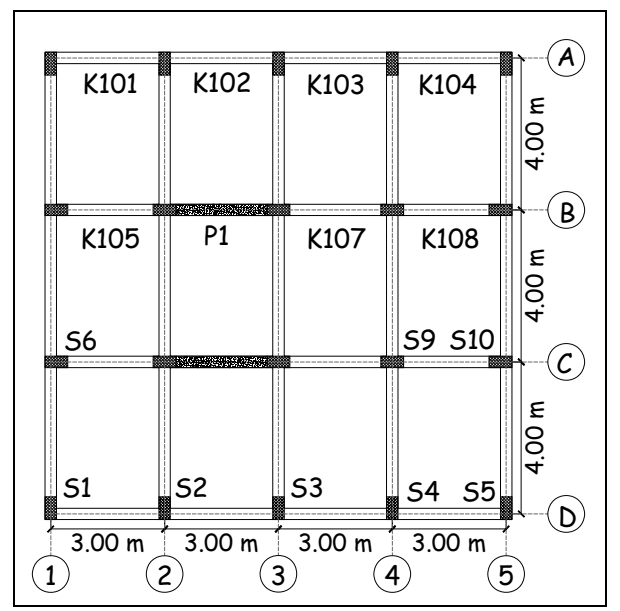

Figure 2.9 Plan view of the retrofitted case of the example building

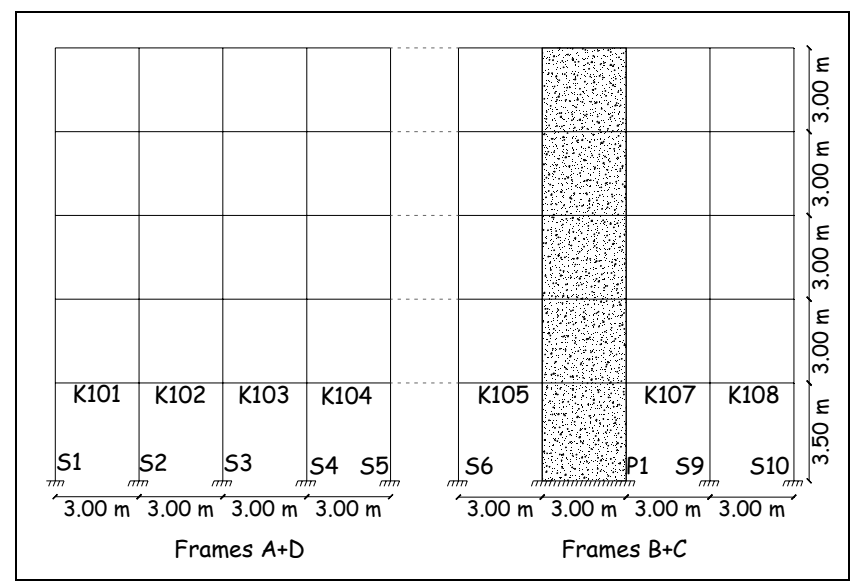

Figure 2.10 2D frame model of the retrofitted case of the example building 


\subsubsection{Target Displacement Demand}

An eigenvalue analysis was conducted by considering cracked stiffnesses of members in order to compute effective fundamental period of the building. Masses including dead loads and $30 \%$ of live loads were lumped at mass centers of each story. Effective fundamental period of the retrofitted building was determined as 0.47 seconds which is longer than 0.40 second corner period of the response spectrum constructed for Z2. Thus equal displacement rule is valid and coefficient $C_{1}$ is equal to 1 (Equation 2.3). Employing Equation 2.1 maximum inelastic roof displacement demand of the retrofitted building was calculated as $\delta_{t}=0.105 \mathrm{~m}$. This was $0.170 \mathrm{~m}$ for the existing building.

A displacement profile having an inverted triangular shape conforming to a uniform drift distribution that is compatible with the calculated roof displacement demand was imposed elastically to the wall-frame system for calculating the member deformation demands.

\subsubsection{Member Deformation Demands}

Employing linear elastic uniform drift analysis in which target displacement response was adopted, chord rotation demands were calculated at column lower and upper ends. As a demonstration, chord rotation at lower end of column 1S1 is shown below referring to Figure 2.3 and Equation 2.5.

$$
C R_{1 S 1, i}=\frac{\Delta}{l_{c}}-\theta_{i}=\frac{0.0206}{3}-0=0.0068
$$

\subsubsection{Member Deformation Capacities}

Chord rotation capacity calculated at a column end is the sum of yield and plastic rotation capacities at that section. Rotation capacity is calculated by employing moment-curvature analysis in which axial load effect is taken into account. Axial load levels were assumed not to vary significantly due to earthquake loading. Thus axial loads on columns under gravity loading i.e. dead and reduced live loads were used in capacity calculations. 
Plastic rotation or plastic curvature capacity is controlled by strain limits corresponding to particular seismic performance damage levels. Since chord rotation capacity is calculated by employing the moment area theorem, another parameter, namely column shear-span length is needed. Column end moments are taken from uniform drift analysis using Equation 2.7 in which shear-span lengths were defined. In addition to the damage limit states, curvature value onset of bar buckling calculated by a bar buckling model suggested by Moyer and Kowalsky (2003) is also shown but not used for performance evaluation. This model establishes a relation between flexural tension strains and reinforcement bar buckling.

In the case of shear walls added to the existing system, a composite section formed by (existing column-shear wall-existing column) combination was considered (Figure 2.11). Initial strains due to gravity loading on existing columns were taken into account.

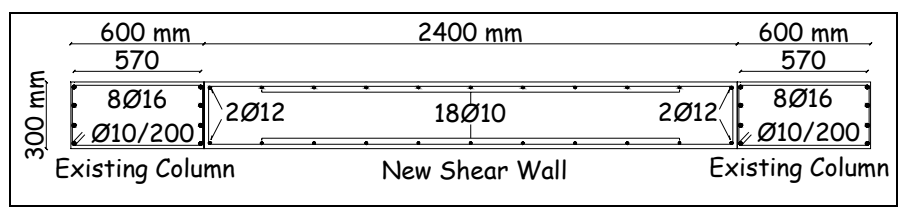

Figure 2.11 Reinforcement detailing of the retrofit shear wall

On Figure 2.12 Moment-Curvature analysis and particular damage limits in terms of curvatures are summarized. Figure 2.13 shows strain distribution on the composite wall section with initial strain distributions on the existing columns due to gravity loading.

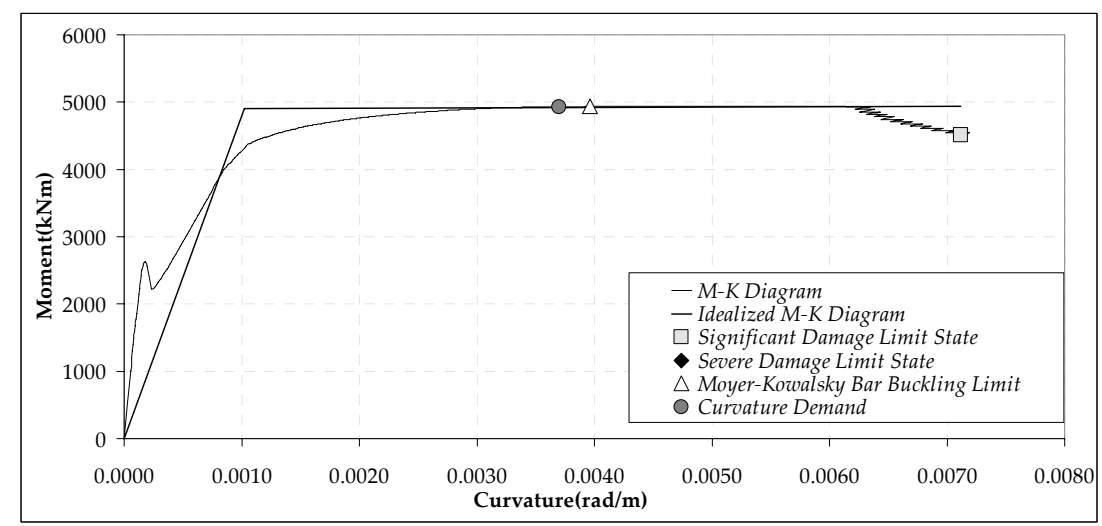

Figure 2.12 Moment-Curvature curve of the retrofit shear wall given in Figure 2.11 


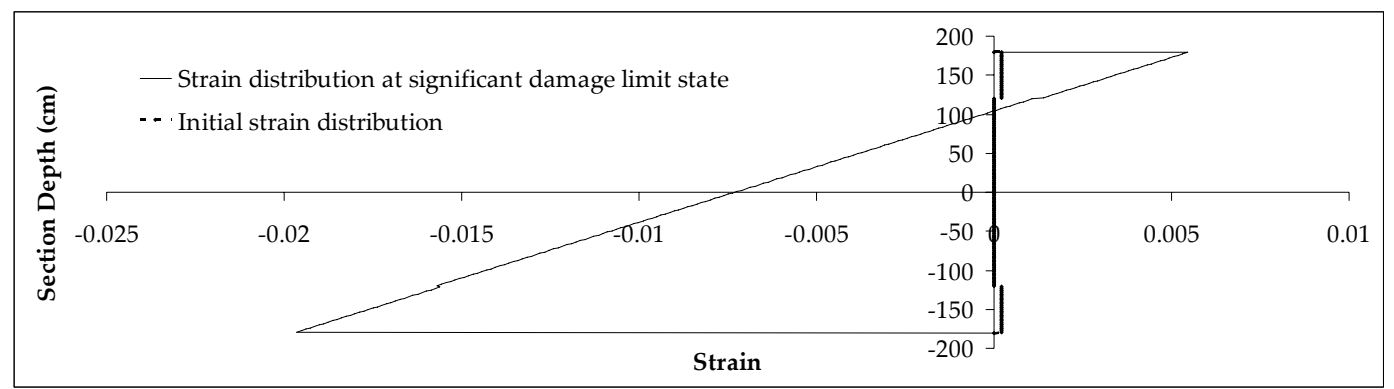

Figure 2.13 Strain distirbution of composite shear wall section

\subsubsection{Final Retrofit Design}

Chord rotation demands of existing columns corresponding to an earthquake having 2475 years of return period, under which Life Safety performance was required, were compared with calculated chord rotation capacities. Figure 2.14 illustrates the comparison graphically. All capacities exceed demands, hence the design is verified. Columns not meeting chord rotation demands can be strengthened in order to increase ductility through interventions like FRP wrapping.

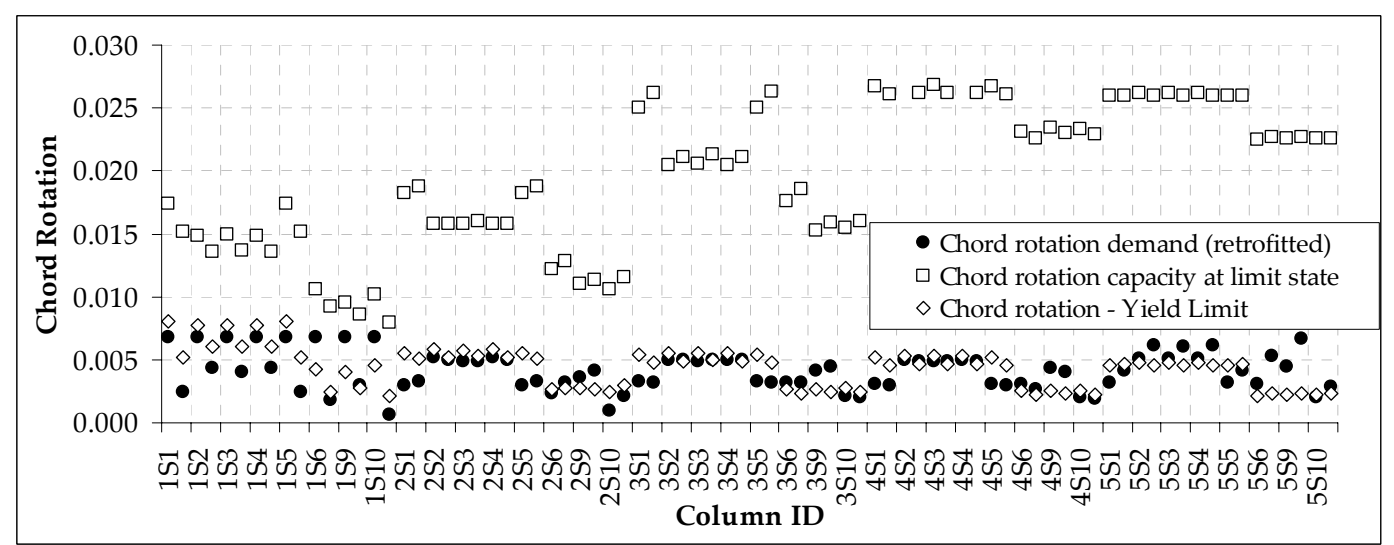

Figure 2.14 Chord rotation demands vs. chord rotation capacities of columns 


\subsubsection{Checking the Failure Modes}

In order to fulfill retrofit design, none of the structural members can be permitted to fail in shear. In this sense failure modes of members were determined by comparing shear capacities and shear demands. Shear demand of a member was taken the lesser of capacity shear compatible with moment capacities, and shear demand calculated from uniform drift analysis at the performance point. Members anticipated to fail in brittle mode have to be retrofitted in order to increase their shear capacities. Most common intervention method for this purpose is to wrap deficient member with RC jackets. In this particular analytical case, shear capacities of columns and beams were calculated together with the corresponding shear demands. It was observed that no brittle behavior was anticipated for any existing member in the retrofitted case. 


\section{CHAPTER 3}

\section{VERIFICATION OF THE DISPLACEMENT-BASED RETROFIT DESIGN METHODOLOGY}

Success in the estimation of nonlinear deformation demands is crucial in verifying a retrofit design methodology. In this study deformation demands in terms of chord rotations were estimated by employing a linear elastic analysis which were utilized as design parameters for developing retrofit solutions in member or system level. Pushover analyses results of frame systems retrofitted with shear walls reveal that displacement responses approximately fit to uniform drift distribution. Assuming that drift response of the retrofitted system is uniformly distributed over the height, an equivalent linear elastic analysis of the retrofitted building is carried out to calculate the member chord rotation demands.

As a verification and check of the methodology proposed herein, pushover analysis was conducted for the retrofitted case of the analytical frame examined in the previous chapter. Improvement in seismic performance after retrofitting was examined by employing assessment procedures of TEC 2007. Chord rotation demands were calculated at the performance point for Life Safety performance level. Deformation demands obtained from two different approaches were compared in order to validate the uniform drift approach.

Additionally, another comparative study is presented in this chapter that involves forcebased retrofit solution of the investigated building. Displacement-based and force-based 
solutions were compared to observe the differences between conventional and alternative displacement-based approaches.

\subsection{Verification of Retrofit Design and Uniform Drift Approach}

In order to verify the retrofit design conducted by employing uniform drift approach, improvement in seismic performance through retrofitting was examined first. In this sense change in load carrying capacities and displacement responses were compared. Moreover seismic performance of the retrofitted frame was evaluated for Life Safety performance objective by employing nonlinear methods of TEC 2007. Thus retrofitted wall-frame system designed in accordance with uniform drift approach was pushed nonlinearly to a target roof displacement demand where nonlinearity was defined with lumped plasticity at member ends. Target roof displacement demand of the retrofitted frame was calculated as $0.105 \mathrm{~m}$ by employing the coefficient method. Since effective fundamental period of the building was longer than the corner period of the spectrum constructed for stiff soil conditions, equal displacement rule is valid and inelastic roof displacement demand was taken equal to inelastic roof displacement demand. In Figure 3.1, representative capacity curves of the existing and retrofitted buildings are shown together with target roof displacement demands calculated for the earthquake having a return period of 2475 years.

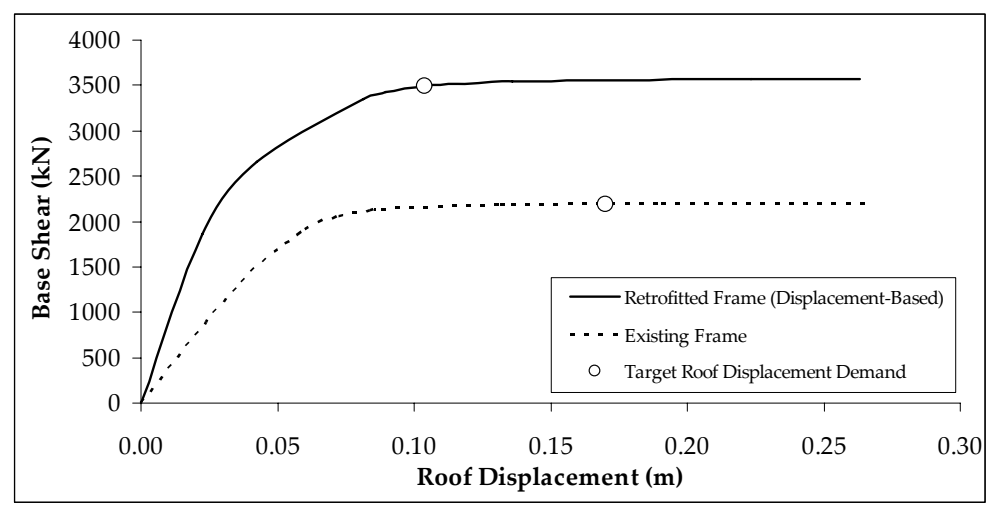

Figure 3.1 Capacity curves of the existing and displacement-based retrofitted frames

As can be seen in the Figure 3.1 added shear walls improved both lateral load carrying capacity and lateral rigidity significantly. Behavior of the structural system transformed 
from shear to flexural behavior as well since the shear wall dominates the behavior of the building. Moreover formation of plastic hinge at the shear wall bases affects the drift response of the wall-frame system. Change in behavior and nonlinearity can be followed through the distribution of plasticity and drift responses of existing and retrofitted buildings. Plastic hinge mechanism of the existing and retrofitted buildings at the performance points are compared in Figure 3.2. It can be observed on Figure 3.2.1 that plasticity was condensed at the first two stories of the existing frame. Since strong column weak beam principle was violated, yielding of column ends took place before the spanning beams reach their capacities, leading to a mechanism at the lower two stories.

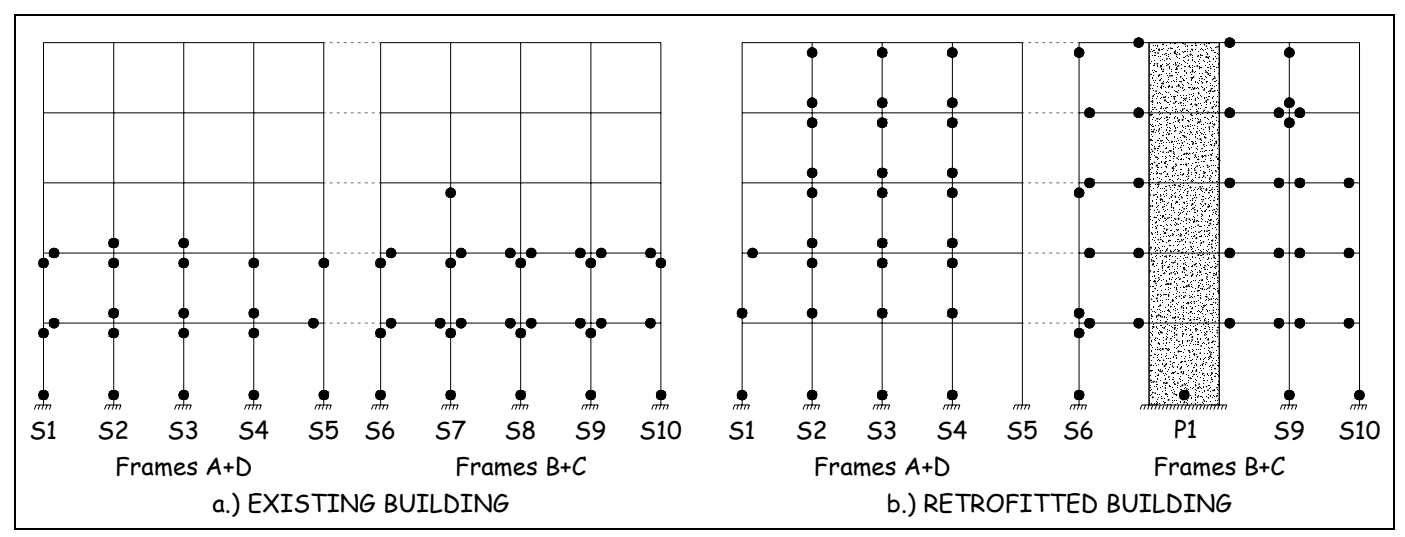

Figure 3.2 Plastic hinge distributions along the existing and retrofitted buildings at the performance points

Additionally, the nonlinear assessment procedure of TEC 2007 was followed in order to evaluate the seismic performance of the retrofitted building. Damage levels for columns and beams deformed beyond elastic limits are presented in Figures 3.3 and 3.4, respectively. All members were classified as ductile since no shear failure was anticipated at the performance point. Evaluation results of global seismic performance for Life Safety level are summarized in Table 3.1. On this table, percentage of beams and percentage of story shear force carried by columns which are not capable of meeting the significant damage limit state are given for each story. 
Table 3.1 Global seismic performances of existing and retrofitted cases of the frame

\begin{tabular}{ccccc|cccc}
\multicolumn{5}{c|}{ EXISTING } & \multicolumn{4}{c}{ RETROFITTED } \\
\hline \hline Story & $V_{n}$ & $V_{N C}$ & $\%$ NC & $\%$ NC & $V_{n}$ & $V_{N C}$ & $\%$ NC & $\%$ NC \\
No. & $(k N)$ & $(k N)$ & shear & beams & $(k N)$ & $(k N)$ & shear & beams \\
\hline 1 & 2193 & 2193 & 100.00 & 37.5 & 3491 & 0 & 0 & 0 \\
2 & 1986 & 841 & 42.36 & 0 & 3288 & 0 & 0 & 0 \\
3 & 1590 & 0 & 0.00 & 0 & 2792 & 0 & 0 & 0 \\
4 & 1033 & 0 & 0.00 & 0 & 1954 & 0 & 0 & 0 \\
5 & 366 & 0 & 0.00 & 0 & 794 & 0 & 0 & 0 \\
\hline
\end{tabular}

NC: Members failing to satisfy the required performance

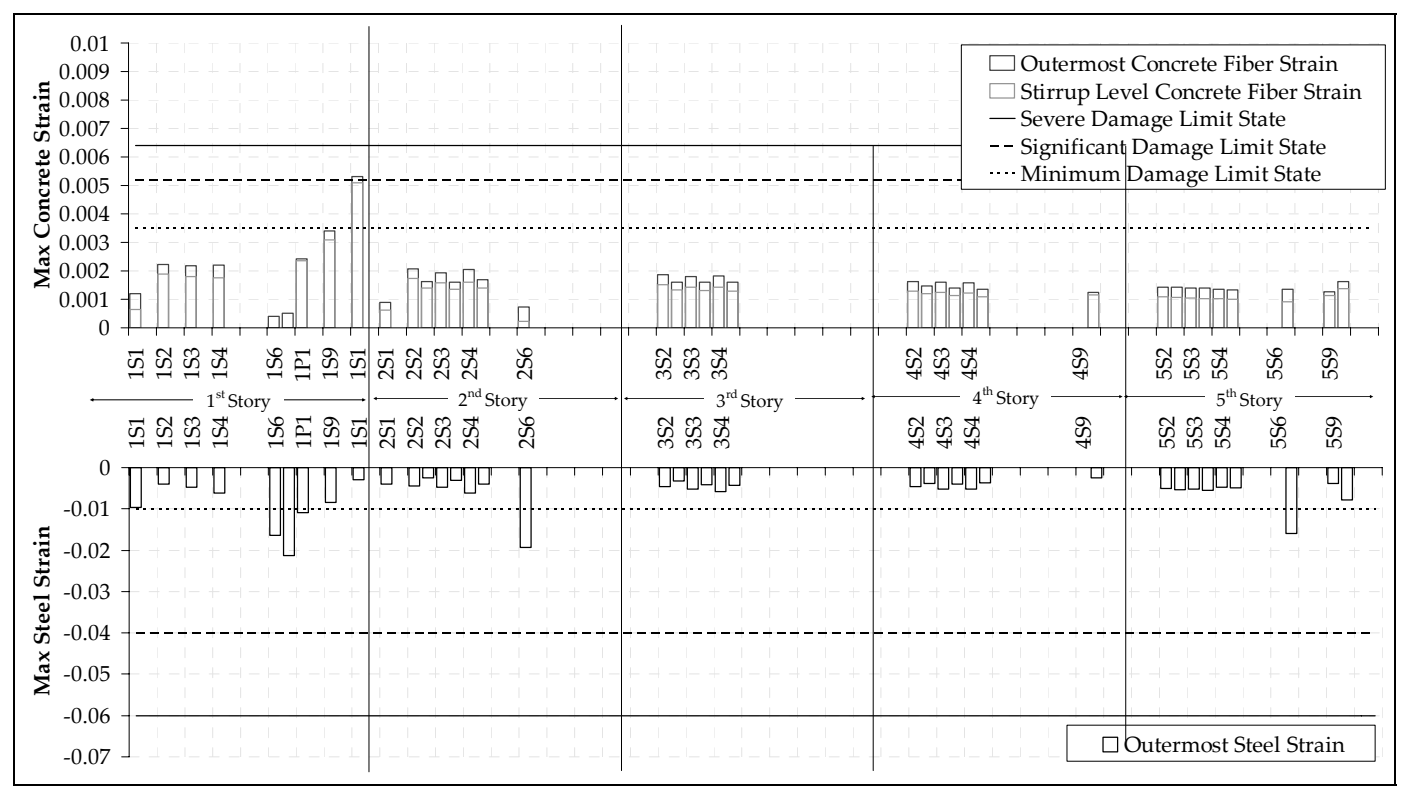

Figure 3.3 Damage levels of the columns

In order to evaluate the validity of uniform drift approach, results of pushover analysis were utilized. Evaluation of the basic assumption of uniform drift approach, which assumes drift response of the retrofitted system as uniformly distributed along building height, was made by comparing story displacement and interstory drift distributions obtained from uniform drift and pushover analyses. Figure 3.5 summarizes comparison of drift responses of the existing and retrofitted cases. As the behavior of building system transforms into flexure from shear, interstory drift demands decrease in the lower stories significantly and increase slightly at the higher stories which can be observed in Figures 
3.5. However increase in drift demands is tolerable due to the lateral rigidity increase with new walls. Yielding at the wall base also plays role in transformation of drift response to uniform. Drift responses calculated from uniform drift and pushover analysis are compared in Figure 3.5 as well at the same roof displacement at which the shear wall is onset of yielding. As observed in Figure 3.5, uniform drift assumption is satisfactory to catch drift demands especially for the first story which is critical for the retrofit design.

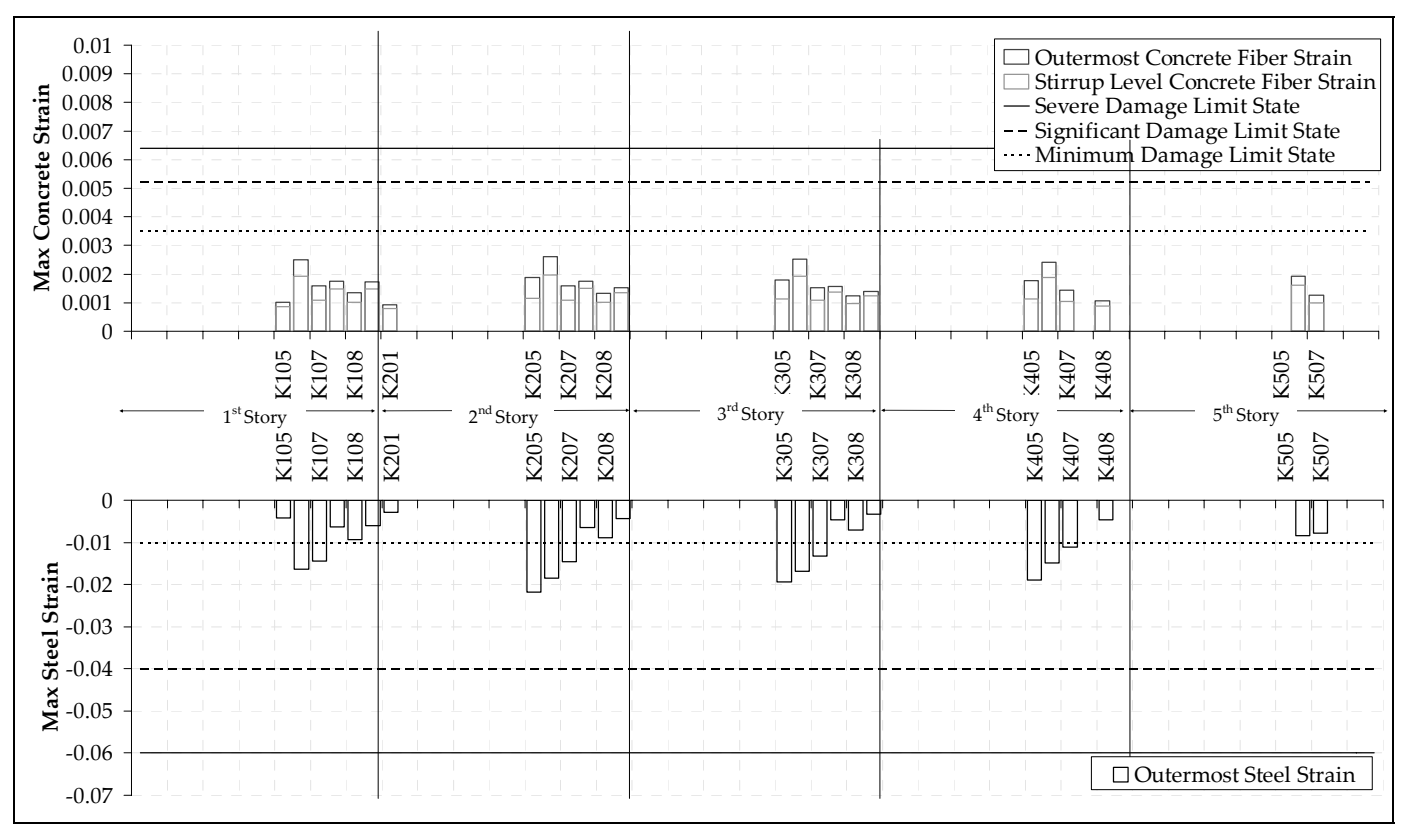

Figure 3.4 Damage levels of the beams
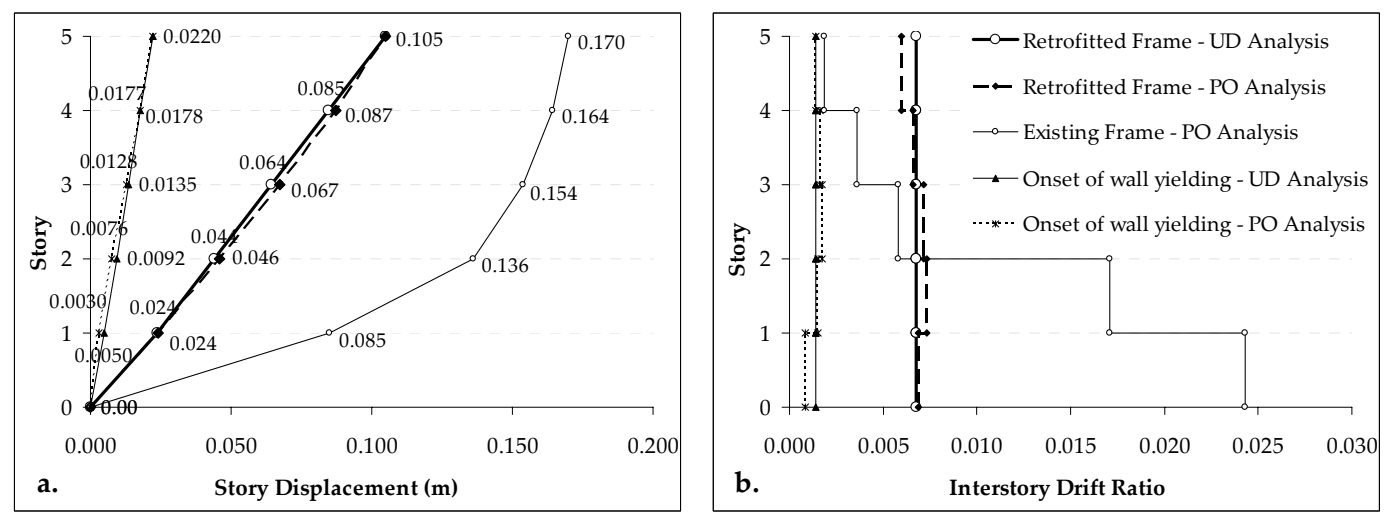

Figure 3.5 a. Displacement, b. interstory drift distributions of the existing and retrofitted frames predicted with uniform drift and pushover analyses 
Deformation demands in terms of chord rotations were calculated for the column ends at the performance point by employing Equation 2.5. As a comparative presentation of how added shear walls affected the chord rotation demands of existing column ends, chord rotation demands were also calculated for the existing and retrofitted cases of the building at its performance point by employing pushover analysis. Chord rotation demands computed from uniform drift and pushover analyses of the existing and retrofitted frames are compared at the same target roof displacement in Figure 3.6. It should be noted that these columns have not been retrofitted in the retrofit design.

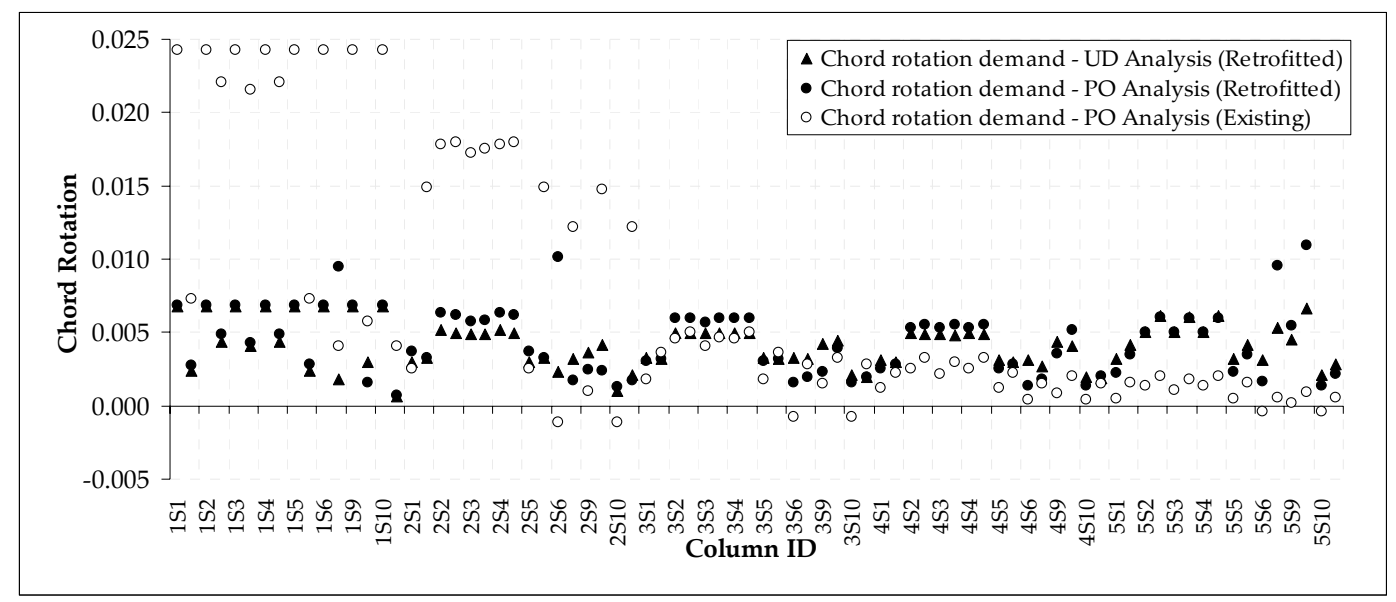

Figure 3.6 Chord rotation demands of the columns

It is observed that the results are usually reasonably close; however significant differences occur only at the ends of columns in tension adjacent to the shear wall. Considering this observation, columns denoted as S6 and S9 need further attention. One can follow on the chart illustrated in Figure 3.6 that changing the existing shear frame system into a wallframe system i.e. flexure dominant wall behavior, chord rotation demands at the first two stories decreased considerably whereas at the top story a slight increase in deformation demands was observed as it was in drift distributions as well.

\subsection{Force-Based Retrofit Solution}

After verifying uniform drift approach as a simplified displacement-based retrofit design methodology, the example frame was retrofitted by employing a force-based method as 
well in order to compare retrofit solutions suggested by the two alternative approaches. By this way, efficiency and economy of the methods were investigated.

In order to employ force-based retrofit methods, seismic performance of the retrofitted frame was evaluated to satisfy Life Safety objective. In this sense linear elastic procedures defined in TEC 2007 were used. According to these specifications, cracked stiffnesses of reinforced concrete members were used in the analysis. Moreover force reduction factor $R$ was taken as unity and calculated base shear was factored by 0.85 representing the first mode mass participation ratio. Failure modes of existing members were determined. In case of the retrofitted frame all columns and beams were classified as ductile. Seismic performances of ductile members were evaluated by comparing their demand-to-reservedcapacity ratio with particular limits specified for damage levels. Evaluation results given in Table 3.2 yielded in a global sense that addition of shear walls barely was enough to satisfy the Life Safety objective. No more interventions were needed for existing columns to improve performance.

Table 3.2 Global seismic performances of the retrofitted frame Linear Elastic Assessment Results of the Retrofitted Frame

\begin{tabular}{ccc}
\hline \hline $\begin{array}{c}\text { Story } \\
\text { No. }\end{array}$ & $\begin{array}{c}\% \text { NC } \\
\text { beams per story }\end{array}$ & $\begin{array}{c}\text { \% story shear } \\
\text { carried by }\end{array}$ C columns \\
\hline 1 & 0 & 0 \\
2 & 14 & 0 \\
3 & 14 & 0 \\
4 & 0 & 0 \\
5 & 14 & 0 \\
\hline
\end{tabular}

NC: Members failing to satisfy the required performance

Demand-to-reserved-capacity ratio of shear wall P1 was calculated as 3.67. The ratio is less than 4 which is the value corresponding to the significant damage level limit stated in TEC 2007 for shearwalls with unconfined boundaries. 


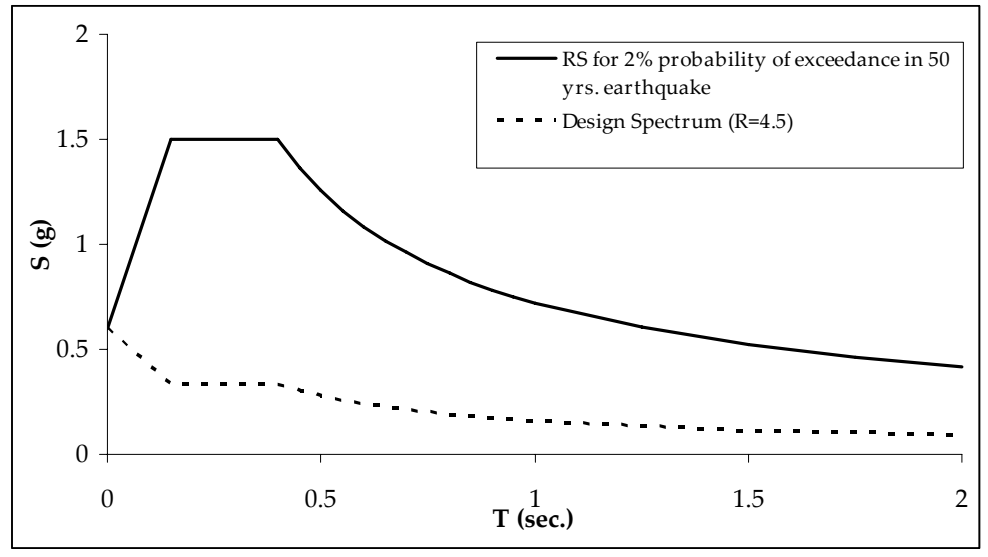

Figure 3.7 Design and code spectra for an earthquake having $2 \%$ probability of exceedance in 50 years

Concluding the seismic performance evaluation of existing members, shear walls added to the existing frame system were designed by employing force-based procedures defined in TEC 2007. Assuming the building response is dominated by the first mode and no torsional irregularity is anticipated, equivalent static lateral loads were calculated under a design spectrum constructed for an earthquake having $2 \%$ probability of exceedance in 50 years. Figure 3.7 illustrates the design spectrum used in the design of added shear walls. Design spectrum was obtained by reducing the code spectrum by $R=4.5$. Nonlinear analyses of medium rise reinforced concrete buildings retrofitted with shear walls reveal that reducing elastic forces by 4.5 is reasonable to estimate ductility demands. Following specifications defined in TEC 2007 for ductile shear walls, confined ends were formed within the walls. Reduced elastic forces calculated by using the design spectrum were employed in capacity design of the new shear walls. Moment envelope of the shear walls used in design is shown in Figure 3.8. 


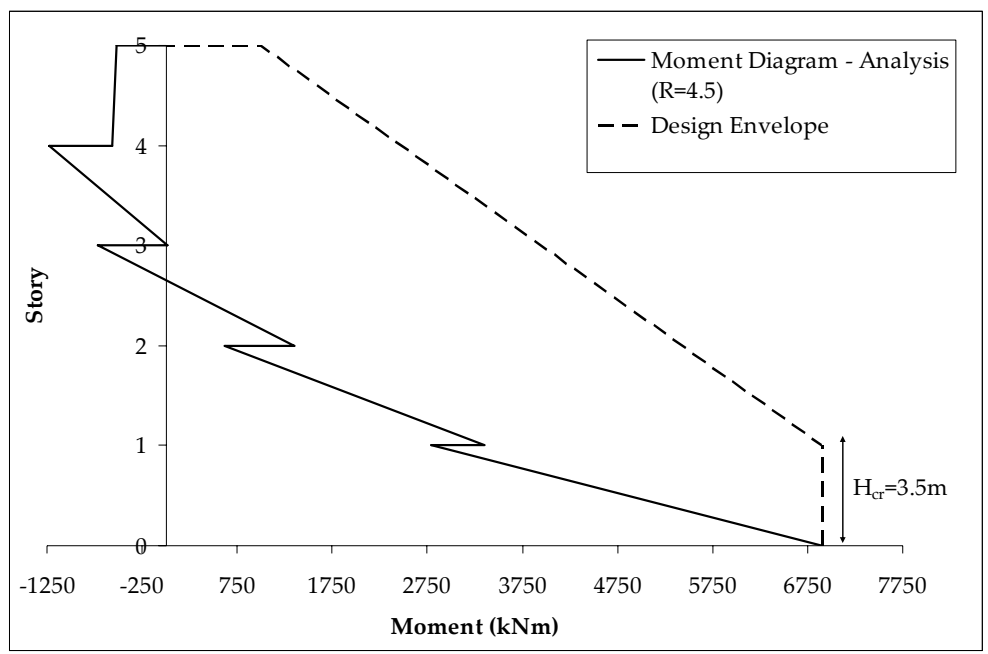

Figure 3.8 Moment envelope used in shear wall design

\subsection{Comparison of Force-Based and Displacement-Based Retrofit Solutions}

Deficient frame presented in Chapter 2 was retrofitted following the two different approaches explained in Sections 2.2.1 and 3.2. In displacement-based approach, in which a proposed linear elastic analysis method was used, deformation demands and limit states were employed as design parameters. On the other hand, in force-based approach reduced elastic forces and conventional design specifications for new buildings of TEC 2007 were used. Considering the results of retrofit design solutions for the two approaches, it was concluded that no interventions for columns were suggested in both approaches. However differences were observed in shear wall detailing. In displacement-based design, no confined ends were formed at wall boundaries whereas existing columns were used as boundary elements. Existing columns were also included in capacity calculations. In forcebased retrofit design, following the specifications for shear walls defined in TEC 2007, shear walls added to the existing frame system was classified as slender walls considering total height to length ratio of the walls. Along the critical height of the walls which was determined as $3.5 \mathrm{~m}$, confined end zones were formed.

Longitudinal reinforcement ratio of 0.0025 which is a code minimum value was sufficient for the infill portion of the new shear wall in order to meet deformation demands determined with uniform drift analysis. On the other hand in force-based design the 
amount of longitudinal reinforcement in terms of volumetric ratio increased to 0.0121 . Detailing of shear walls suggested by two design approaches are compared in Figure 3.9.

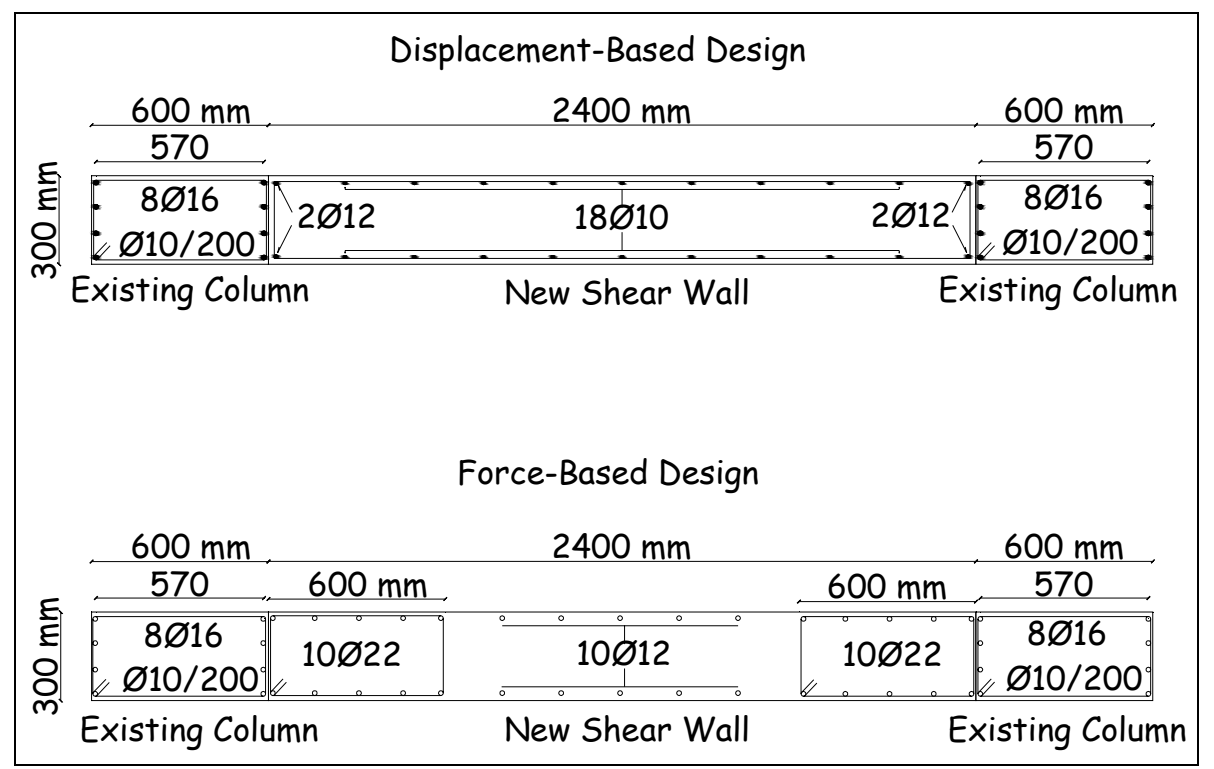

Figure 3.9 Shear wall detailing according to displacement-based and force-based retrofit designs

Axial load - moment capacity at the base of shear wall P1 obtained for force-based and displacement-based designs are shown in Figure 3.10. Additionally in Figure 3.11 moment curvature analysis results are compared for the force-based and displacement-based designs of the shear wall P1. Although displacement-based design gives lower moment capacity values due to no confinement at boundaries and less longitudinal reinforcement amount, it is capable of meeting the deformation demands and shear demands at the performance point. It can be stated that force-based design results in unrealistic force demands and excess amounts of reinforcement. Shear demands differ as well since shear demand is taken as the demand at the performance point having a value of $1105 \mathrm{kN}$ which yields a minimum transverse reinforcement ratio of 0.0025 . In force-based design this ratio becomes 0.0045 due to a capacity shear demand of $2509 \mathrm{kN}$. 


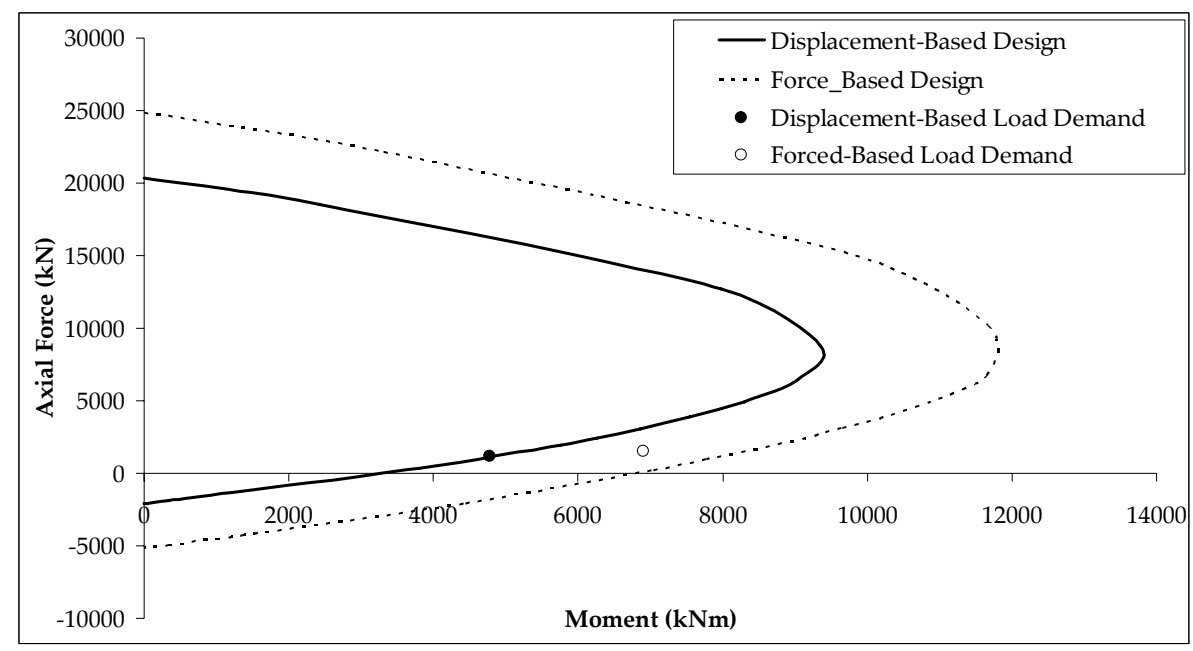

Figure 3.10 Axial force-moment interaction diagrams according to displacement-based and force-based retrofit designs

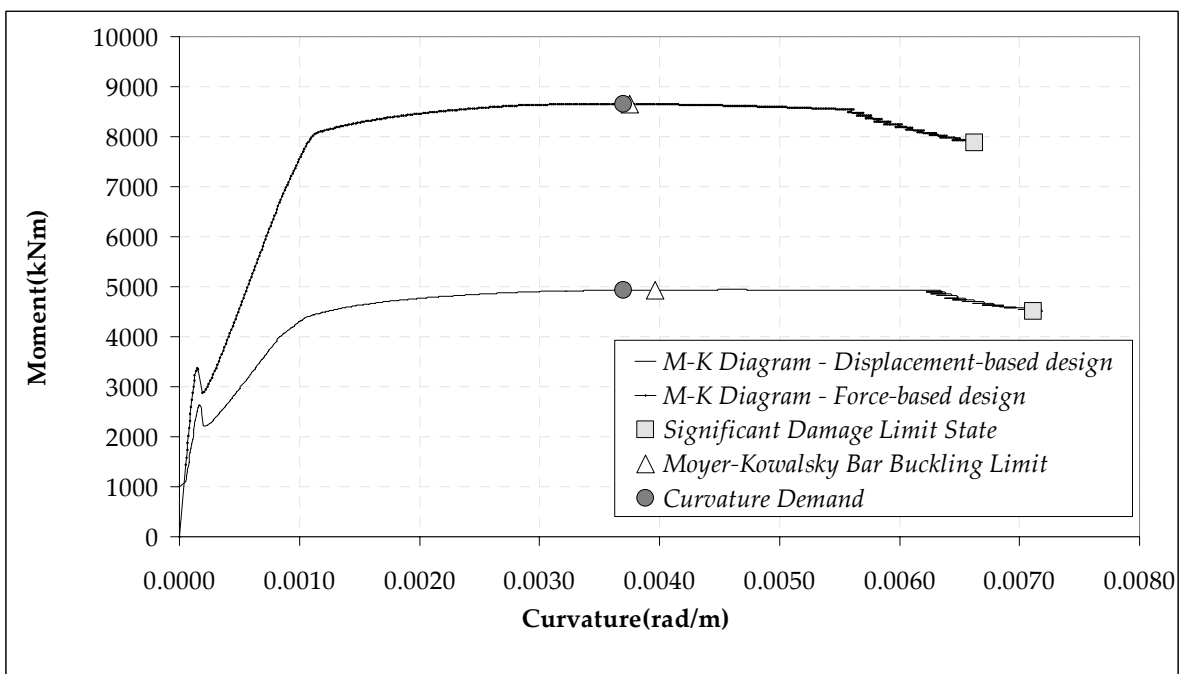

Figure 3.11 Moment-curvature diagrams of force-based and displacement-based design solutions or the shear wall P1

Due to different longitudinal reinforcement amounts, shear walls have different moment capacities obviously. In Figure 3.12, capacity curves of force-based and displacement-based retrofitted buildings reflect the difference in lateral load carrying capacities. Although both of the cases have the same lateral rigidity, their target roof displacement demands are different due to different load carrying capacities. Having a lesser lateral load carrying capacity, target roof displacement demand of the displacement-based retrofitted building is 
more as shown in Figure 3.12. In case of the force-based retrofit design target roof displacement demand was calculated as same in displacement-based design since equal displacement rule is valid and both buildings have same fundamental period.

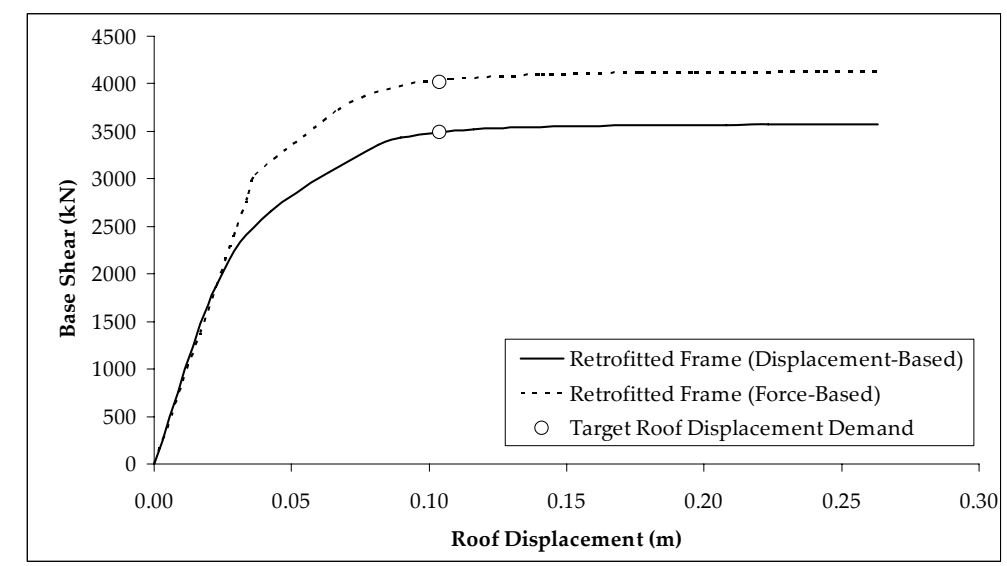

Figure 3.12 Capacity curves of force-based and displacement-based retrofitted frames 


\title{
CHAPTER 4
}

\section{CASE STUDY I - SEISMIC REHABILITATION OF A FOUR STORY SCHOOL BUILDING}

\begin{abstract}
A four story school building composed of reinforced concrete frame system was examined as a case study. Seismic performance of the existing building was evaluated first and deficiencies were determined in both member and system levels. Then the existing structural system was retrofitted by following the proposed displacement-based retrofit design methodology. As a comparative study, force-based retrofit solution is also presented. In order to verify design, inelastic seismic performance evaluation of the displacement-based retrofitted building is given in this chapter as well.
\end{abstract}

\subsection{Existing Condition of the Building}

Existing school building shown in Figure 4.1 is composed of four story reinforced concrete frame system. In X direction there are four frames. Columns of frames located on B and C axes are oriented in the $\mathrm{X}$ direction whereas columns of frames located on $\mathrm{A}$ and $\mathrm{D}$ axes are oriented in the $\mathrm{Y}$ direction. Cross section dimension of columns at the first three stories are $300 \times 600 \mathrm{~mm}$, and they are $300 \times 500 \mathrm{~mm}$ at the fourth story. All beams are $300 \times 700 \mathrm{~mm}$ in dimension. Heights of the first three stories are $3.15 \mathrm{~m}$ and it reduces to $3.1 \mathrm{~m}$ at the fourth story. Plan view of the building is shown in Figure 4.2.

Existing material strengths were obtained by field and laboratory tests. Existing concrete strength was obtained as low as $7 \mathrm{MPa}$ and characteristic yield strength of reinforcement 
bars was determined as $220 \mathrm{MPa}$. Volumetric ratio of longitudinal reinforcement in columns was measured as 0.017 . In case of beams, tension reinforcement ratio was 0.009 and compression reinforcement ratio was 0.006 at the supports. In all member sections $\Phi 8 / 200 \mathrm{~mm}$ stirrups with a hook angle of $90^{\circ}$ were used. Thus compressive concrete strain limit at the stirrup level for significant damage limit state was taken as 0.0035 .

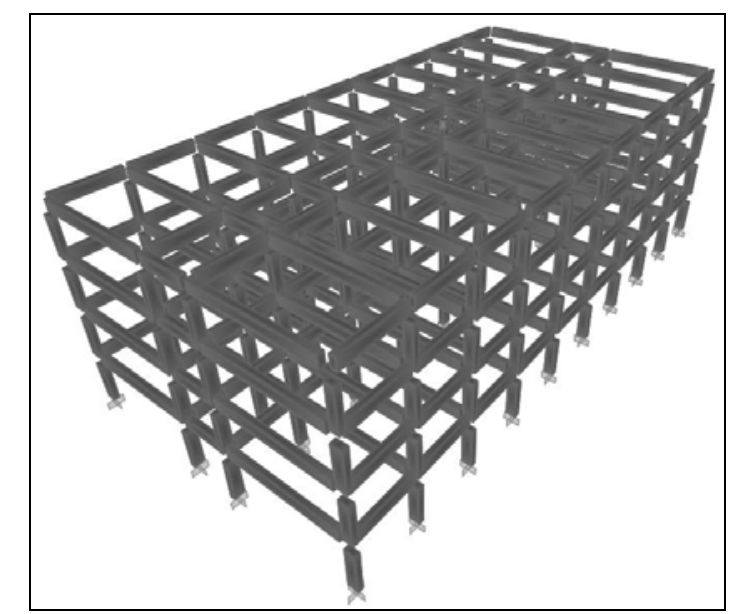

Figure 4.1 3D Mathematical model of the four story existing school building

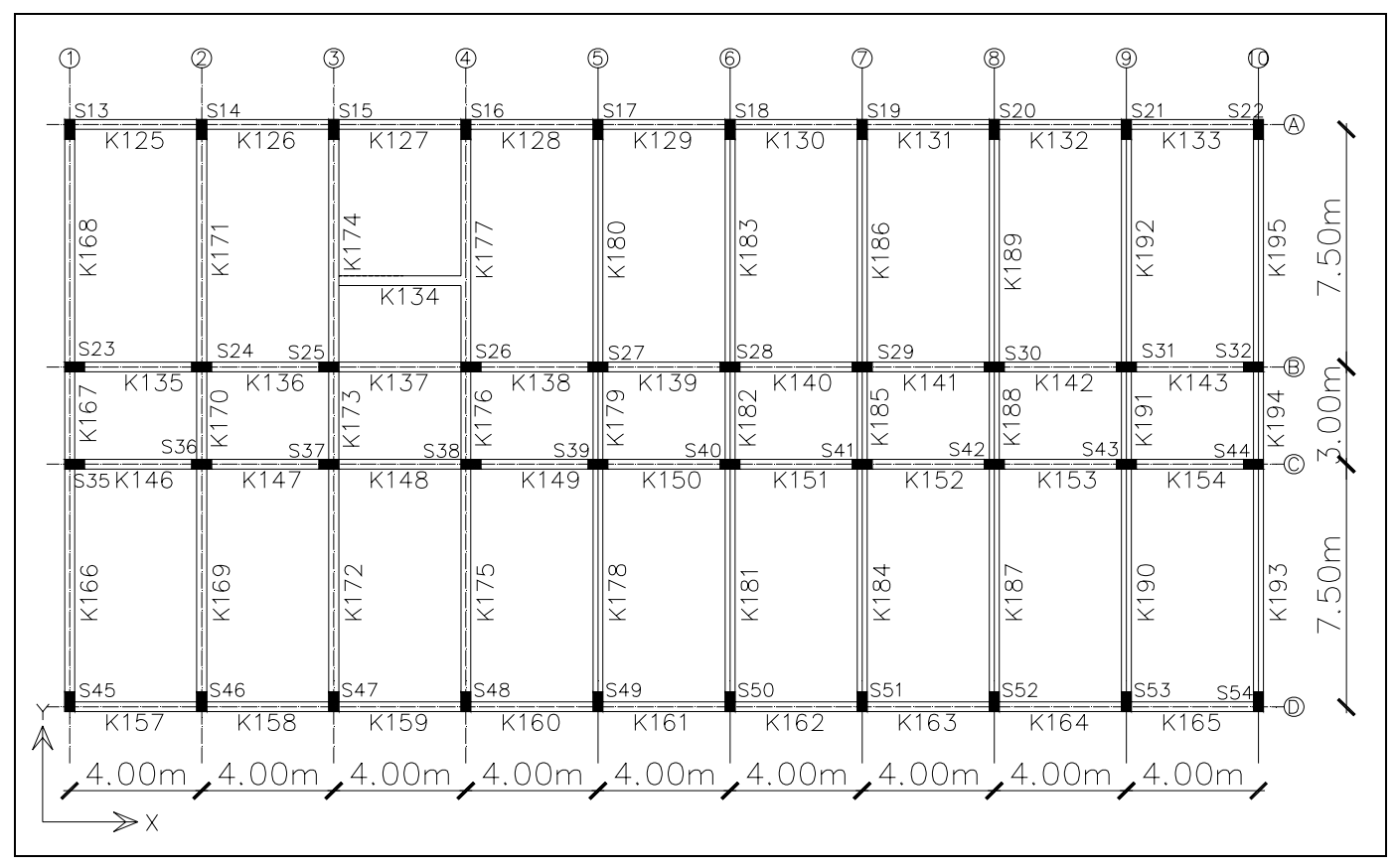

Figure 4.2 Plan view of the four story existing school building 
Local soil conditions were classified as stiff soil, corresponding to Z2 soil type according to TEC 2007. Since Life Safety performance objective was selected, response spectrum was constructed for Z2 soil type for an earthquake having $2 \%$ probability of exceedance in 50 years, which corresponds to a 2475 return period event. According to Life Safety criteria for school buildings stated in TEC 2007 , not more than $20 \%$ of story shear should be carried by deficient columns in a story except the top story and not more than $30 \%$ of the beams in a story should be classified as deficient in the considered earthquake direction.

In order to evaluate seismic performance whether the building satisfies Life Safety objective or not in the $\mathrm{X}$ and $\mathrm{Y}$ directions, nonlinear assessment procedure of TEC 2007 was followed. Pushover analysis was conducted in $+X$ and $+Y$ directions using cracked stiffnesses of reinforced concrete members. Capacity curves of the existing building in the $X$ and $\mathrm{Y}$ directions are shown in Figure 4.3. Effective fundamental periods in the $\mathrm{X}$ and $\mathrm{Y}$ directions were computed as 0.61 seconds and 0.80 seconds, respectively. Target roof displacement demands under the considered design earthquake were calculated for $\mathrm{X}$ and $\mathrm{Y}$ directions as $0.132 \mathrm{~m}$ and $0.186 \mathrm{~m}$, respectively. Existing building was pushed in both directions separately until the roof level reached the target roof displacement.

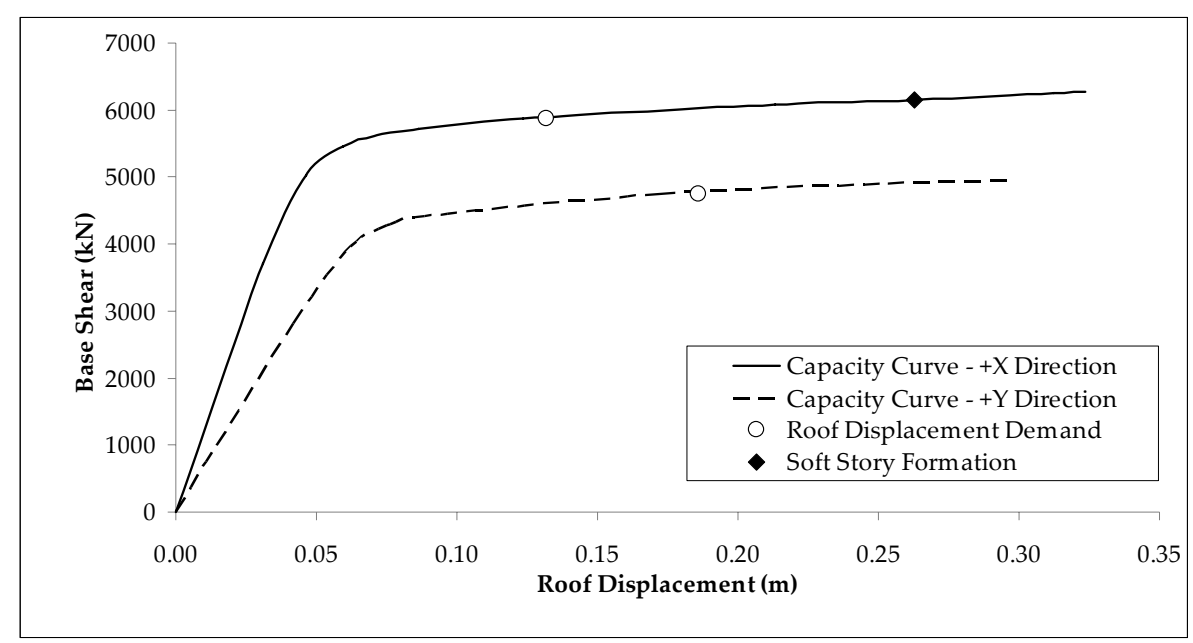

Figure 4.3 Capacity curves of the existing building

Due to low material strength and lack of proper seismic detailing, existing columns and beams were observed not to meet deformation demands anticipated at the performance 
point. Damage levels of reinforced concrete members going beyond elastic deformation at the performance point computed by pushover analysis in the $\mathrm{X}$ and $\mathrm{Y}$ directions are presented in Figures 4.4, 4.5, 4.6, and 4.7. Considering X direction, plasticity spreads over the first two story members. All of the first story columns were classified as deficient in meeting the limit of significant damage level in both directions. Additionally, more than $30 \%$ of the beams deformed beyond significant damage limit in the considered earthquake direction at the first and second stories. Global performance evaluation of the existing building is summarized in Table 4.1 for both $\mathrm{X}$ and $\mathrm{Y}$ loading directions.

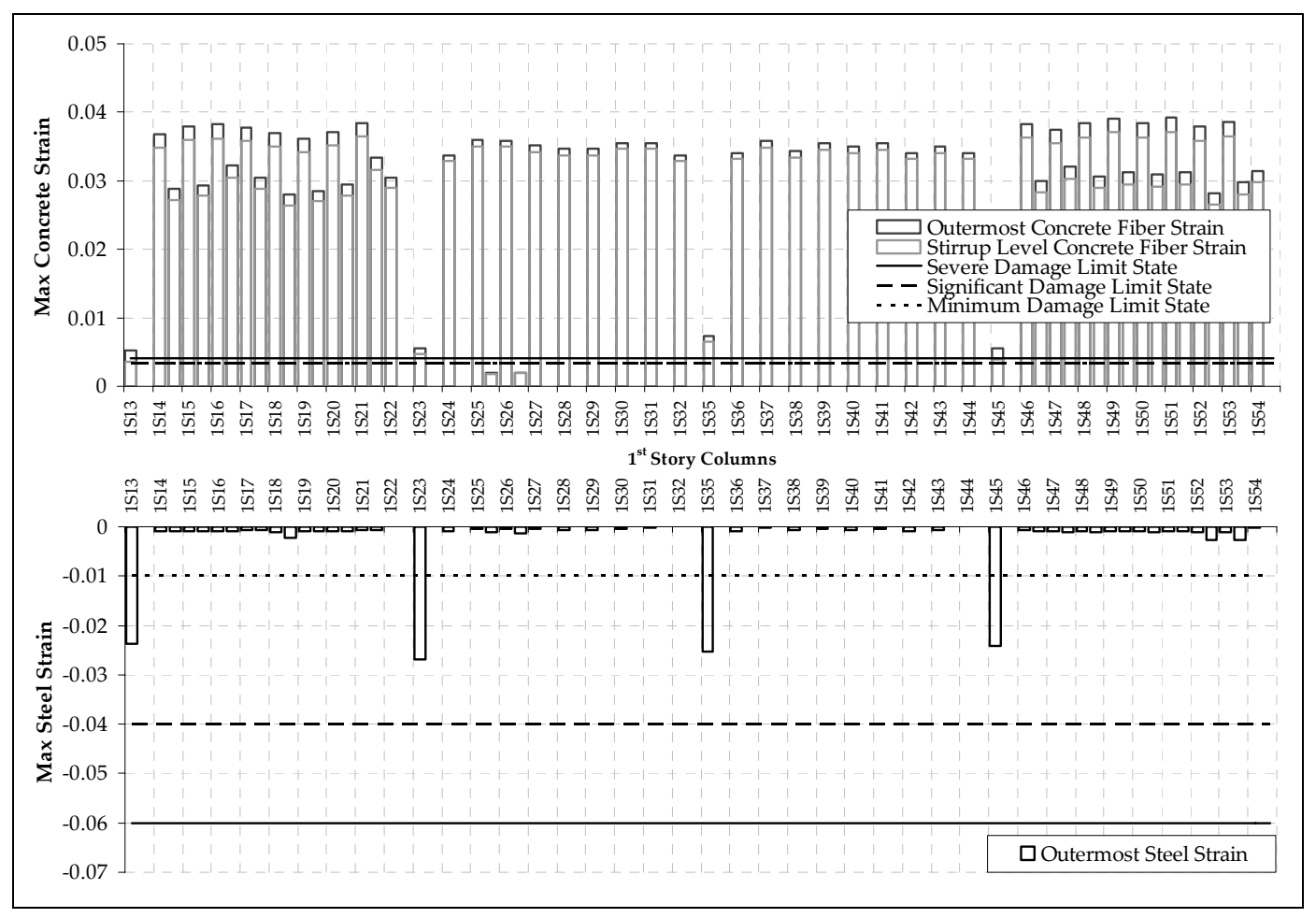

Figure 4.4 Damage levels of the columns in the X direction loading 


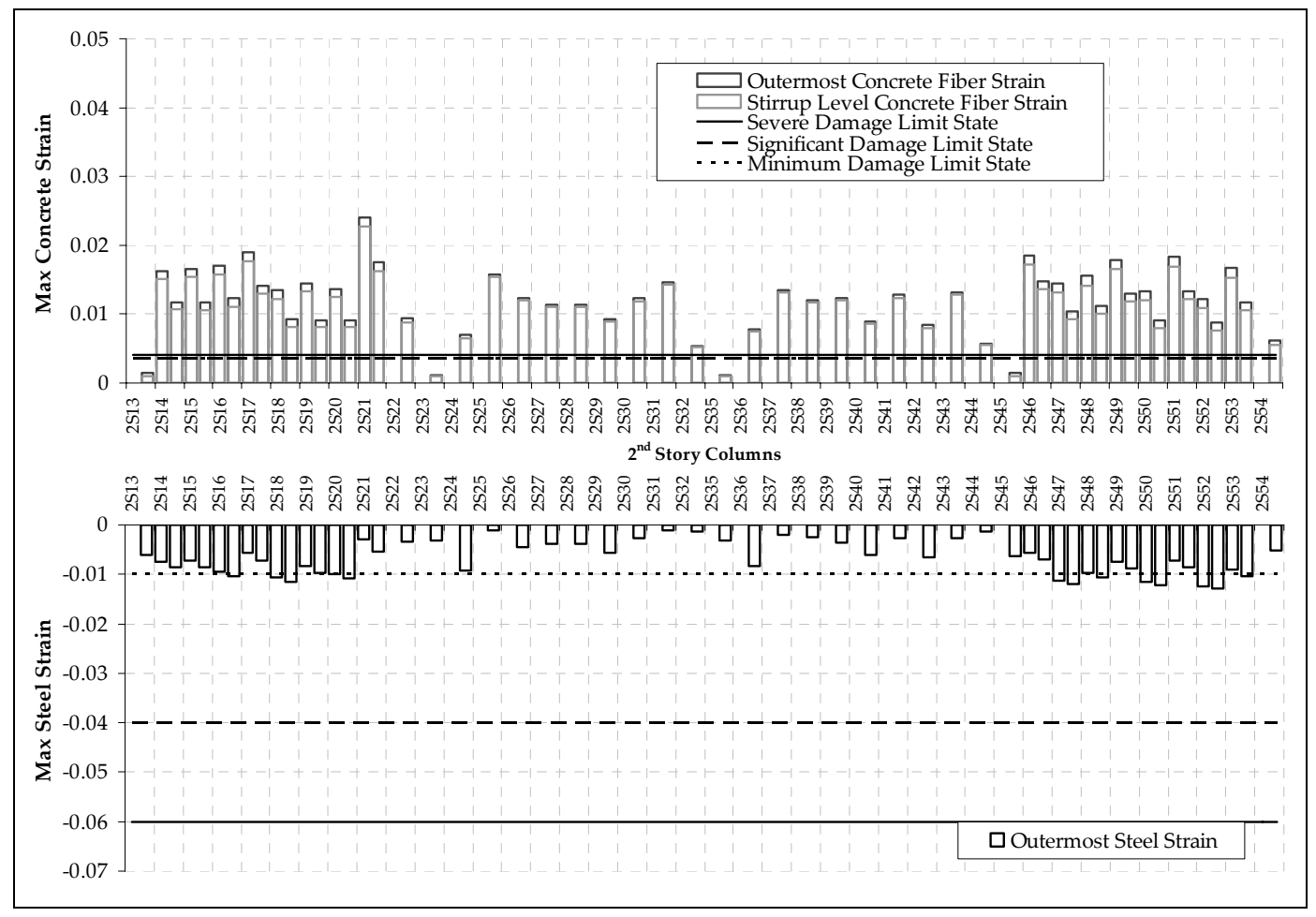

Figure 4.4 Damage levels of the columns in the $\mathrm{X}$ direction loading (continued)

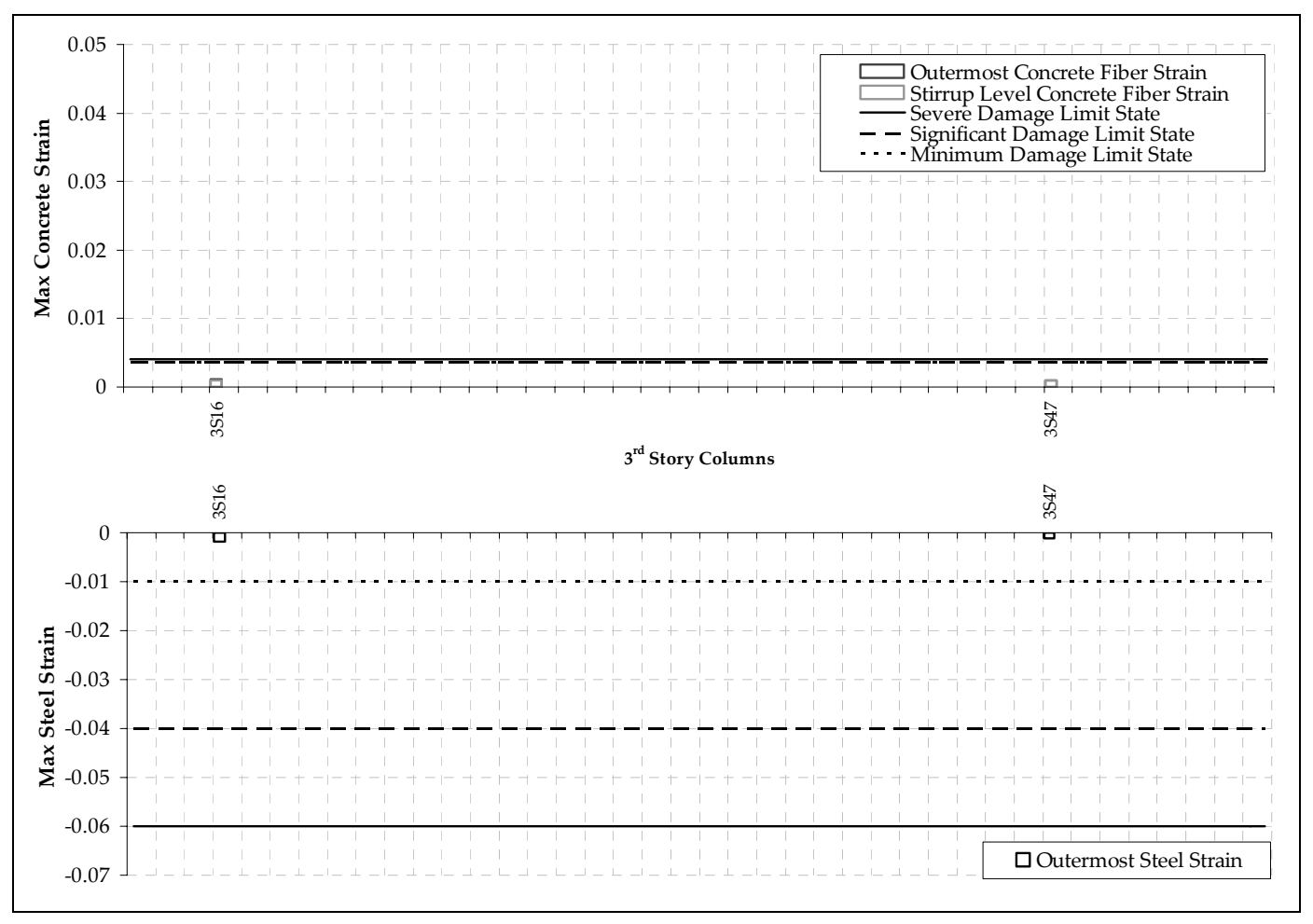

Figure 4.4 Damage levels of the columns in the $\mathrm{X}$ direction loading (continued) 


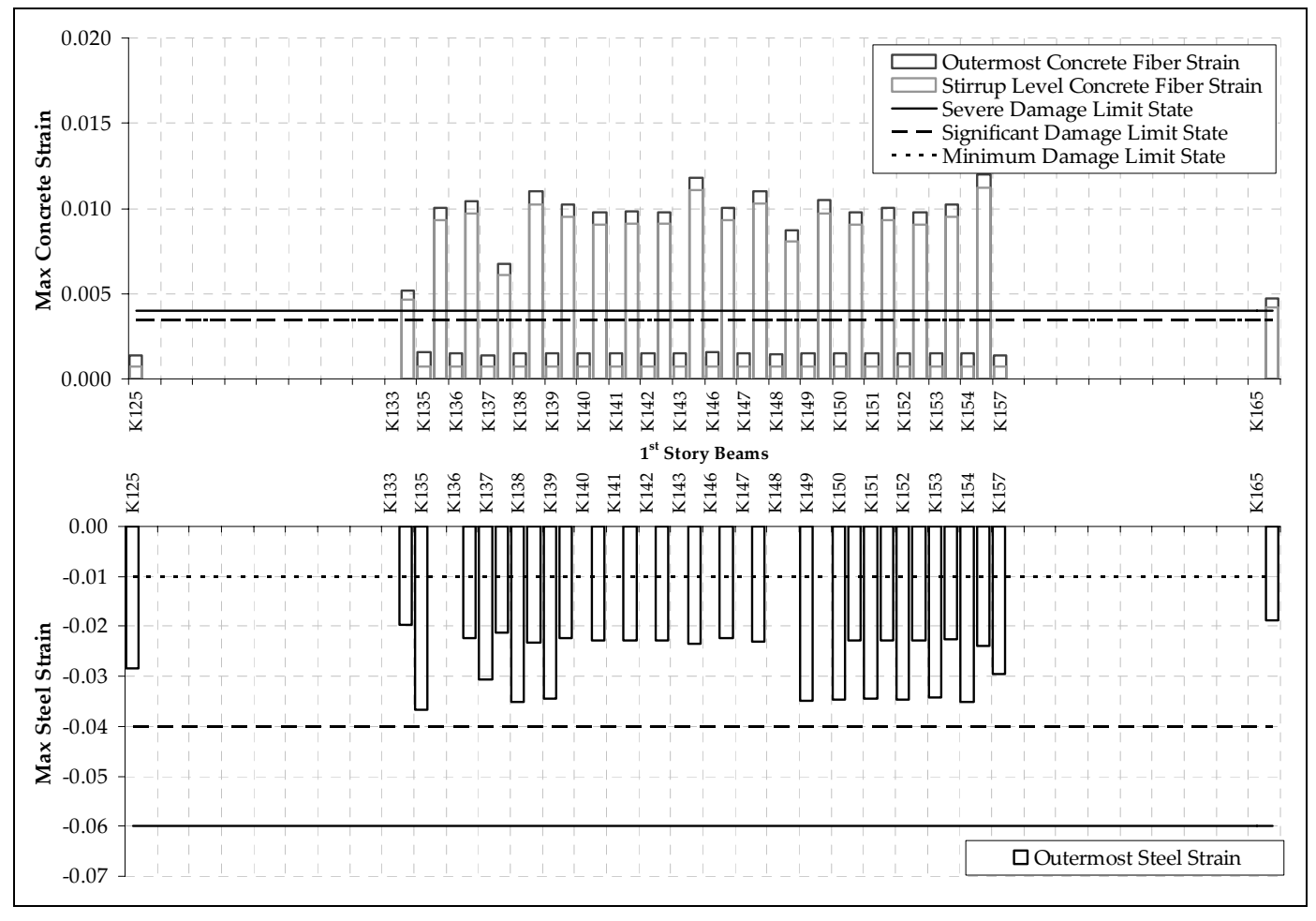

Figure 4.5 Damage levels of the beams in the $X$ direction loading

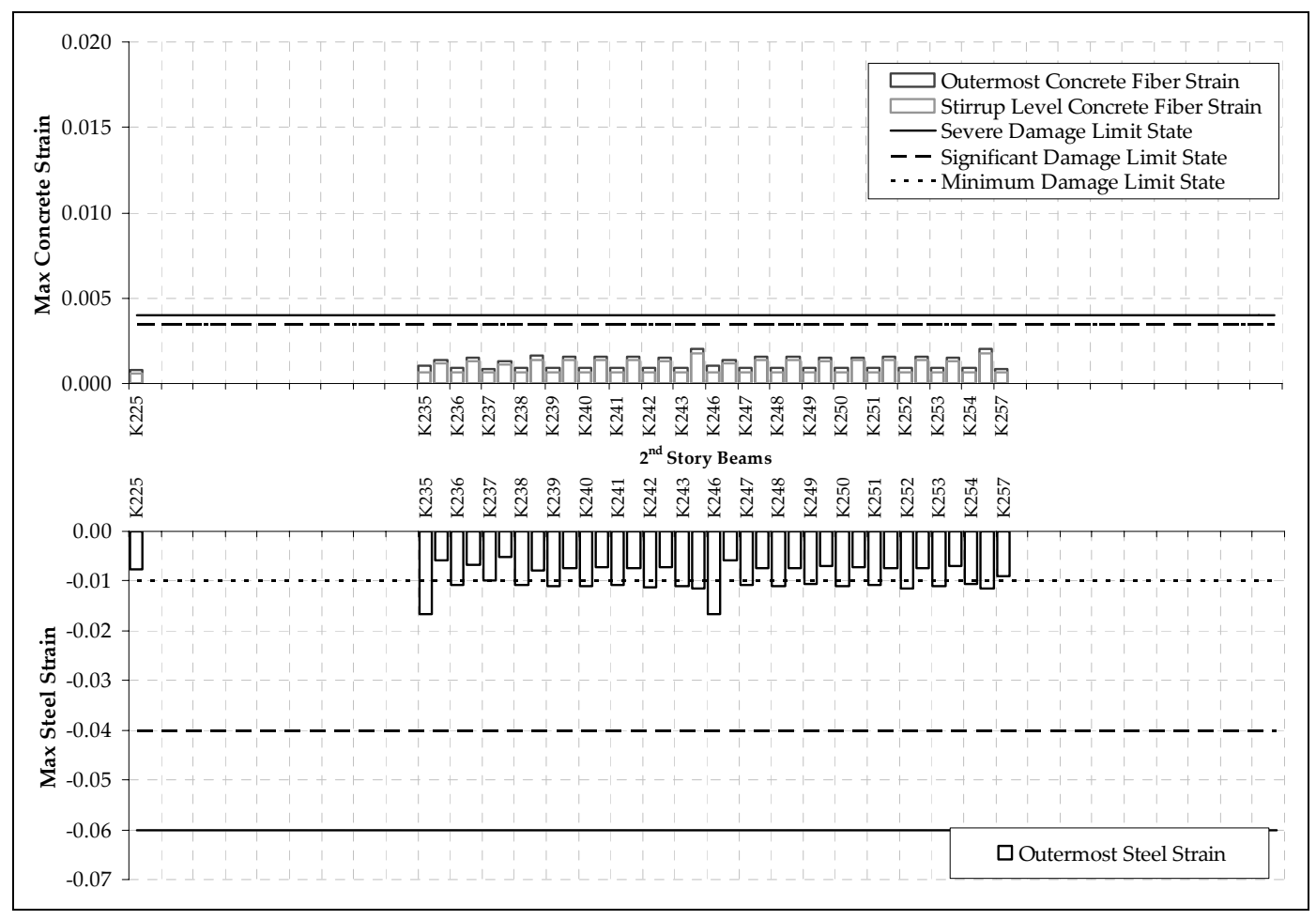

Figure 4.5 Damage levels of the beams in the $\mathrm{X}$ direction loading (continued) 
On the other hand, in $\mathrm{Y}$ direction yielding of columns and beams were observed at the third story in addition to the first two stories. According to assessment results the existing building was not able to satisfy Life Safety performance level. Global performance evaluation of the building is summarized in Table 4.1.

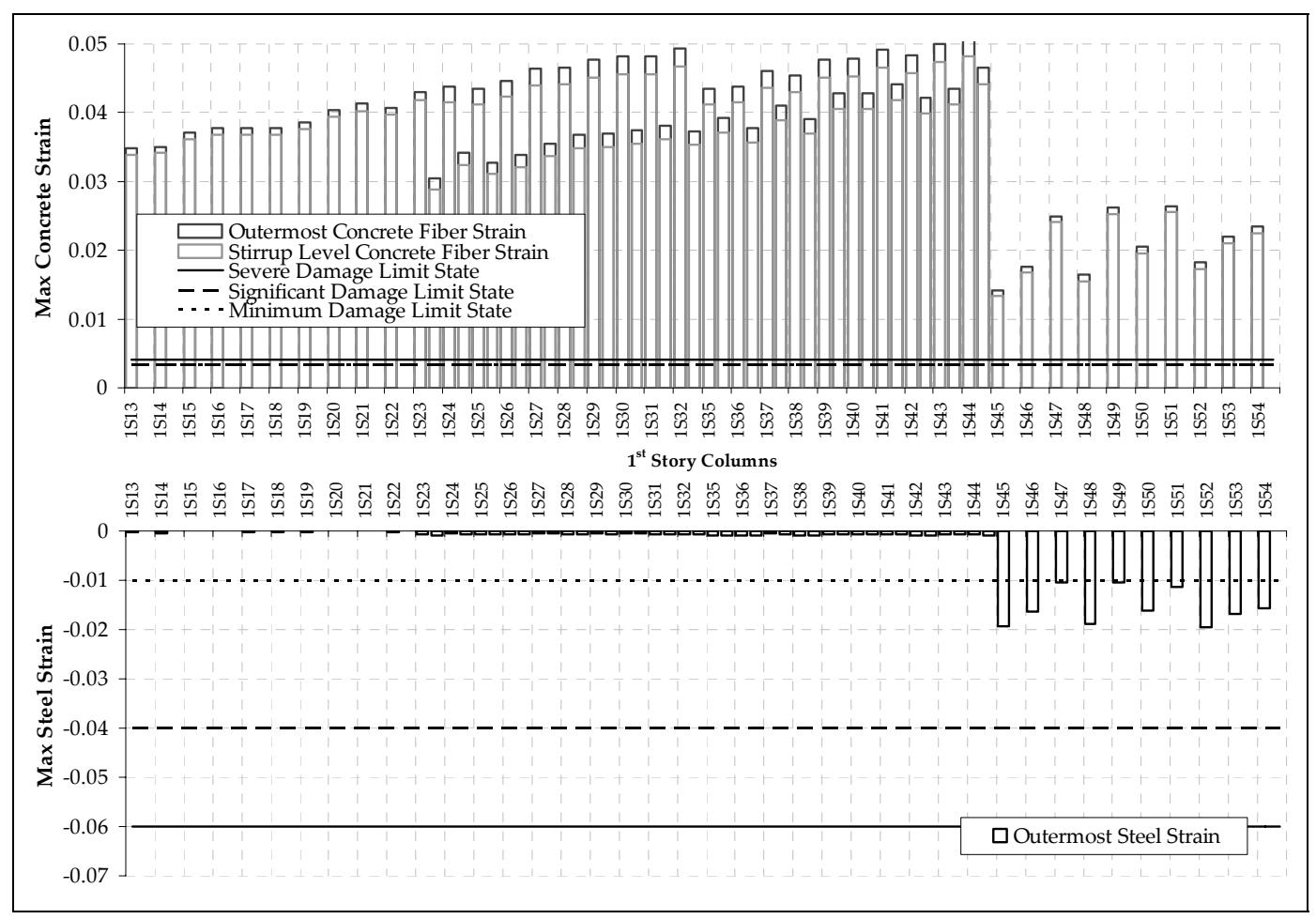

Figure 4.6 Damage levels of the columns in the $\mathrm{Y}$ direction loading 


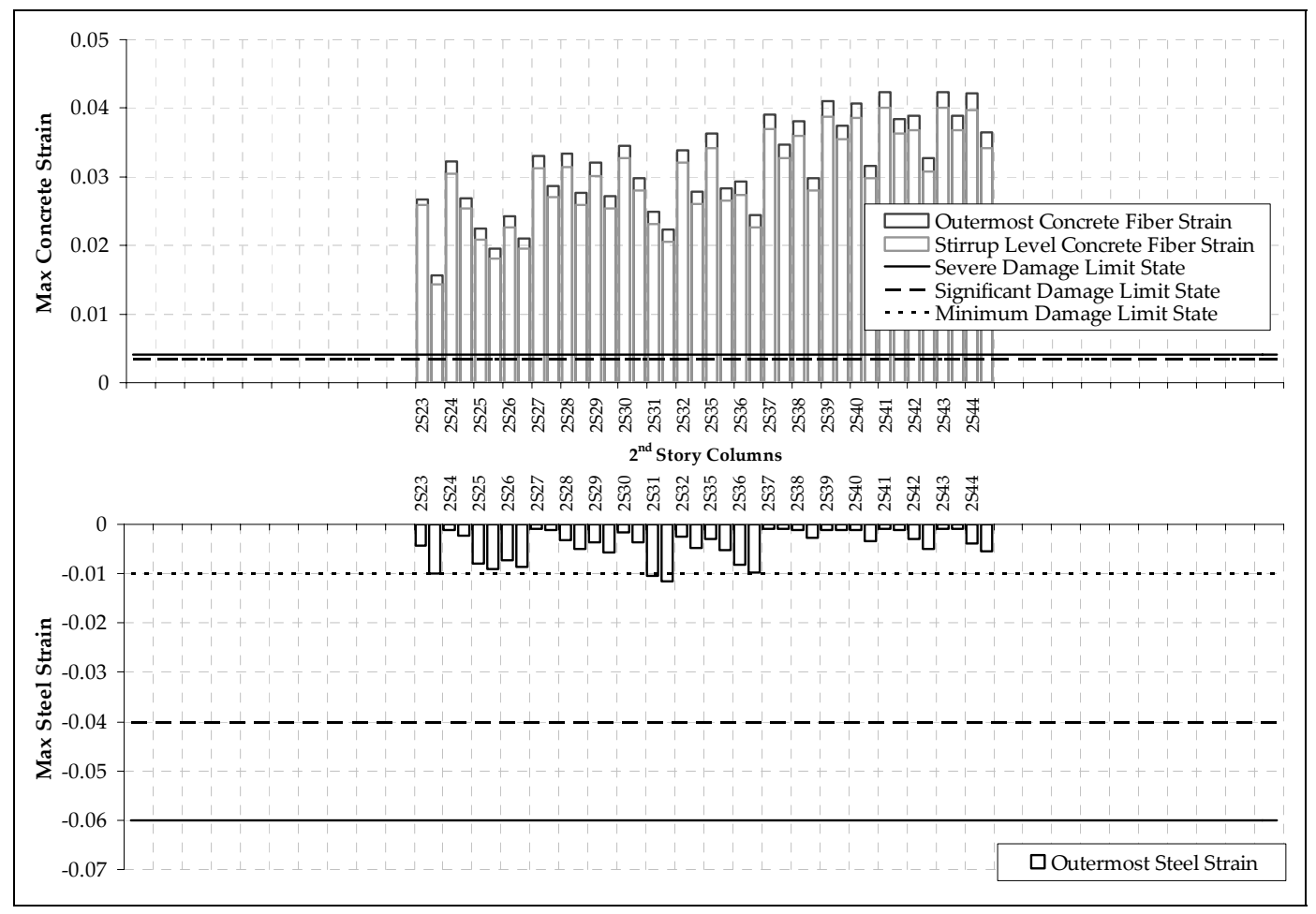

Figure 4.6 Damage levels of the columns in the $Y$ direction loading (continued)

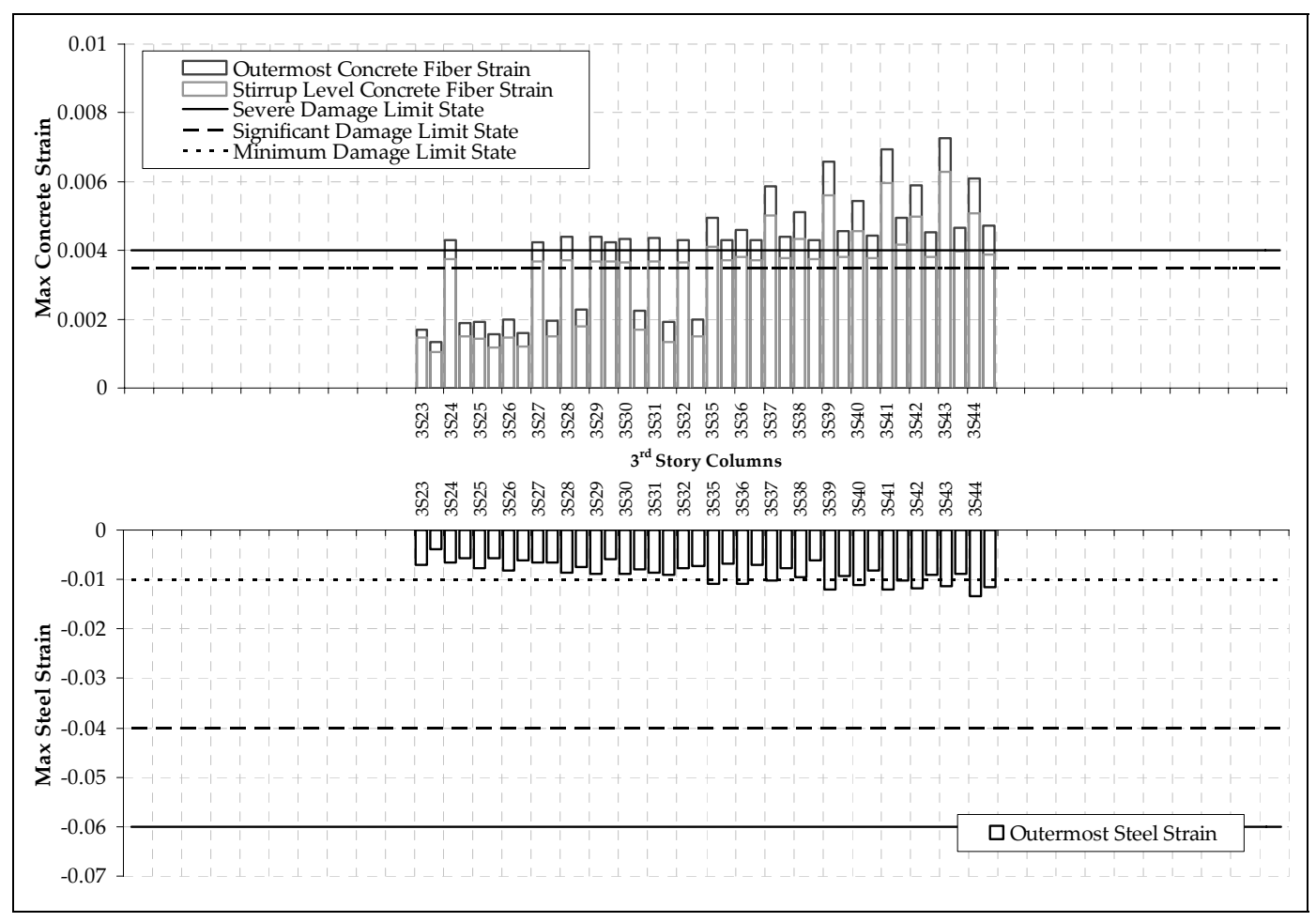

Figure 4.6 Damage levels of the columns in the Y direction loading (continued) 


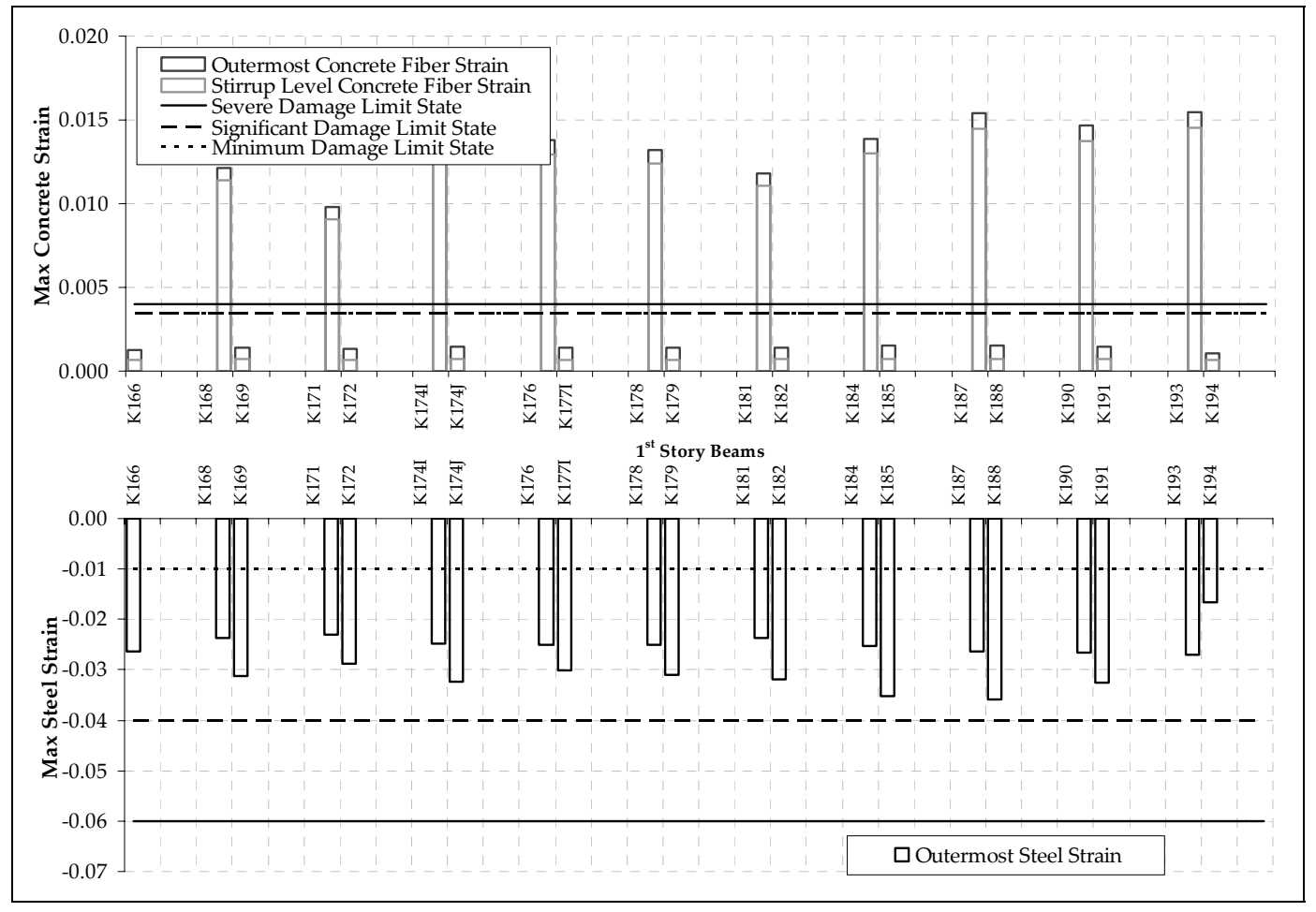

Figure 4.7 Damage levels of the beams in the $\mathrm{Y}$ direction loading

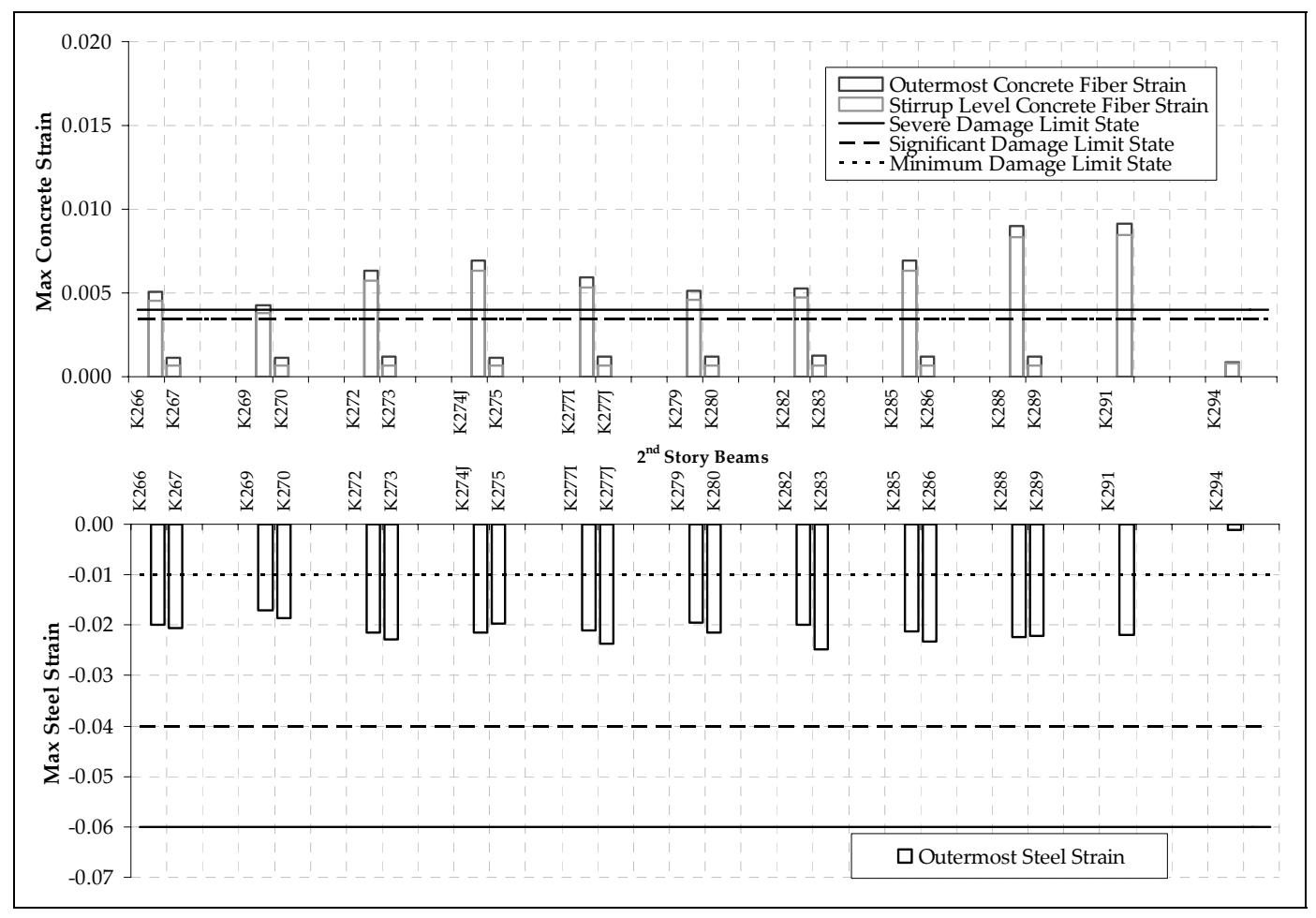

Figure 4.7 Damage levels of the beams in the $Y$ direction loading (continued) 


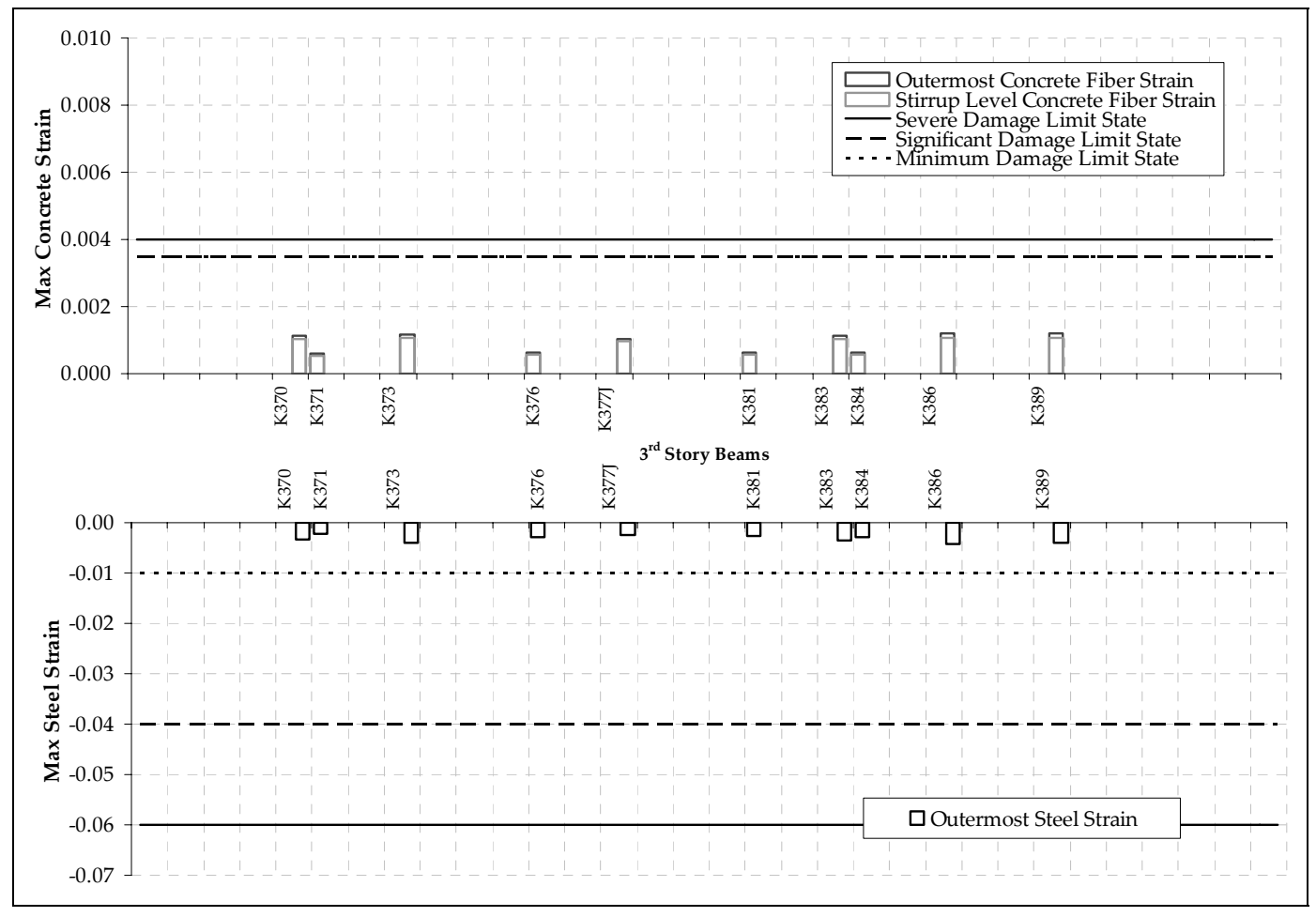

Figure 4.7 Damage levels of the beams in the $Y$ direction loading (continued)

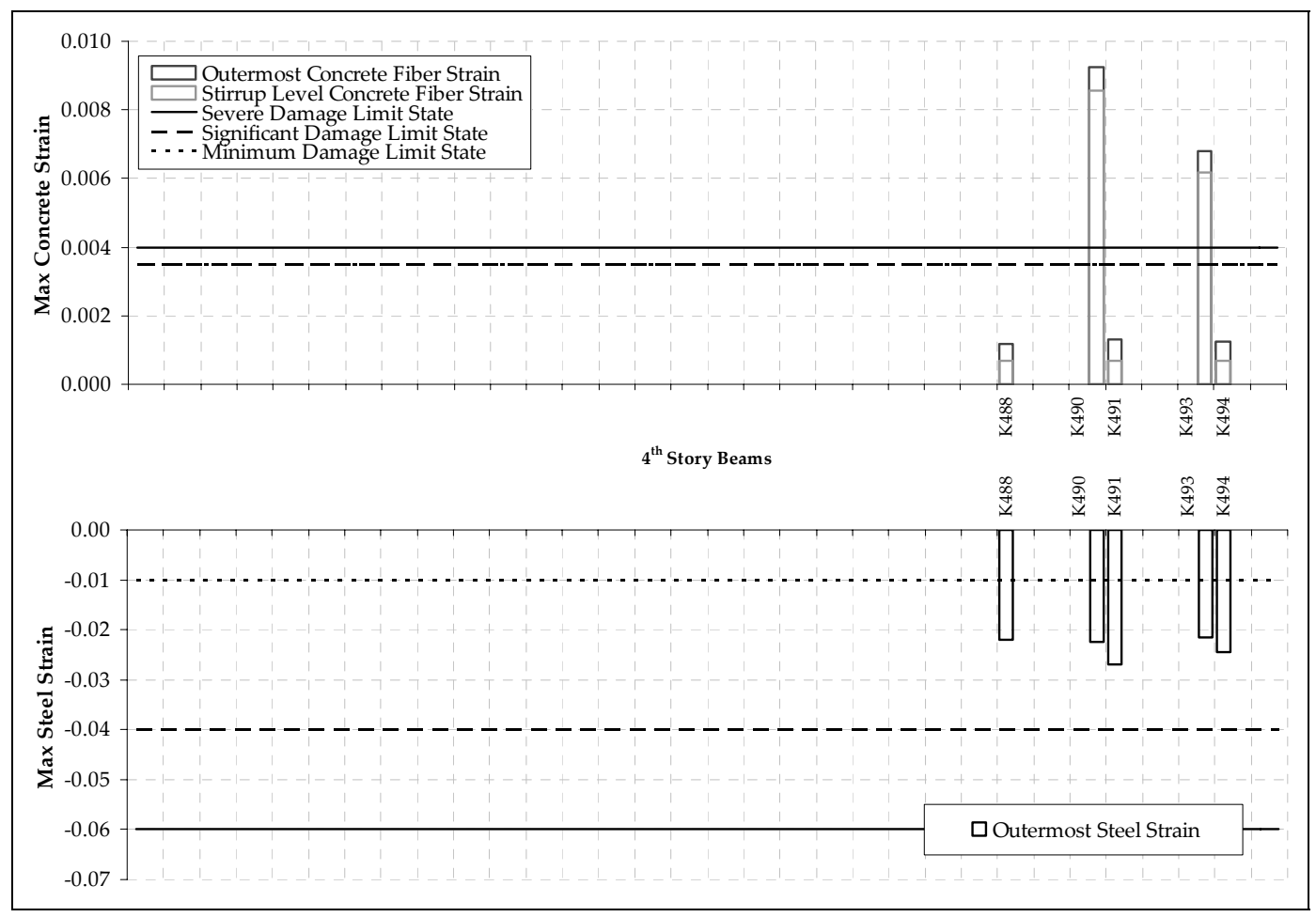

Figure 4.7 Damage levels of the beams in the $\mathrm{Y}$ direction loading (continued) 
Table 4.1 Global performance of the existing building

\begin{tabular}{|c|c|c|c|c|c|c|c|c|c|}
\hline \multicolumn{5}{|c|}{ X Direction } & \multicolumn{5}{|c|}{ Y Direction } \\
\hline $\begin{array}{l}\text { Story } \\
\text { No. }\end{array}$ & $\begin{array}{l}V_{s t r} \\
(k N)\end{array}$ & $\begin{array}{l}V_{N C} \\
(k N)\end{array}$ & $\% N C$ & $\begin{array}{l}\% N C \\
\text { Beams }\end{array}$ & $\begin{array}{c}\text { Story } \\
\text { No. }\end{array}$ & $\begin{array}{l}V_{s t r} \\
(k N)\end{array}$ & $\begin{array}{l}V_{N C} \\
(k N)\end{array}$ & $\% N C$ & $\begin{array}{l}\% \text { NC } \\
\text { Beams }\end{array}$ \\
\hline 1 & 5900 & 5900 & 100.00 & 55.56 & 1 & 4775 & 47775 & 100.00 & 31.25 \\
\hline 2 & 5213 & 4877 & 93.55 & 0.00 & 2 & 4256 & 1975 & 46.41 & 31.25 \\
\hline 3 & 3640 & 0 & 0.00 & 0.00 & 3 & 2993 & 1581 & 52.84 & 0.00 \\
\hline 4 & 1364 & 0 & 0.00 & 0.00 & 4 & 1121 & 0 & 0.00 & 6.25 \\
\hline
\end{tabular}

\subsection{Implementation of the Retrofit Design Methodology The Verification of Design}

Considering the calculated deficiencies, retrofit strategy should intend to reduce deformation demands at lower story members. In this sense, four shear walls having cross section dimensions of $300 \times 3250 \mathrm{~mm}$ and two shear walls having cross section dimensions of 300x6900 mm were added in the $X$ and $Y$ directions, respectively. The ratio of the cross section area of shear walls in the considered earthquake direction to the floor area is 0.008 in the $\mathrm{X}$ and 0.007 in the $\mathrm{Y}$ direction. 3D mathematical model and plan view of the retrofitted building are shown in Figure 4.8 and Figure 4.9, respectively.

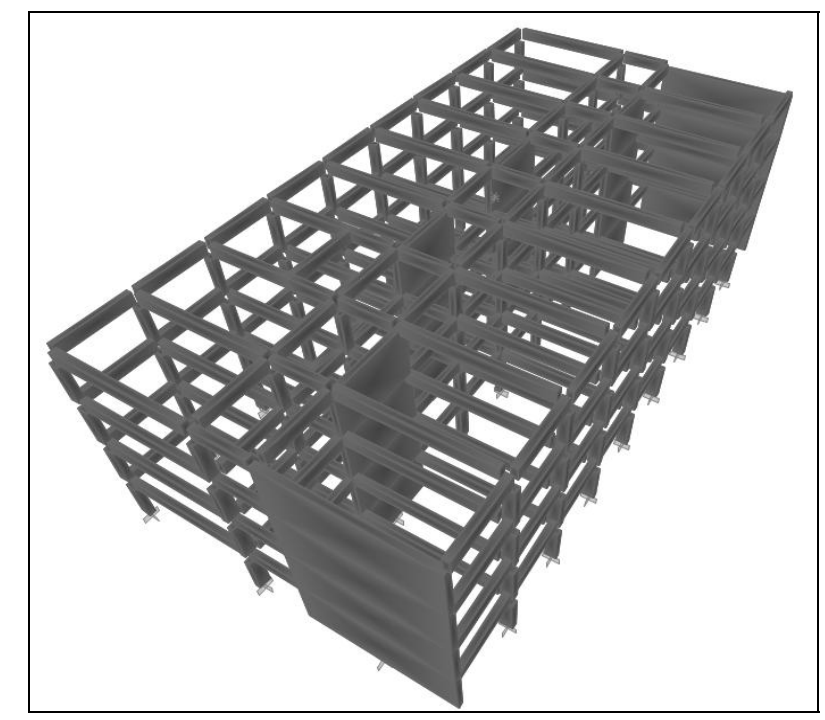

Figure 4.8 3D Mathematical model of the retrofitted four story school building 


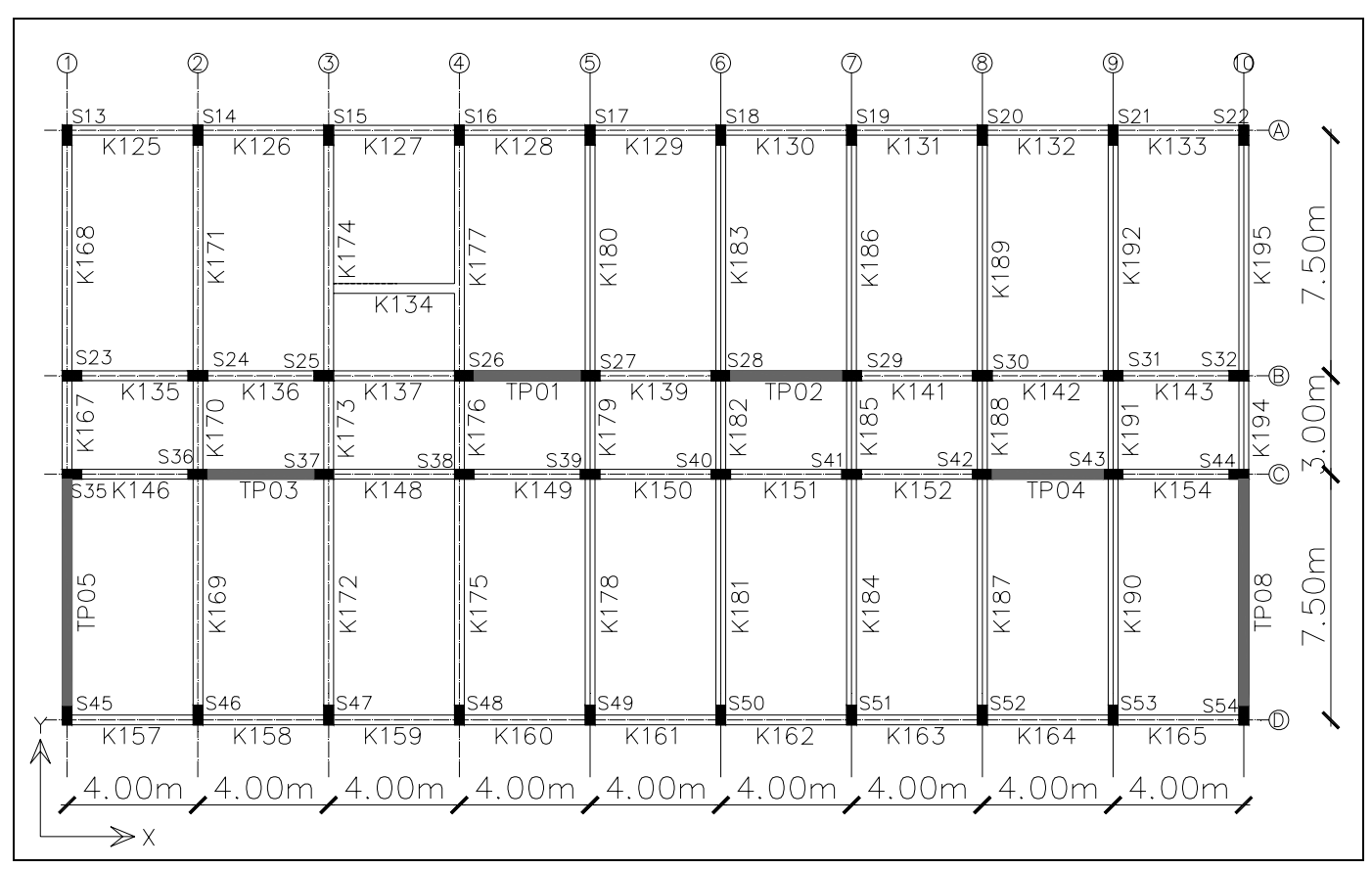

Figure 4.9 Plan view of the retrofitted building

Characteristic concrete strength was taken as $20 \mathrm{MPa}$ in compression and characteristic yield strength of reinforcement bars was taken as $420 \mathrm{MPa}$ for new members.

Shear walls were located not to disturb symmetry in plan and not to intervene with the architectural functions. Effective fundamental periods in both directions were computed by using cracked stiffnesses of reinforced concrete members. Effective fundamental periods in the $\mathrm{X}$ and $\mathrm{Y}$ directions were computed as $0.29 \mathrm{sec}$. and $0.23 \mathrm{sec}$. respectively. These periods were 0.61 and 0.80 seconds before retrofitting with the added walls. Employing Equation 2.1, target roof displacement demands were computed as $0.053 \mathrm{~m}$ and $0.036 \mathrm{~m}$ for the $\mathrm{X}$ and Y directions, which were $0.132 \mathrm{~m}$ and $0.186 \mathrm{~m}$ before retrofitting. Target roof displacements and corresponding uniform drift distributions computed for the design earthquake having $2 \%$ probability of exceedance in 50 years are shown in Figures 4.10 and 4.11 together with the drift profile of the existing and retrofitted buildings at the associated performance points. 

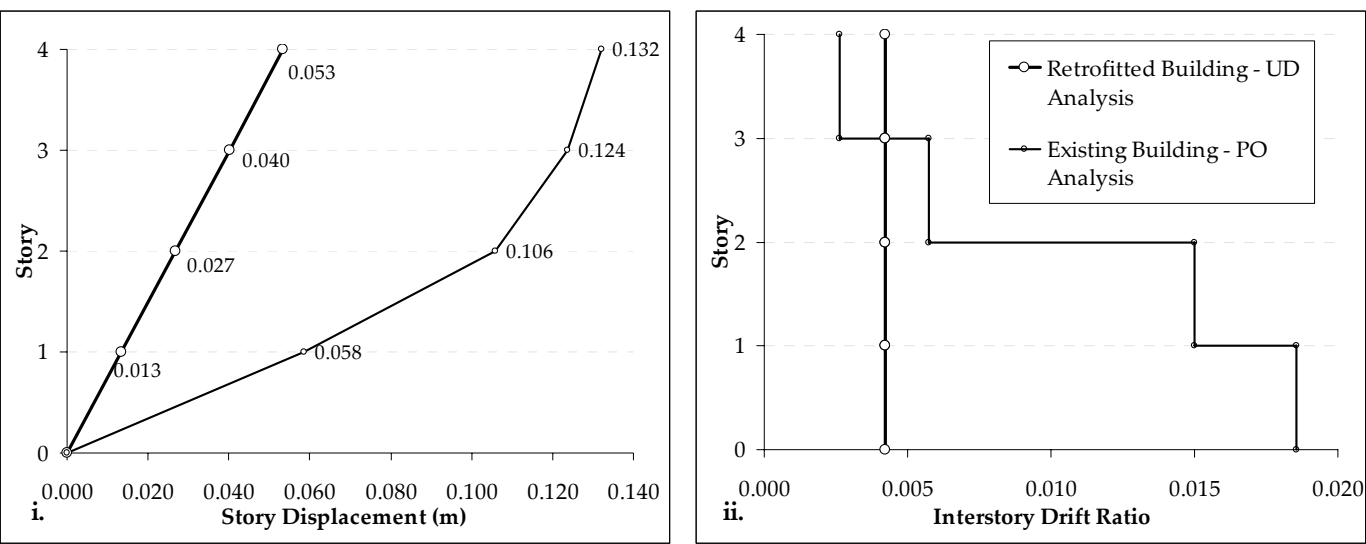

Figure 4.10 i. Story displacements, ii. Interstory drift distributions in X direction
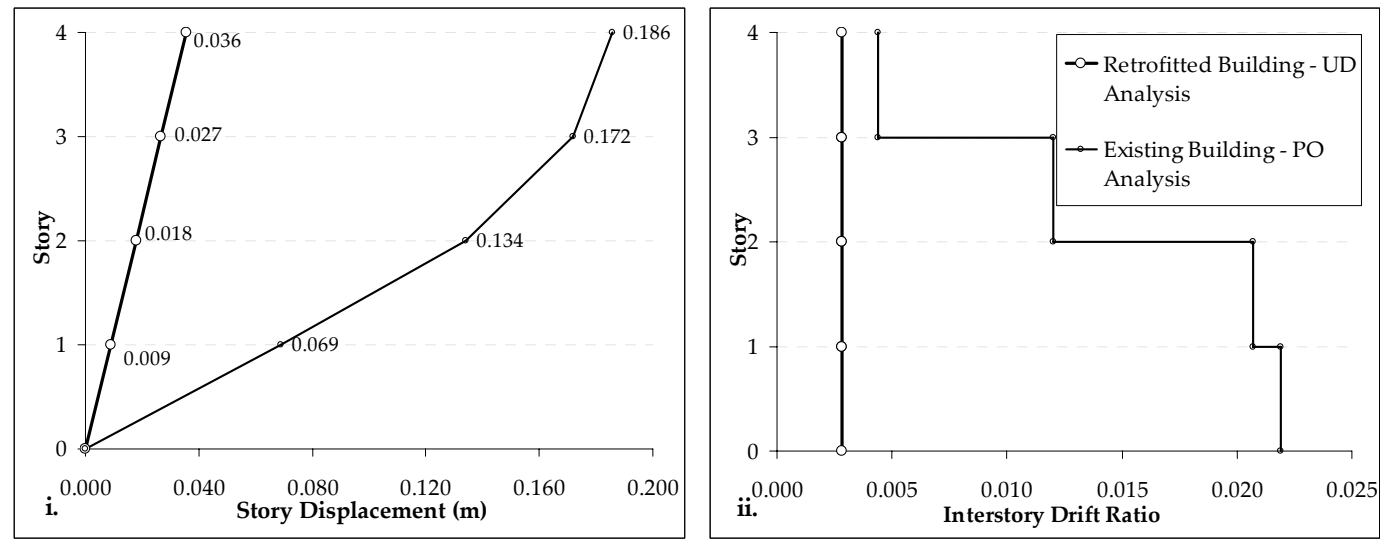

Figure 4.11 i. Story displacements, ii. Interstory drift distributions in $\mathrm{Y}$ direction

Imposing the drift distributions shown in Figures 4.10 and 4.11 by employing a linear elastic analysis, chord rotation demands were calculated and presented in Figures 4.12 and 4.13 together with the chord rotation capacities at the significant damage limit of the columns in order to determine deficient columns. Interventions may be required in order to increase their deformation capacities or shear strengths. 


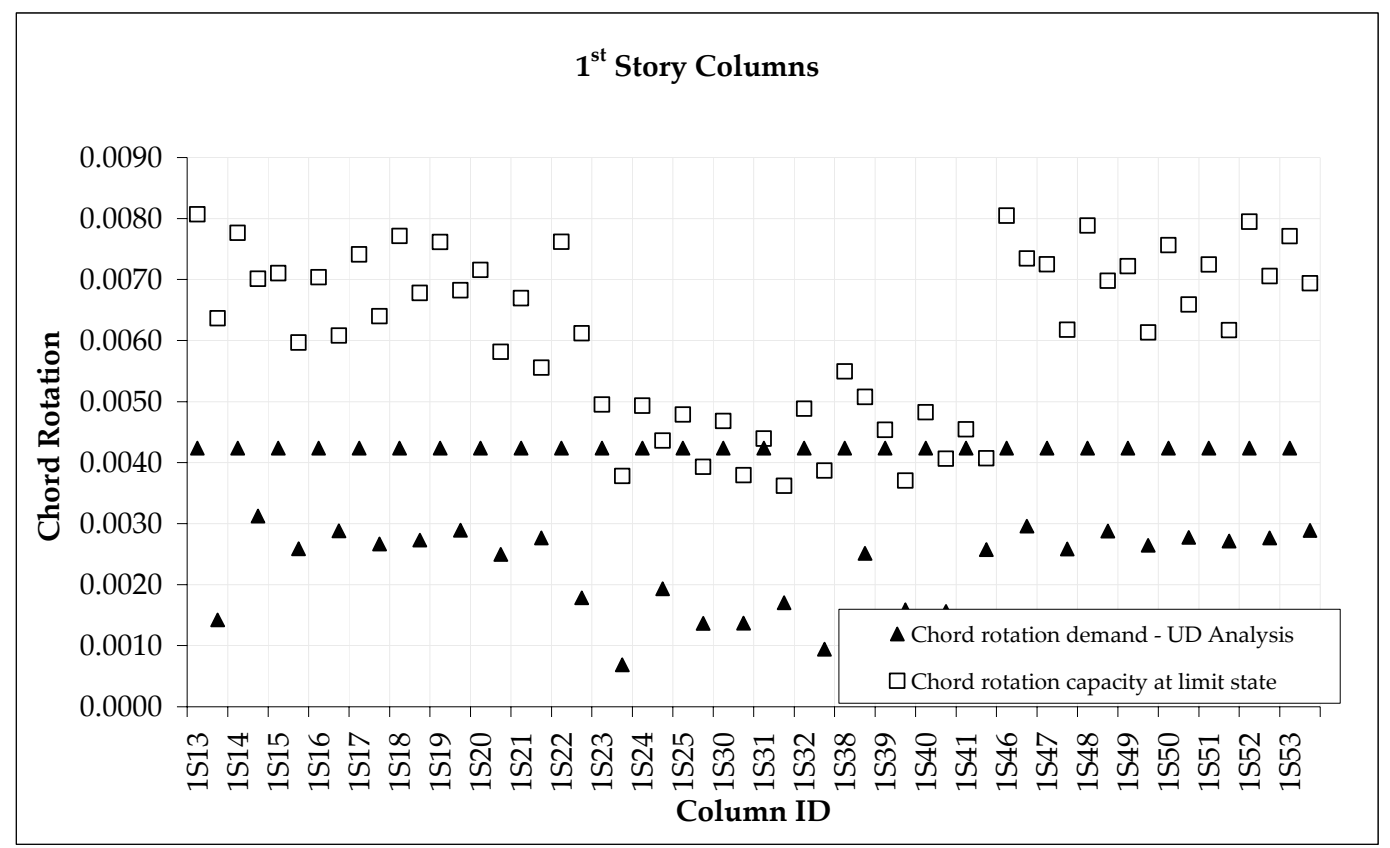

Figure 4.12 Comparison of chord rotation demands and capacities for columns in the $X$ direction for significant damage performance level

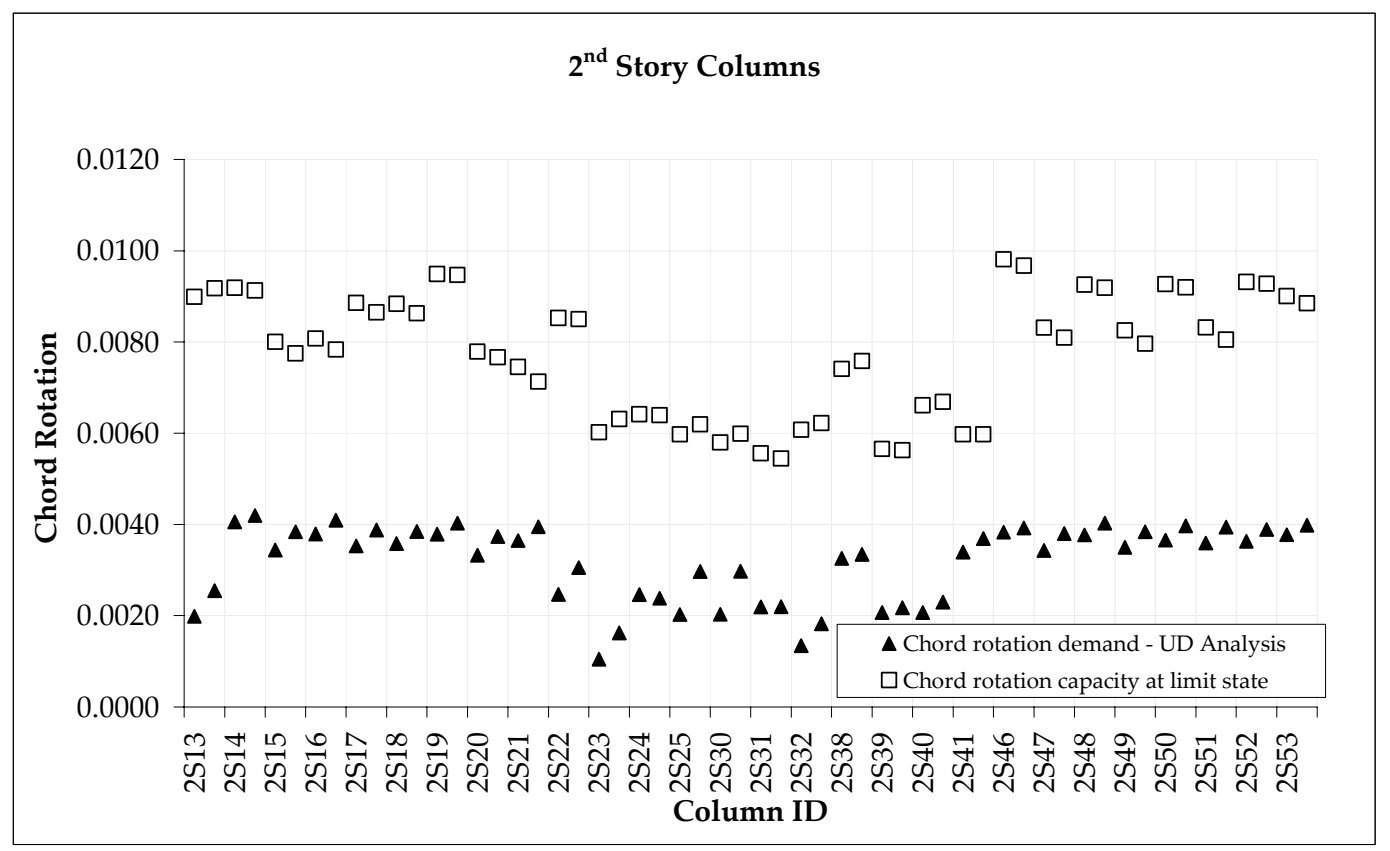

Figure 4.12 Comparison of chord rotation demands and capacities for columns in the $\mathrm{X}$ direction for significant damage performance level (continued) 


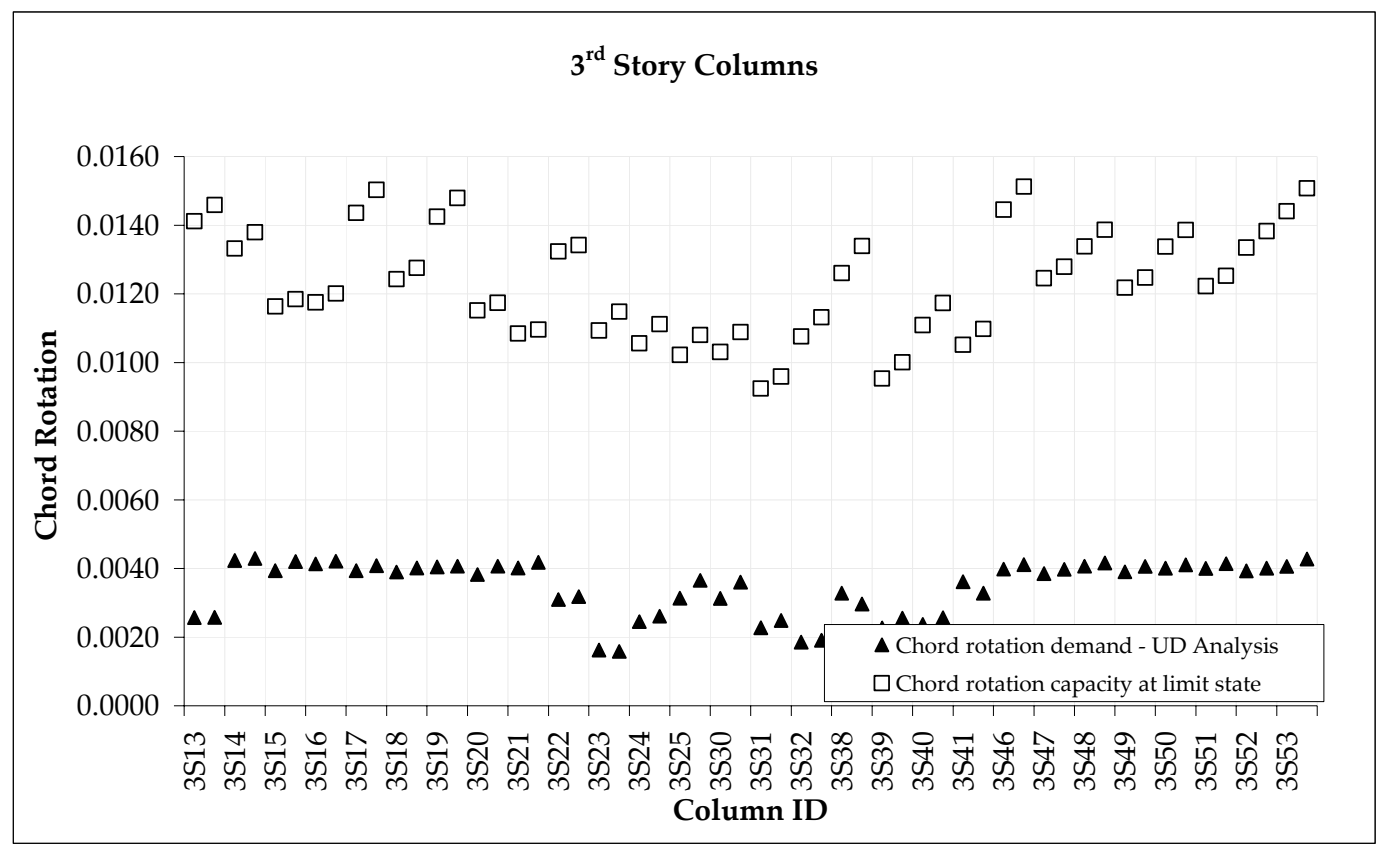

Figure 4.12 Comparison of chord rotation demands and capacities for columns in the $X$ direction for significant damage performance level (continued)

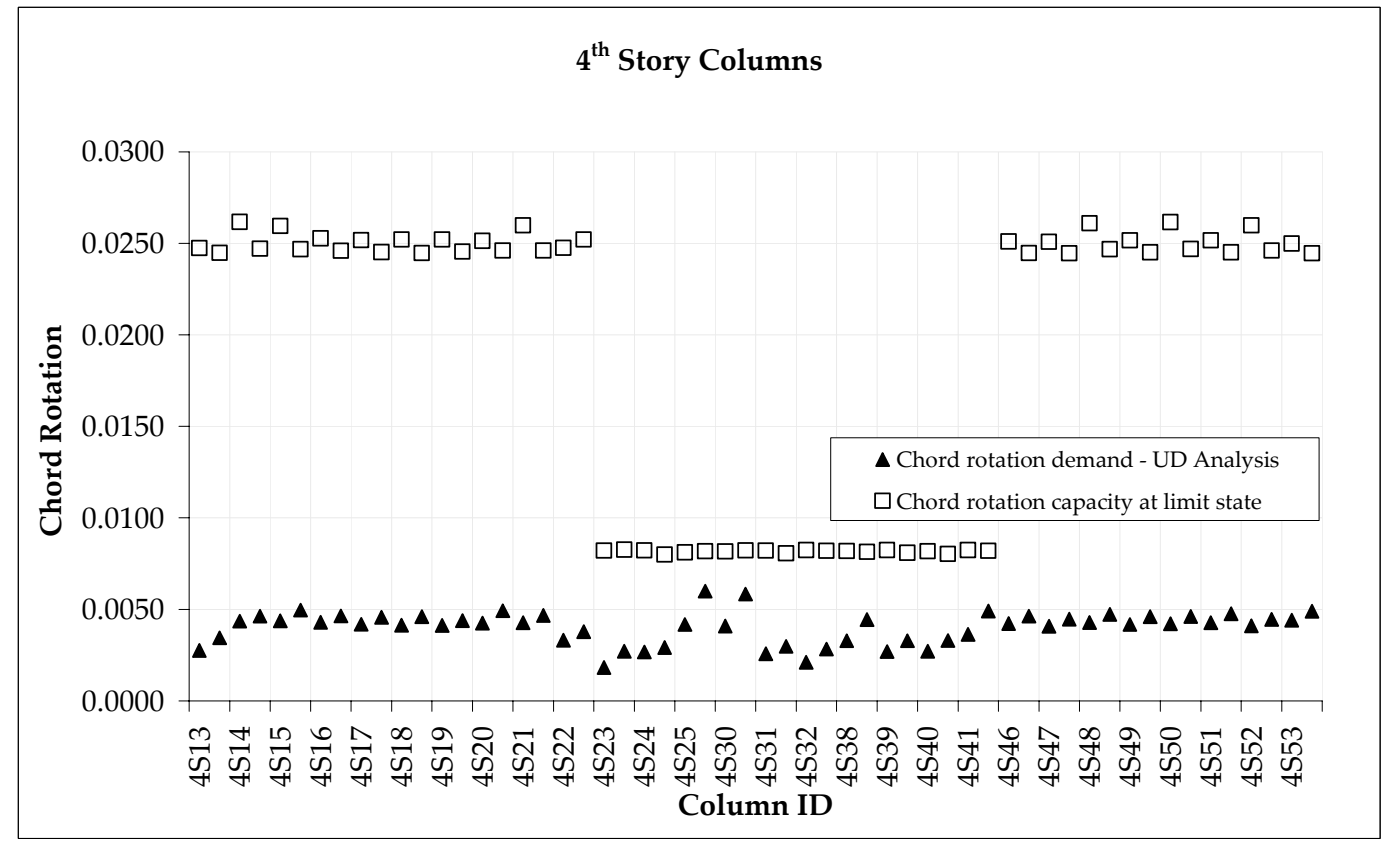

Figure 4.12 Comparison of chord rotation demands and capacities for columns in the $X$ direction for significant damage performance level (continued) 


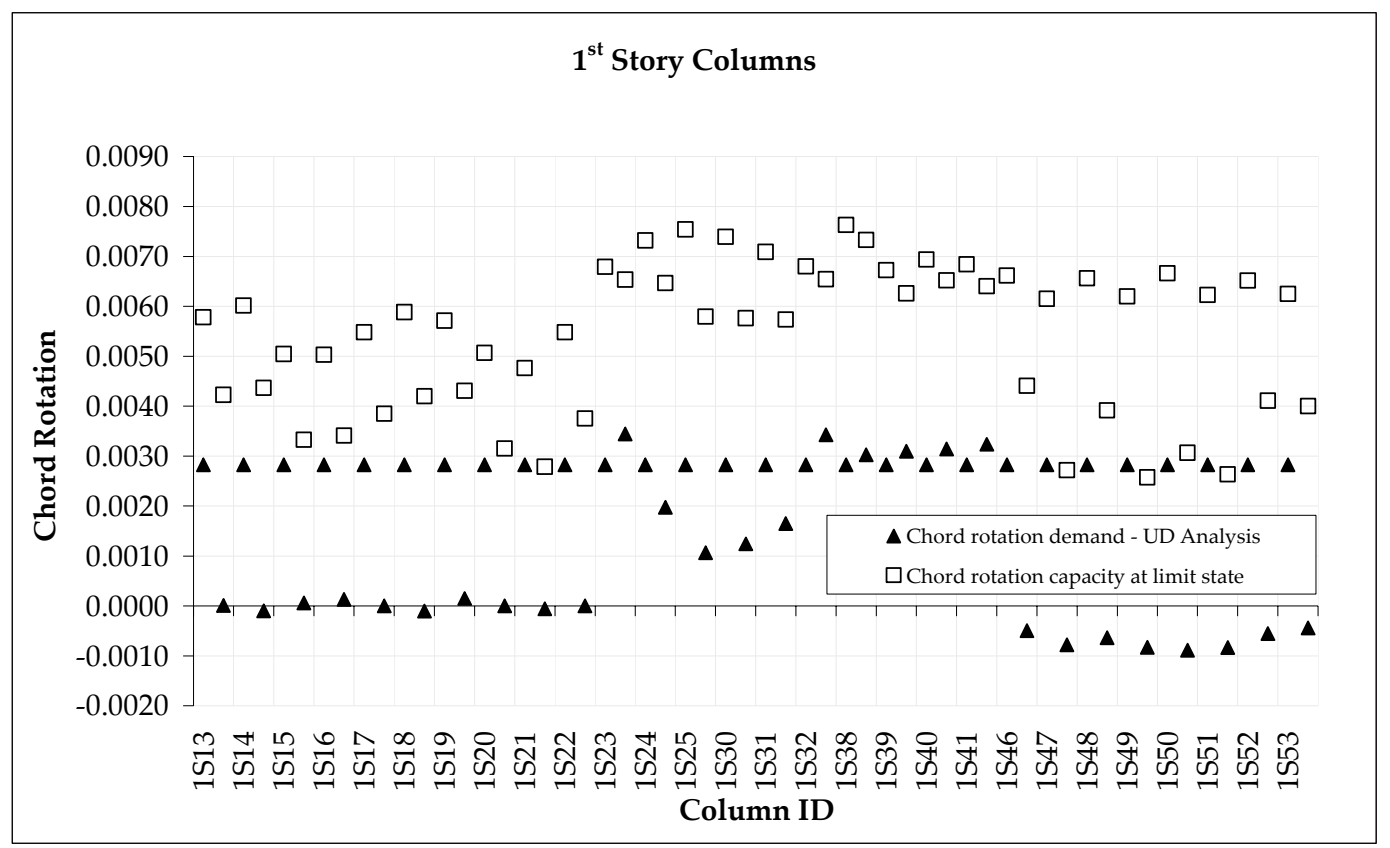

Figure 4.13 Comparison of chord rotation demands and capacities for columns in the $Y$ direction for significant damage performance level

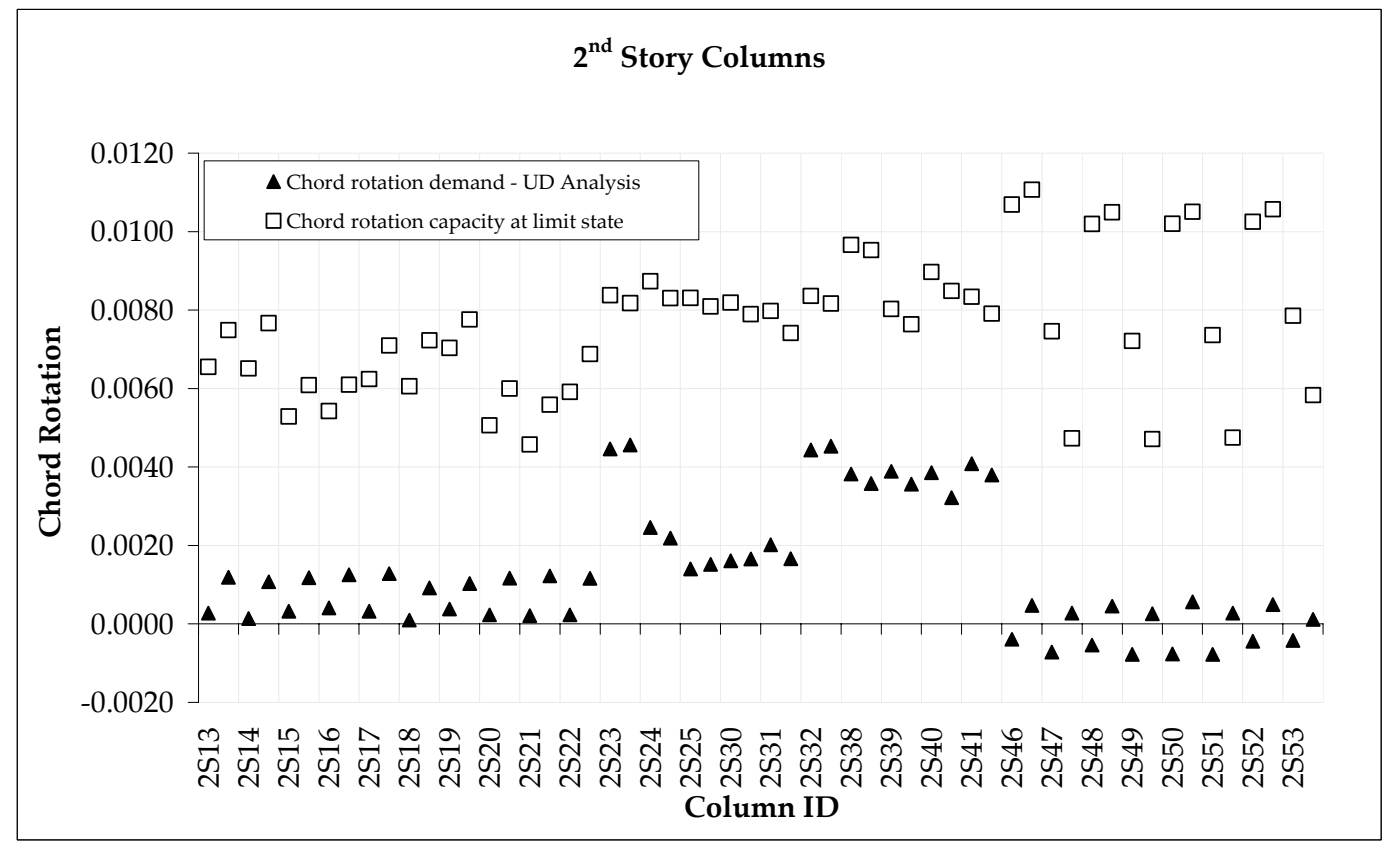

Figure 4.13 Comparison of chord rotation demands and capacities for columns in the $\mathrm{Y}$ direction for significant damage performance level (continued) 


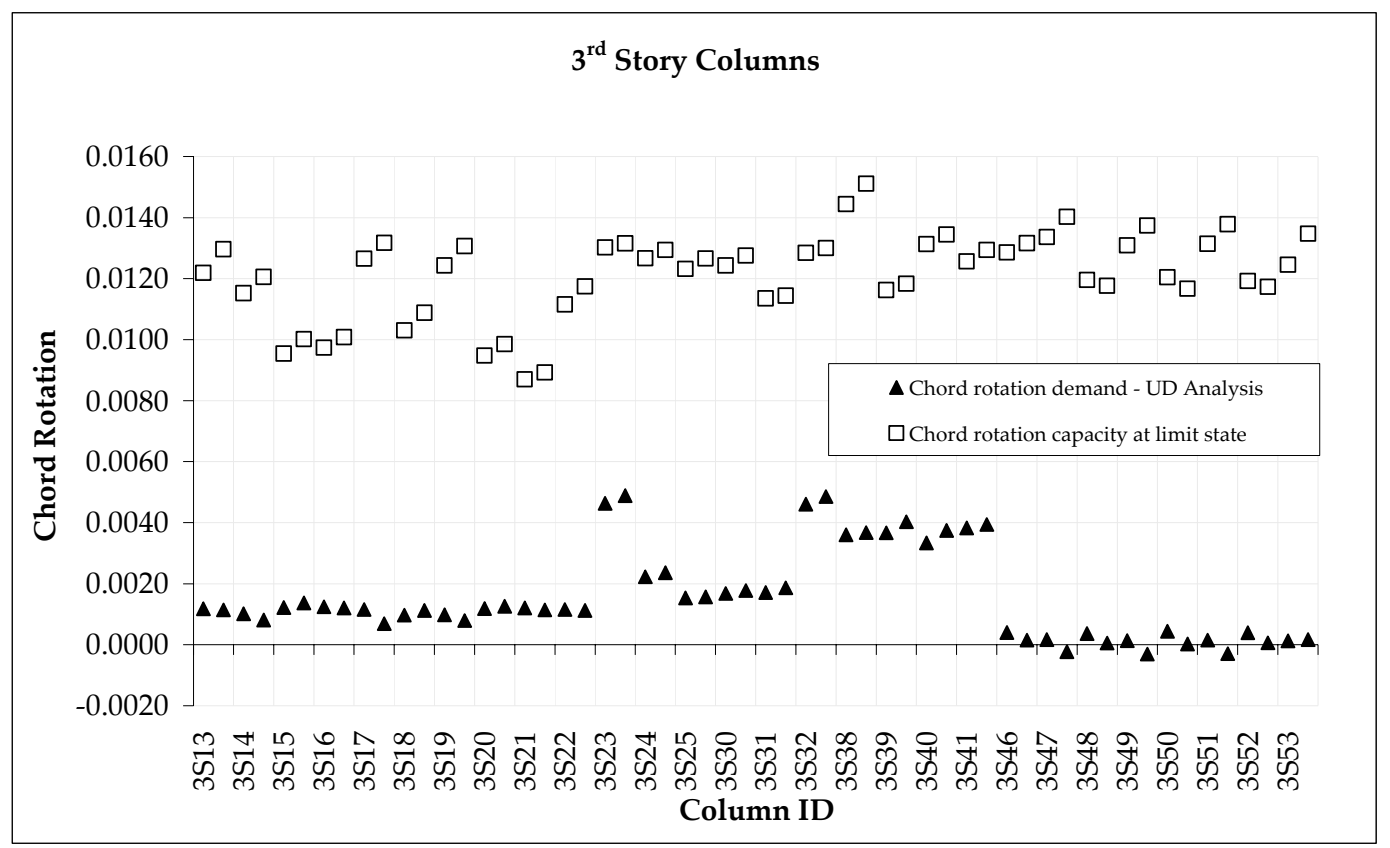

Figure 4.13 Comparison of chord rotation demands and capacities for columns in the $Y$ direction for significant damage performance level (continued)

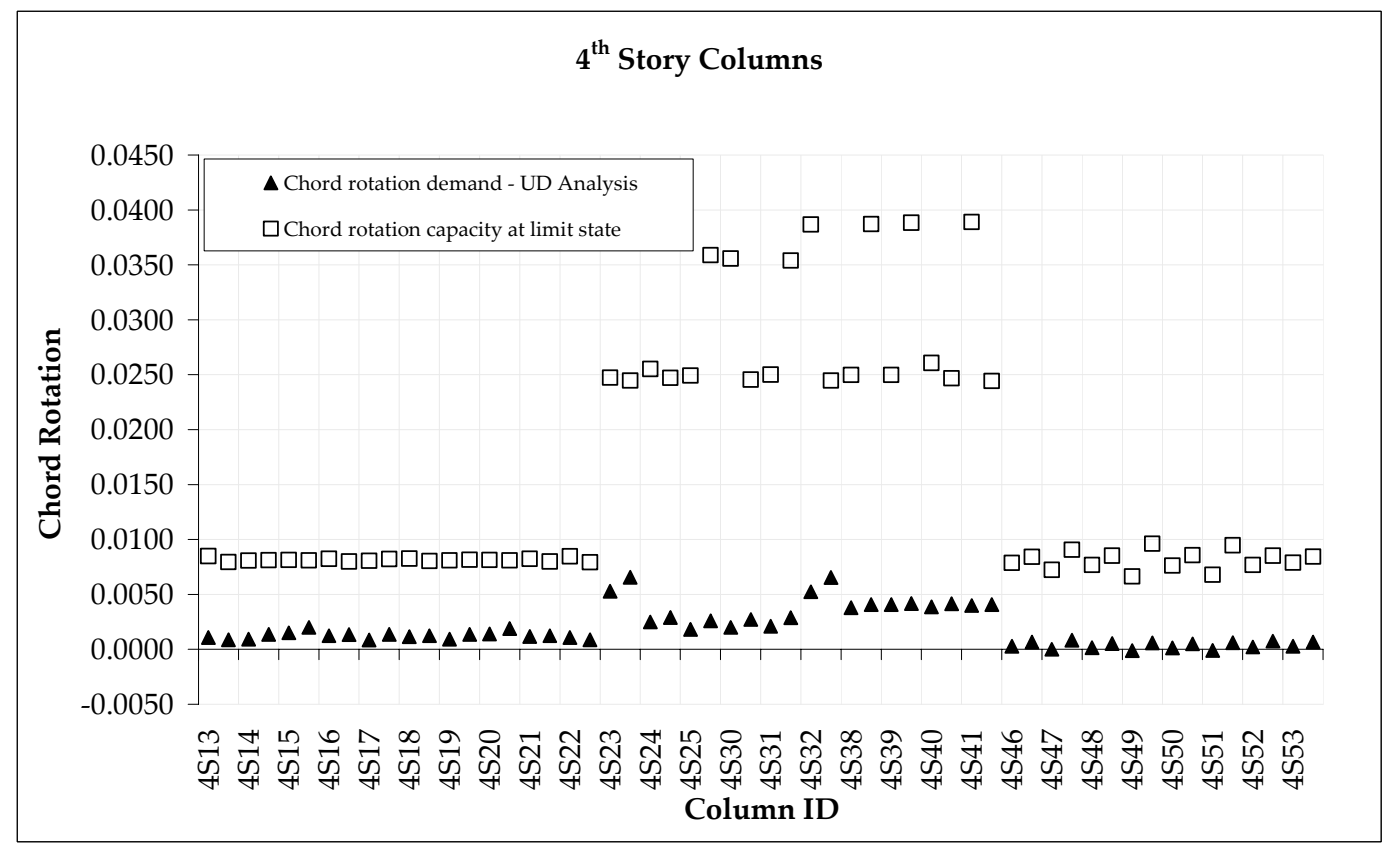

Figure 4.13 Comparison of chord rotation demands and capacities for columns in the $Y$ direction for significant damage performance level (continued) 
It can be observed from Figures 4.12 and 4.13 that none of the column chord rotation demands exceeds chord rotation capacities calculated at the significant damage limit state. Adding shear walls successfully limited the deformation demands in columns due to increased lateral rigidity.

In order to prevent brittle failure of reinforced concrete members, shear demands occur were compared with shear capacities. Columns S24, S25, S30, S31, S38, S39, S40, and S41 at the first story of the retrofitted building were classified as brittle. Thus, these columns were wrapped with FRP sheets to increase shear capacity. FRP design was made by following the procedures stated in TEC 2007. Details of FRP design for column S25 is given below as an example. Shear demand of the column S25 at the first story was calculated as $191 \mathrm{kN}$, however shear capacity of the column was $164 \mathrm{kN}$. In order to increase its shear capacity, FRP sheets having thickness of $0.165 \mathrm{~mm}$ were wrapped around the column with a spacing of $150 \mathrm{~mm}$.

$\begin{array}{cccl}n_{f} & 1 & \text { where } & \\ t_{f}(\mathrm{~mm}) & 0.165 & & \\ w_{f}(\mathrm{~mm}) & 85 & n_{f} & \text { Number of FRP layers } \\ E_{f}(\mathrm{MPa}) & 230000 & t_{f} & \text { Thickness of one layer FRP sheet } \\ \varepsilon_{f} & 0.004 & w_{f} & \text { Width of FRP sheets } \\ d(\mathrm{~mm}) & 585 & E_{f} & \text { Elastic modulus of FRP sheets } \\ s_{f}(\mathrm{~mm}) & 0.165 & S_{f} & \text { Spacing between FRP sheets } \\ \varepsilon_{u} & 0.01 & \varepsilon_{f} & \text { Strain limit of FRP } \\ V_{f}(k N) & 47.5 & d & \text { Depth of section } \\ V_{c}(k N) & 93.1 & V_{f} & \text { Increase in shear capacity due to FRP wrapping } \\ V_{s}(k N) & 49.4 & V_{c} & \text { Shear capacity by concrete } \\ V_{r}(k N) & 191.6 & V_{s} & \text { Shear capacity by steel } \\ V_{\max }(k N) & 336.6 & V_{r} & \text { Shear capacity of retrofitted column }\end{array}$

Detailing of shear walls intends to satisfy the computed chord rotation demands at the bases of walls. Existing columns were taken into account as boundary elements of the walls. Bar buckling phenomenon in the existing columns was also considered as a limiting state of deformation capacities. Moment - curvature analysis results and particular limit states in terms of curvatures are presented for shear walls TP01 and TP05 in Figures 4.14 and 4.16 together with reinforcement and section detailing of the walls in Figures 4.15 and 
4.17. Longitudinal reinforcement ratio in web section of shear walls TP01 and TP05 is 0.0025 corresponding to the minimum ratio stated in TEC 2007. In case of shear, lateral reinforcement ratio is 0.0025 as well, which is the minimum ratio stated in TEC 2007. This amount of minimum lateral reinforcement was sufficient to meet the shear demands of $1551 \mathrm{kN}$ for TP01 and $2941 \mathrm{kN}$ for TP05.

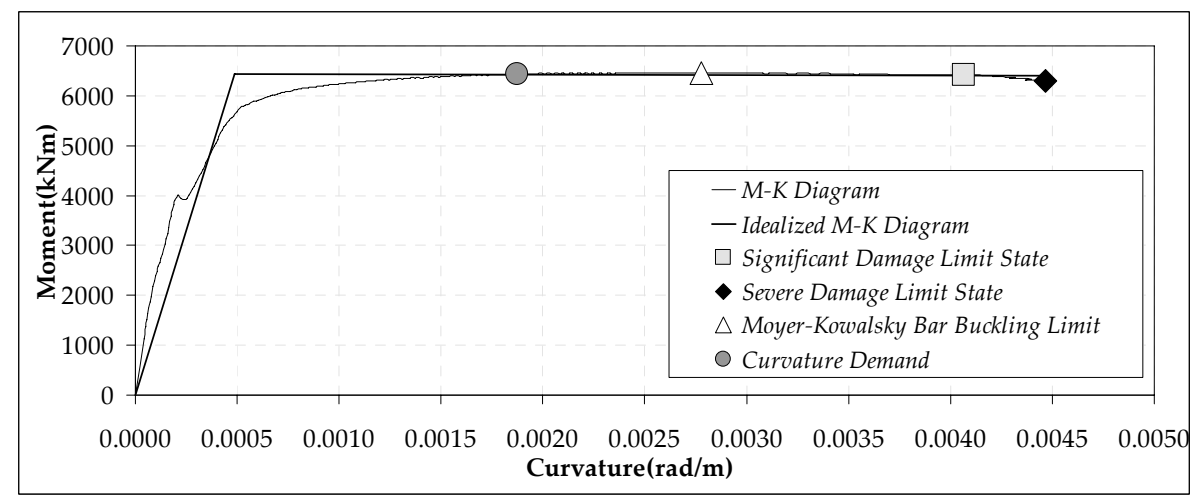

Figure 4.14 Moment curvature analysis of shear wall TP01

\begin{tabular}{|c|c|c|c|}
\hline \multirow{3}{*}{$\begin{array}{l}\text { E. } \\
\text { Eे } \\
\text { D } \\
\text { ' }\end{array}$} & $\begin{array}{c}600 \mathrm{~mm} \\
570\end{array}$ & $3250 \mathrm{~mm}$ & $\begin{array}{c}600 \mathrm{~mm} \\
570\end{array}$ \\
\hline & $\begin{array}{c}4 \varnothing 24+4 \varnothing 20 \\
\varnothing 8 / 200\end{array}$ & $32 \varnothing 10$ & $\begin{array}{c}4 \varnothing 24+4 \varnothing 20 \\
\varnothing 8 / 200\end{array}$ \\
\hline & Existing Colun & TP01 & Existing Colum \\
\hline
\end{tabular}

Figure 4.15 Detailing of TP01

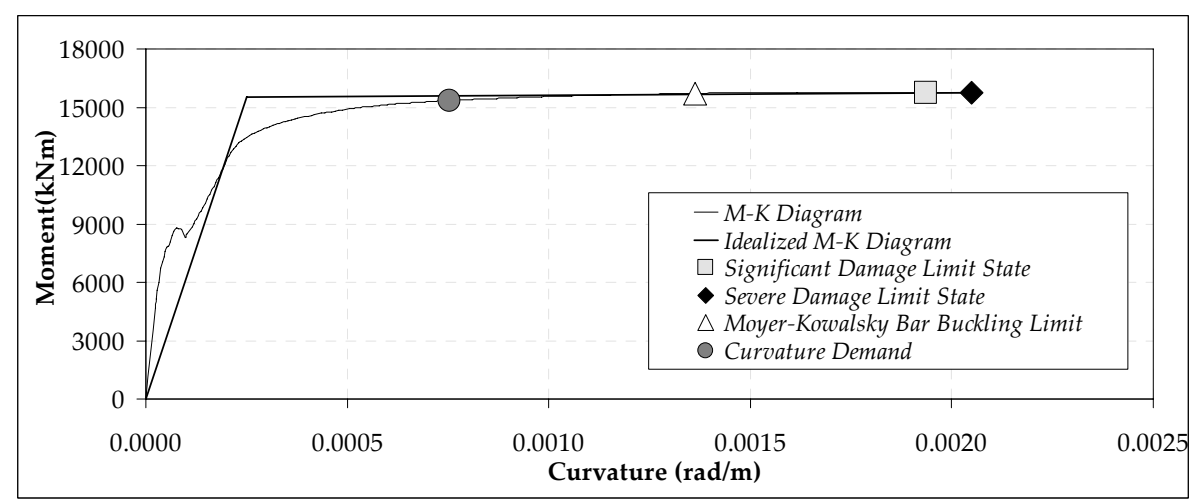

Figure 4.16 Moment curvature analysis of shear wall TP05 


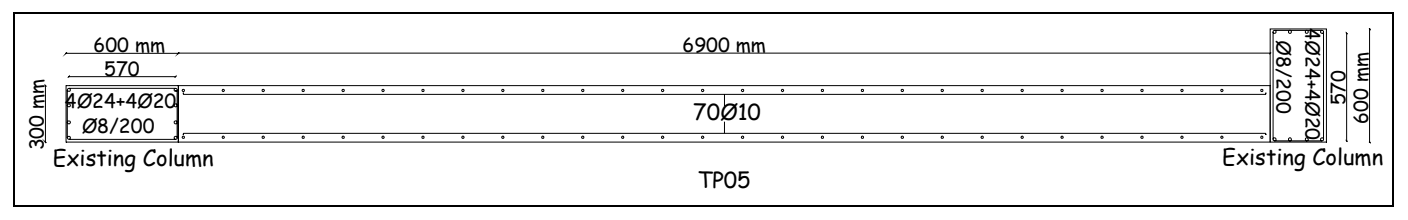

Figure 4.17 Detailing of TP05

\subsection{Verification of the Proposed Retrofit Design Methodology}

Retrofit design was verified through nonlinear evaluation of seismic performance at Life Safety in both $\mathrm{X}$ and $\mathrm{Y}$ directions of loading. Thus, pushover analysis was conducted. Capacity curves of existing and retrofitted buildings are shown in Figure 4.18. Increase in both lateral load carrying capacity and lateral stiffness is clearly observed in Figure 4.18 as a result of new added shear walls.

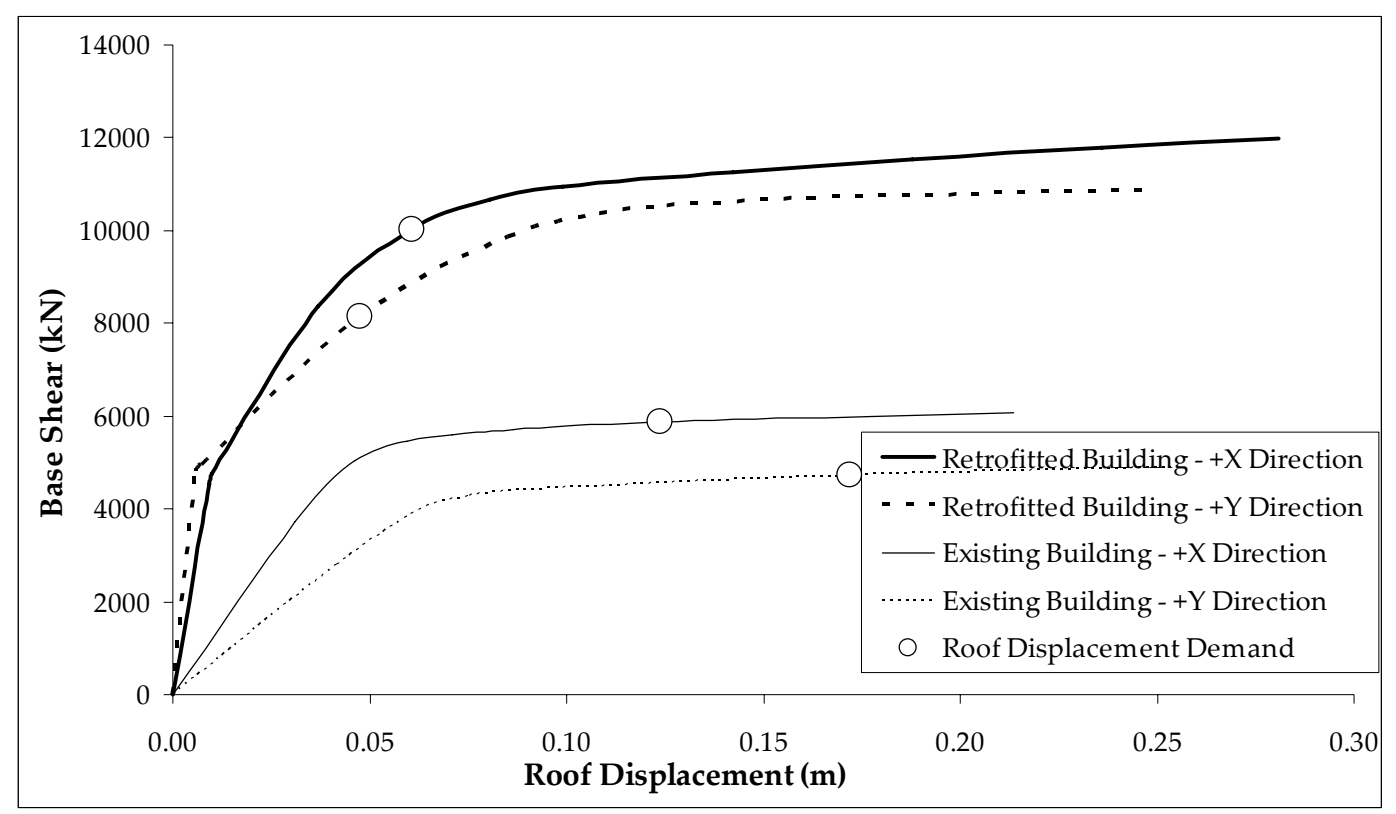

Figure 4.18 Capacity curves of the retrofitted and existing buildings 
Drift distributions of existing and retrofitted buildings are shown in Figures 4.19 and 4.20 whereas chord rotation demands calculated by employing uniform drift and pushover analyses are compared in Figures 4.21 and 4.22. Following Figures 4.21 and 4.22, it is observed that addition of shear walls decreased chord rotation demands of the existing columns significantly. Additionally, comparing chord rotation demands calculated from uniform drift and pushover analyses, it can be concluded that results are compatible with each other. Especially for the first story columns uniform drift results estimate the chord rotation demands obtained from the pushover analysis quite well.
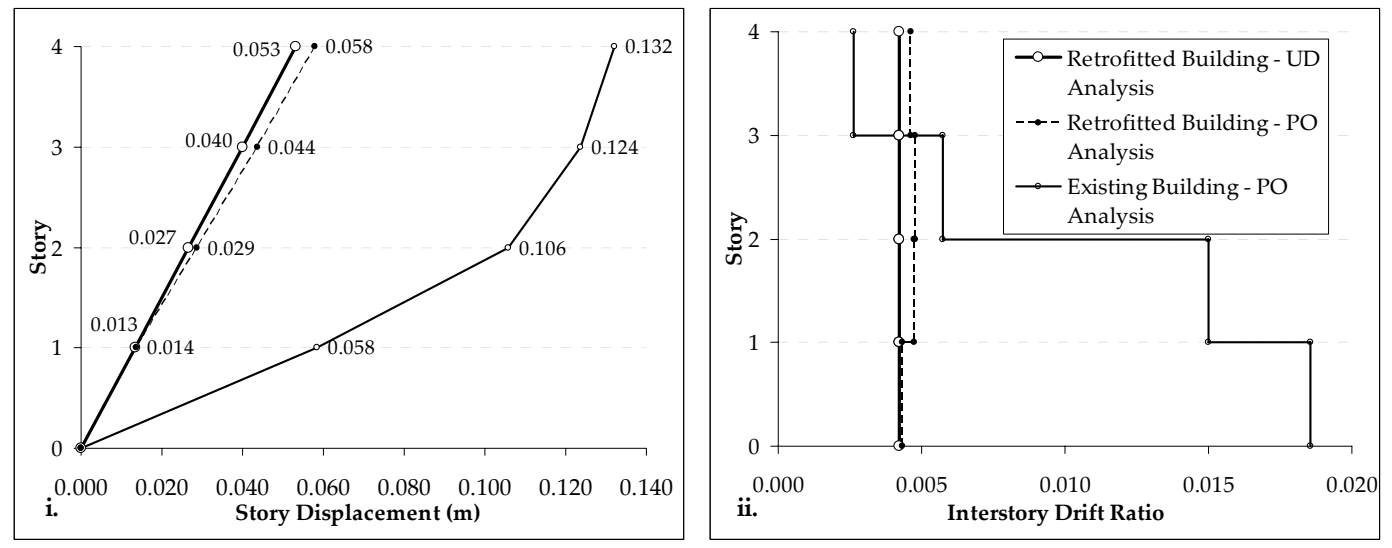

Figure 4.19 i. Story displacements, ii. Interstory drift distributions in X direction
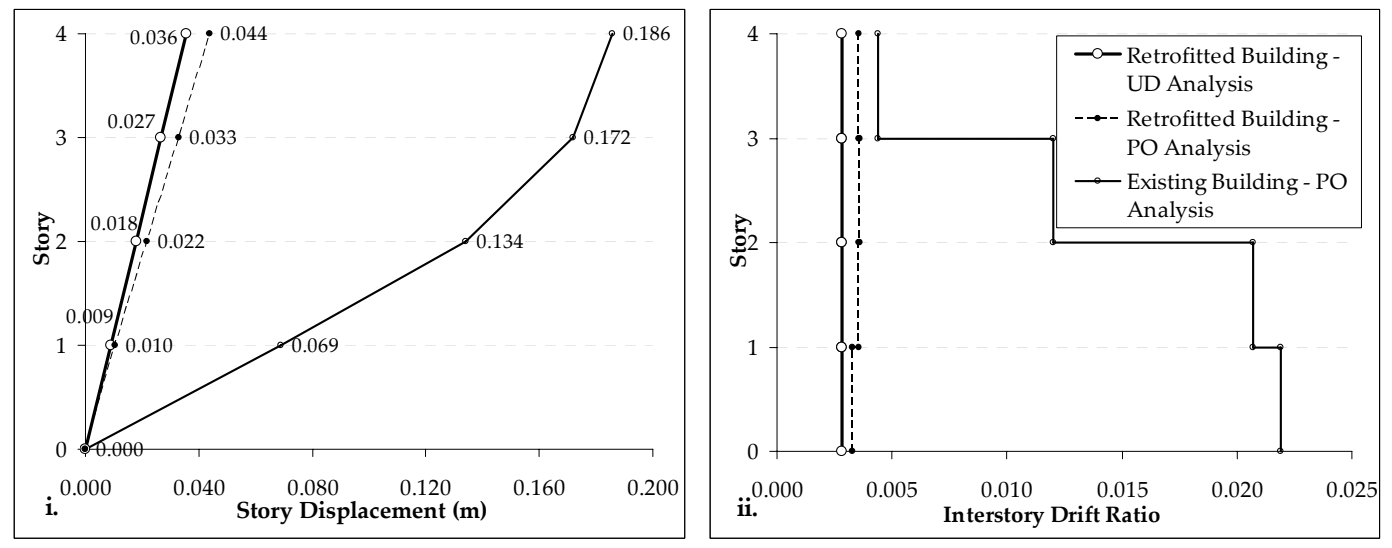

Figure 4.20 i. Story displacements, ii. Interstory drift distributions in $Y$ direction 


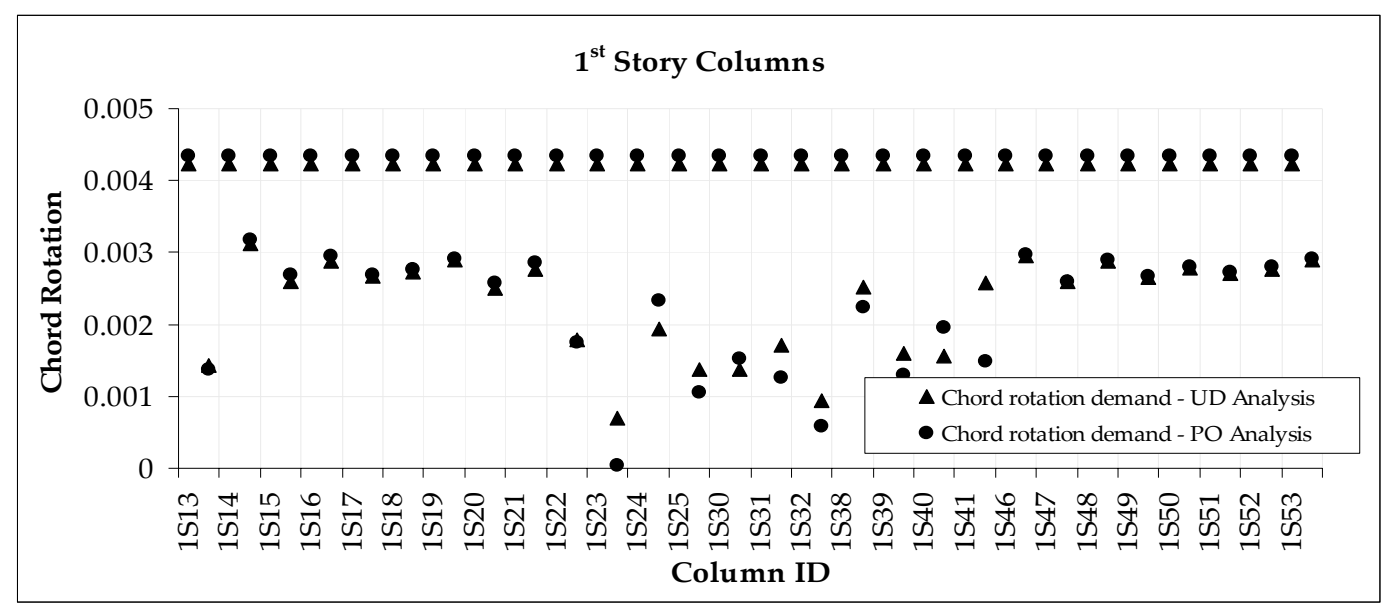

Figure 4.21 Chord rotation demands of the columns in the $\mathrm{X}$ direction loading

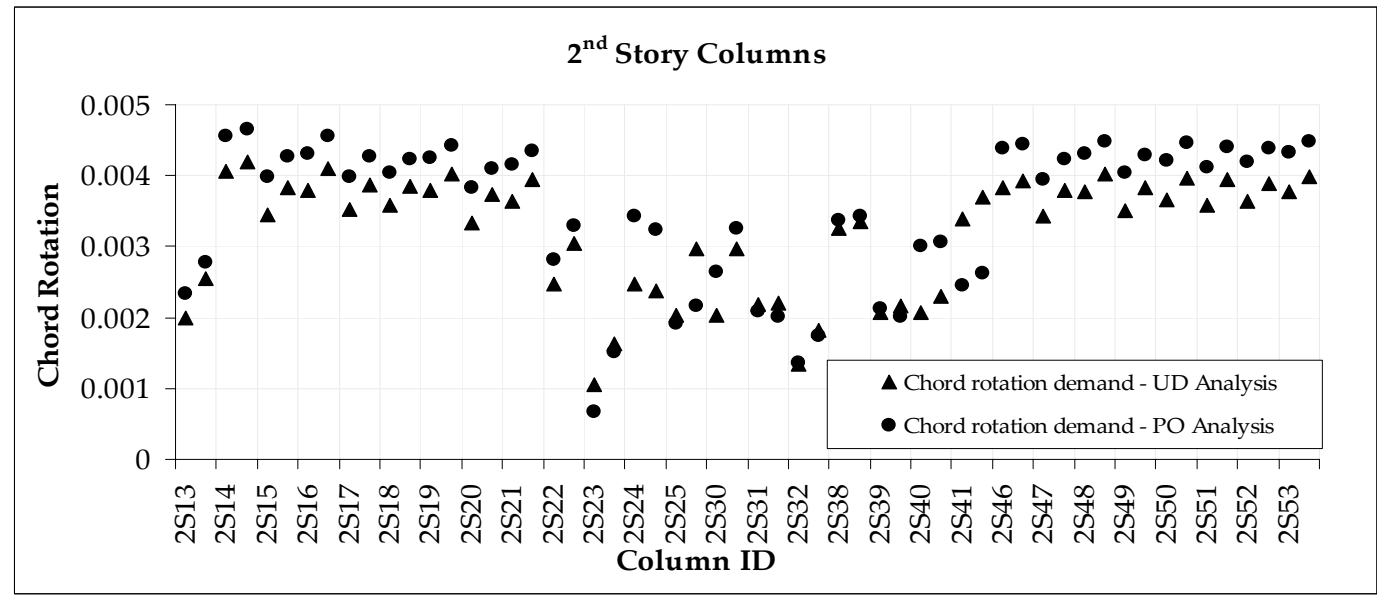

Figure 4.21 Chord rotation demands of the columns in the $X$ direction loading (continued)

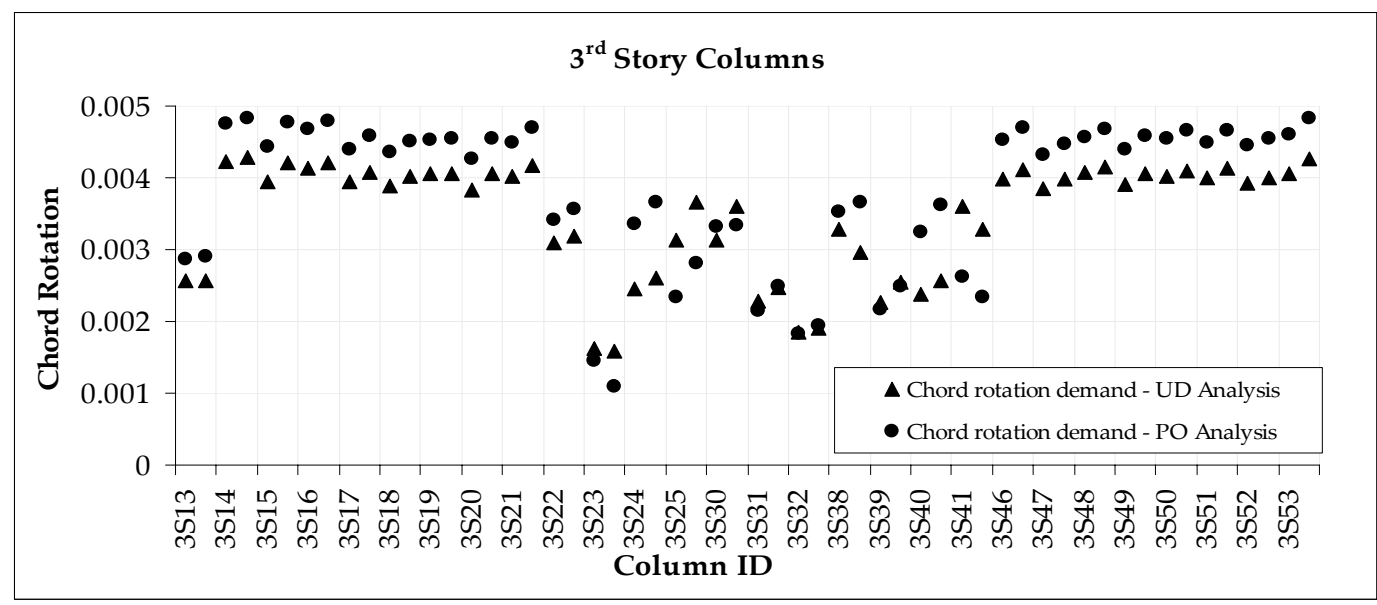

Figure 4.21 Chord rotation demands of the columns in the $\mathrm{X}$ direction loading (continued) 


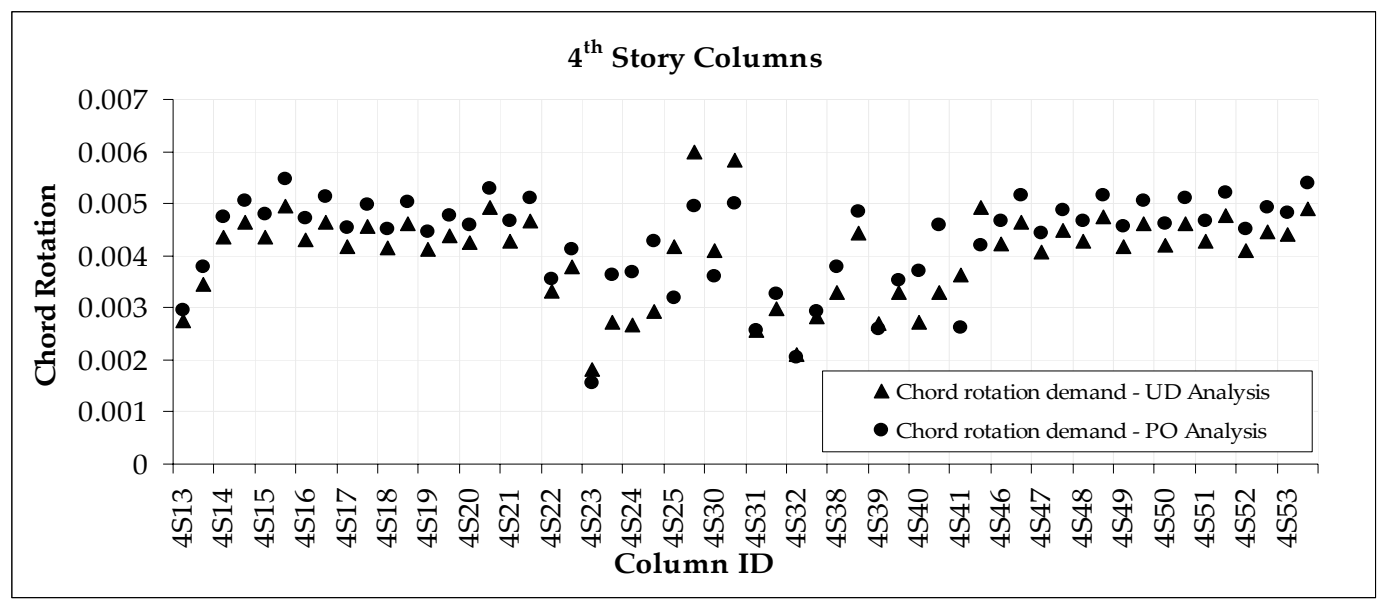

Figure 4.21 Chord rotation demands of the columns in the $\mathrm{X}$ direction loading (continued)

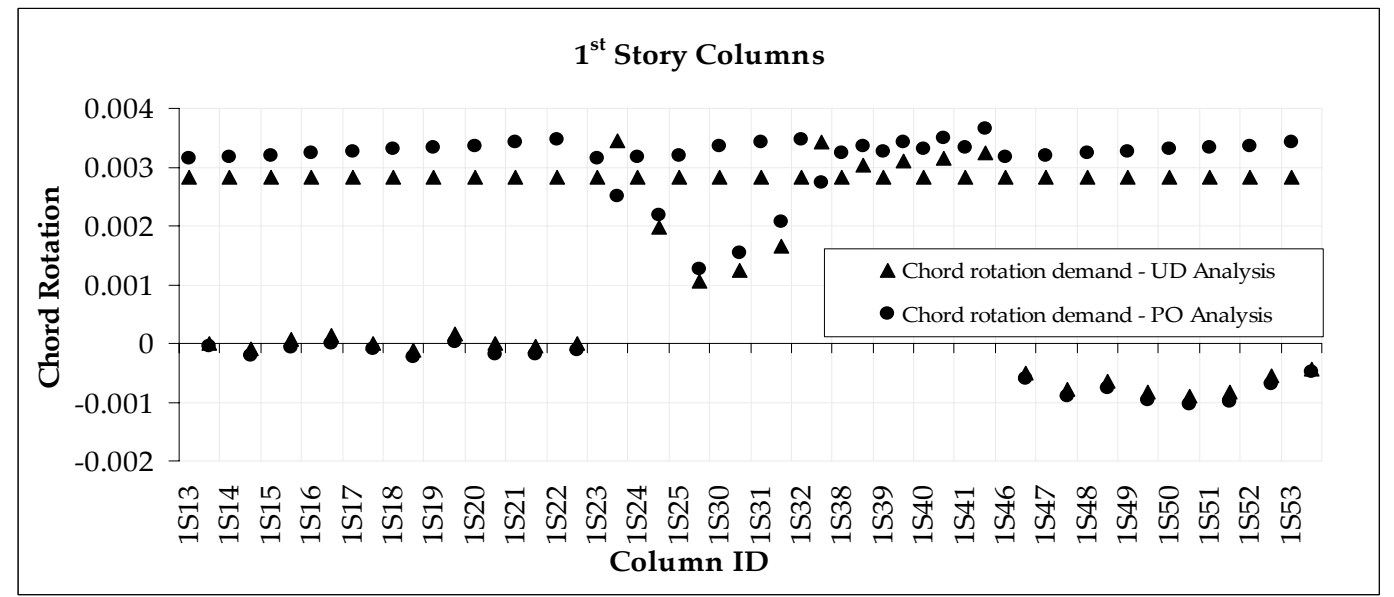

Figure 4.22 Chord rotation demands of the columns in the $\mathrm{Y}$ direction loading

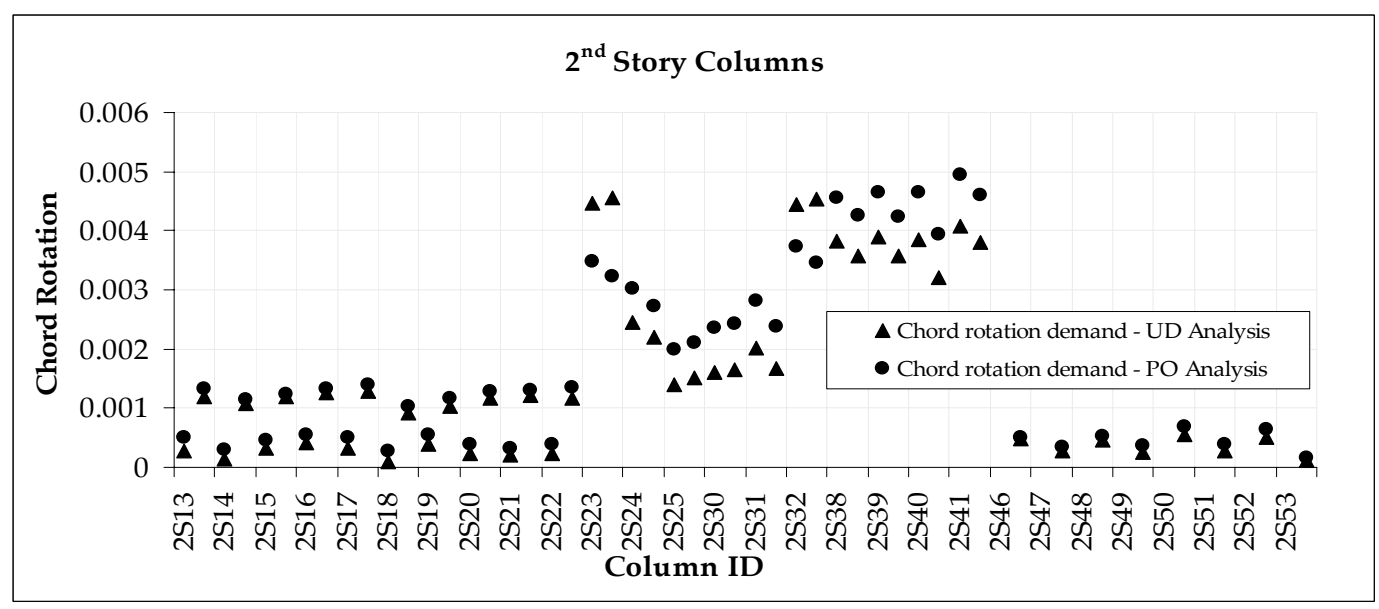

Figure 4.22 Chord rotation demands of the columns in the Y direction loading (continued) 


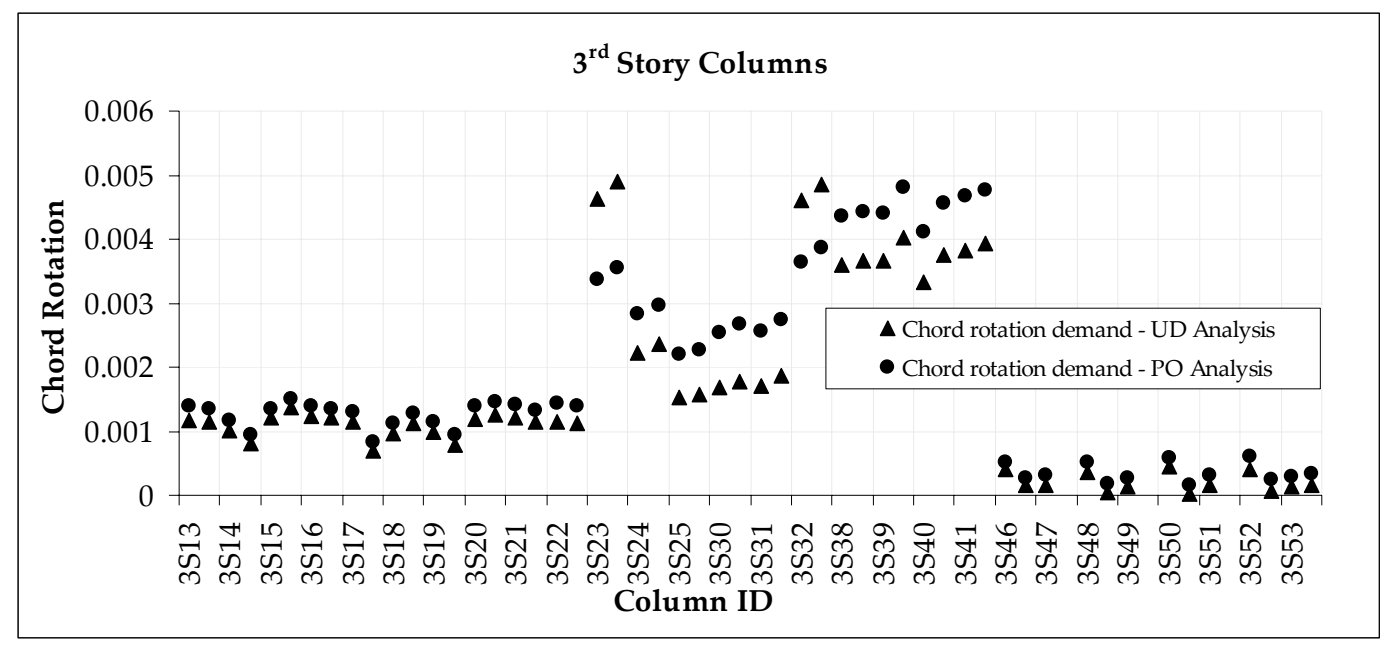

Figure 4.22 Chord rotation demands of the columns in the $Y$ direction loading (continued)

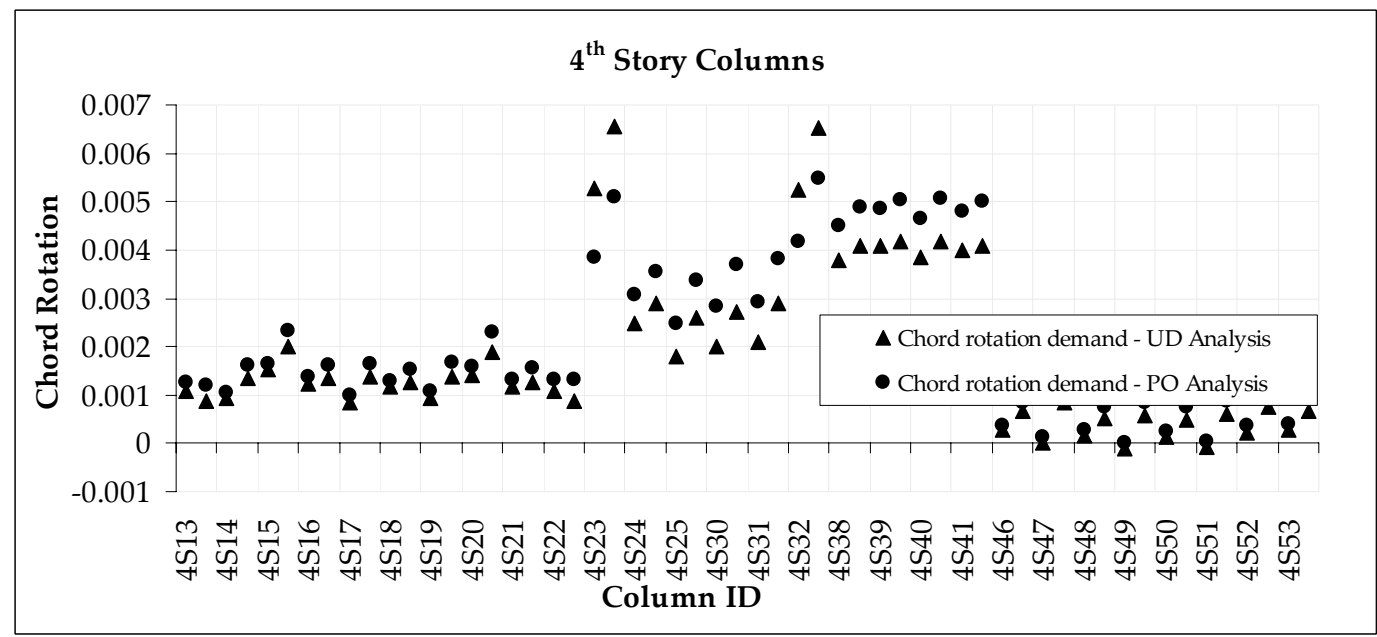

Figure 4.22 Chord rotation demands of the columns in the $\mathrm{Y}$ direction loading (continued)

As a verification of retrofit design, nonlinear assessment results of the retrofitted building is given for the $\mathrm{X}$ and $\mathrm{Y}$ directions in Figures 4.23, 4.24, 4.25, 4.26, 4.27 and 4.28 for yielded columns, beams and shear walls separately. Global performance of the retrofitted building is summarized in Table 4.2. According to Table 4.2 four story school building satisfies the Life Safety performance level defined in TEC 2007 for an earthquake having a return period of 2475 years. 
Table 4.2 Global performance of the retrofitted building

\begin{tabular}{|c|c|c|c|c|c|c|c|c|c|}
\hline \multicolumn{5}{|c|}{ X Direction } & \multicolumn{5}{|c|}{ Y Direction } \\
\hline $\begin{array}{c}\text { Story } \\
\text { No. }\end{array}$ & $\begin{array}{l}V_{s t r} \\
(k N)\end{array}$ & $\begin{array}{l}V_{N C} \\
(k N)\end{array}$ & $\% N C$ & $\begin{array}{l}\% \text { NC. } \\
\text { Beams }\end{array}$ & $\begin{array}{l}\text { Story } \\
\text { No. }\end{array}$ & $\begin{array}{l}V_{s t r} \\
(k N)\end{array}$ & $\begin{array}{l}V_{N C} \\
(k N)\end{array}$ & $\% N C$ & $\begin{array}{l}\% \text { NC } \\
\text { Beams }\end{array}$ \\
\hline 1 & 9884 & 191 & 1.93 & 0.00 & 1 & 7910 & 0 & 0.00 & 0.00 \\
\hline 2 & 9125 & 0 & 0.00 & 0.00 & 2 & 7283 & 0 & 0.00 & 0.00 \\
\hline 3 & 6938 & 0 & 0.00 & 0.00 & 3 & 5535 & 0 & 0.00 & 0.00 \\
\hline 4 & 3115 & 0 & 0.00 & 0.00 & 4 & 2488 & 0 & 0.00 & 0.00 \\
\hline
\end{tabular}

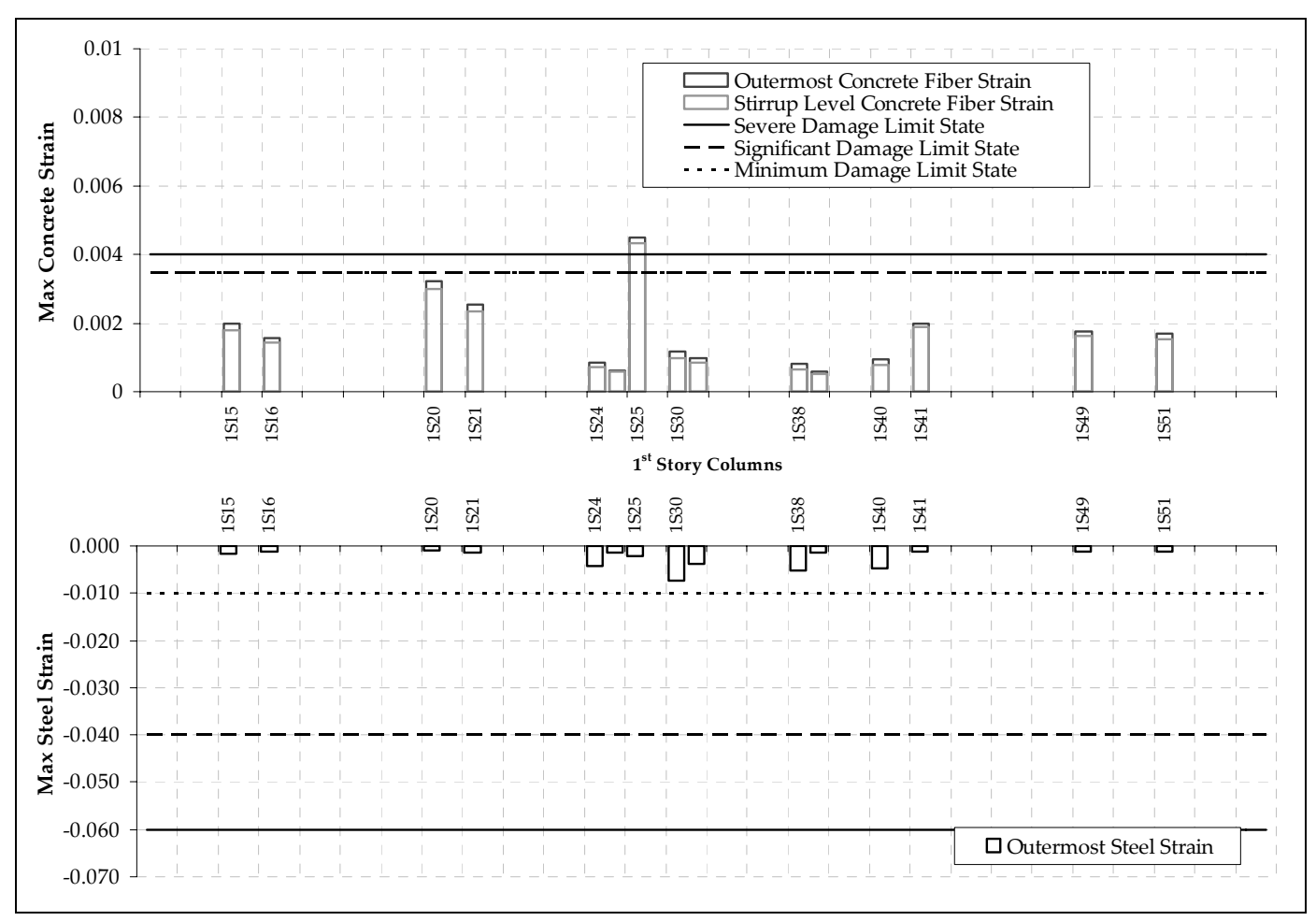

Figure 4.23 Damage levels of the columns in the $\mathrm{X}$ direction loading 


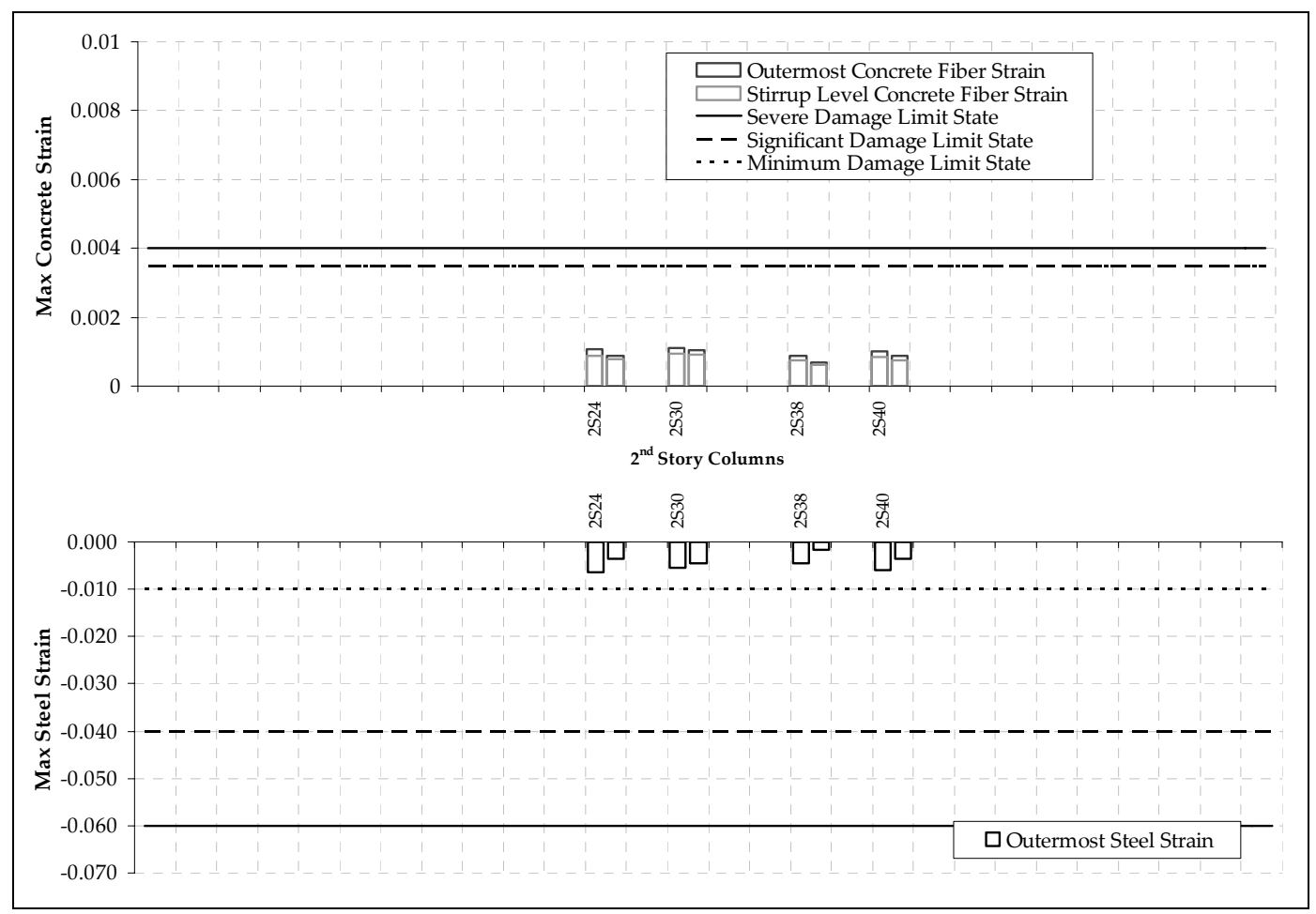

Figure 4.23 Damage levels of the columns in the $\mathrm{X}$ direction loading (continued)

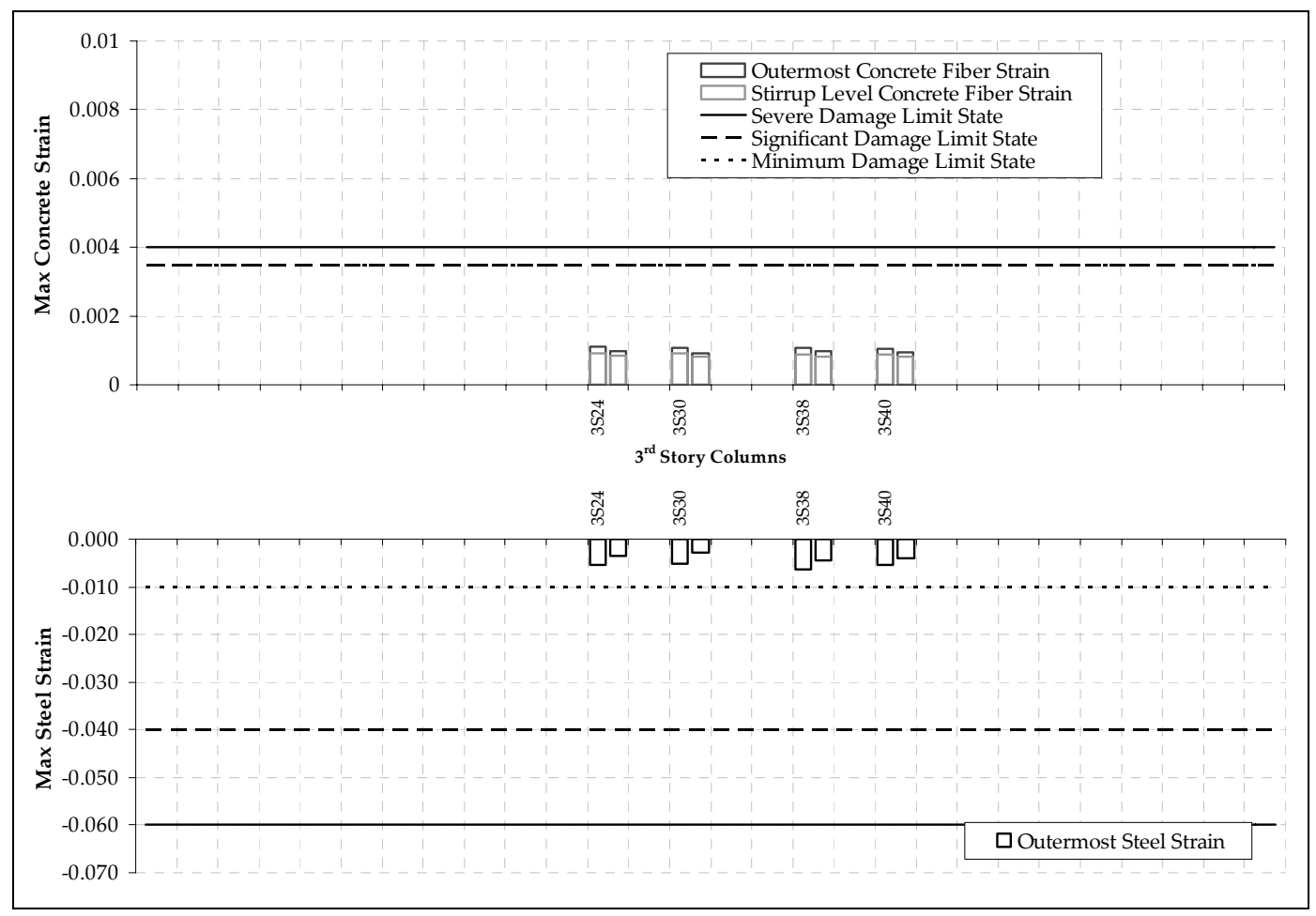

Figure 4.23 Damage levels of the columns in the $\mathrm{X}$ direction loading (continued) 


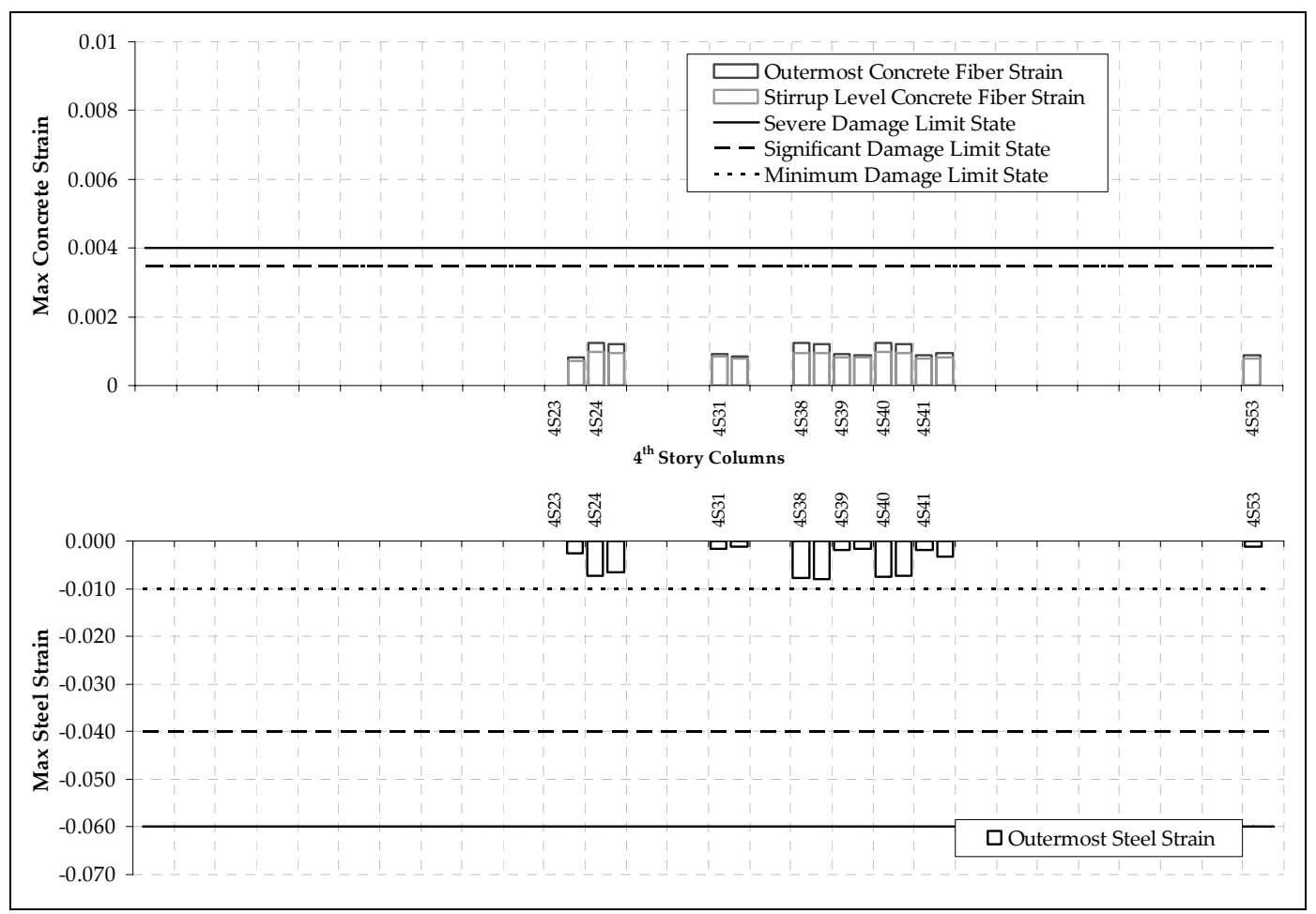

Figure 4.23 Damage levels of the columns in the X direction loading (continued)

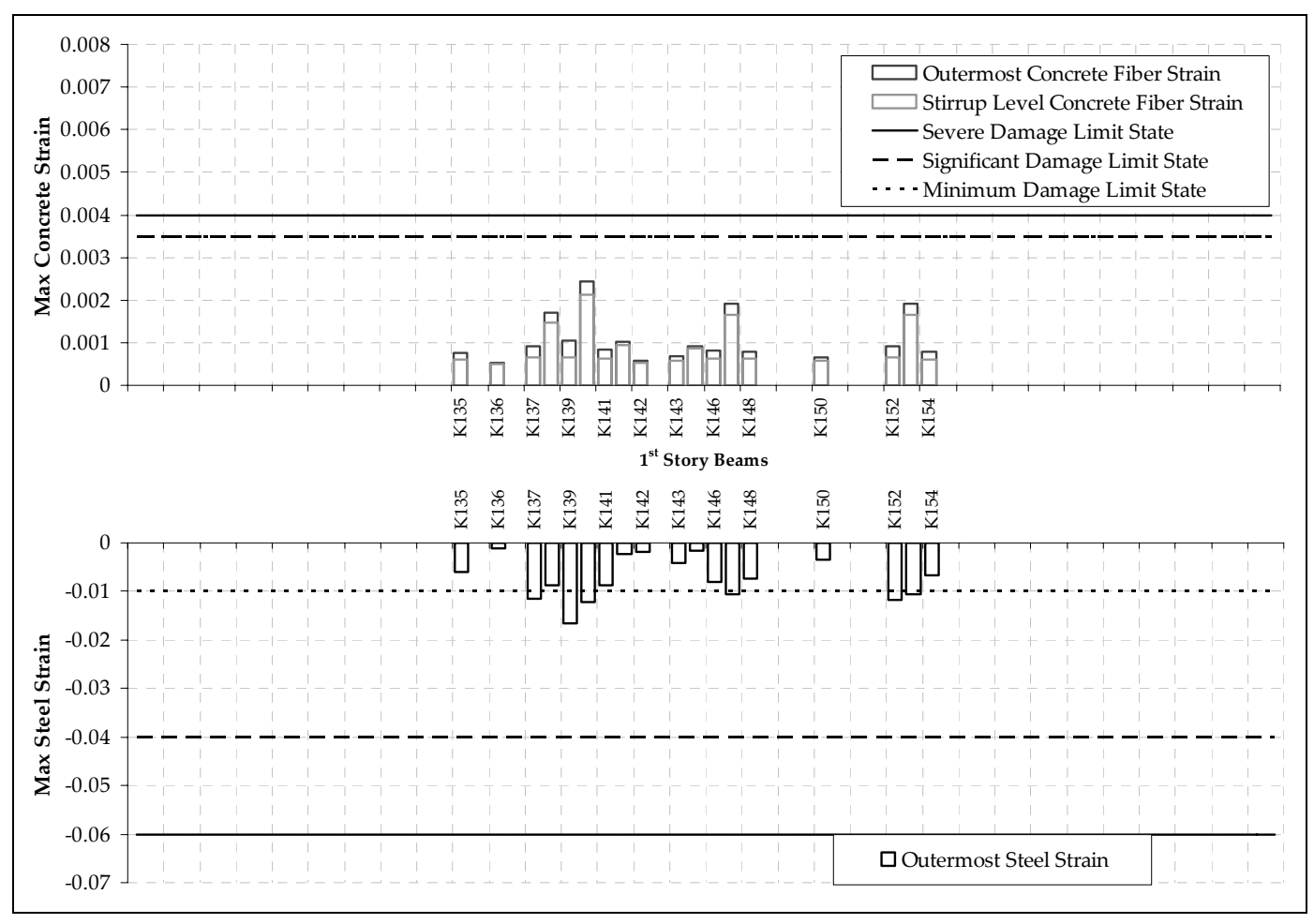

Figure 4.24 Damage levels of the beams in the $\mathrm{X}$ direction loading 


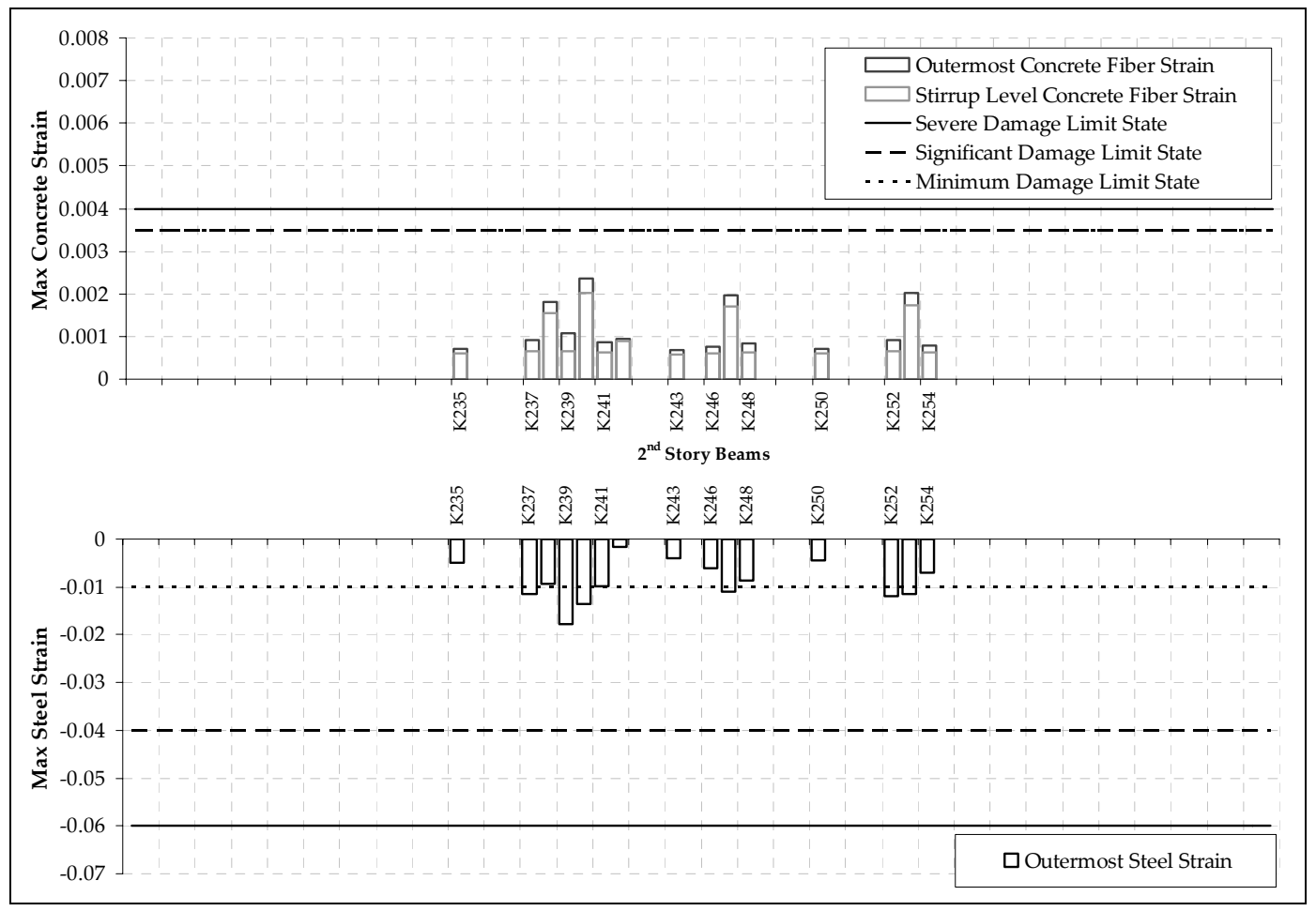

Figure 4.24 Damage levels of the beams in the $\mathrm{X}$ direction loading (continued)

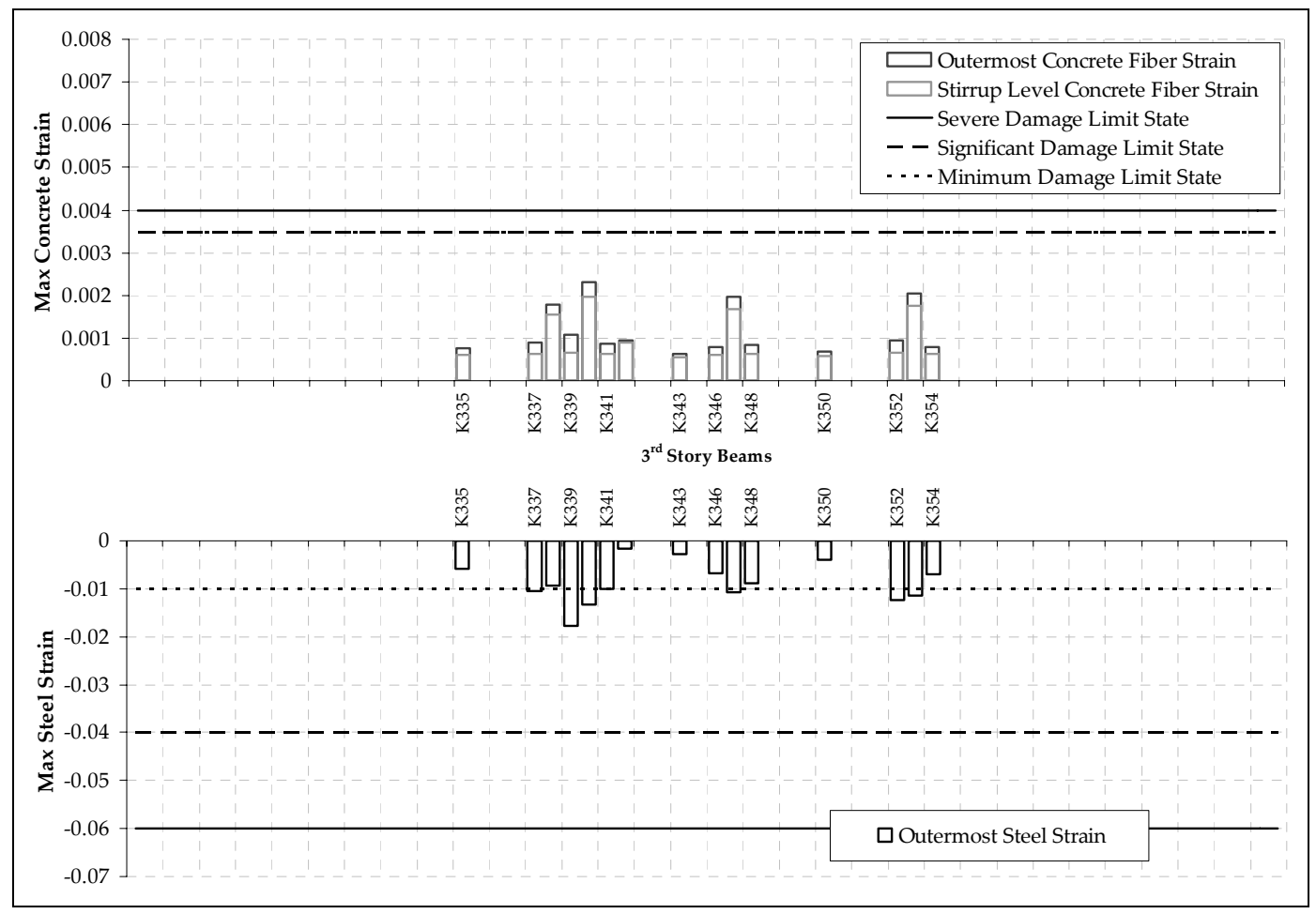

Figure 4.24 Damage levels of the beams in the $\mathrm{X}$ direction loading (continued) 


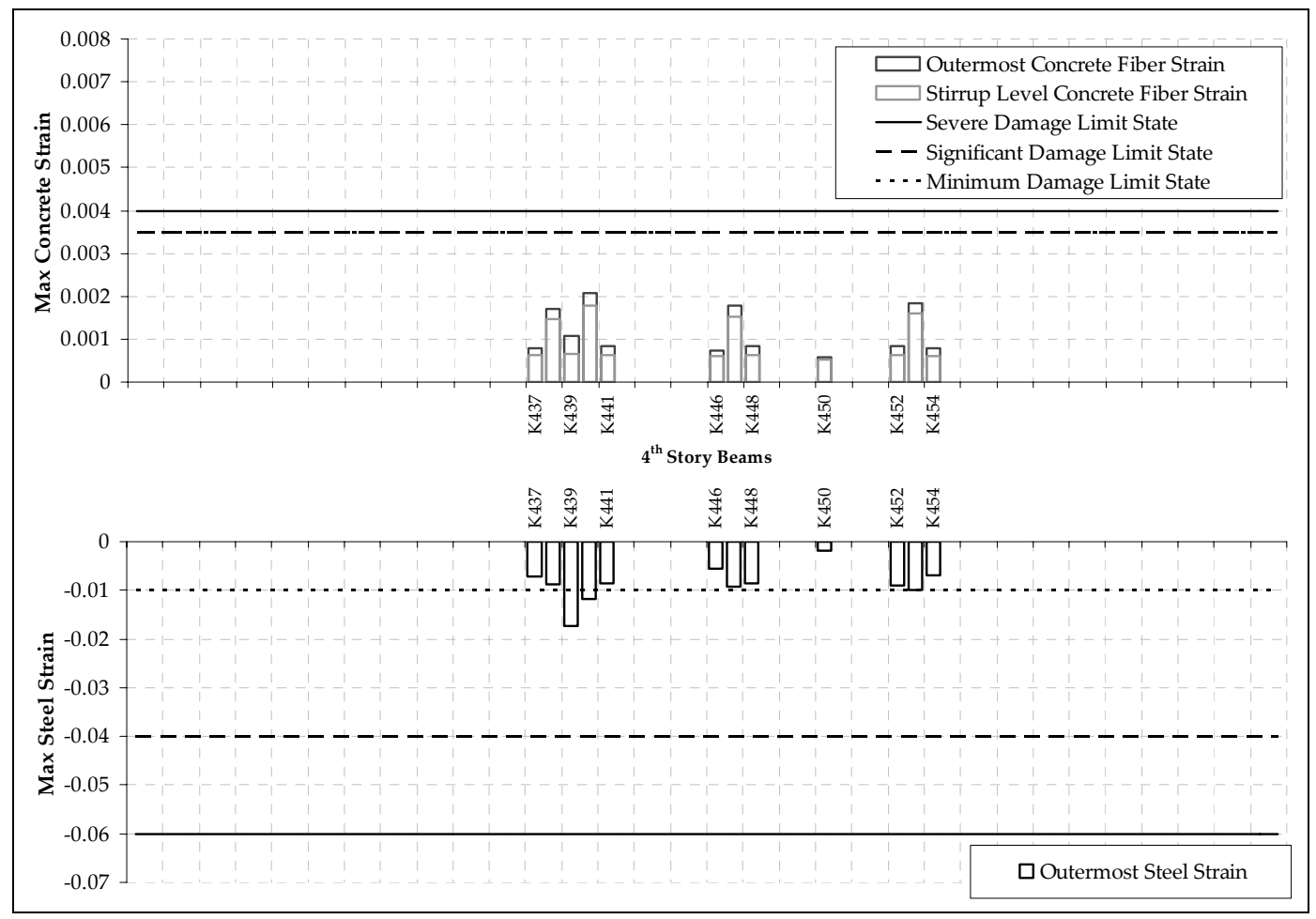

Figure 4.24 Damage levels of the beams in the $X$ direction loading (continued)

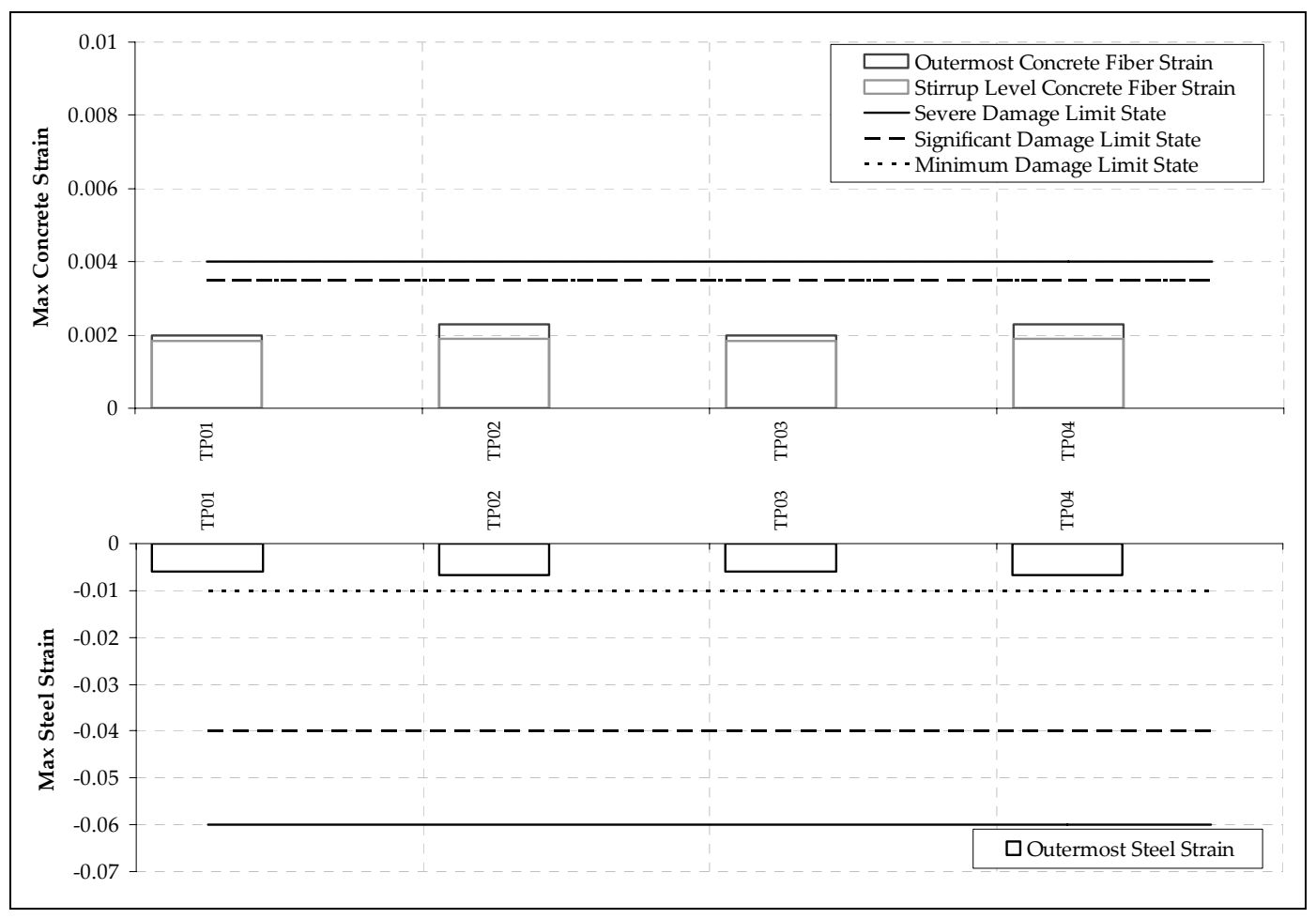

Figure 4.25 Damage levels of the shear walls in the $X$ direction loading 


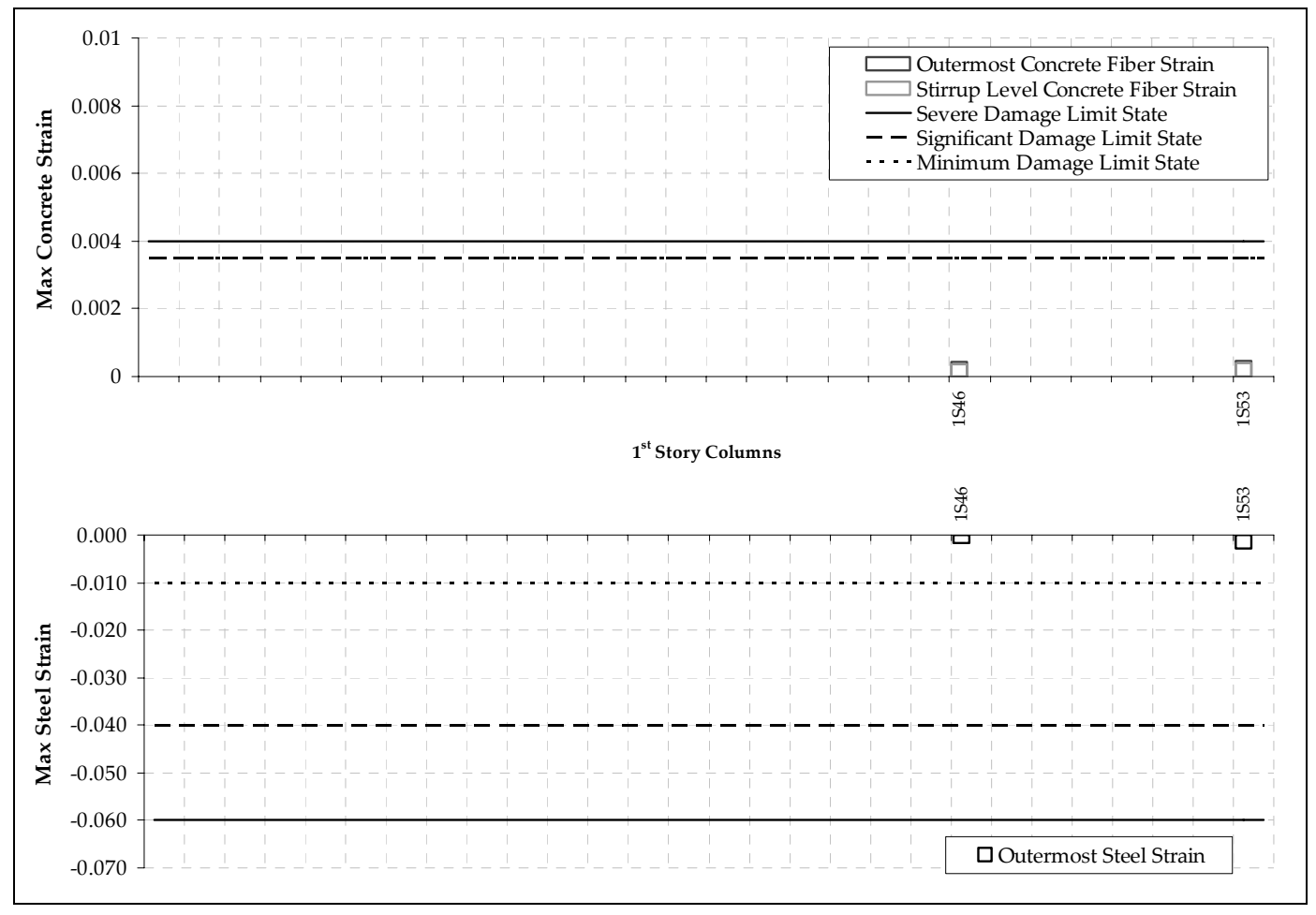

Figure 4.26 Damage levels of the columns in the $\mathrm{Y}$ direction

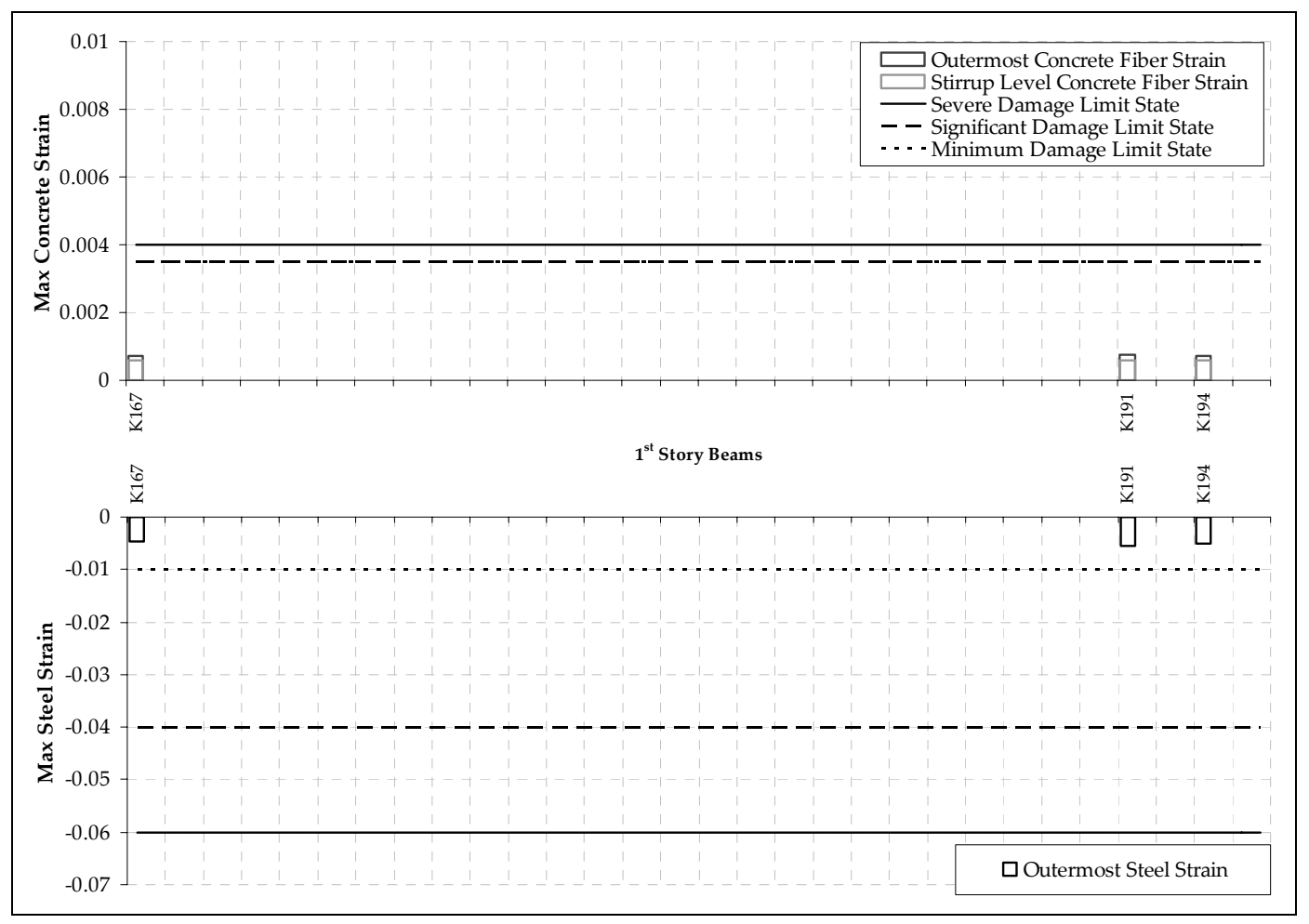

Figure 4.27 Damage levels of the beams in the $Y$ direction 


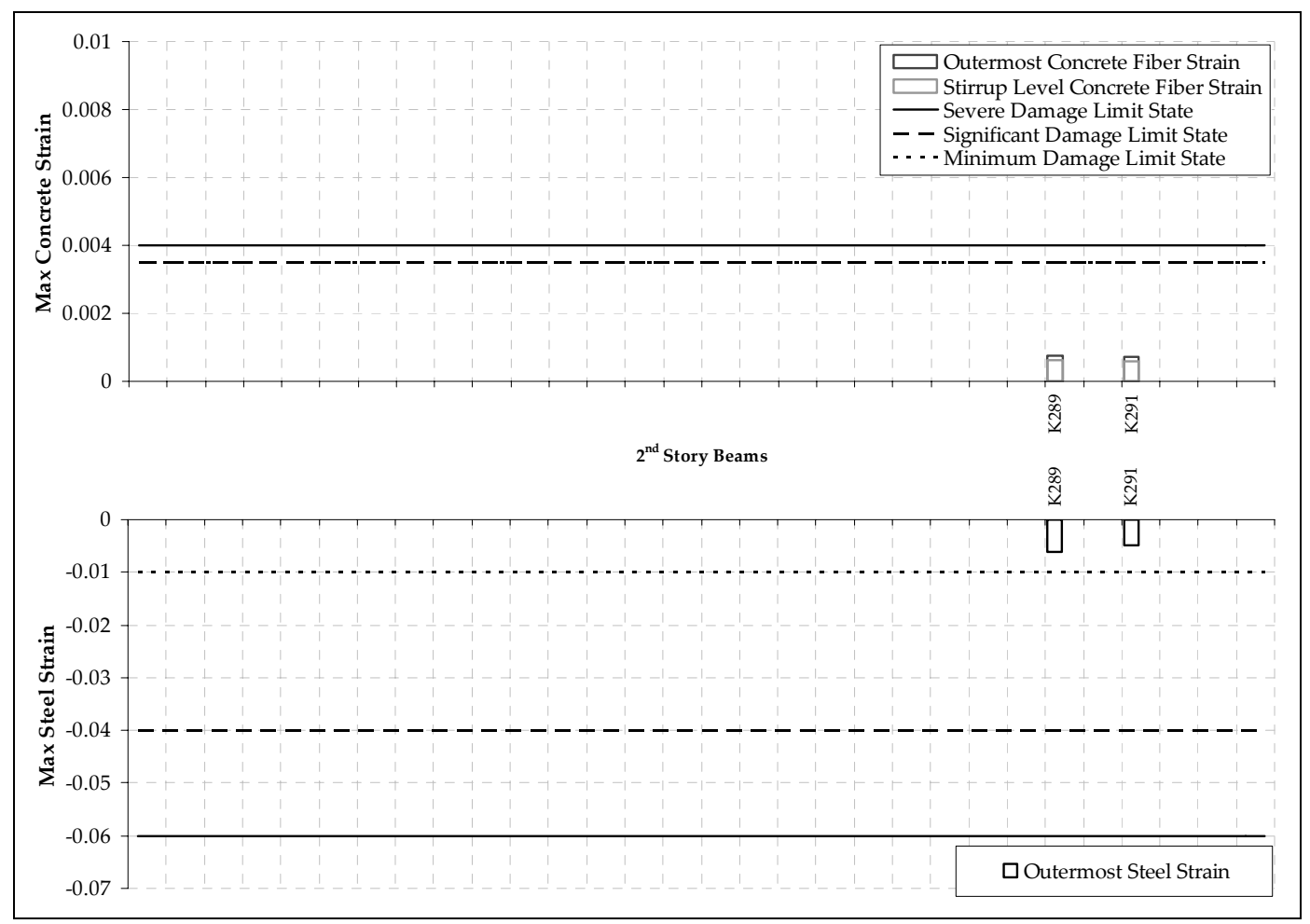

Figure 4.27 Damage levels of the beams in the $Y$ direction (continued)

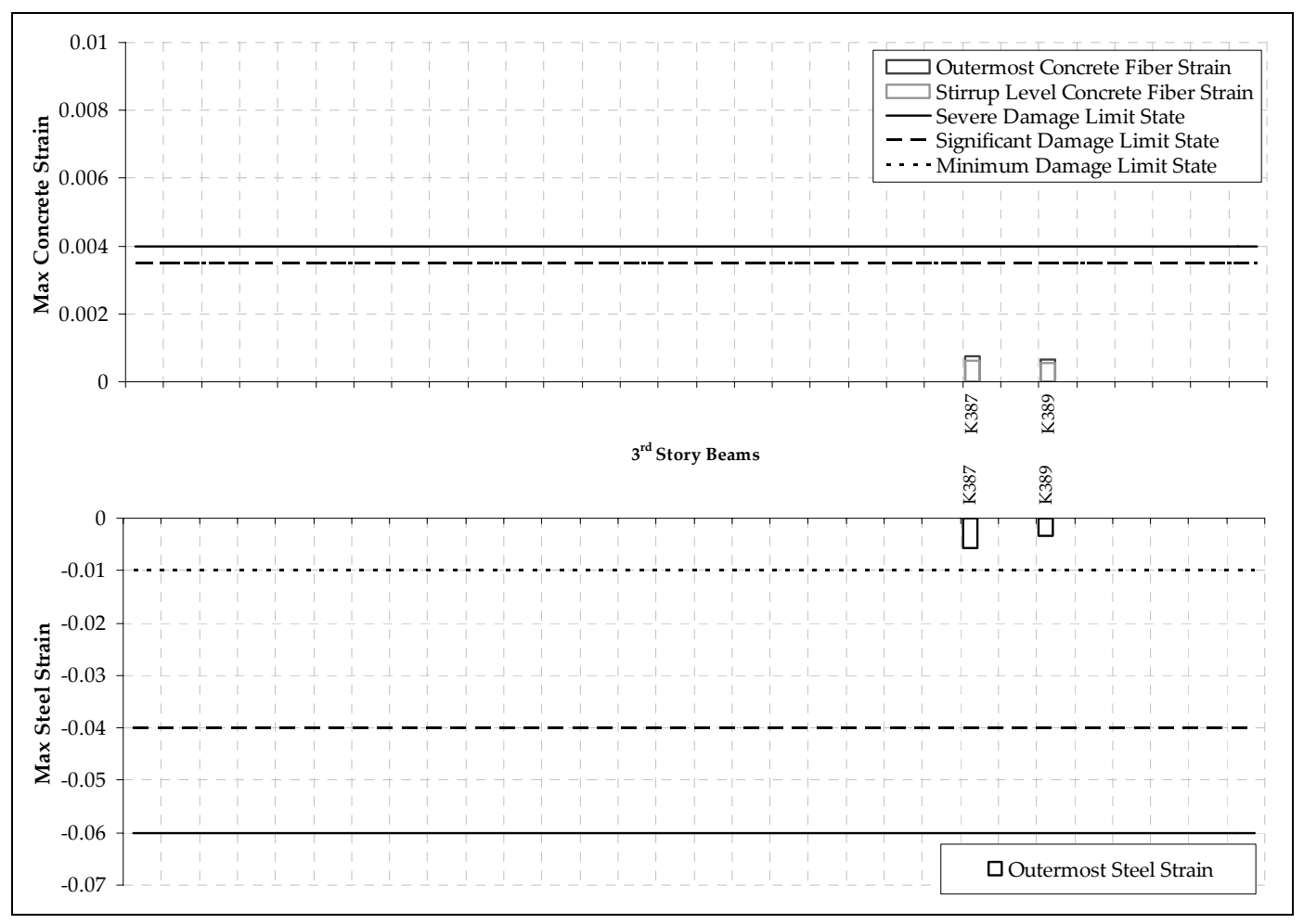

Figure 4.27 Damage levels of the beams in the $Y$ direction (continued) 


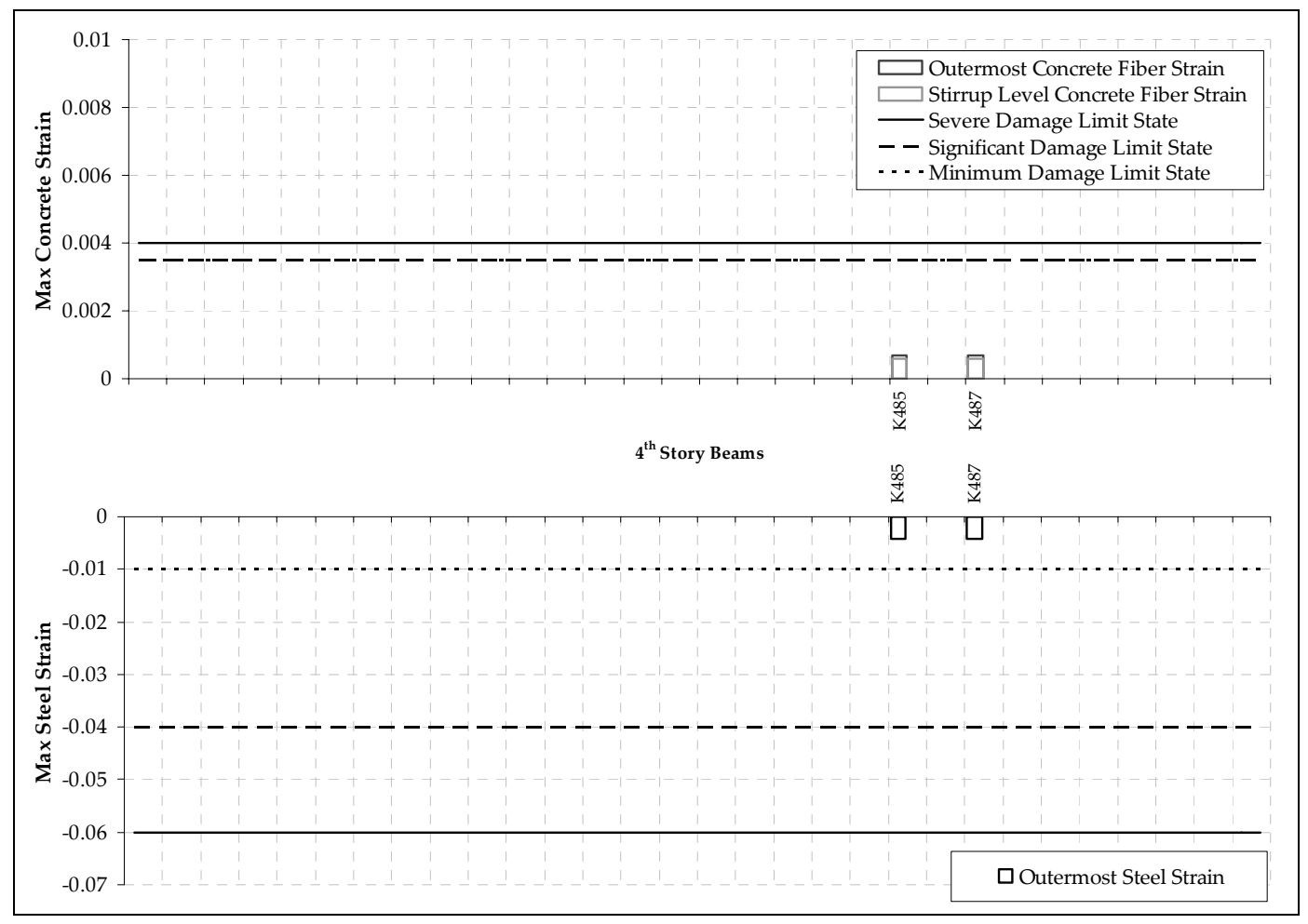

Figure 4.27 Damage levels of the beams in the $Y$ direction (continued)

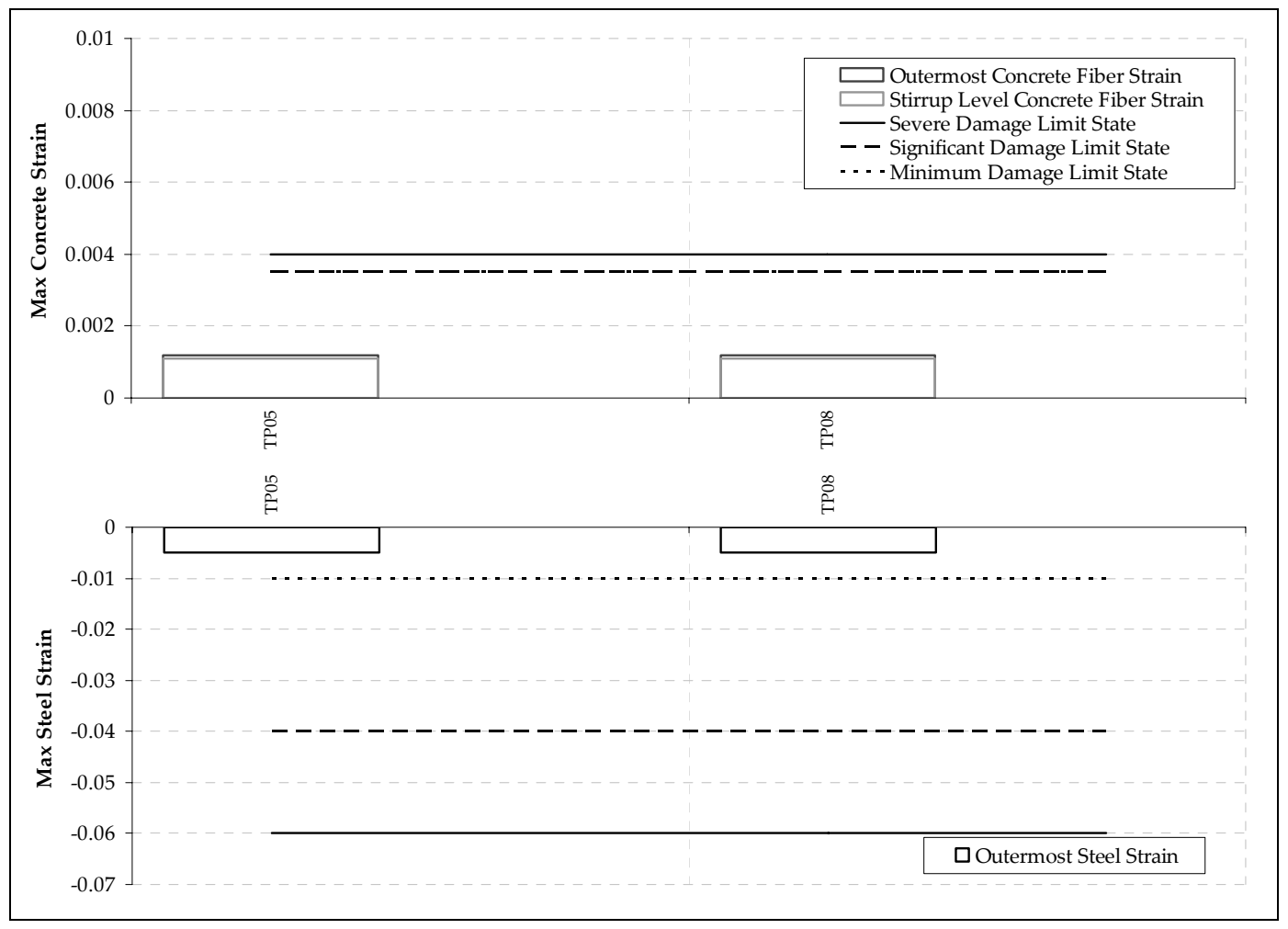

Figure 4.28 Damage levels of the shear walls in the $\mathrm{Y}$ direction loading 


\subsection{Force-Based Rehabilitation of the Building}

The existing four story school building was retrofitted by employing a force-based linear elastic procedure as well. First story plan of the force-based retrofitted building is shown in Figure 4.29. In order to determine deficient columns in the retrofitted system, linear assessment methods defined in TEC 2007 were used. Columns S23, S24, S31, S32, and S3841 at the first story were not capable of meeting demand-capacity-ratio limits of significant damage level stated in TEC 2007. In this sense these columns were strengthened by wrapping with RC jackets having a thickness of $150 \mathrm{~mm}$.

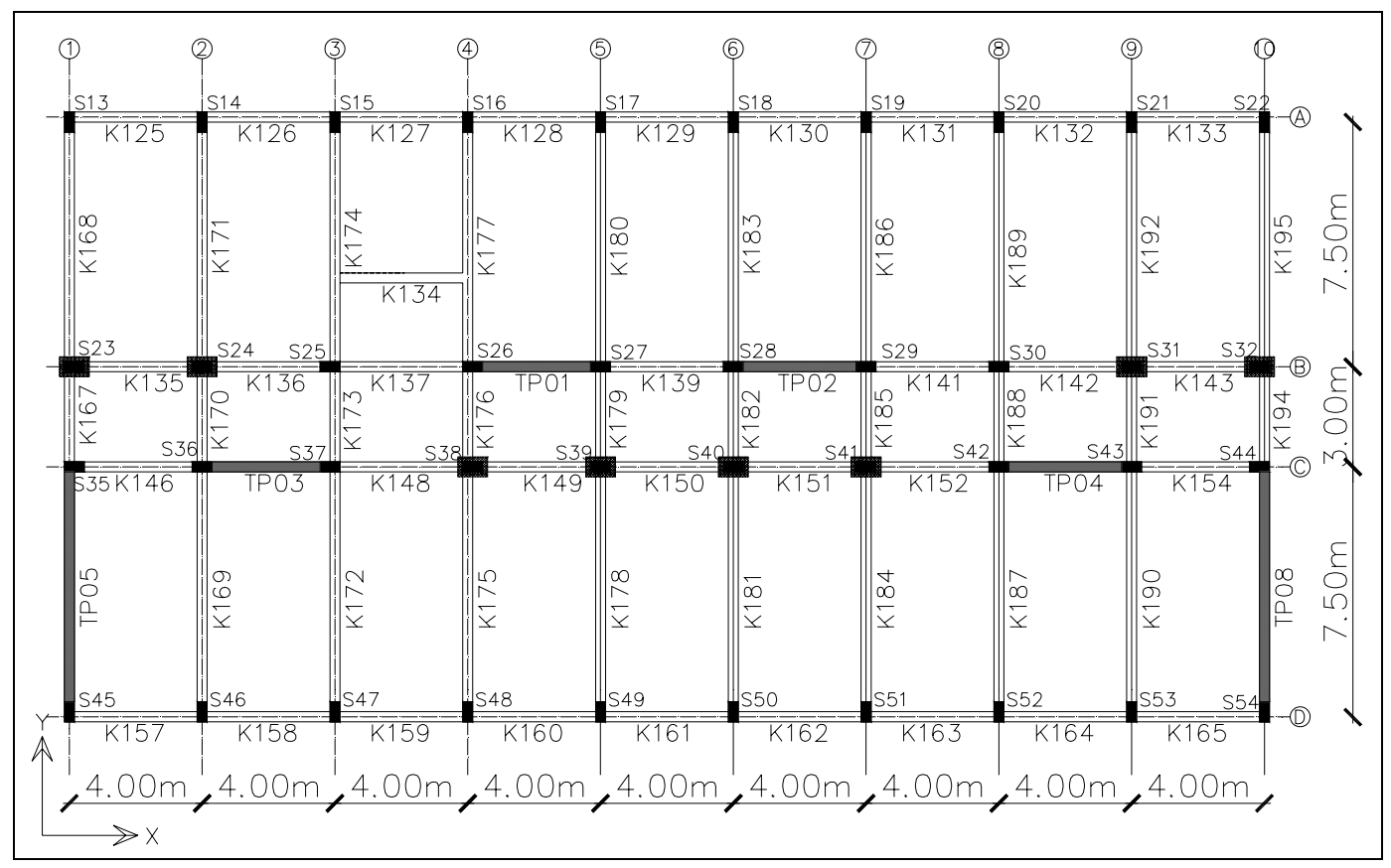

Figure 4.29 Plan view of the force-based retrofitted building

In the design of new shear walls, design spectrum was obtained by reducing the response spectrum used for seismic performance evaluation which represents an earthquake having a return period of 2475 years by $\mathrm{R}=4.5$. According to TEC 2007, TP01-04 were classified as slender walls. Thus, along the critical height which was taken as $3.5 \mathrm{~m}$, confined ends were formed at the wall boundaries. Longitudinal reinforcement ratio needed for shear walls in the $\mathrm{X}$ direction was determined as 0.01 by following the design procedures for shear walls given in TEC 2007. On the other hand, shear walls TP05 and TP08 were classified as squat 
walls and detailed accordingly. For these shear walls, no confined ends were needed according to TEC 2007. Longitudinal reinforcement ratio was determined as 0.0068 for TP05 and TP08. In case of shear design, shear demand was calculated as $3223 \mathrm{kN}$ for TP01 and $7266 \mathrm{kN}$ for TP05. These demands yielded transverse reinforcement ratios of 0.0072 and 0.0078 for TP01 and TP05 respectively. Detailing and axial P-M interaction diagrams for shear walls TP01 and TP05 are presented in Figures 4.30, 4.31, 4.32, and 4.33.

\subsection{Comparison of Displacement-Based and Force-Based Retrofit Solutions}

Displacement-based and force-based retrofit solutions for the school building were compared in system and member levels. Considering the retrofitted columns in the displacement-based retrofitted case, FRP wrapping was determined as sufficient to increase shear strength and deformation capacity. On the other hand in the force-based design, in order to decrease axial force demands and increase both shear and deformation capacities, deficient columns were strengthened by RC jackets. However, nonlinear analysis results revealed that FRP wrapping is sufficient as a retrofit solution. According to linear elastic procedures, columns S23-24, S31-32, S38-39, and S40-41 at the first story were deficient. In case of the displacement-based procedure columns S24-25, S30-31, S38-41 at the first story were strengthened with FRP sheets due to lack of deformation and shear capacities. For other columns deformation demands were computed as less than the deformation capacities. Nonlinear assessment results also confirm this result.

Detailing of the added shear walls in the $\mathrm{X}$ and $\mathrm{Y}$ directions according to displacementbased and force-based designs are compared in Figures 4.30, 4.31, 4.32, and 4.33 for two walls along with the corresponding P-M interaction diagrams and P-M demands for the force-based design. 


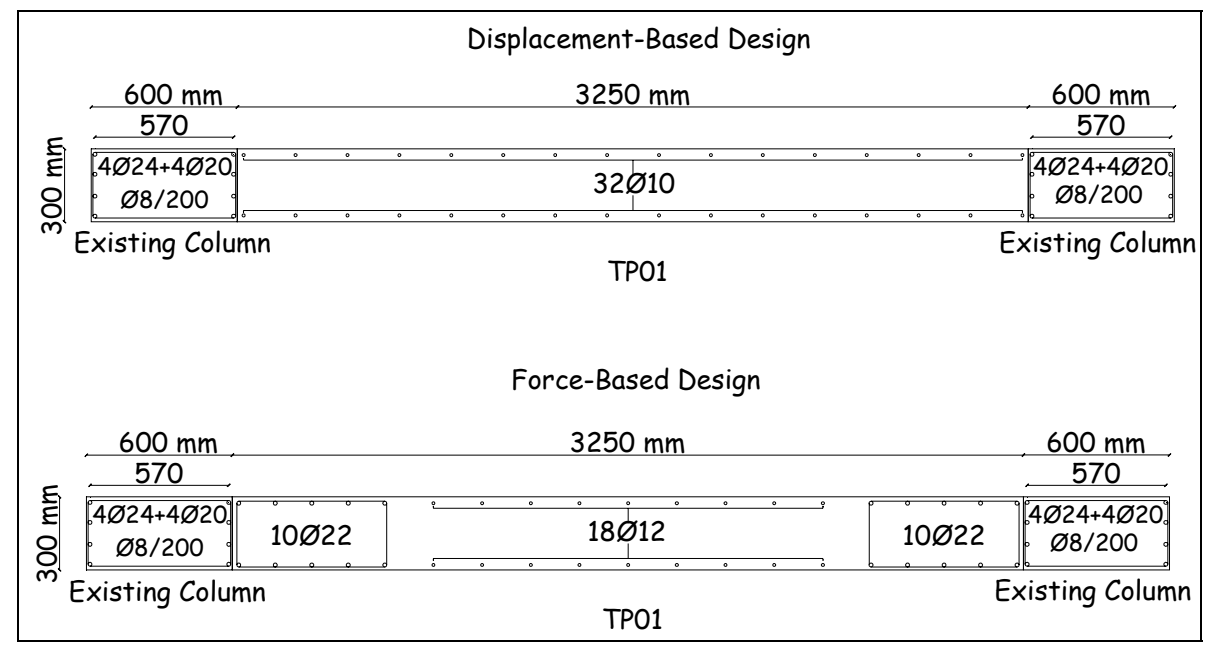

Figure 4.30 Detailing of the shear wall TP01 according to the displacement-based and forcebased designs

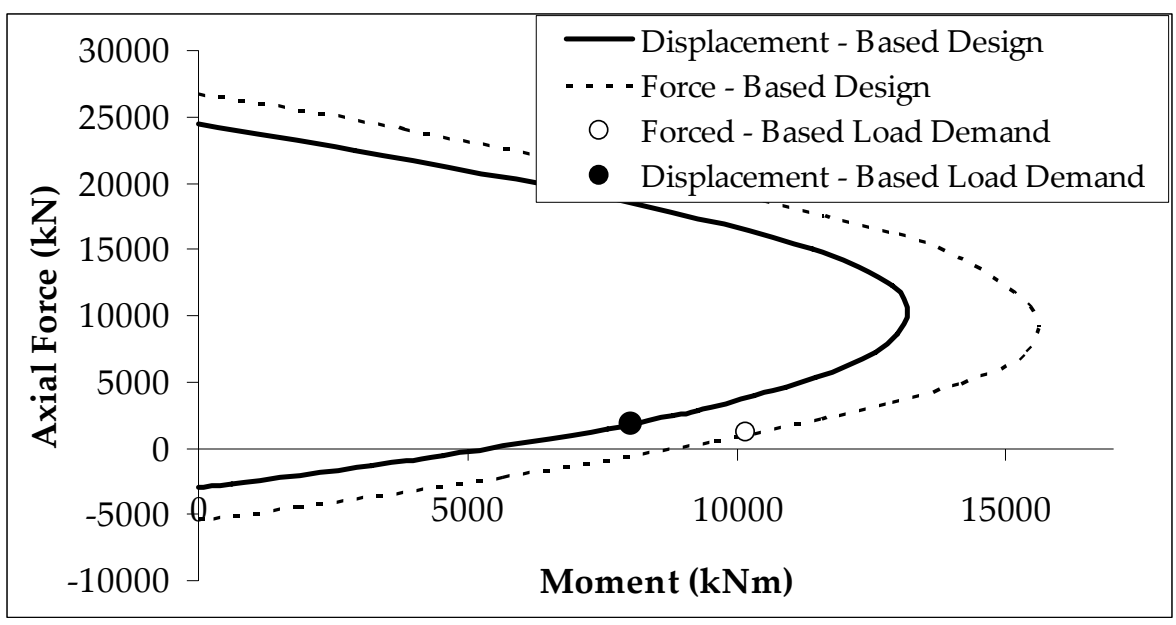

Figure 4.31 P-M Interaction diagrams of the shear wall TP01 according to the displacementbased and forced-based designs

In force-based design, confined end regions were formed at the boundaries of slender shear walls by following TEC 2007. In displacement-based design, deformation demands were satisfied with the given detailing in Figures 4.30 and 4.32 without any confined ends. It can be concluded that, displacement-based design gives more economic solutions considering the longitudinal reinforcement used in the shear walls. 


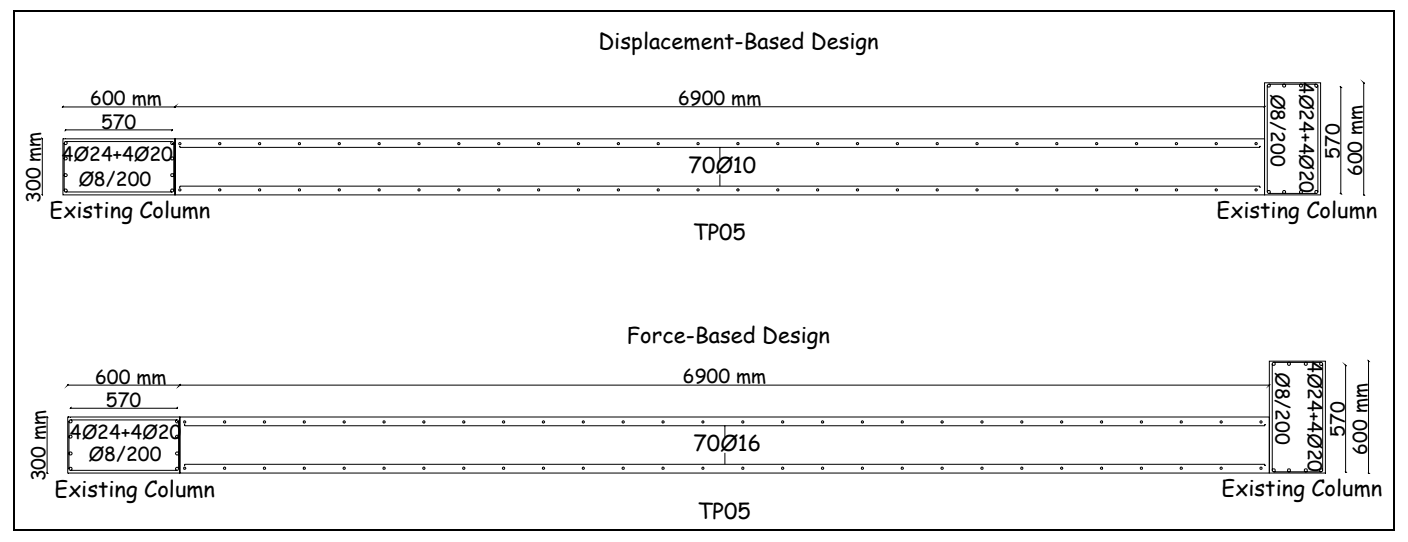

Figure 4.32 Detailing of the shear wall TP05 according to the displacement-based and forcebased designs

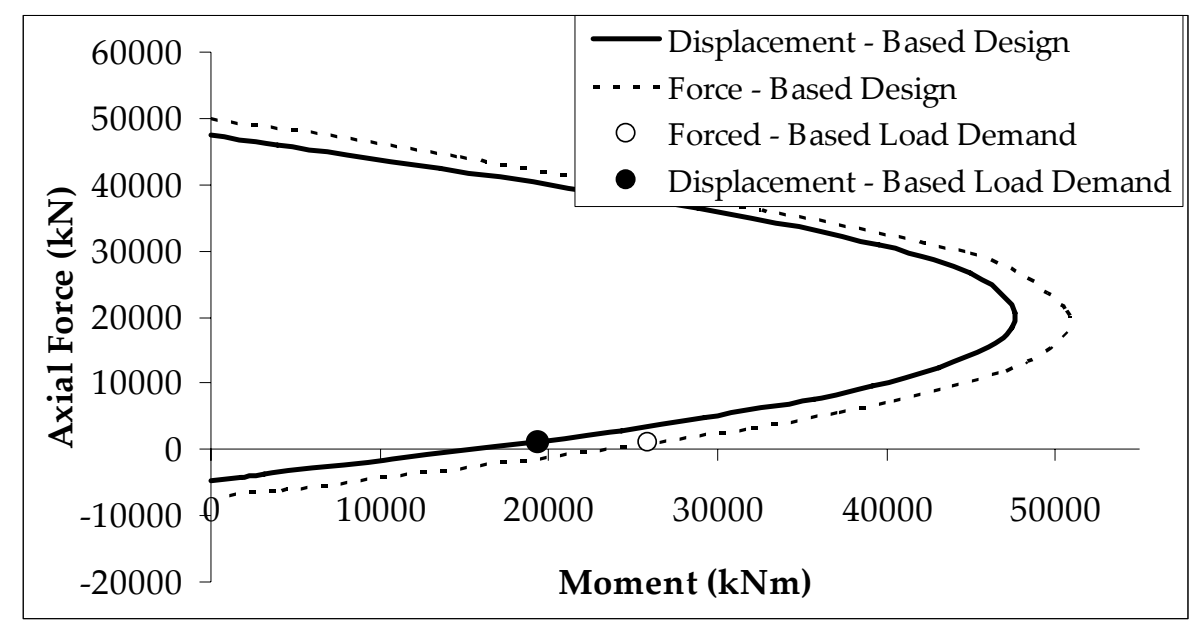

Figure 4.33 P-M Interaction diagrams of the shear wall TP05 according to the displacementbased and forced-based designs

In order to compare retrofit solutions in system level, nonlinear analysis was conducted for both retrofit cases of the school building. Capacity curves in the $\mathrm{X}$ and $\mathrm{Y}$ directions are shown in Figure 4.34 for both retrofit cases. It is apparent in Figure 4.34 that force-based retrofit design offers more strength. However, roof displacement demands of both cases do not differ much. Target roof displacement demands of the force-based retrofitted building are $0.054 \mathrm{~m}$ in $\mathrm{X}$ direction and $0.041 \mathrm{~m}$ in $\mathrm{Y}$ direction for an earthquake having a return period of 2475 years. On the other hand, target roof displacement demands of the 
displacement-based retrofitted building were calculated as $0.058 \mathrm{~m}$ in the $\mathrm{X}$ direction and $0.044 \mathrm{~m}$ in the $\mathrm{Y}$ direction under the same design earthquake.

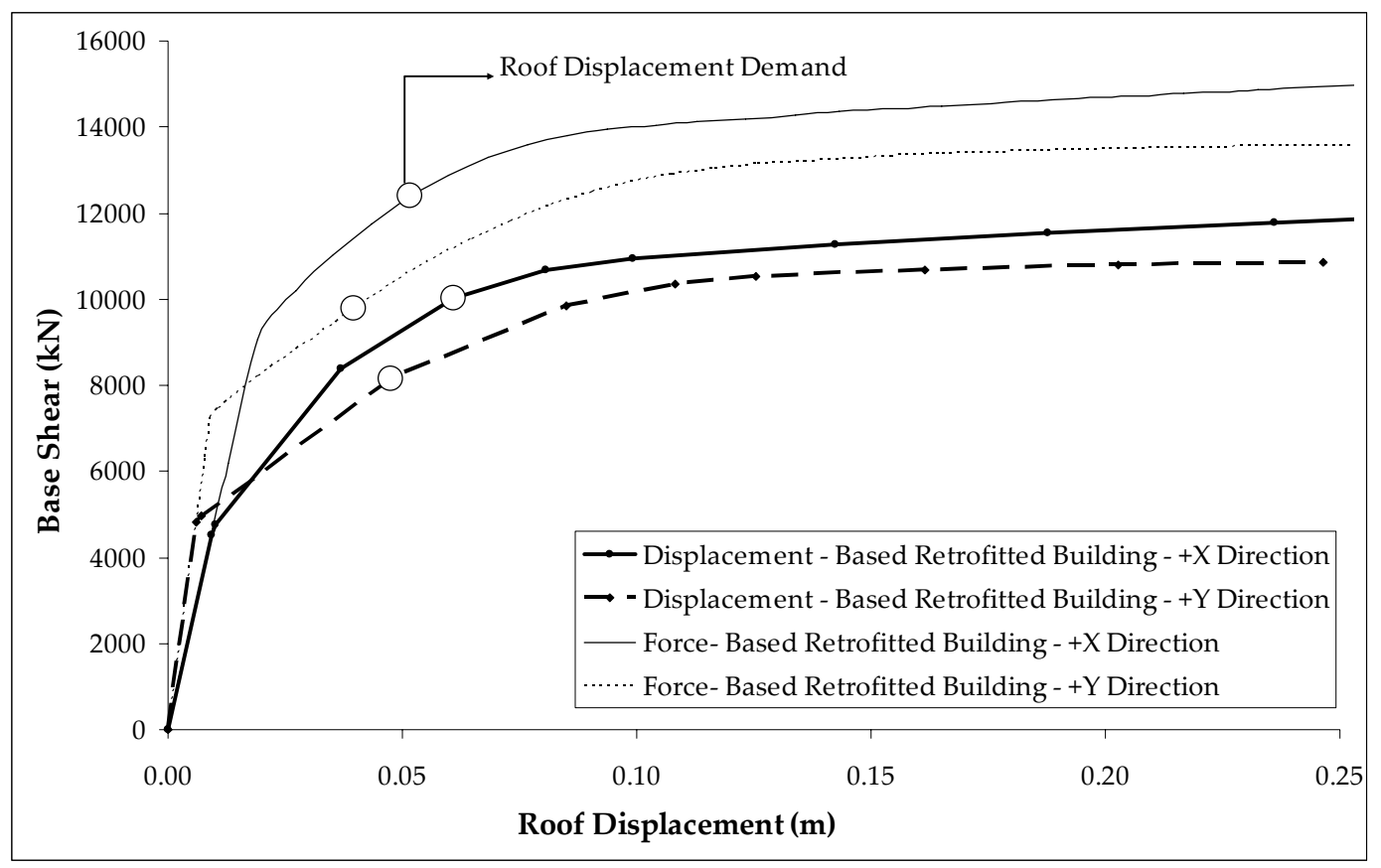

Figure 4.34 Capacity curves of the retrofitted building according to displacement-based and force-based approaches 


\section{CHAPTER 5}

\section{CASE STUDY II - SEISMIC REHABILITATION OF A FOUR STORY DORMITORY BUILDING}

A four story dormitory building composed of reinforced concrete frame system was examined as the second case study. Flow of this chapter is same as that of the previous one.

\subsection{Existing Condition of the Building}

Existing dormitory building shown in Figure 5.1 is composed of four story reinforced concrete frame system. All columns are oriented in the $\mathrm{Y}$ direction. Cross section dimension of all columns except S14, S20, S25 and S31 is $300 \times 600 \mathrm{~mm}$. Square columns S14, S20, S25 and S31 are $300 \times 300 \mathrm{~mm}$. All beams on A, B, C and D axes are 300x500 mm. Other beams are $300 \times 700 \mathrm{~mm}$. Story height along the building is 3 meters. 3D mathematical model and plan view of the building are shown in Figures 5.1 and 5.2, respectively.

Existing concrete strength was taken as $8.5 \mathrm{MPa}$ and yield strength of reinforcement bars was taken as $420 \mathrm{MPa}$. Volumetric ratio of longitudinal reinforcement in columns was taken as 0.01 . In case of beams, tension reinforcement ratio was 0.008 and compression reinforcement ratio was 0.004 at the supports. $\Phi 8 / 200 \mathrm{~mm}$ stirrups with hook angle of $135^{\circ}$ were used as transverse reinforcement in all members and considered as confinement reinforcement. Thus $\rho_{s} / \rho_{s m}$ ratio was calculated as 0.58 which yields a strain limit at stirrup level corresponding to the significant damage limit state of 0.0093 . 
Local soil conditions were classified as Z2 soil type according to TEC 2007. Since Life Safety performance objective was selected, response spectrum was constructed for Z2 soil type for an earthquake having $2 \%$ probability of exceedance in 50 years, which corresponds a 2475 return period event. Life Safety performance requirements are same as that for school type buildings.

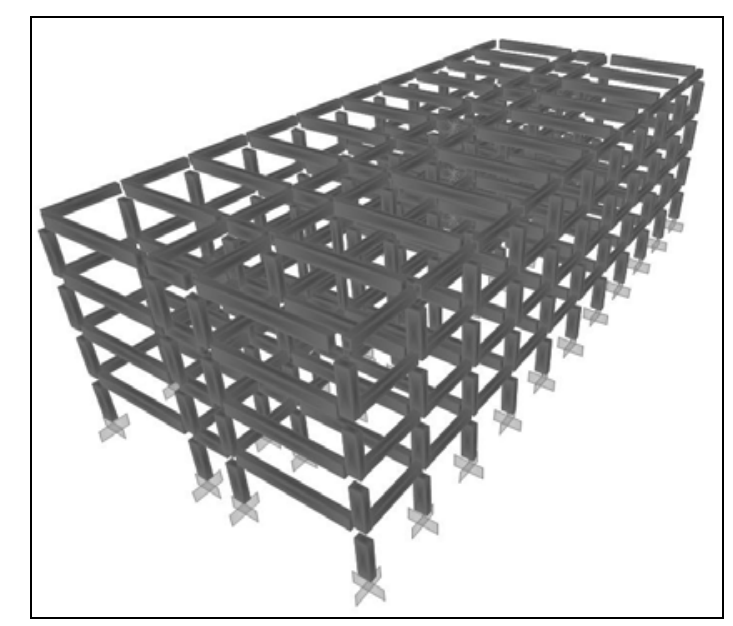

Figure 5.1 3D Mathematical model of the four story existing dormitory building

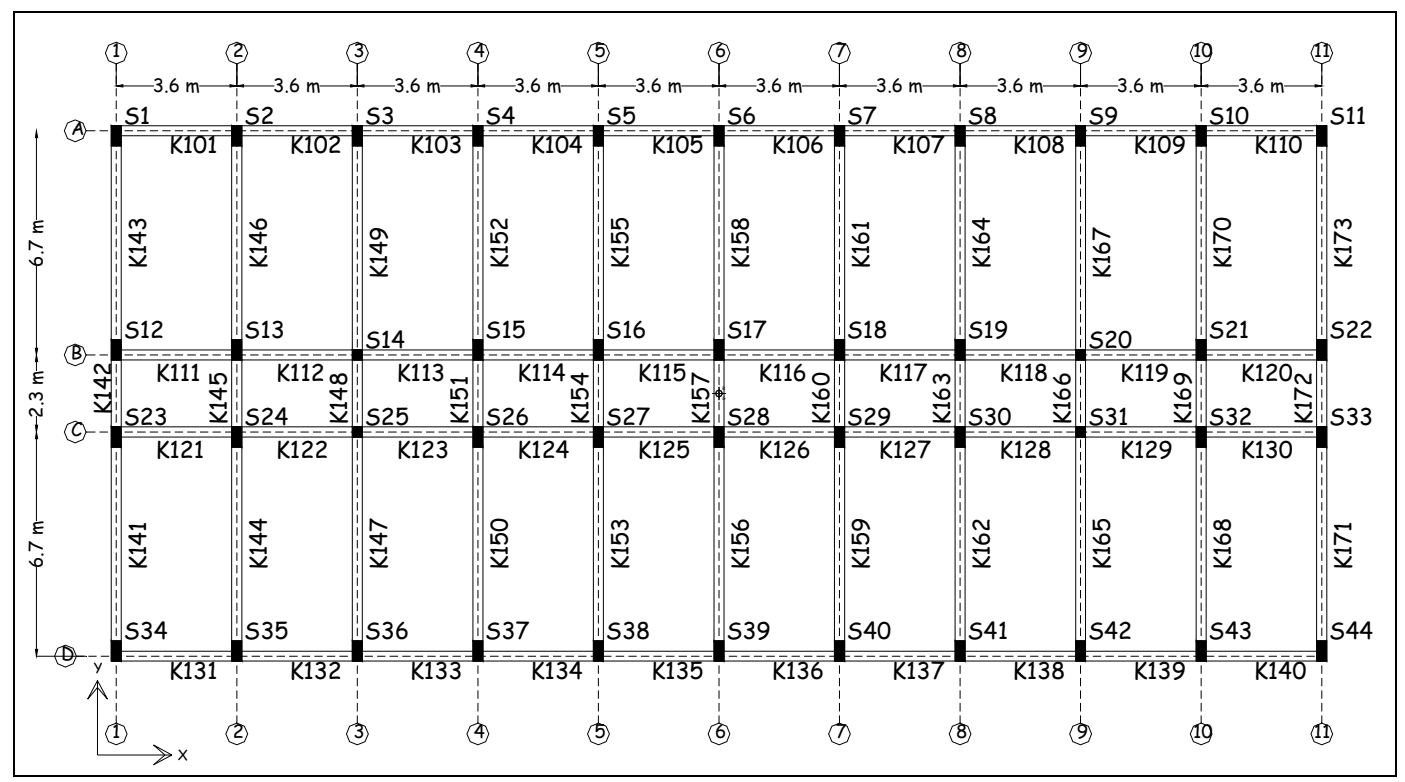

Figure 5.2 Plan view of the four story existing dormitory building 
In order to evaluate seismic performance whether the building satisfies Life Safety objective or not in the $\mathrm{X}$ and $\mathrm{Y}$ directions, nonlinear assessment procedures of TEC 2007 were followed. Pushover analysis was conducted in $+X$ and $+Y$ directions using cracked stiffnesses of reinforced concrete members. Capacity curves are shown in Figure 5.3. Effective fundamental periods in the $\mathrm{X}$ and $\mathrm{Y}$ directions were computed as 0.84 seconds and 0.56 seconds, respectively. Target roof displacement demands under the considered design earthquake were calculated as $0.185 \mathrm{~m}$ for the $\mathrm{X}$ direction and $0.116 \mathrm{~m}$ for the $\mathrm{Y}$ direction. Existing building was pushed in both directions separately until the roof level reached the target roof displacements.

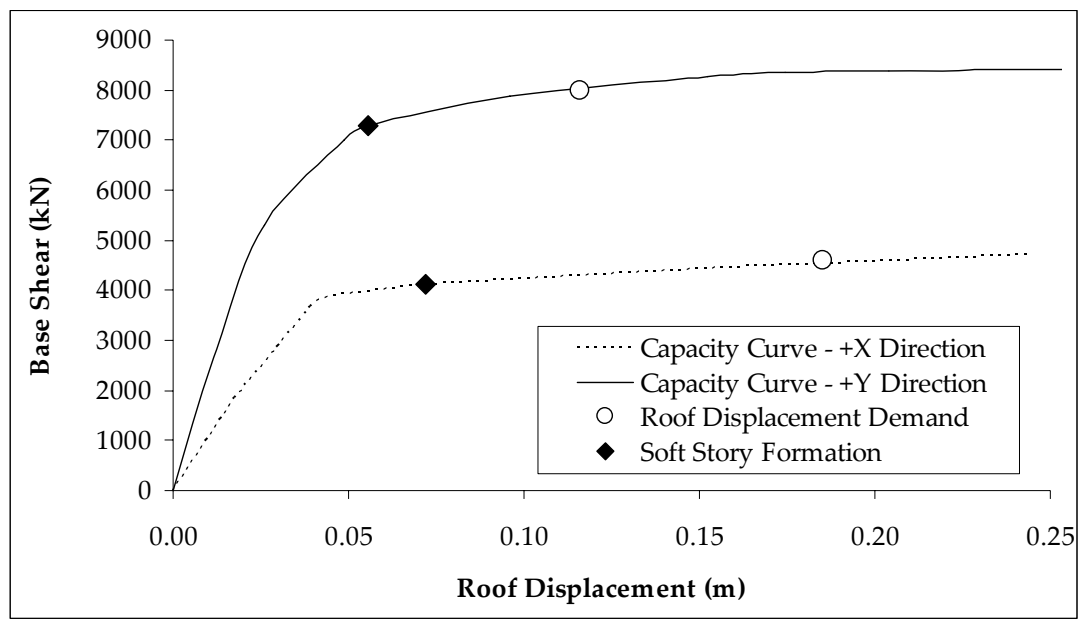

Figure 5.3 Capacity curves of the existing building

Most of the existing columns and beams were observed not to meet deformation demands at the performance point. Damage levels of reinforced concrete members at the performance points computed by pushover analysis in the $\mathrm{X}$ and $\mathrm{Y}$ directions are presented in Figures 5.4, 5.5, 5.6, and 5.7. Considering the $X$ direction, all of the columns at the first story were determined to fail. In the $\mathrm{Y}$ direction more than $80 \%$ of the story shear of the first story is carried by deficient columns. Global performance evaluation of the existing building is summarized in Table 5.1 for both directions. 


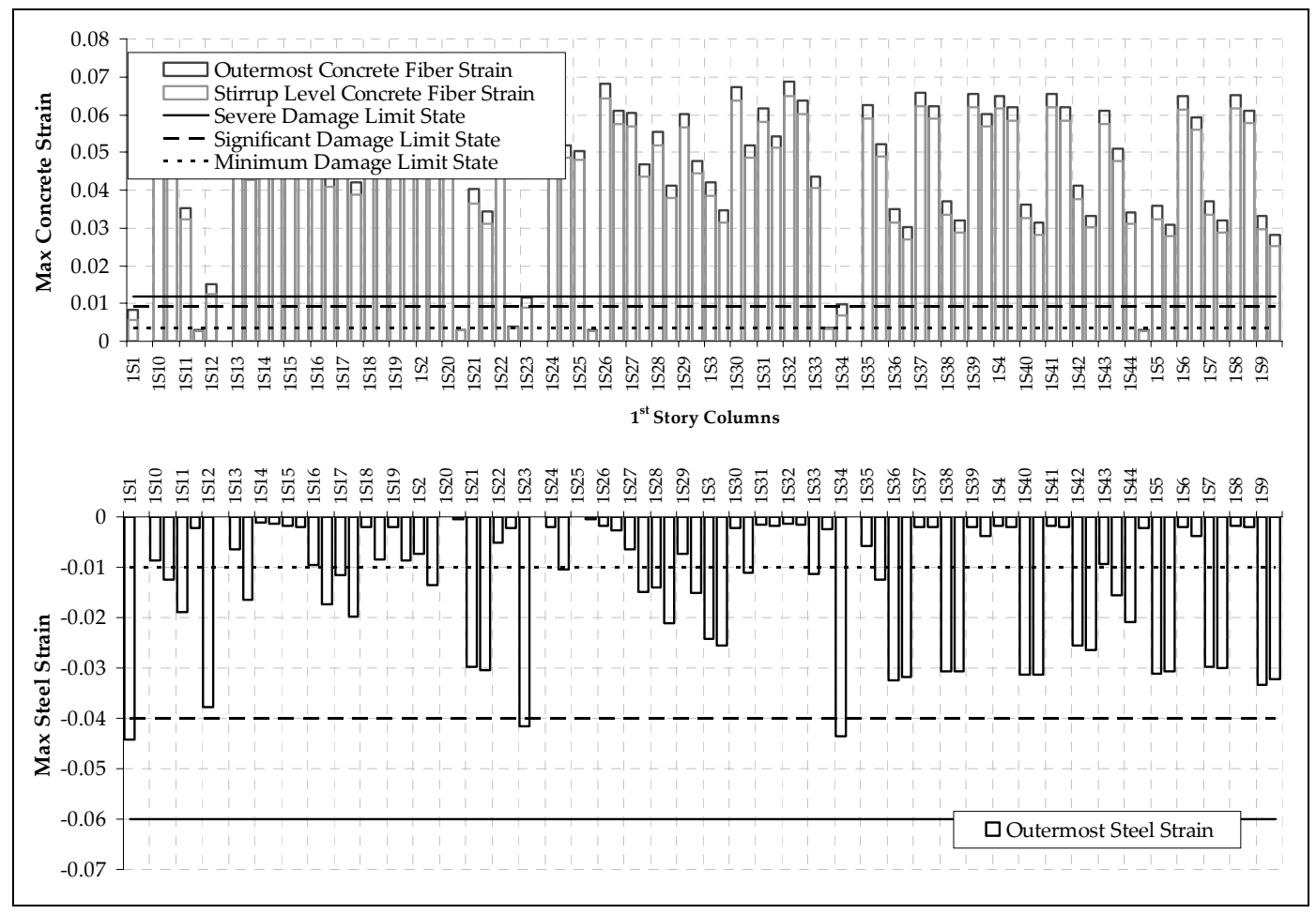

Figure 5.4 Damage levels of the columns in the X direction loading

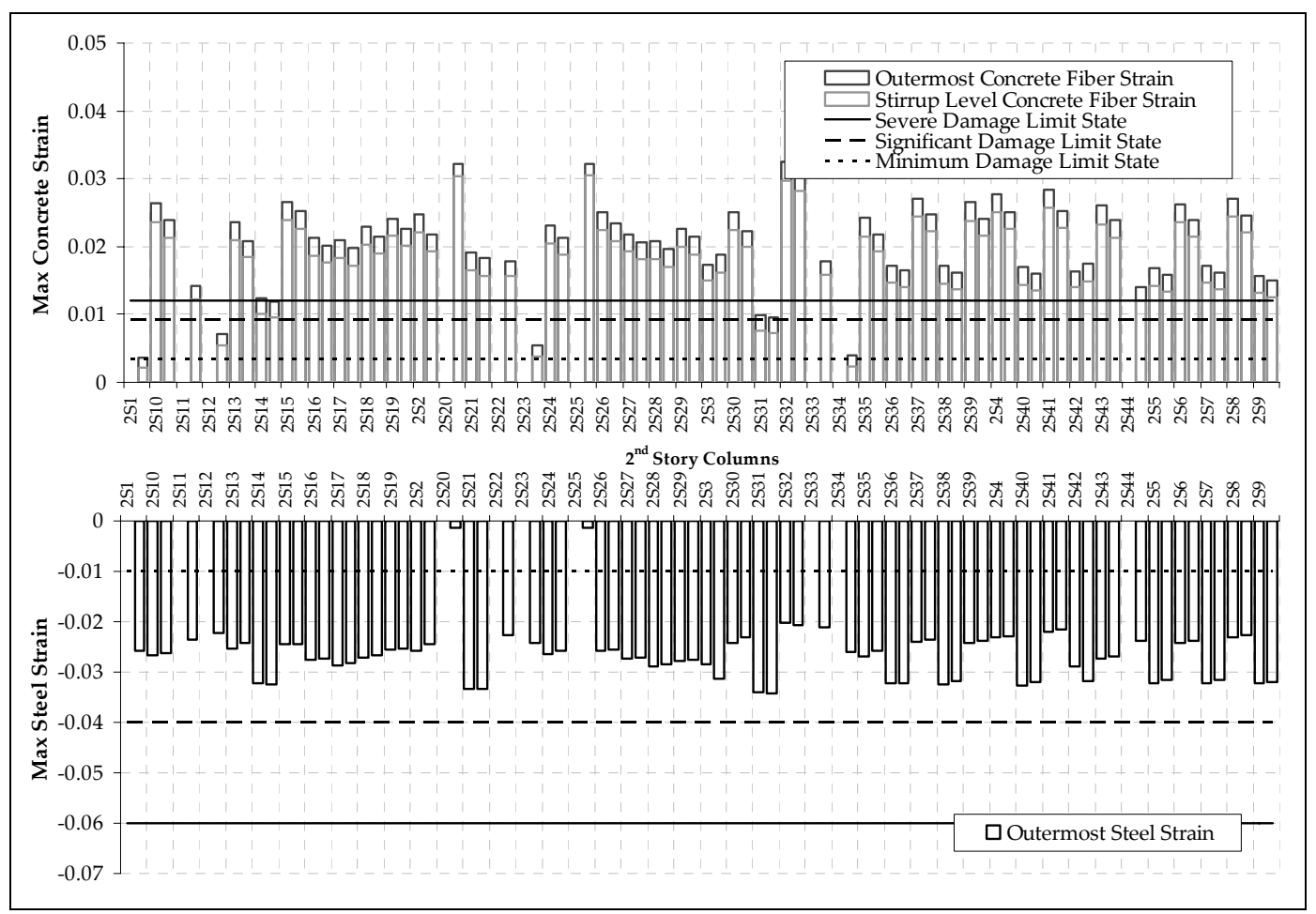

Figure 5.4 Damage levels of the columns in the $\mathrm{X}$ direction loading (continued) 


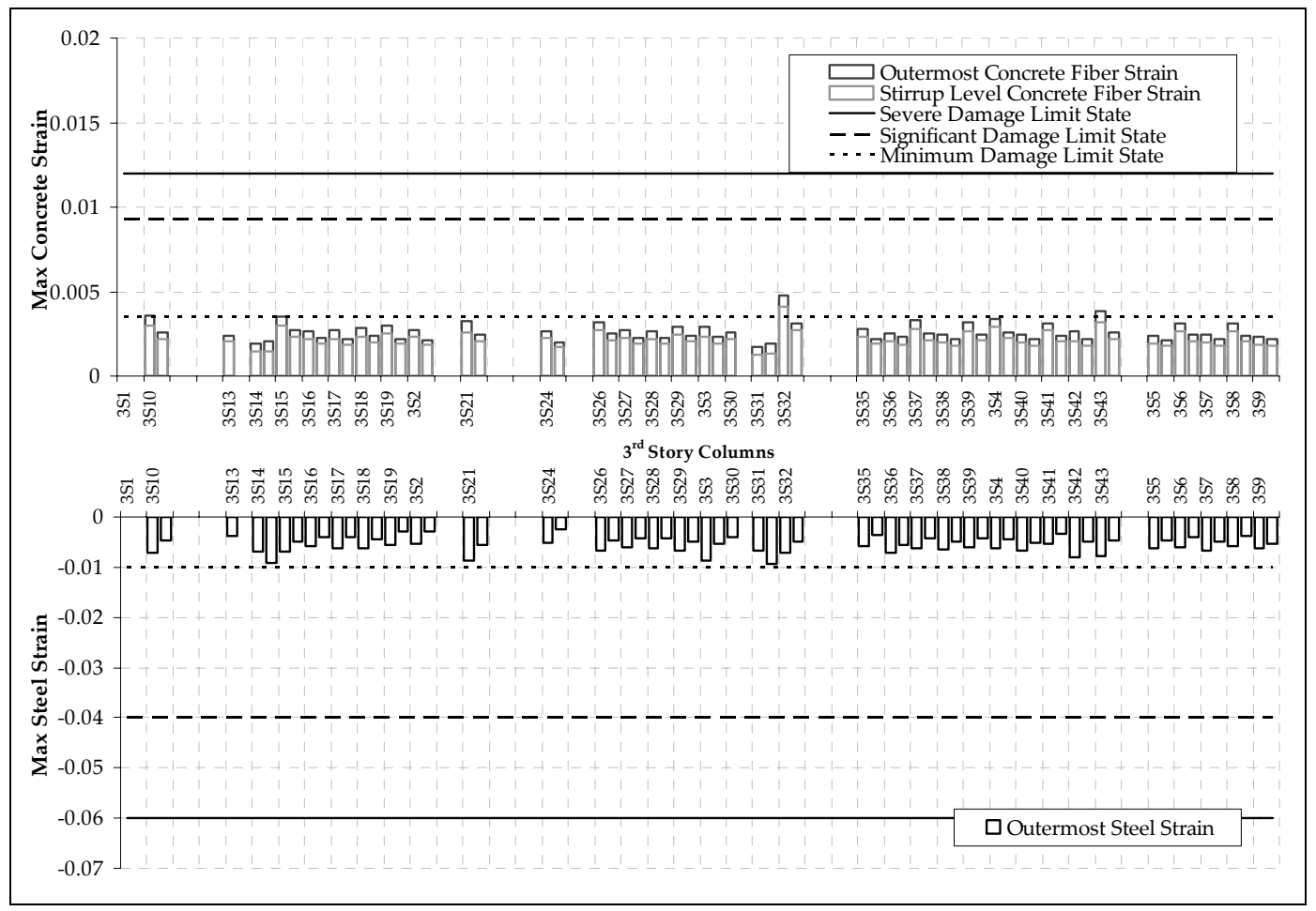

Figure 5.4 Damage levels of the columns in the $X$ direction loading (continued)

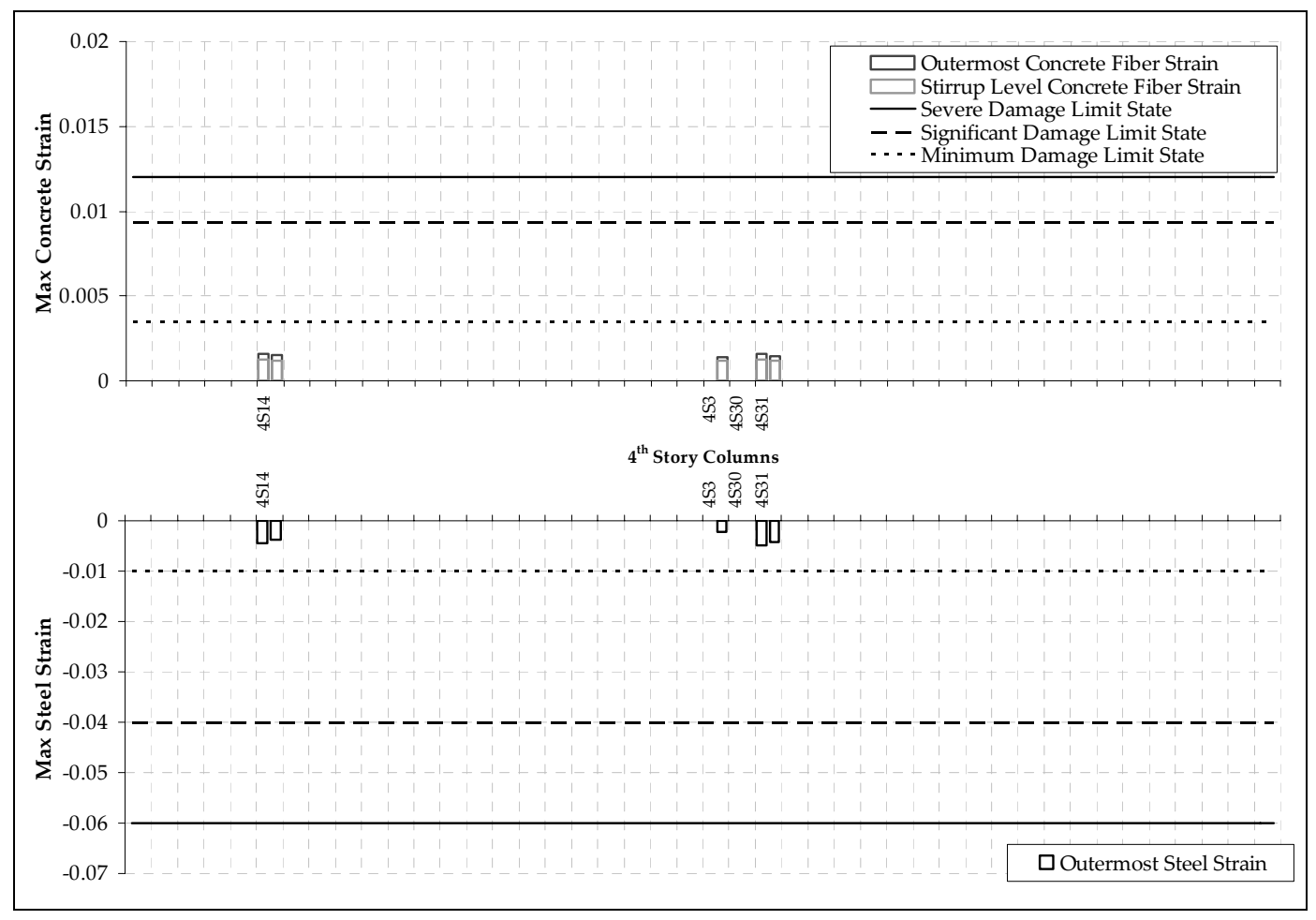

Figure 5.4 Damage levels of the columns in the $X$ direction loading (continued) 


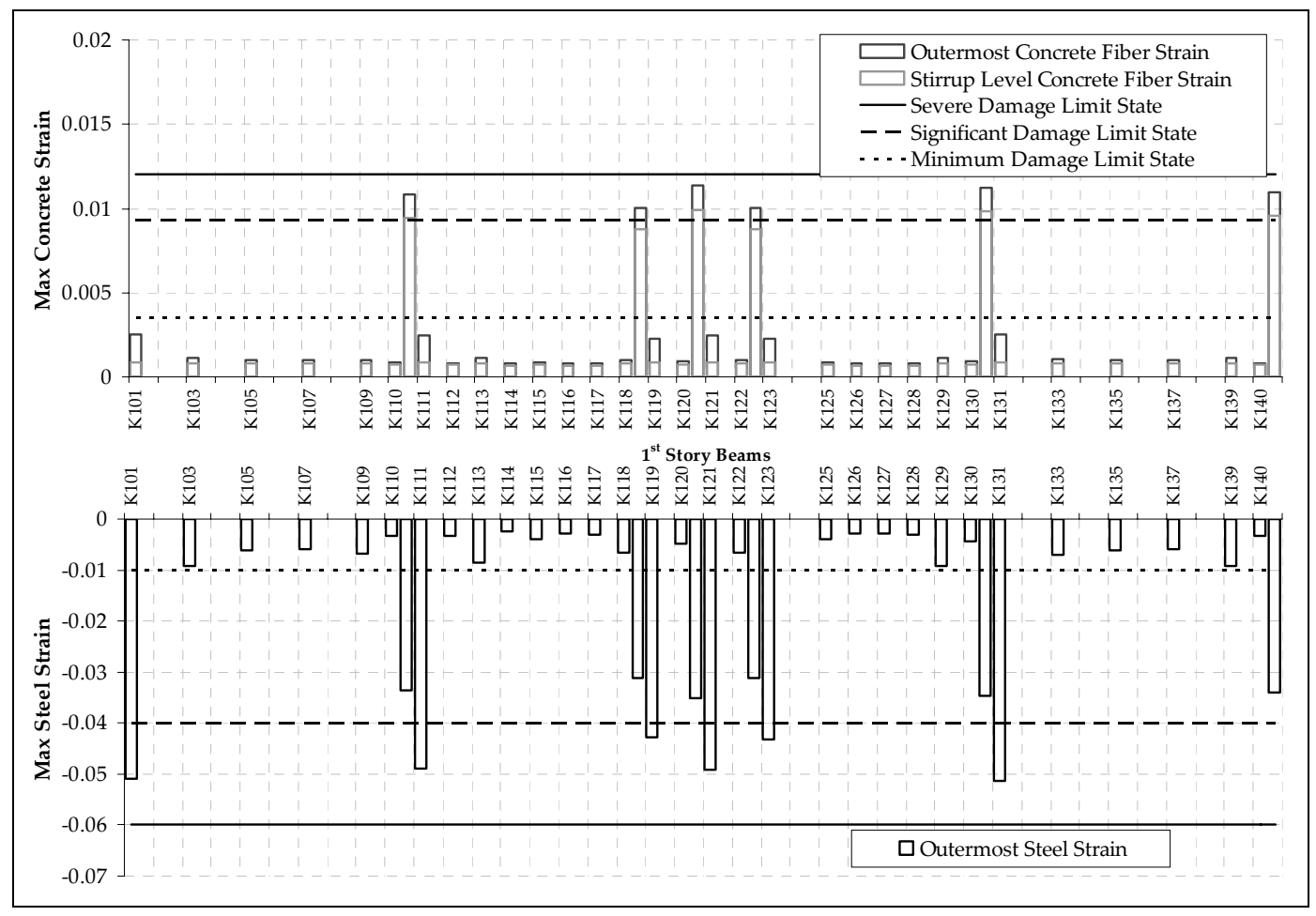

Figure 5.5 Damage levels of the beams in the $\mathrm{X}$ direction loading

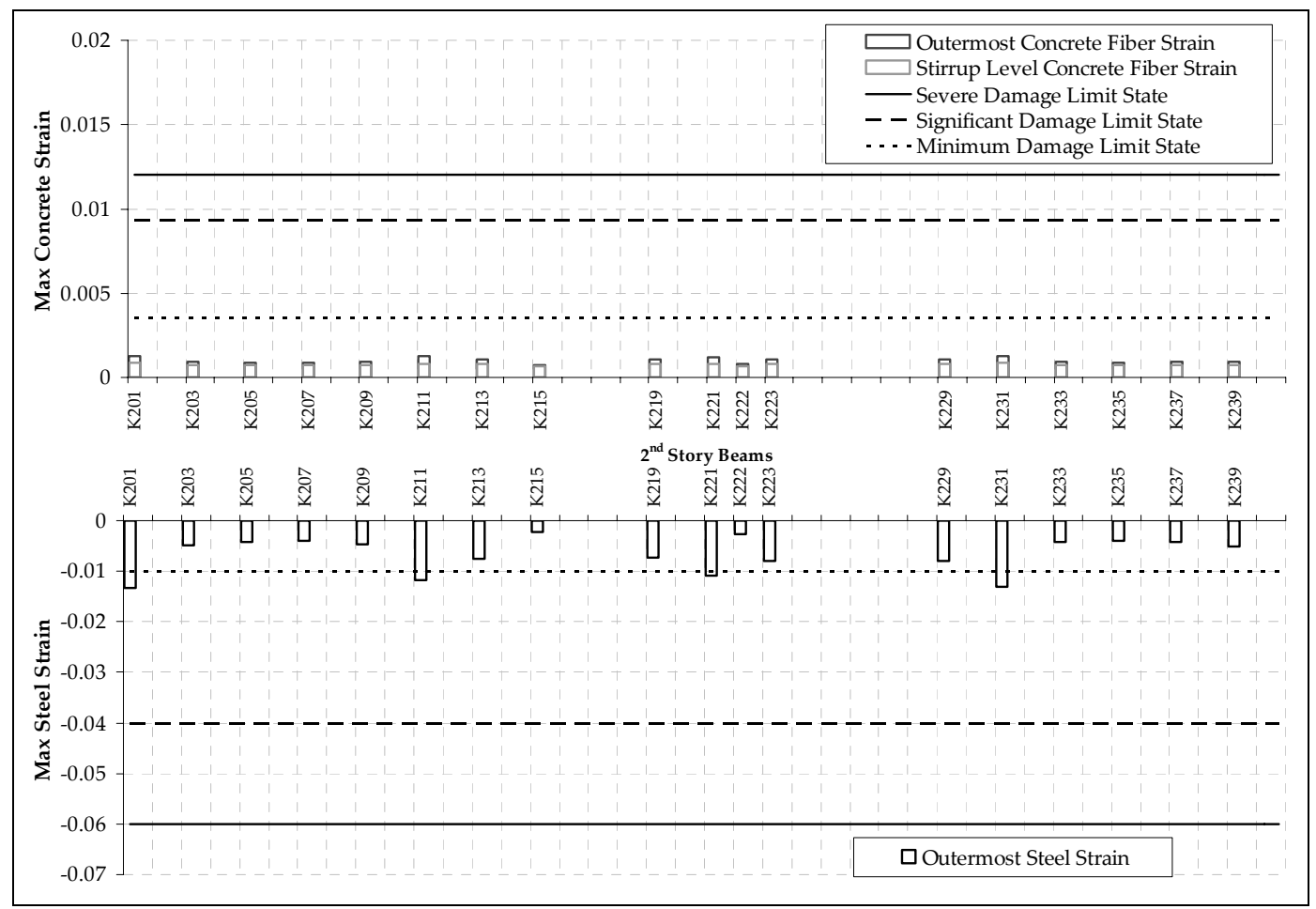

Figure 5.5 Damage levels of the beams in the $\mathrm{X}$ direction loading (continued) 


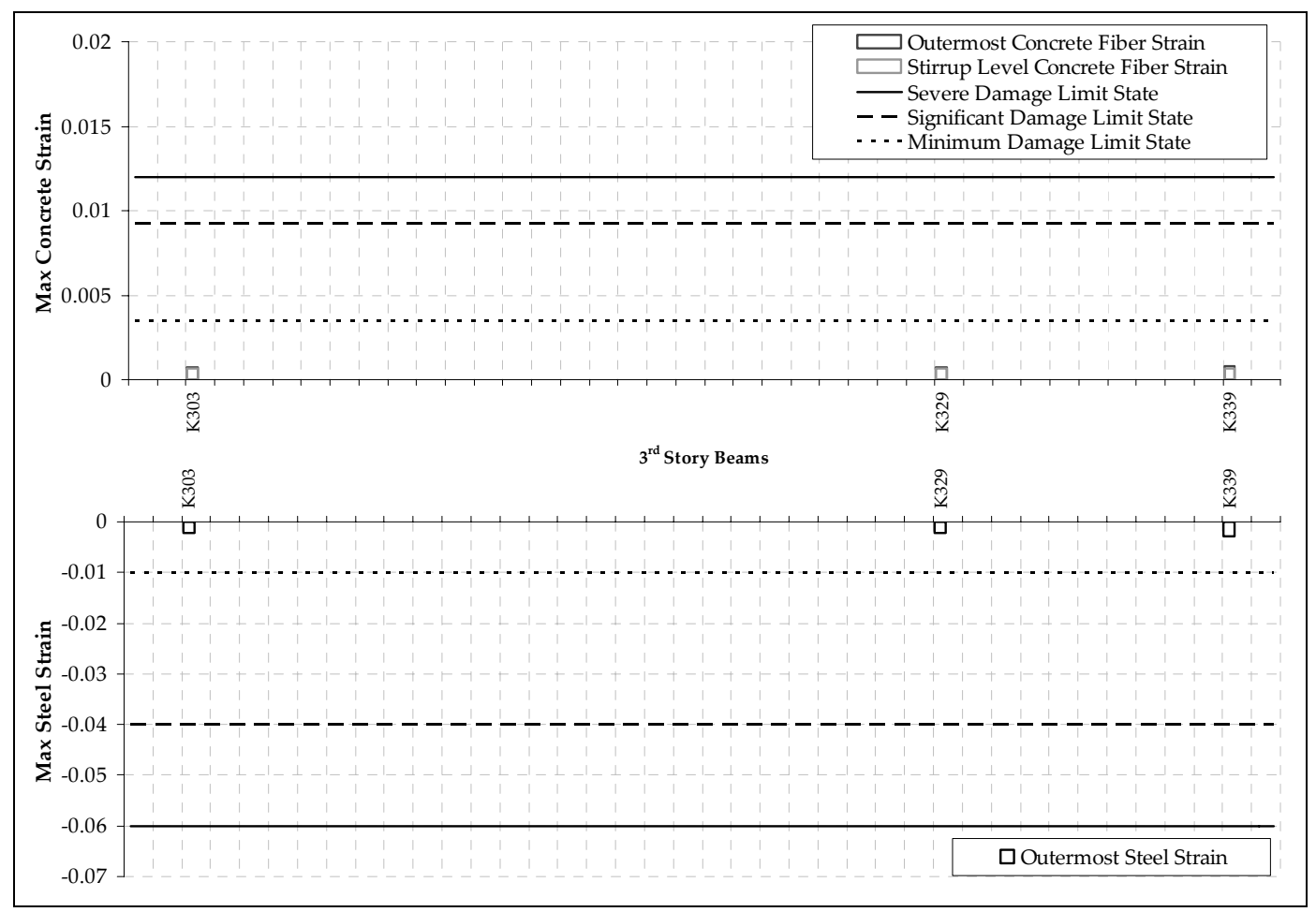

Figure 5.5 Damage levels of the beams in the $\mathrm{X}$ direction loading (continued)

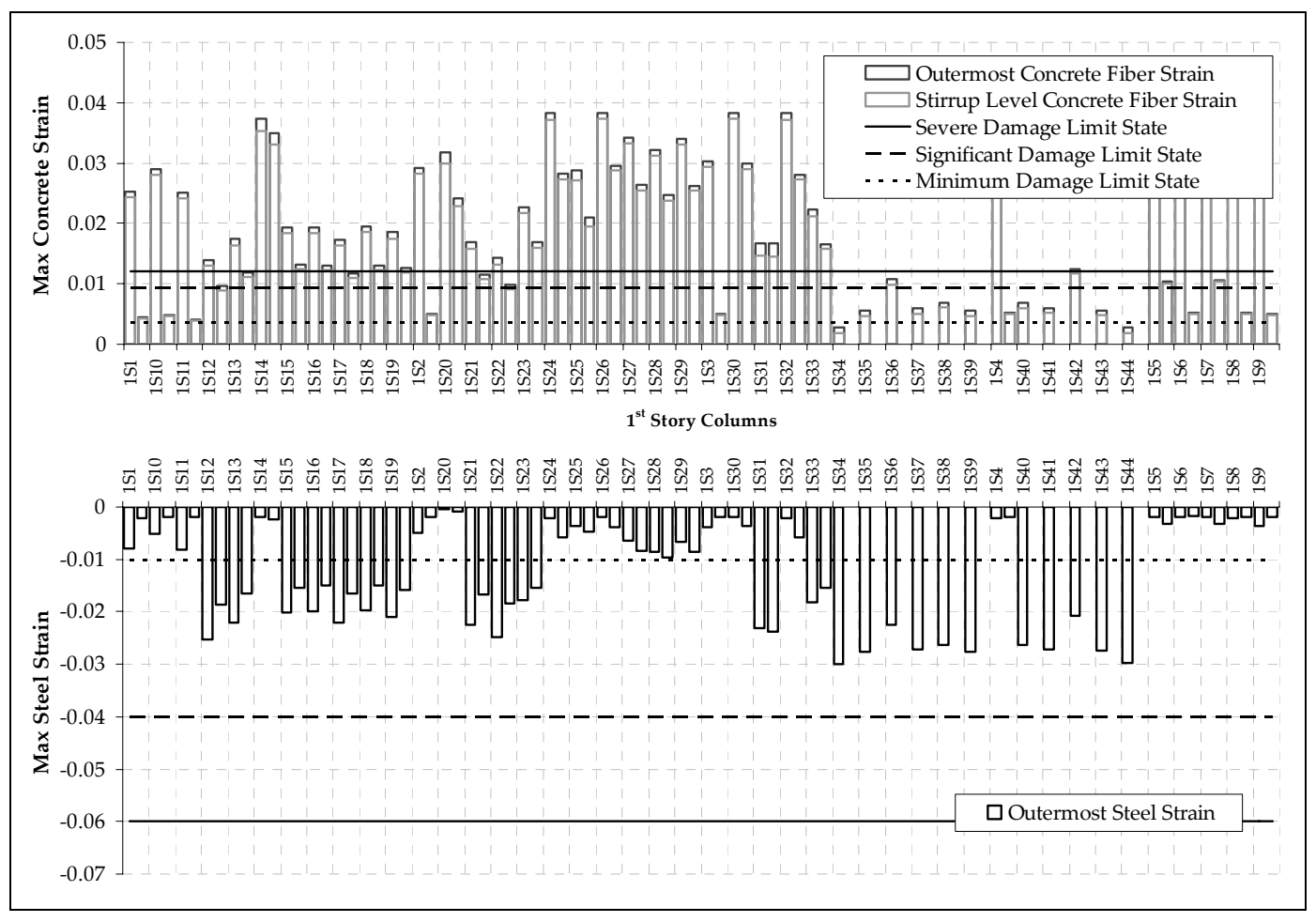

Figure 5.6 Damage levels of the columns in the Y direction loading 


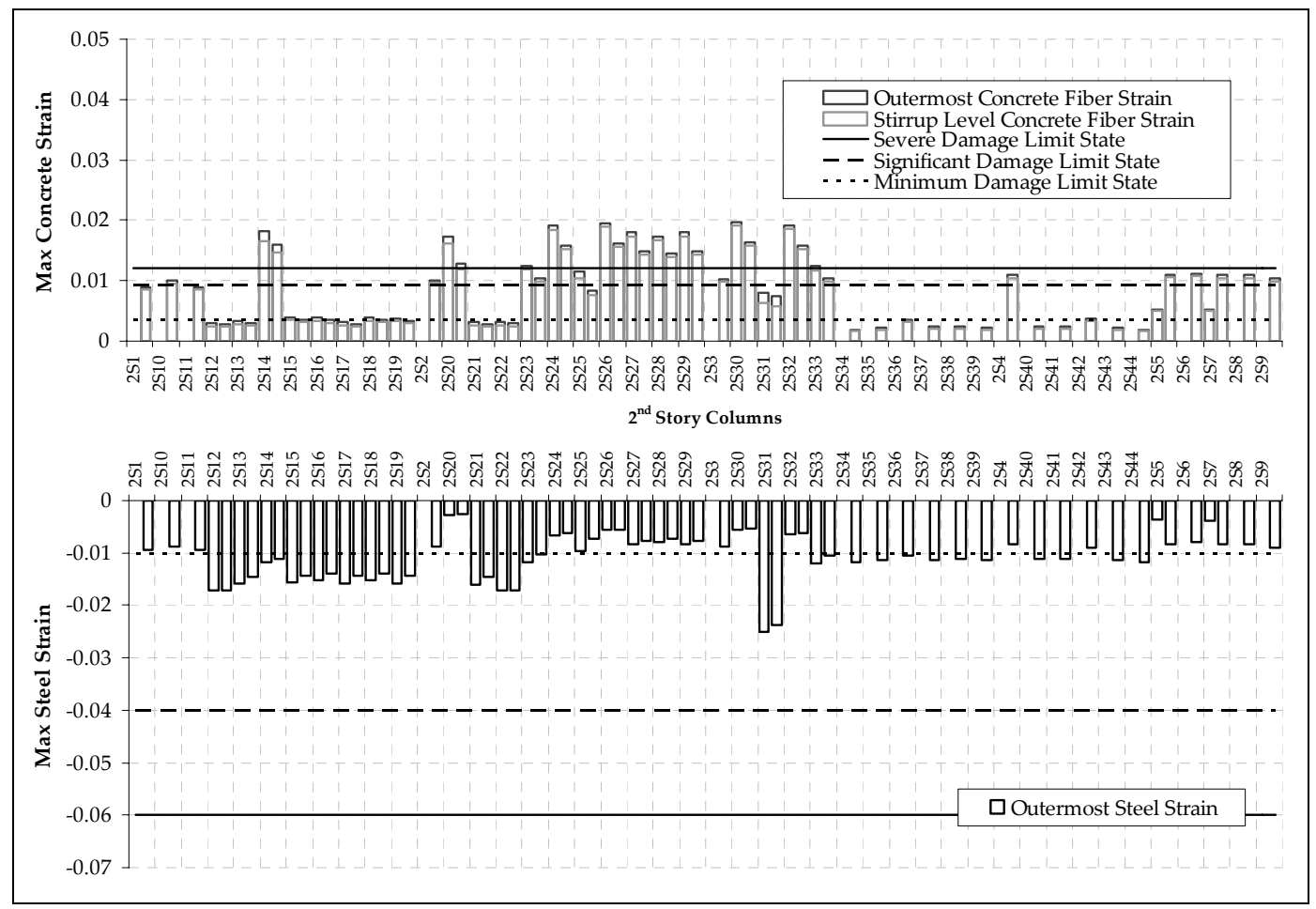

Figure 5.6 Damage levels of the columns in the $Y$ direction loading (continued)

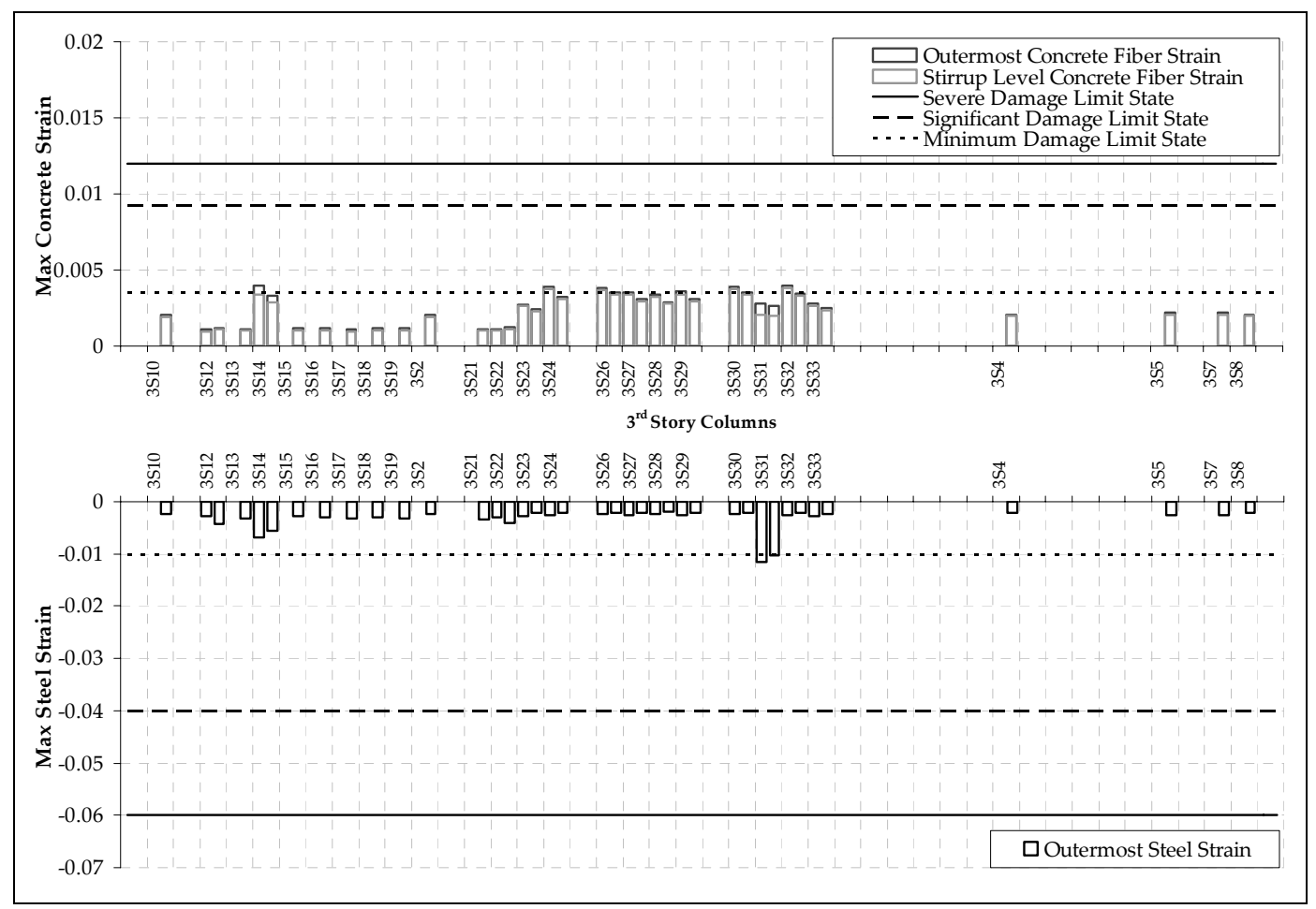

Figure 5.6 Damage levels of the columns in the $Y$ direction loading (continued) 


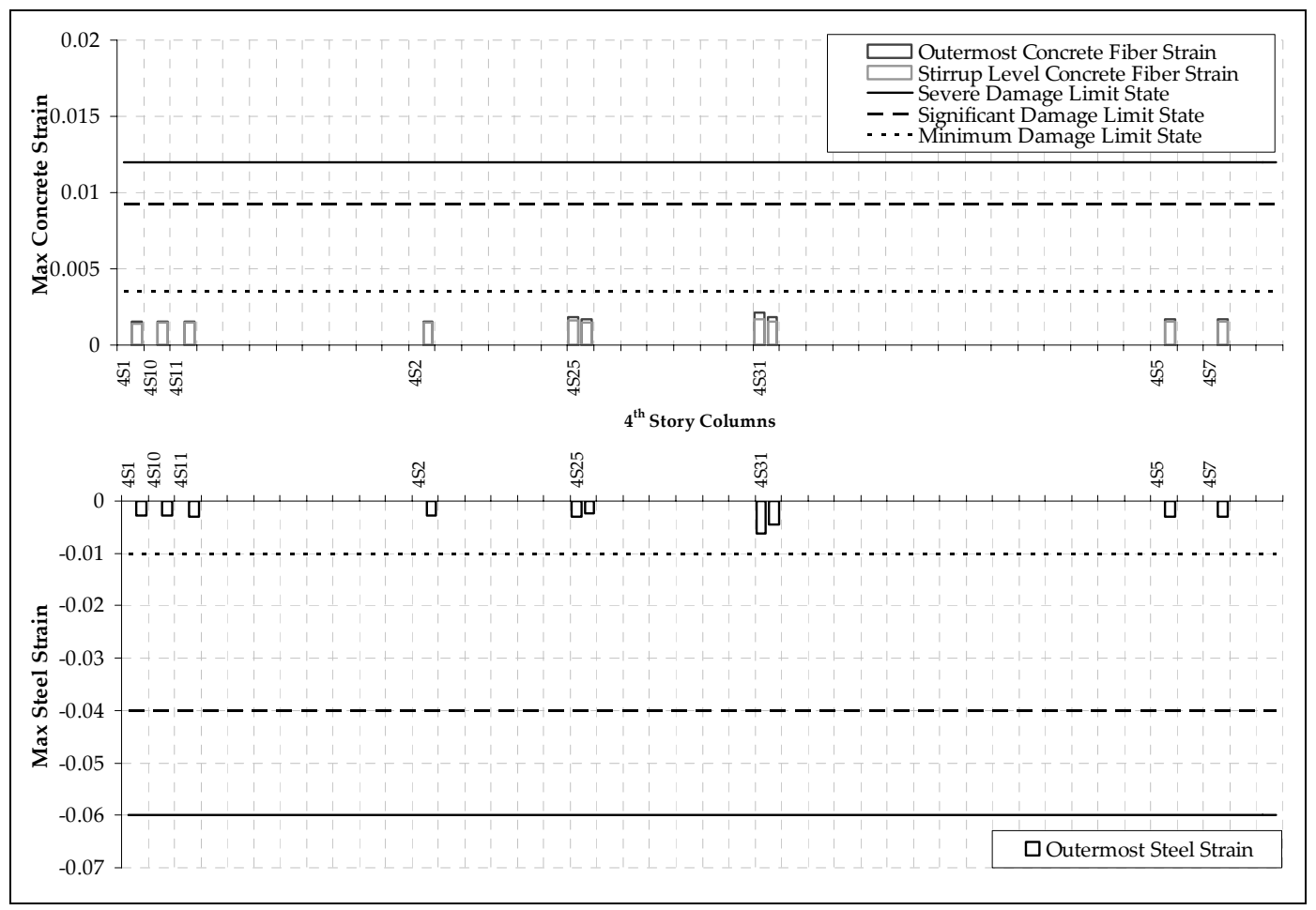

Figure 5.6 Damage levels of the columns in the $Y$ direction loading (continued)

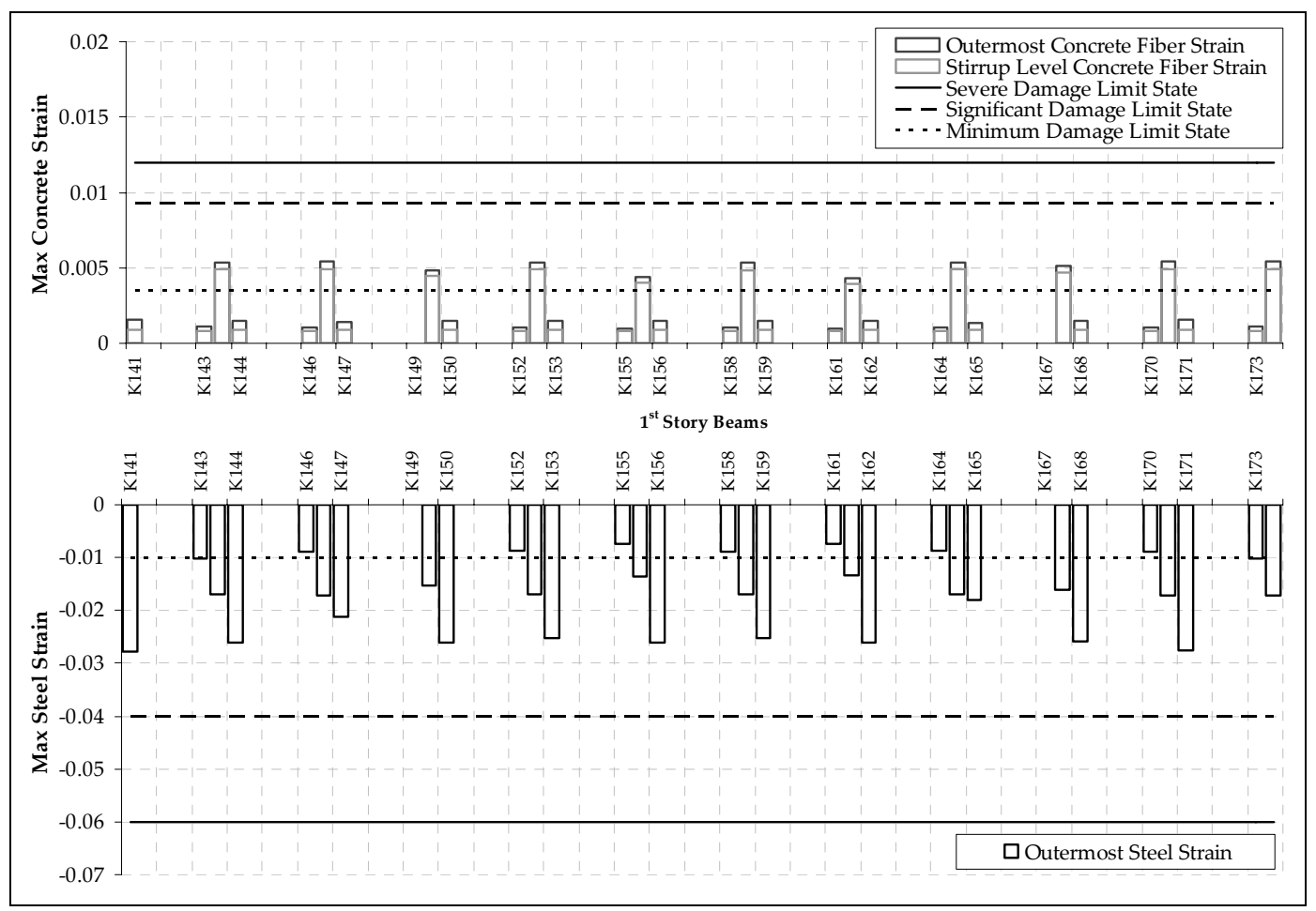

Figure 5.7 Damage levels of the beams in the $Y$ direction loading 


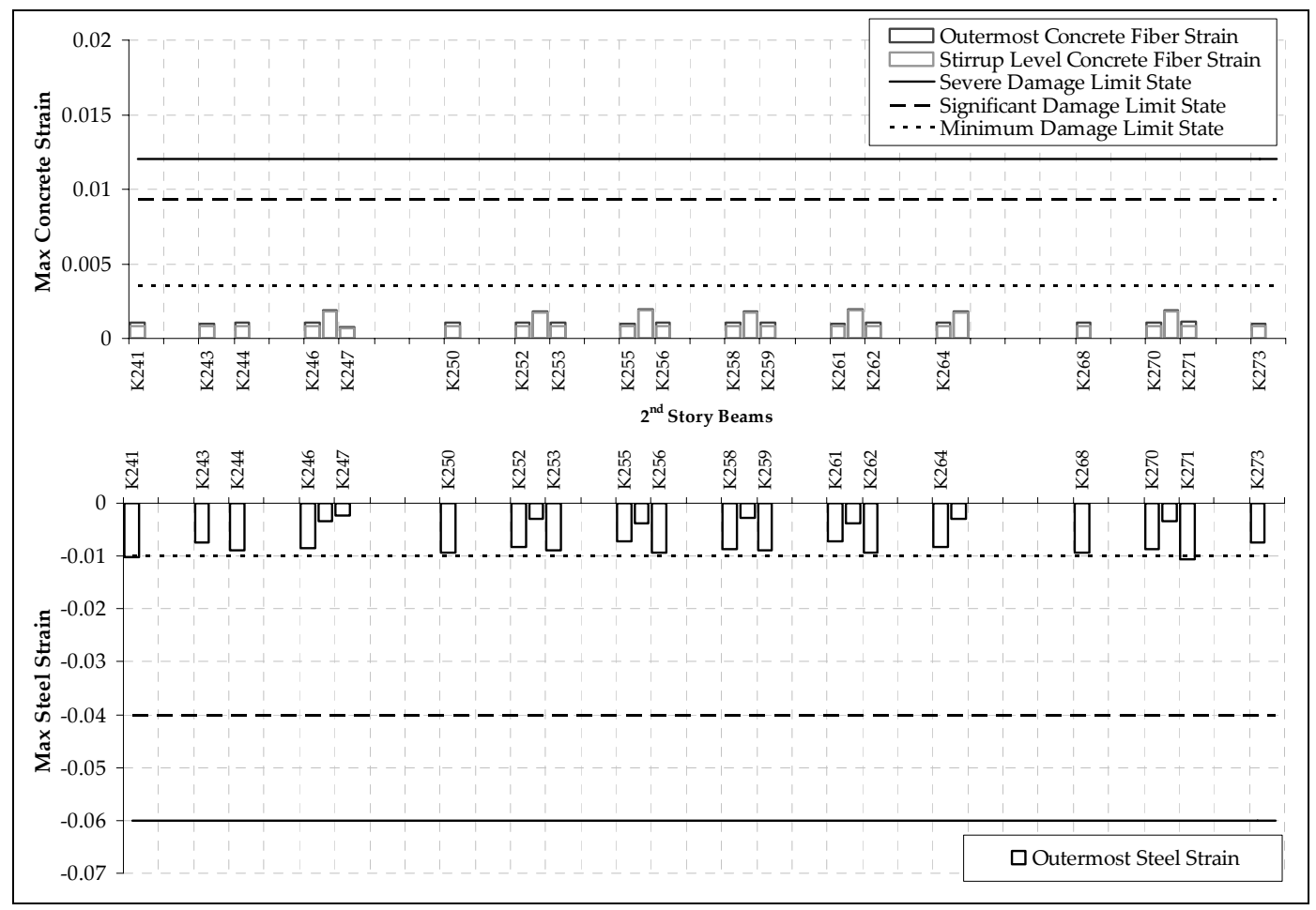

Figure 5.7 Damage levels of the beams in the $\mathrm{Y}$ direction loading (continued)

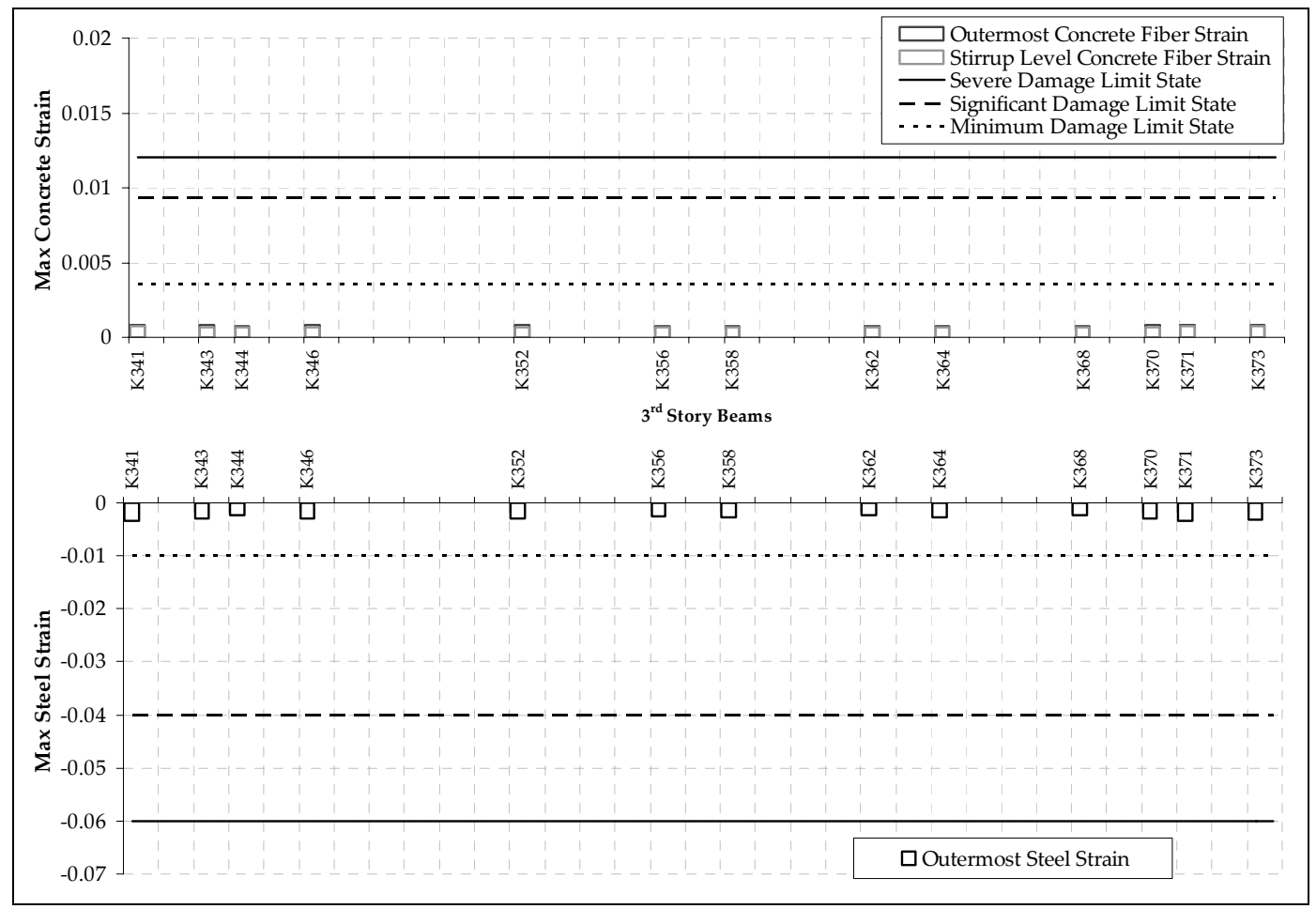

Figure 5.7 Damage levels of the beams in the $\mathrm{Y}$ direction loading (continued) 
Table 5. 1 Global performance of the existing building

\begin{tabular}{|c|c|c|c|c|c|c|c|c|c|}
\hline \multicolumn{5}{|c|}{ X Direction } & \multicolumn{5}{|c|}{ Y Direction } \\
\hline $\begin{array}{c}\text { Story } \\
\text { No. }\end{array}$ & $\begin{array}{c}V_{\text {str }} \\
(k N) \\
\end{array}$ & $\begin{array}{l}V_{N C} \\
(k N) \\
\end{array}$ & $\% N C$ & $\begin{array}{l}\% \text { NC } \\
\text { Beams }\end{array}$ & $\begin{array}{c}\text { Story } \\
\text { No. }\end{array}$ & $\begin{array}{c}V_{\text {str }} \\
(k N) \\
\end{array}$ & $\begin{array}{l}V_{N C} \\
(k N) \\
\end{array}$ & $\% N C$ & $\begin{array}{l}\% \text { NC } \\
\text { Beams }\end{array}$ \\
\hline 1 & 4542 & 4542 & 100.00 & 25.00 & 1 & 8065 & 6633 & 82.24 & 0.00 \\
\hline 2 & 4082 & 3762 & 92.16 & 0.00 & 2 & 7322 & 4082 & 55.75 & 0.00 \\
\hline 3 & 3036 & 0 & 0.00 & 0.00 & 3 & 5507 & 735 & 0.00 & 0.00 \\
\hline 4 & 1498 & 0 & 0.00 & 0.00 & 4 & 2751 & 0 & 0.00 & 0.00 \\
\hline
\end{tabular}

\subsection{Implementation of the Retrofit Design Methodology}

Six shear walls having cross section dimensions of $300 \times 3300 \mathrm{~mm}$ and two shear walls having cross section dimensions of 300x5800 mm were added in the $X$ and $Y$ directions, respectively. The ratio of the cross section area of shear walls in the considered earthquake direction to the floor area is 0.012 in the $\mathrm{X}$ direction and $0.007 \%$ in the $\mathrm{Y}$ directions. 3D mathematical model and plan view of the retrofitted building are shown in Figure 5.8 and Figure 5.9, respectively.

Characteristic concrete strength was taken as $25 \mathrm{MPa}$ and characteristic yield strength of reinforcement bars was taken as $420 \mathrm{MPa}$ for new members.

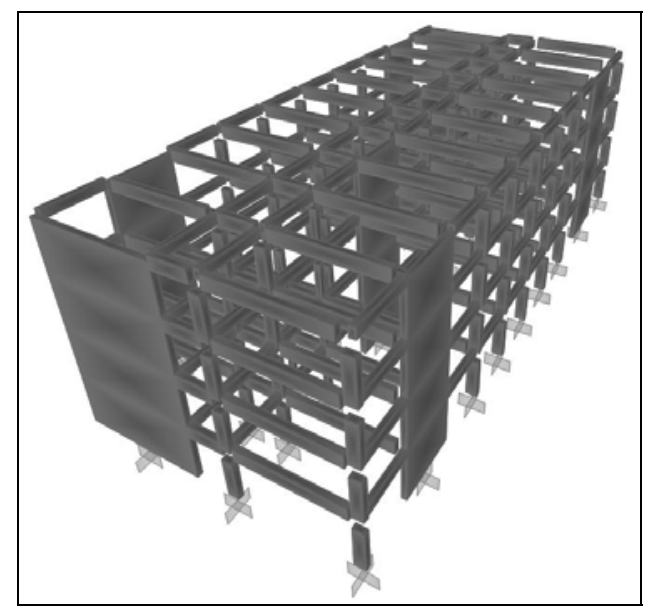

Figure 5.8 3D Mathematical model of the four story retrofitted dormitory building 


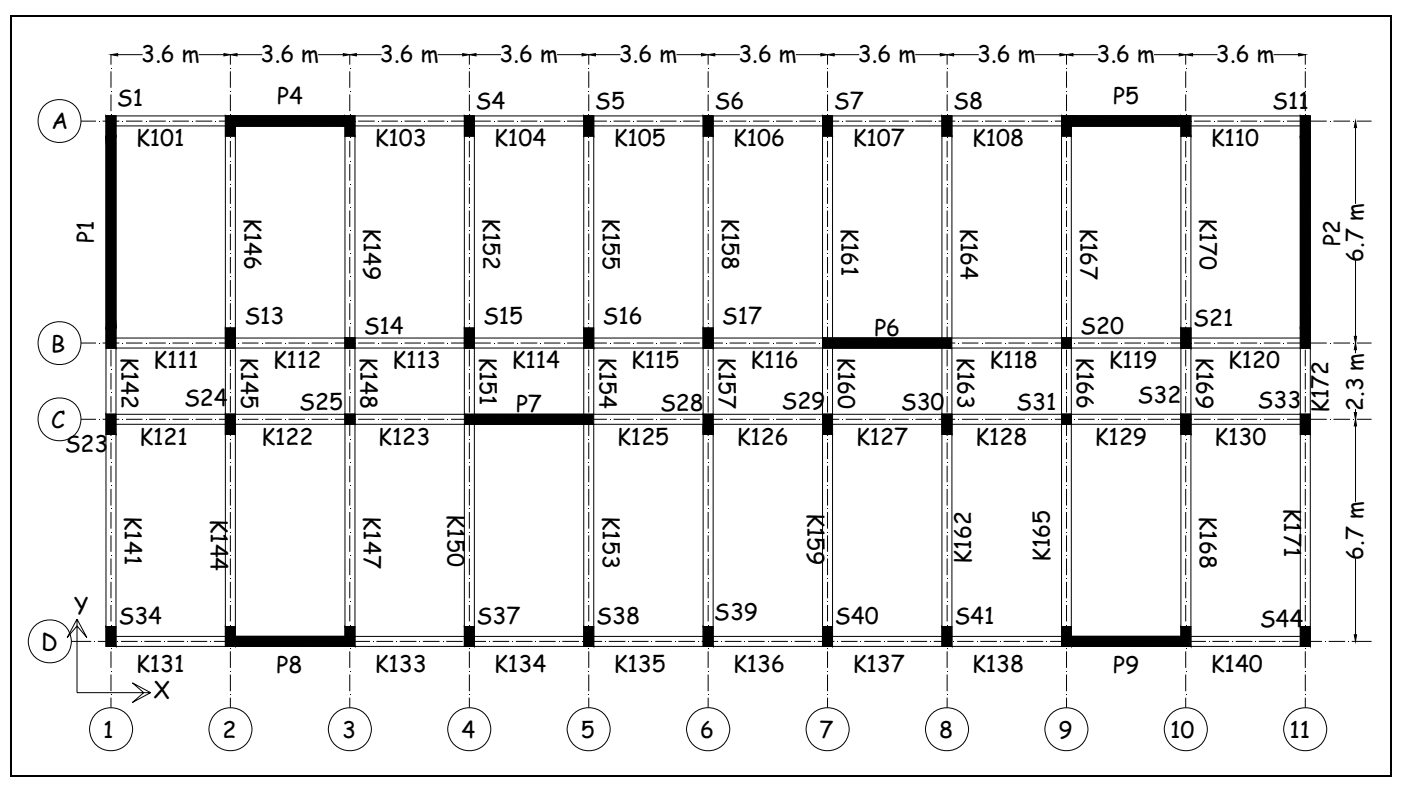

Figure 5.9 Plan view of the retrofitted building

Effective fundamental periods in both directions were computed by using cracked stiffnesses of reinforced concrete members. Effective fundamental periods in the $\mathrm{X}$ and $\mathrm{Y}$ directions were computed as 0.43 and $0.33 \mathrm{sec}$. respectively. These periods were 0.84 and 0.56 seconds before retrofitting with the added walls. Employing Equation 2.1, target roof displacement demands were computed as $0.09 \mathrm{~m}$ and $0.065 \mathrm{~m}$ for the $\mathrm{X}$ and $\mathrm{Y}$ directions, which were $0.185 \mathrm{~m}$ and $0.116 \mathrm{~m}$ before retrofitting. Target roof displacements and corresponding uniform drift distributions computed for the design earthquake having $2 \%$ probability of exceedance in 50 years are shown in Figure 5.8 together with the drift profile of the existing and retrofitted buildings at the associated performance points. 

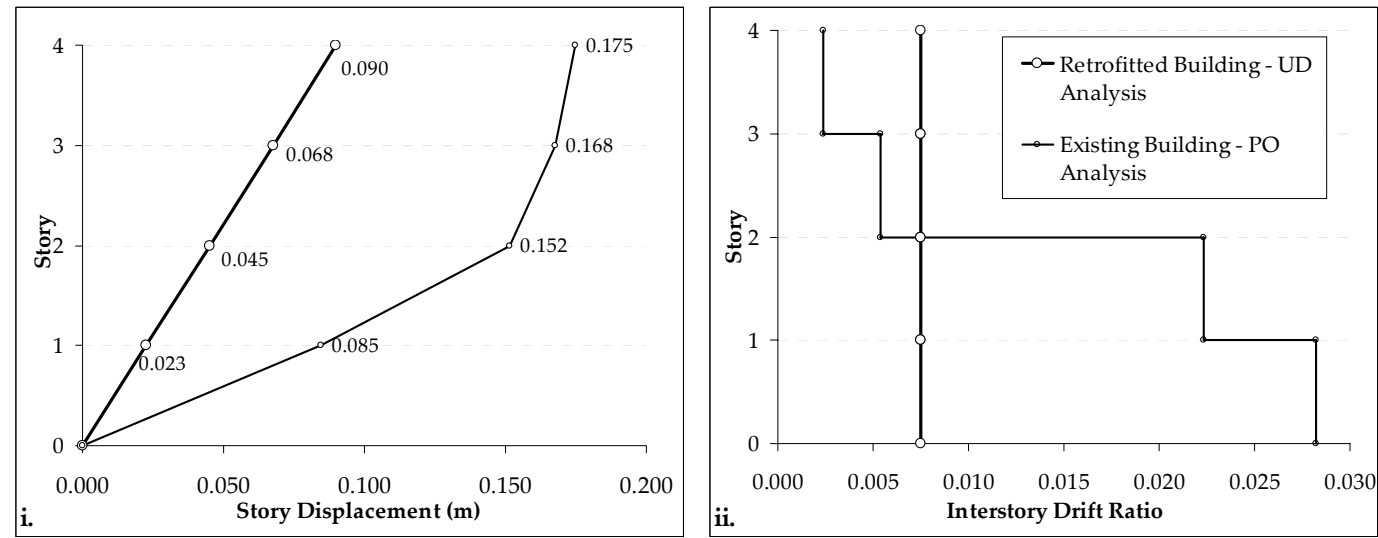

Figure 5.10 i. Story displacements, ii. Interstory drift distributions in $\mathrm{X}$ direction
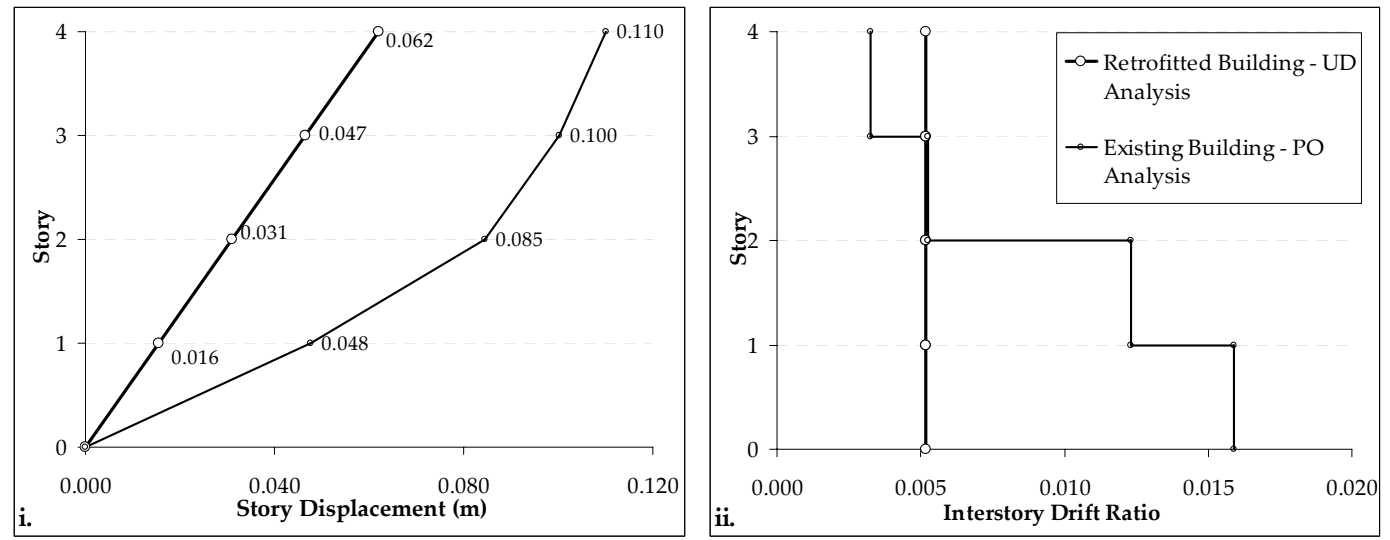

Figure 5.11 i. Story displacements, ii. Interstory drift distributions in Y direction

Imposing the drift distributions shown in Figures 5.10 and 5.11 by employing a linear elastic analysis, chord rotation demands were calculated and presented in Figures 5.12 and Figure 5.13 together with the chord rotation capacities at the significant damage limit of the columns in order to determine deficient columns. Interventions may be required in order to increase their deformation capacities or shear strengths. 


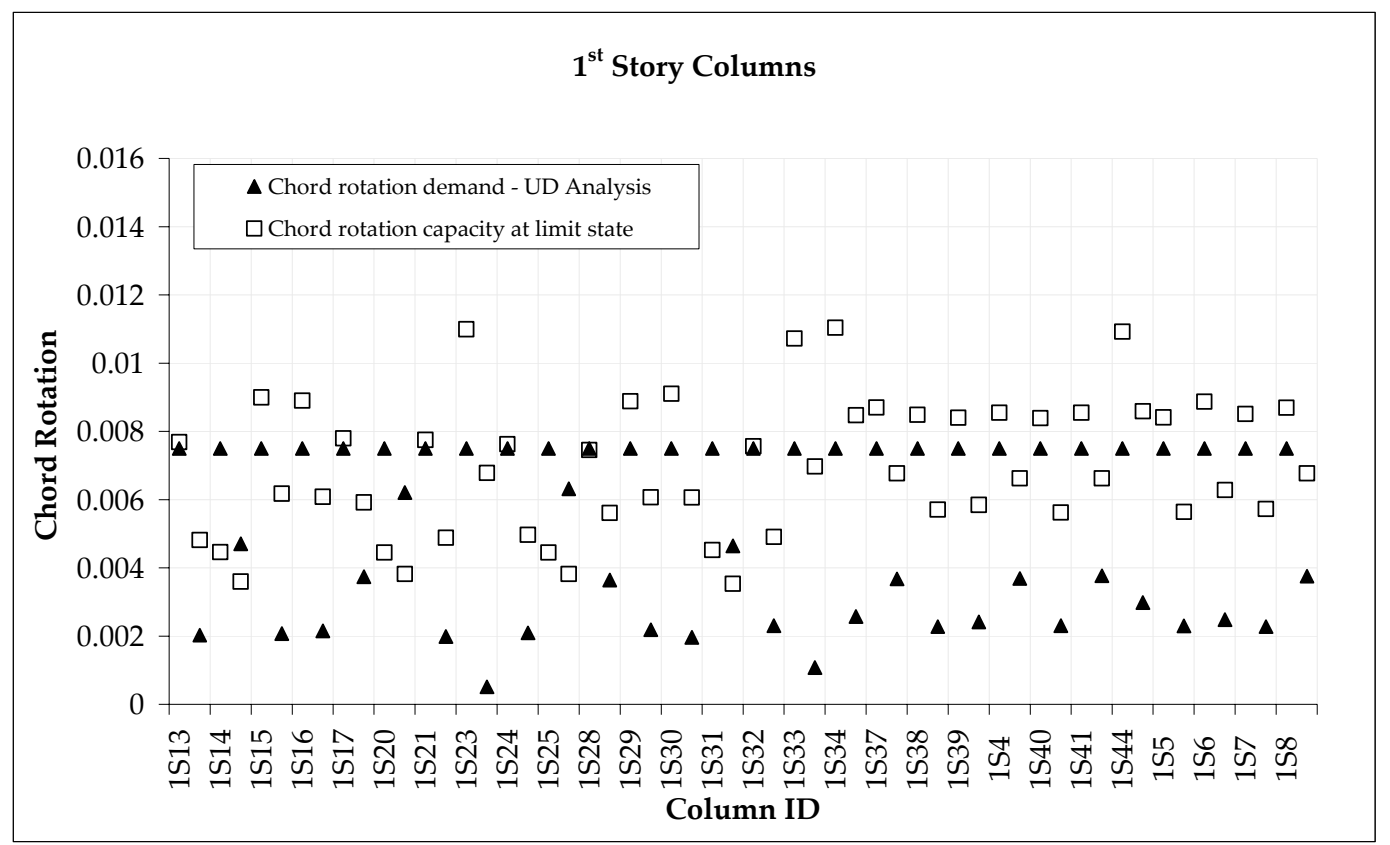

Figure 5.12 Comparison of chord rotation demands and capacities for columns in the $X$ direction for significant damage performance level

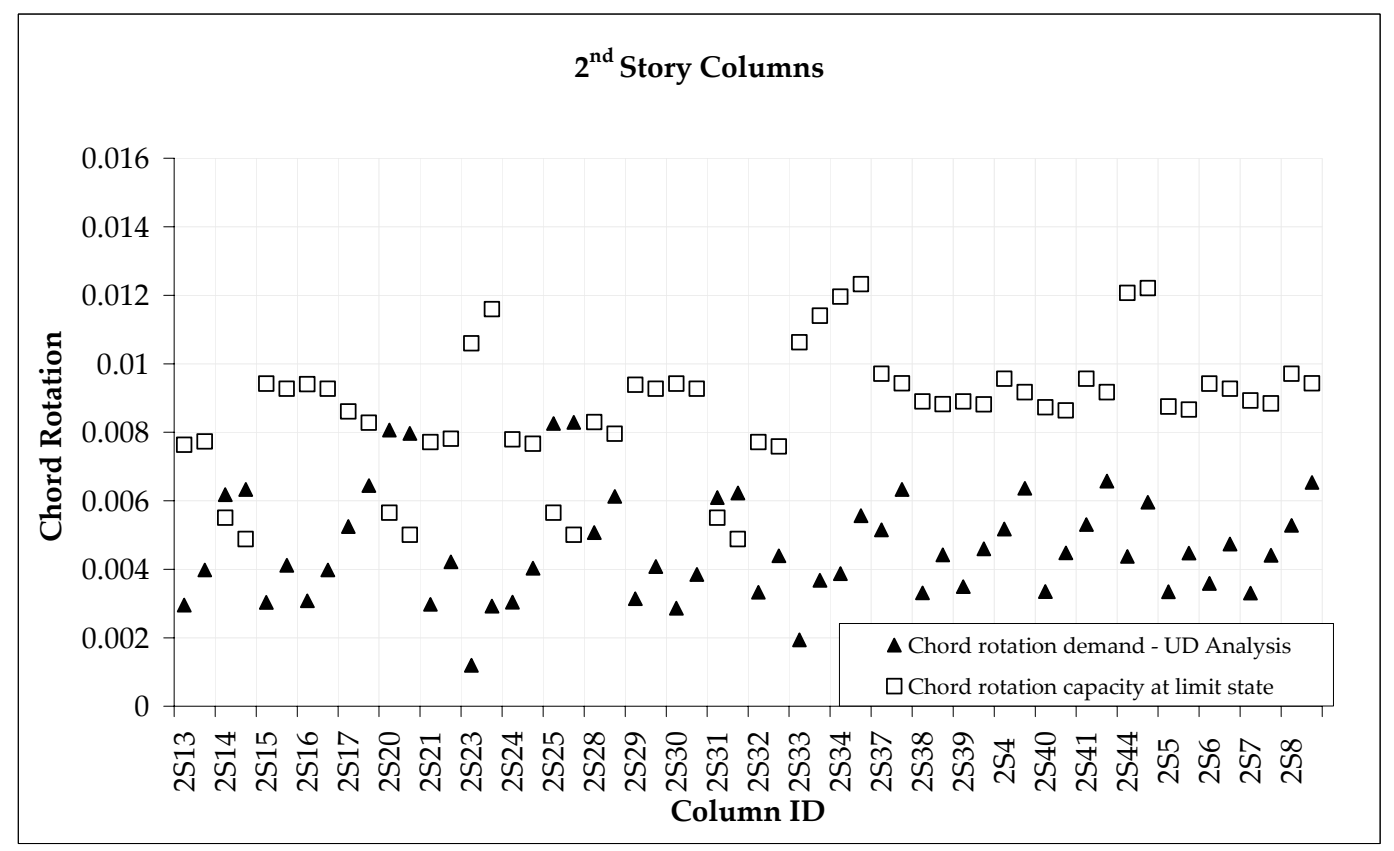

Figure 5.12 Comparison of chord rotation demands and capacities for columns in the $X$ direction for significant damage performance level (continued) 


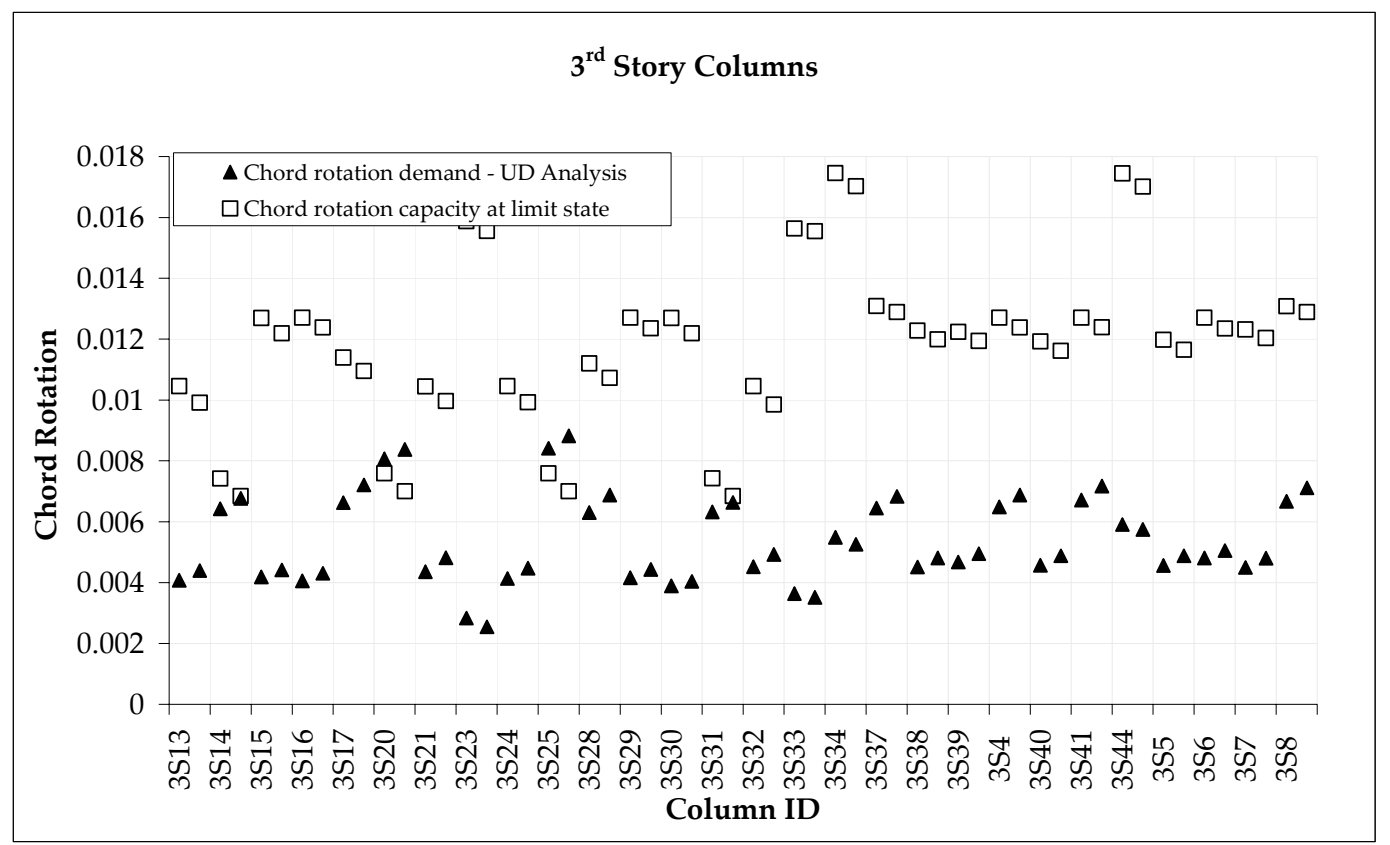

Figure 5.12 Comparison of chord rotation demands and capacities for columns in the $X$ direction for significant damage performance level (continued)

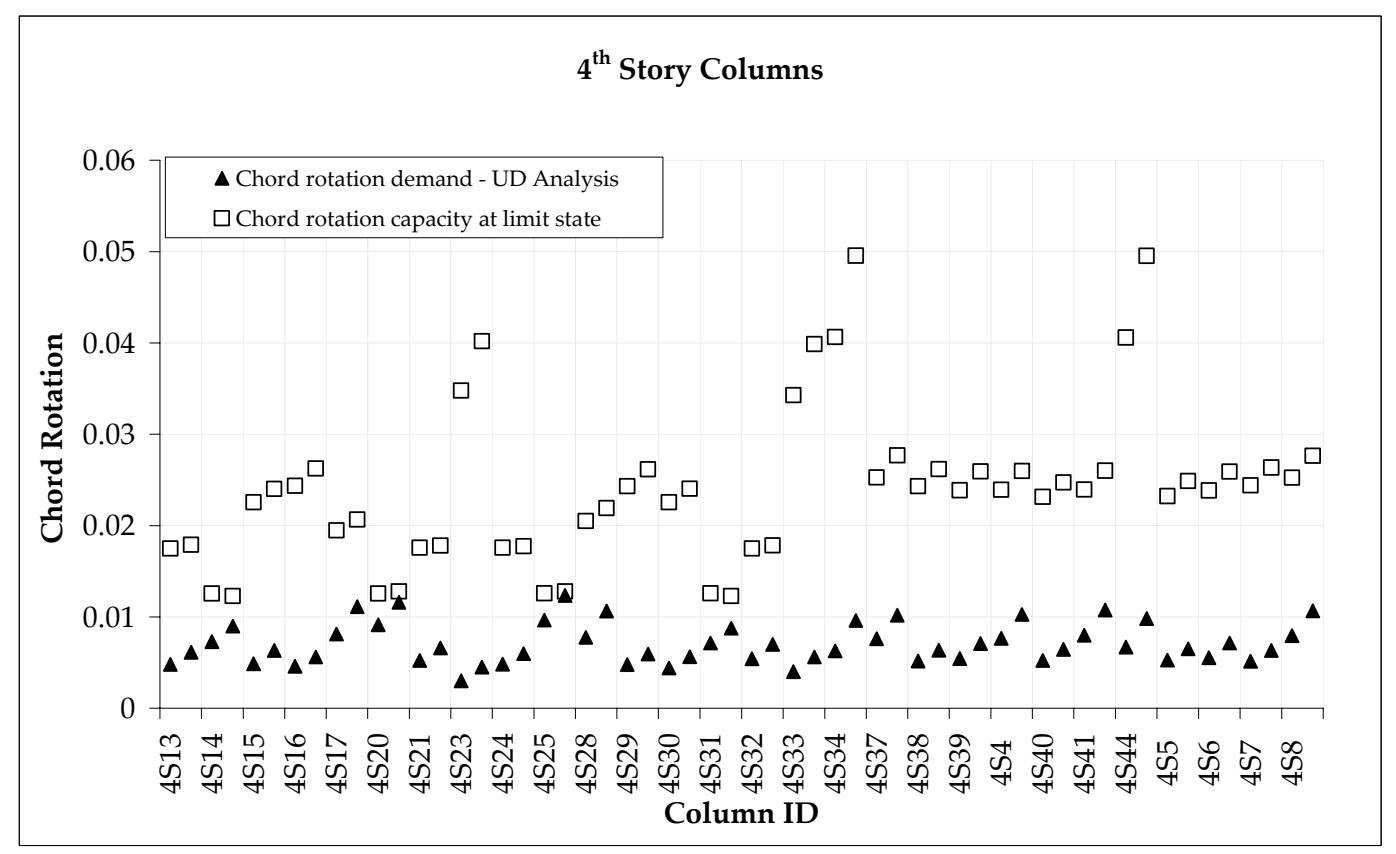

Figure 5.12 Comparison of chord rotation demands and capacities for columns in the $X$ direction for significant damage performance level (continued) 


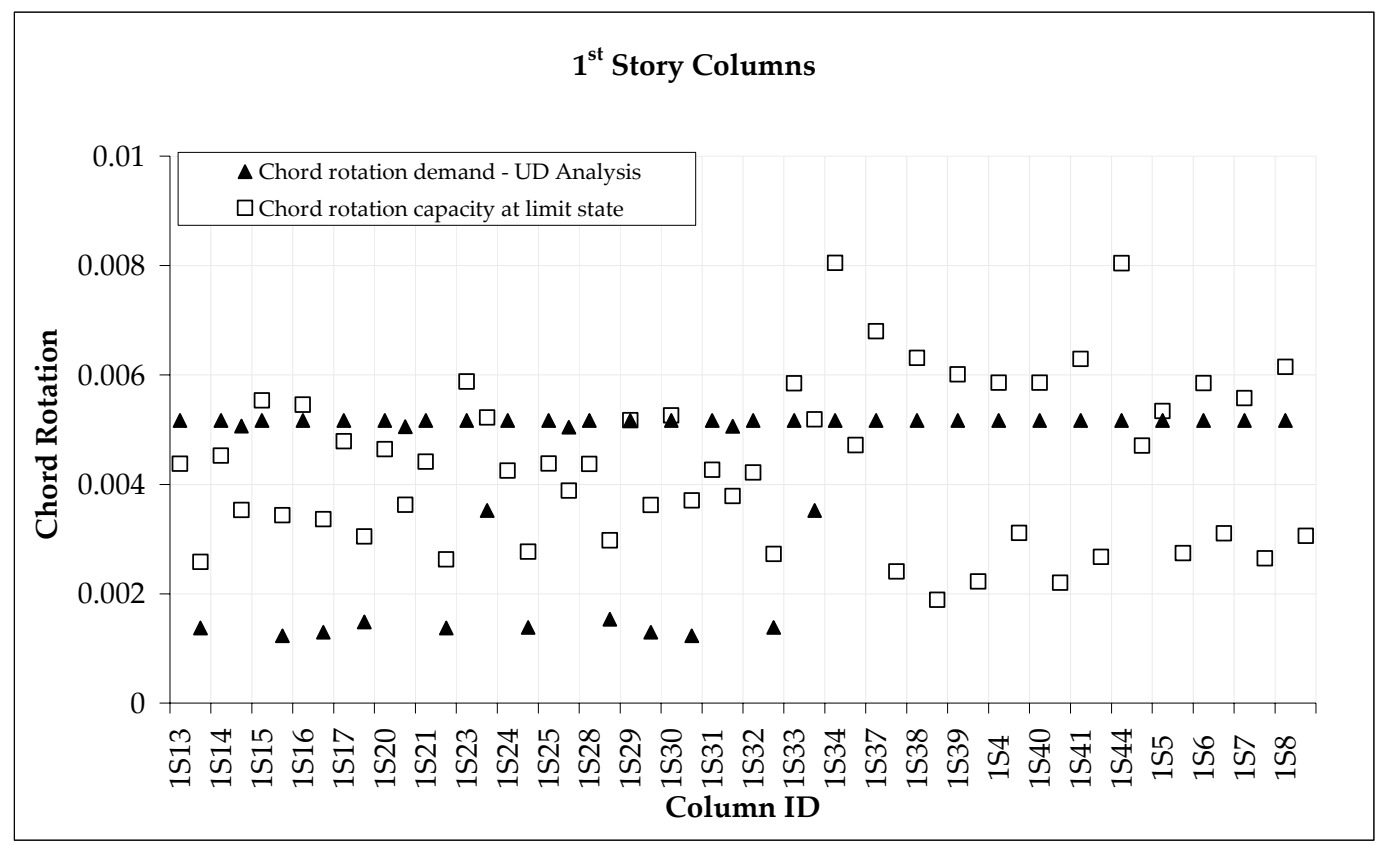

Figure 5.13 Comparison of chord rotation demands and capacities for columns in the $\mathrm{Y}$ direction for significant damage performance level

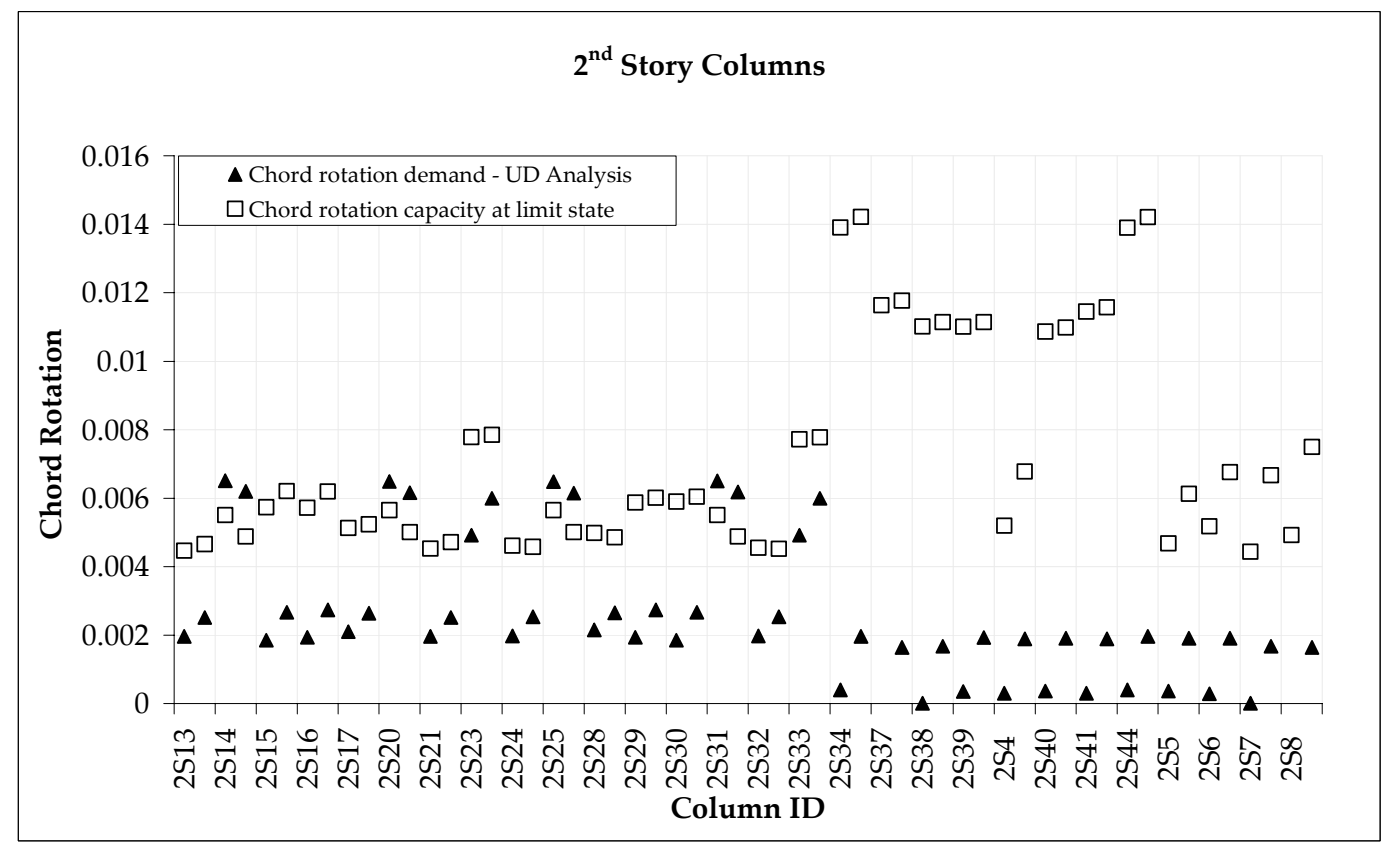

Figure 5.13 Comparison of chord rotation demands and capacities for columns in the $\mathbf{Y}$ direction for significant damage performance level (continued) 


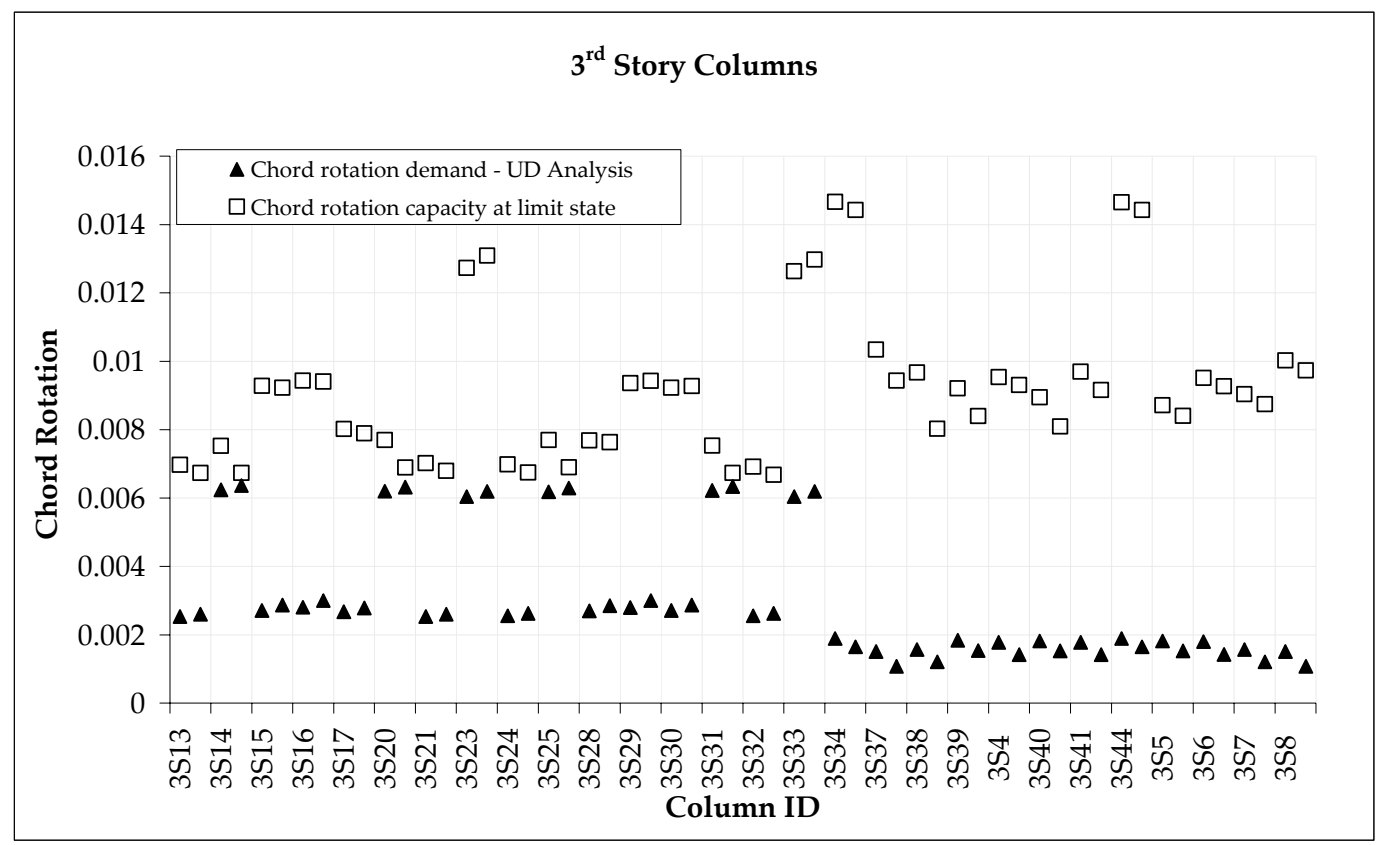

Figure 5.13 Comparison of chord rotation demands and capacities for columns in the $\mathbf{Y}$ direction for significant damage performance level (continued)

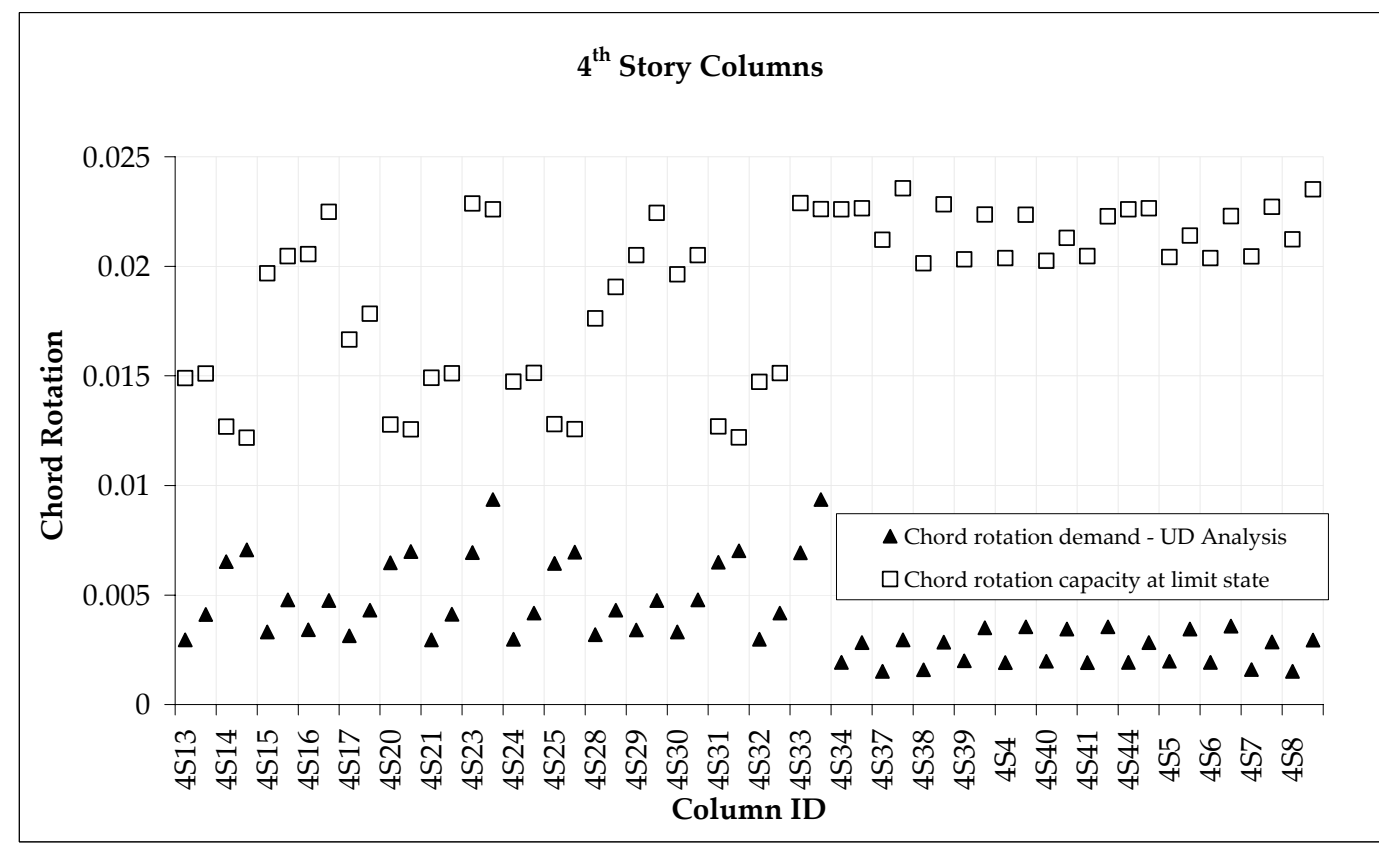

Figure 5.13 Comparison of chord rotation demands and capacities for columns in the $\mathbf{Y}$ direction for significant damage performance level (continued) 
Following the Figures 5.12 and 5.13, chord rotation capacities of the columns S13-14, S17, S20-21, S24-25, S28 and S31-32 were determined as lower than the chord rotation demands. For other columns in the building, chord rotation demands do not exceed the chord rotation capacities calculated at the significant damage limit state. Rectangular columns S13, S17, S21, S24, S28 and S32 were wrapped with FRP sheets at the first story in order to increase their deformation capacities. Wrapping of square columns were made for first two stories. FRP design was made by following the procedures stated in TEC 2007. Details of FRP design of column S14 is given below as an example. $1 \mathrm{~mm}$ thickness of FRP sheets were used for a continuous wrap.

$\begin{array}{lccccl}C \boldsymbol{R}_{\text {demand }} & \mathbf{0 . 0 0 7 5} & E_{f}(\mathrm{MPa}) & 230000 & \text { where } & \\ \boldsymbol{C} \boldsymbol{R}_{\text {cap, } \mathrm{FRP}} & \mathbf{0 . 0 1 0 5} & n_{f} & 1 & n_{f} & \text { Number of FRP layers } \\ & t_{f}(\mathrm{~mm}) & 1 & t_{f} & \text { Thickness of one layer FRP sheet } \\ & \varepsilon_{\text {min }} & 0.004 & E_{f} & \text { Elastic modulus of FRP sheets } \\ & & \varepsilon_{\text {sig }} & 0.0129 & \varepsilon_{\text {min }} & \text { Strain limit for minimum damage } \\ & & \varepsilon_{\text {sev }} & 0.0172 & \varepsilon_{\text {sig }} & \text { Strain limit for significant damage } \\ & & & & \varepsilon_{\text {sev }} & \text { Strain limit for severe damage }\end{array}$

Detailing of shear walls was intends to satisfy the computed chord rotation demands at the bases of walls. Existing columns were taken into account as boundary elements of the walls. Bar buckling phenomenon in the existing columns was also considered as a limiting state of deformation capacities. Moment - curvature analysis results and particular limit states in terms of curvatures are presented for shear walls P4 and P1 are presented together with reinforcement and section detailing of shear walls in Figures 5.14, 5.15, 5.16, and 5.17. Longitudinal reinforcement ratio was 0.0025 in web portions of P4 and P1. In case of shear, lateral reinforcement ratio was 0.0025 in P4 and it was 0.003 in P1. These amounts of lateral reinforcement were sufficient to meet shear demands of $962 \mathrm{kN}$ for P4 and $3242 \mathrm{kN}$ for P1. 


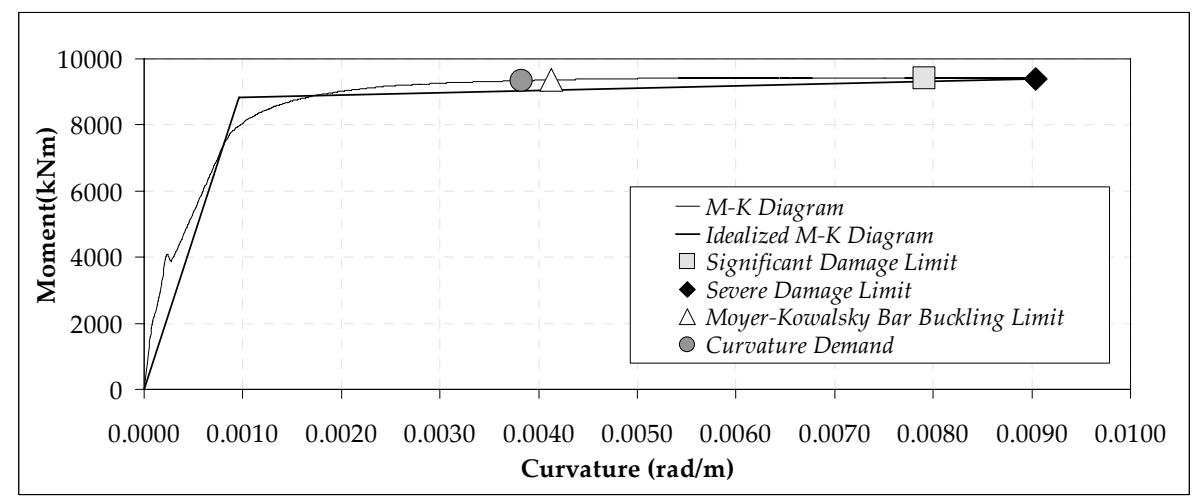

Figure 5.14 Moment curvature analysis of shear wall P4

\begin{tabular}{|lcc|}
\hline & $3300 \mathrm{~mm}$ & $300 \mathrm{~mm}$ \\
\hline & & $900 \mathrm{~mm}$ \\
\hline
\end{tabular}

Figure 5.15 Detailing of P4

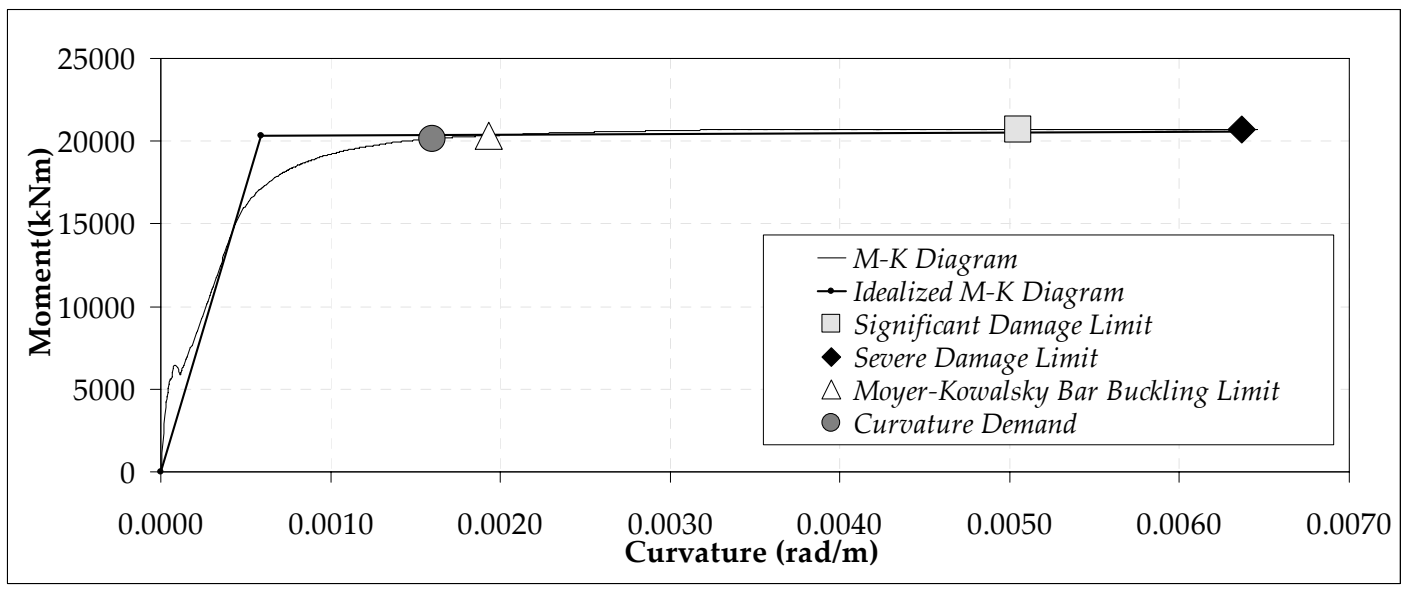

Figure 5.16 Moment curvature analysis of shear wall P1

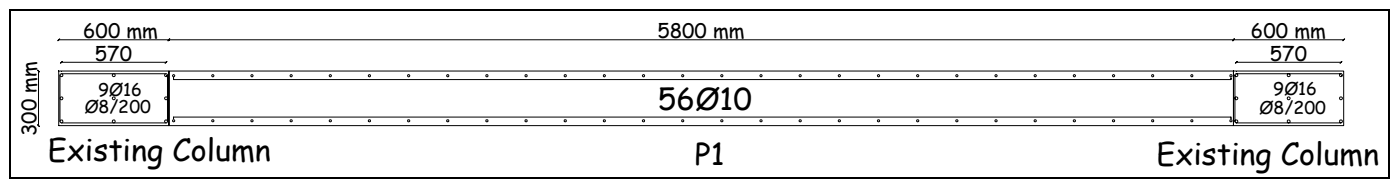

Figure 5.17 Detailing of P1 


\subsection{Verification of the Proposed Retrofit Design Methodology}

Retrofit design was verified through nonlinear evaluation of seismic performance at Life Safety in both $\mathrm{X}$ and $\mathrm{Y}$ directions of loading. Thus, pushover analysis was conducted. Capacity curves of existing and retrofitted buildings are shown in Figure 5.18 together with roof displacement demands. Increase in both lateral load carrying capacity and lateral stiffness is clearly observed in Figure 5.18 as a result of new added shear walls.

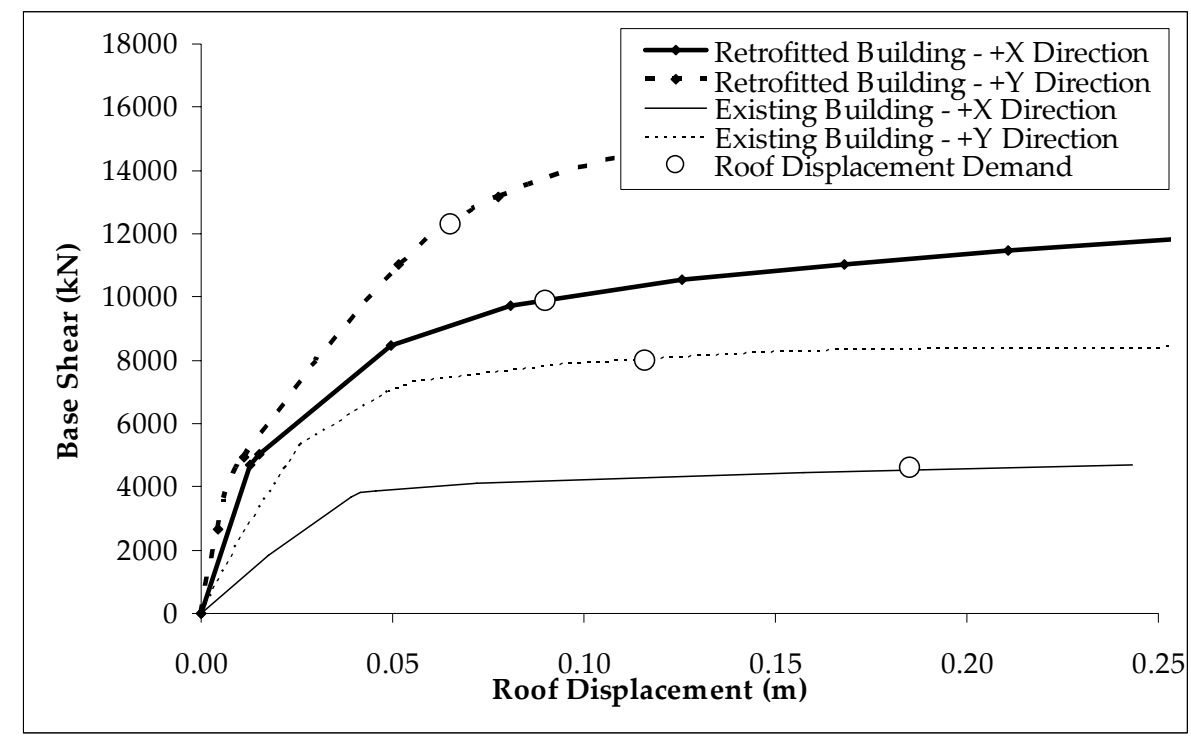

Figure 5.18 Capacity curves of the retrofitted and existing buildings

Drift distributions of existing and retrofitted buildings are shown in Figures 5.19 and 5.20 whereas chord rotation demands calculated by employing uniform drift and pushover analyses are compared in Figures 5.21 and 5.22. It is observed from the Figures 5.21 and 5.22 that addition of shear walls decreased chord rotation demands of the existing columns significantly. Additionally, comparing chord rotation demands calculated from uniform drift and pushover analyses, it can be concluded that results are approximate especially for the first story columns. However, uniform drift analysis may lead unappreciated results for columns in tension. 

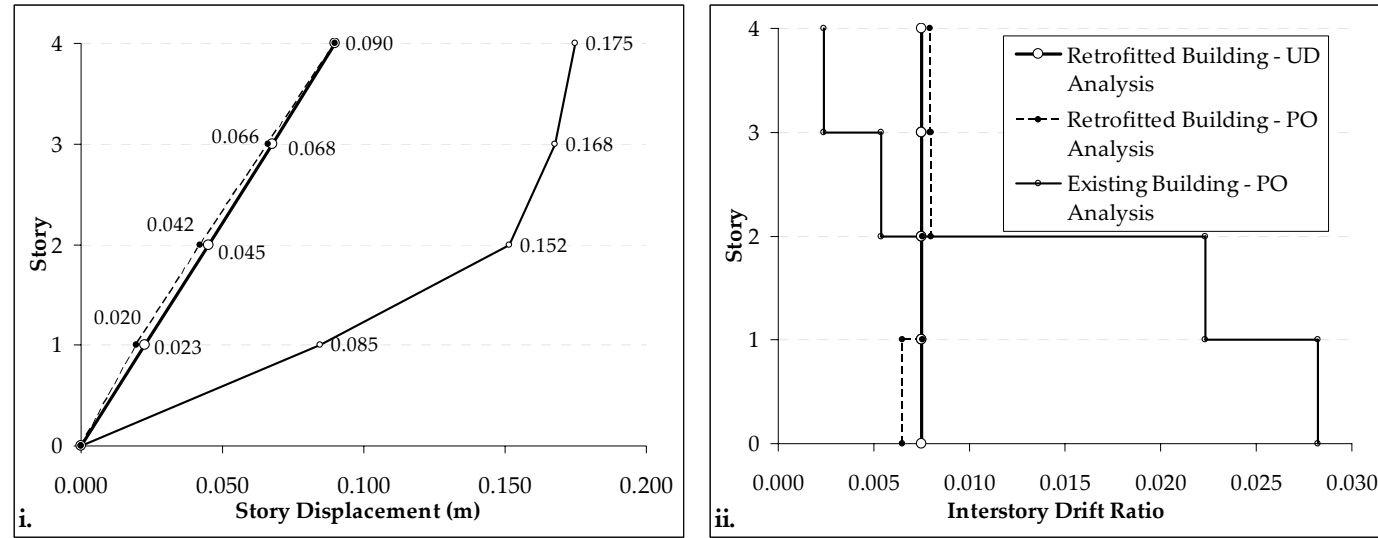

Figure 5.19 i. Story displacements, ii. Interstory drift distributions in X direction
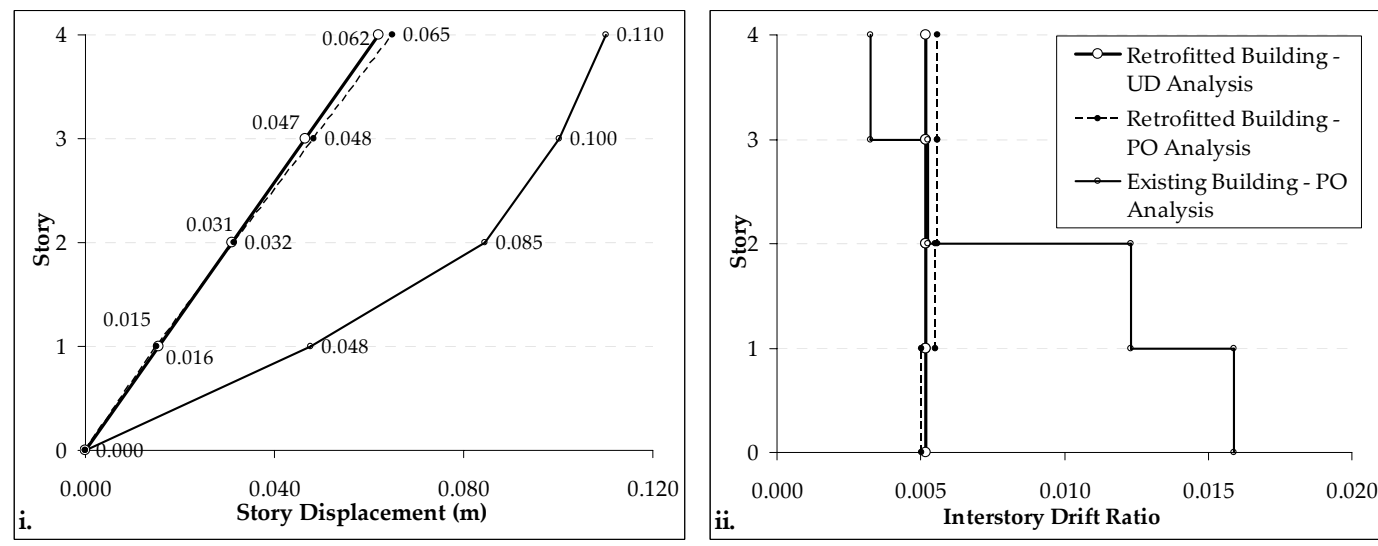

Figure 5.20 i. Story displacements, ii. Interstory drift distributions in Y direction

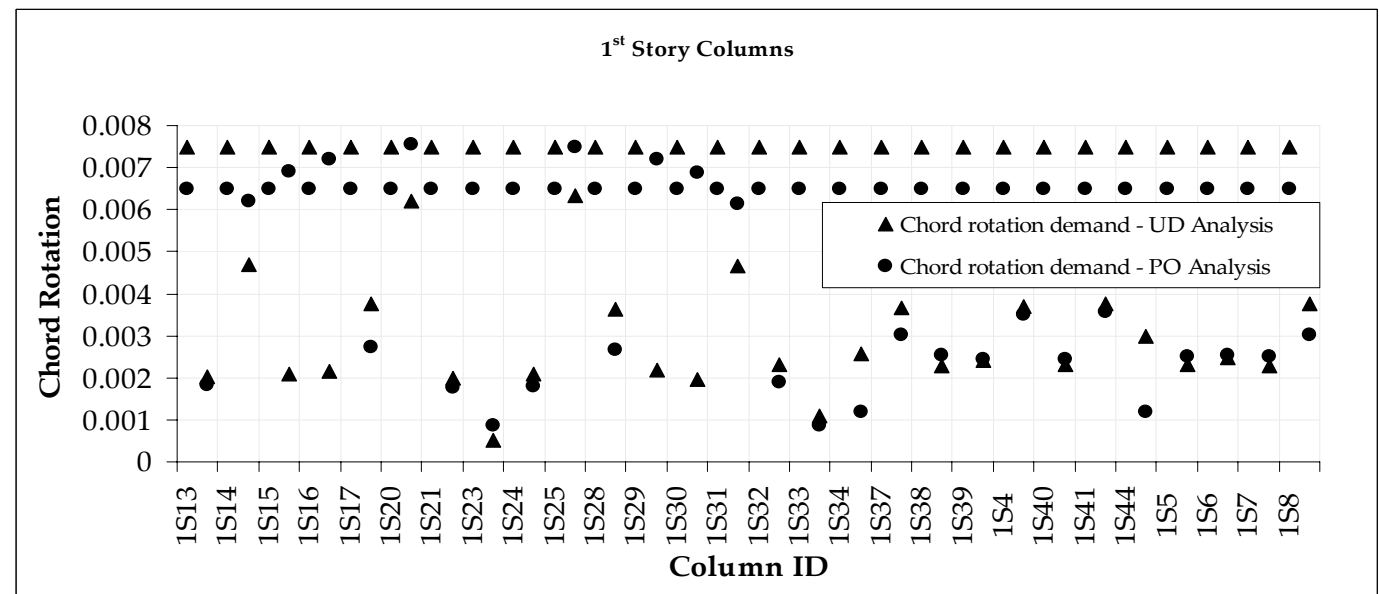

Figure 5.21 Chord rotation demands of the columns in the $\mathrm{X}$ direction loading 


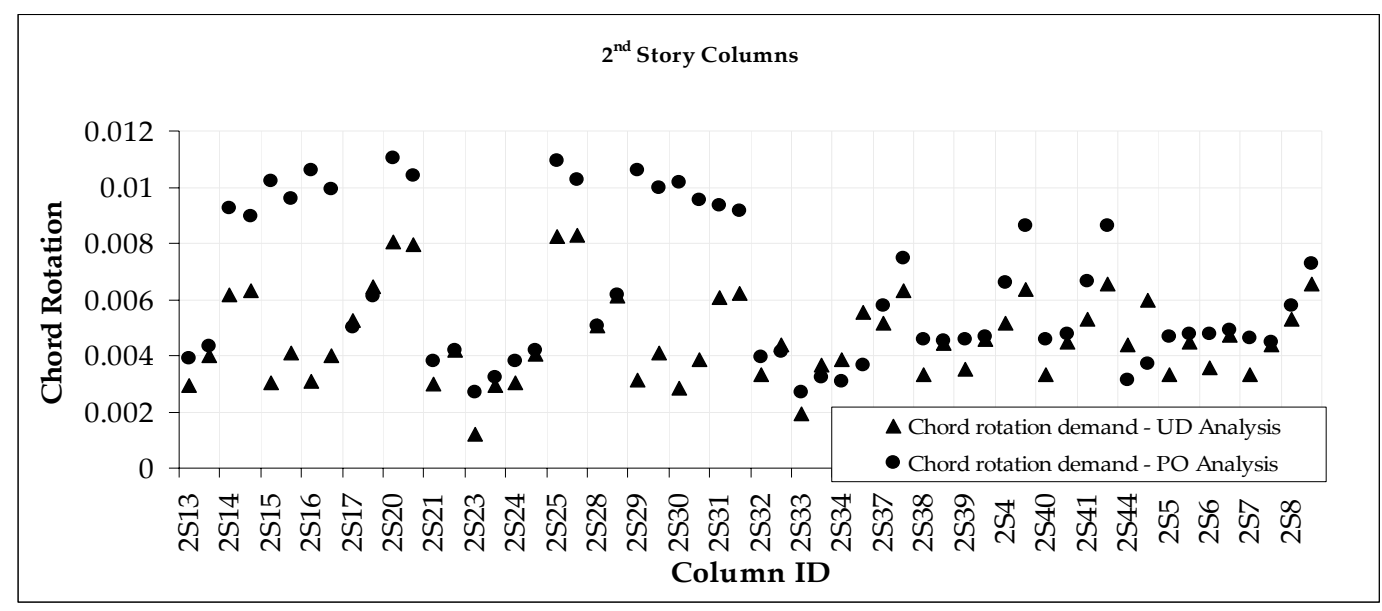

Figure 5.21 Chord rotation demands of the columns in the $X$ direction loading (continued)

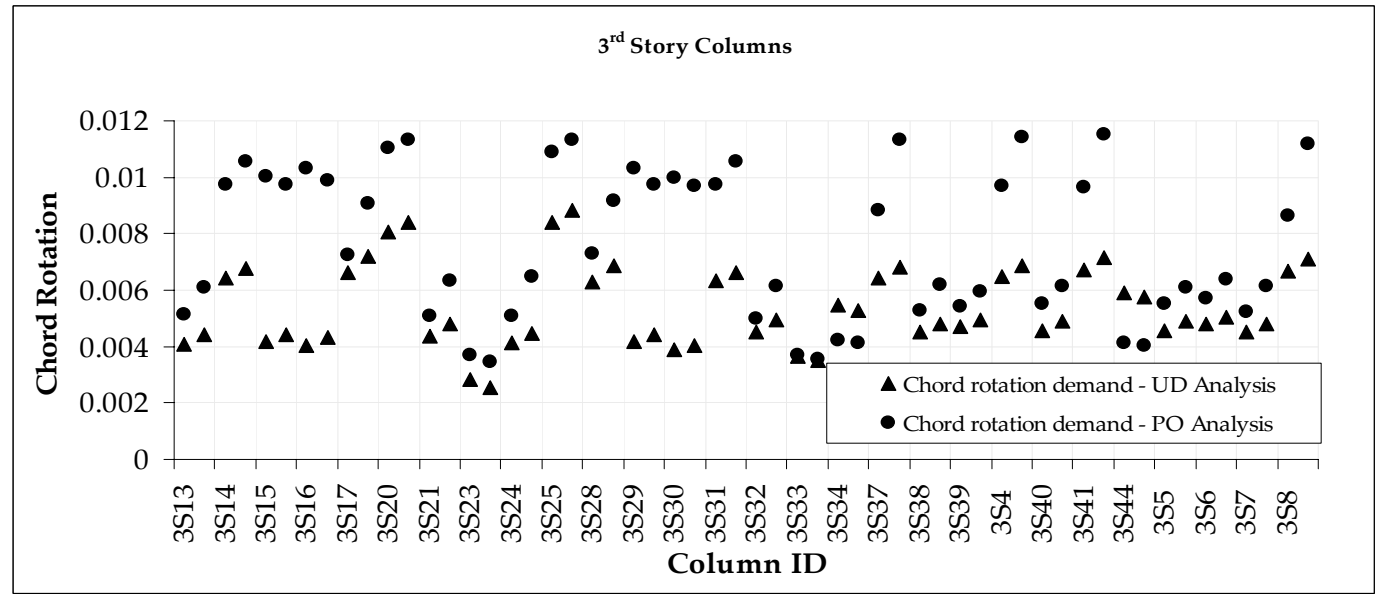

Figure 5.21 Chord rotation demands of the columns in the $\mathrm{X}$ direction loading (continued)

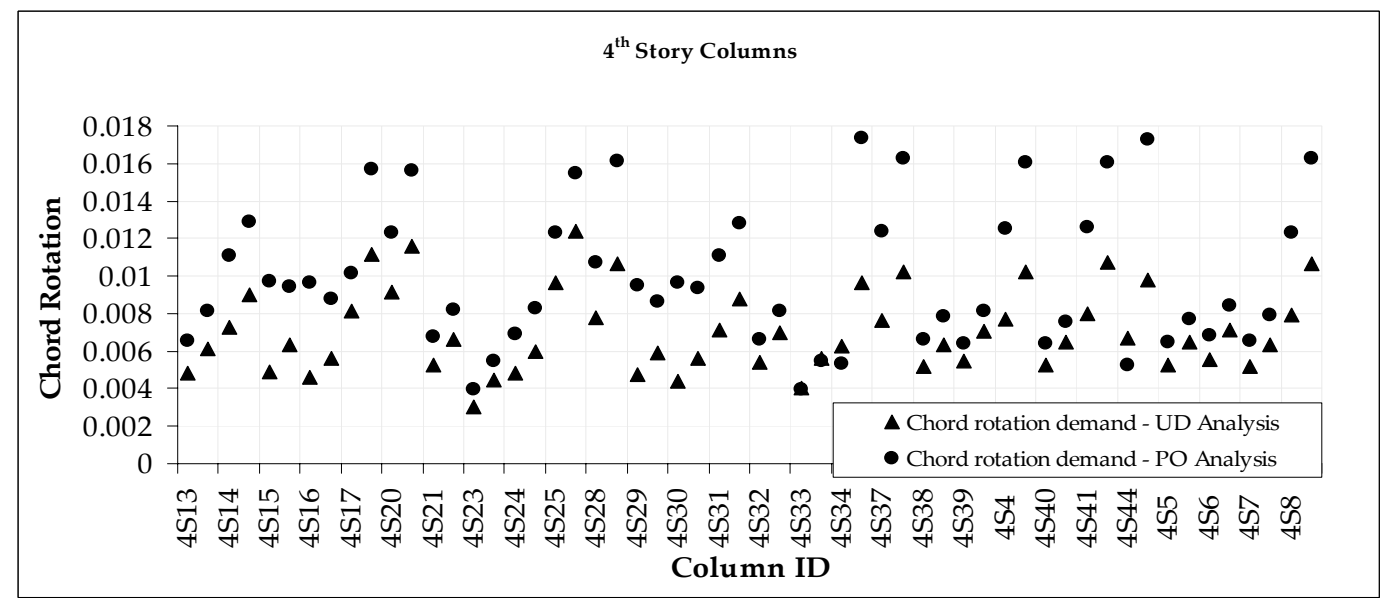

Figure 5.21 Chord rotation demands of the columns in the X direction loading (continued) 


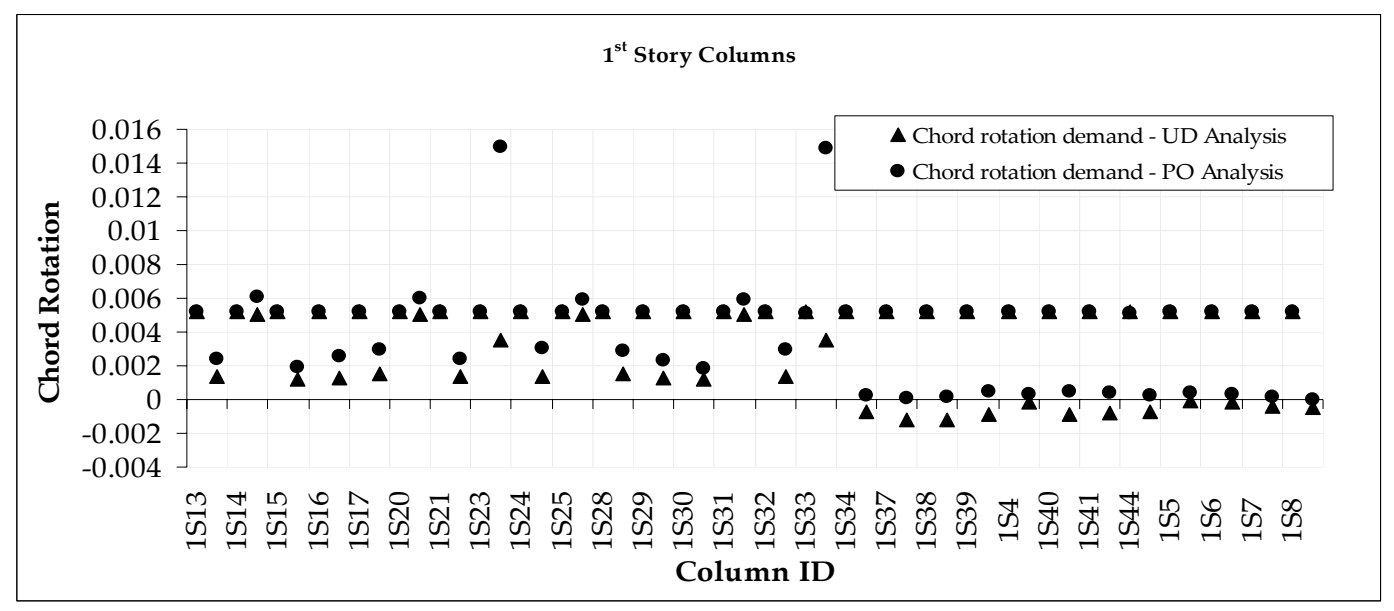

Figure 5.22 Chord rotation demands of the columns in the Y direction loading

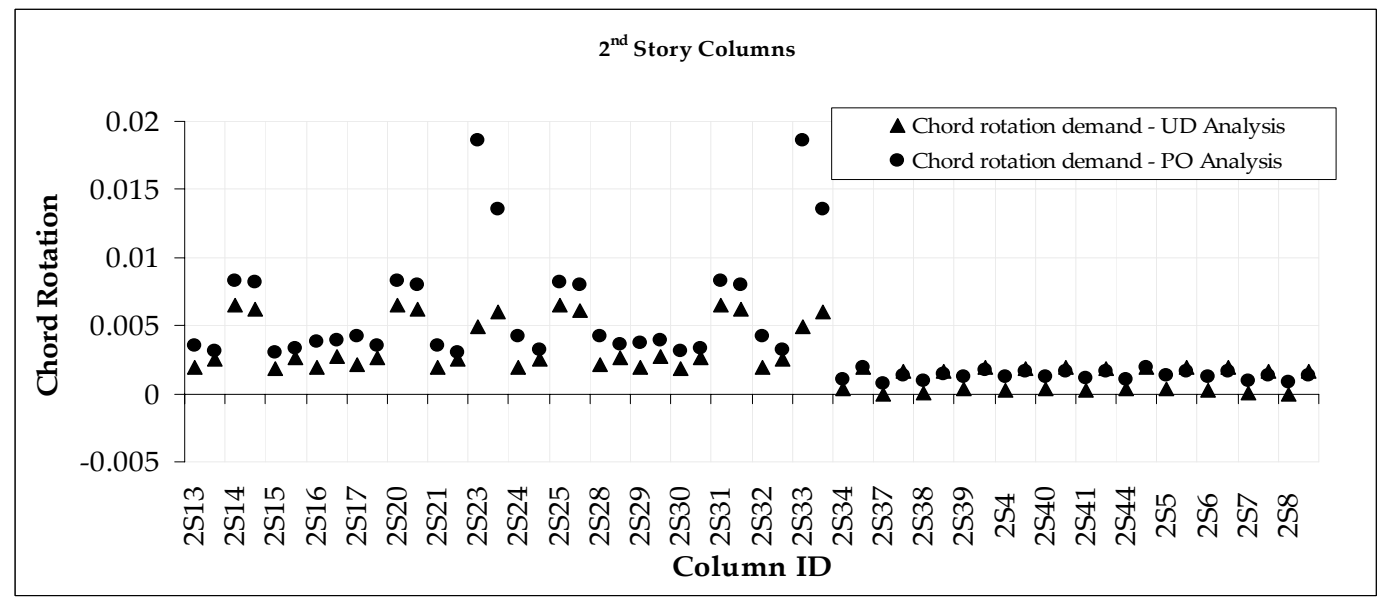

Figure 5.22 Chord rotation demands of the columns in the $\mathrm{Y}$ direction loading (continued)

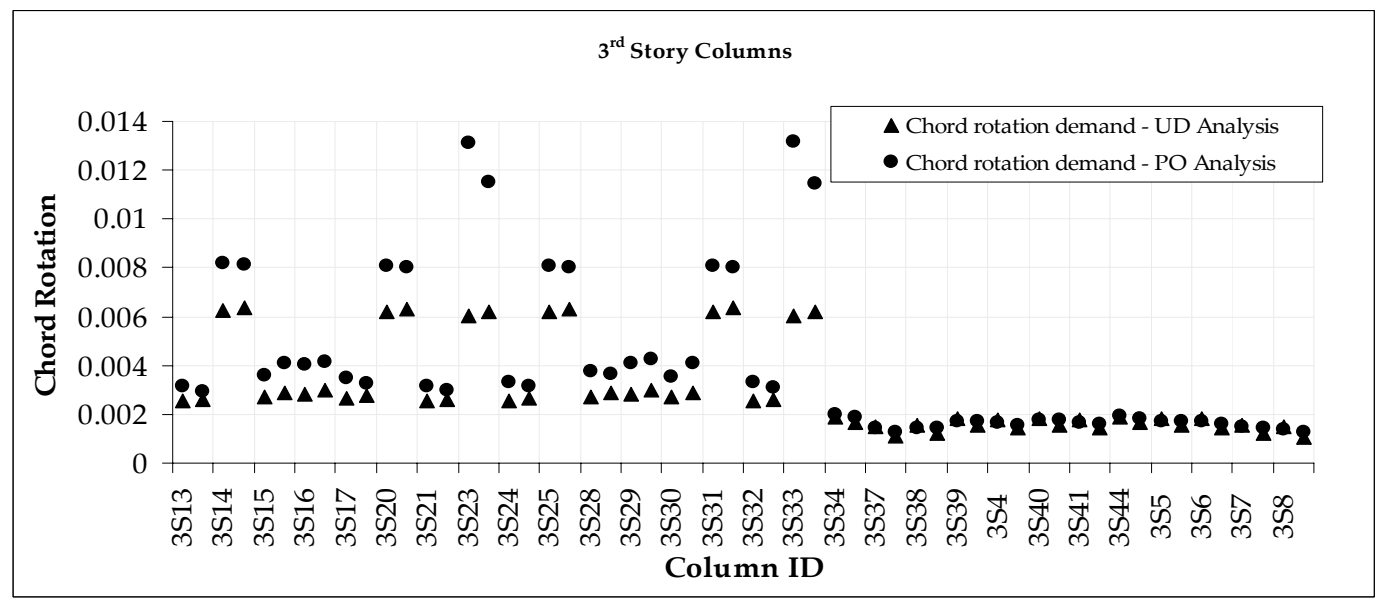

Figure 5.22 Chord rotation demands of the columns in the $\mathrm{Y}$ direction loading (continued) 


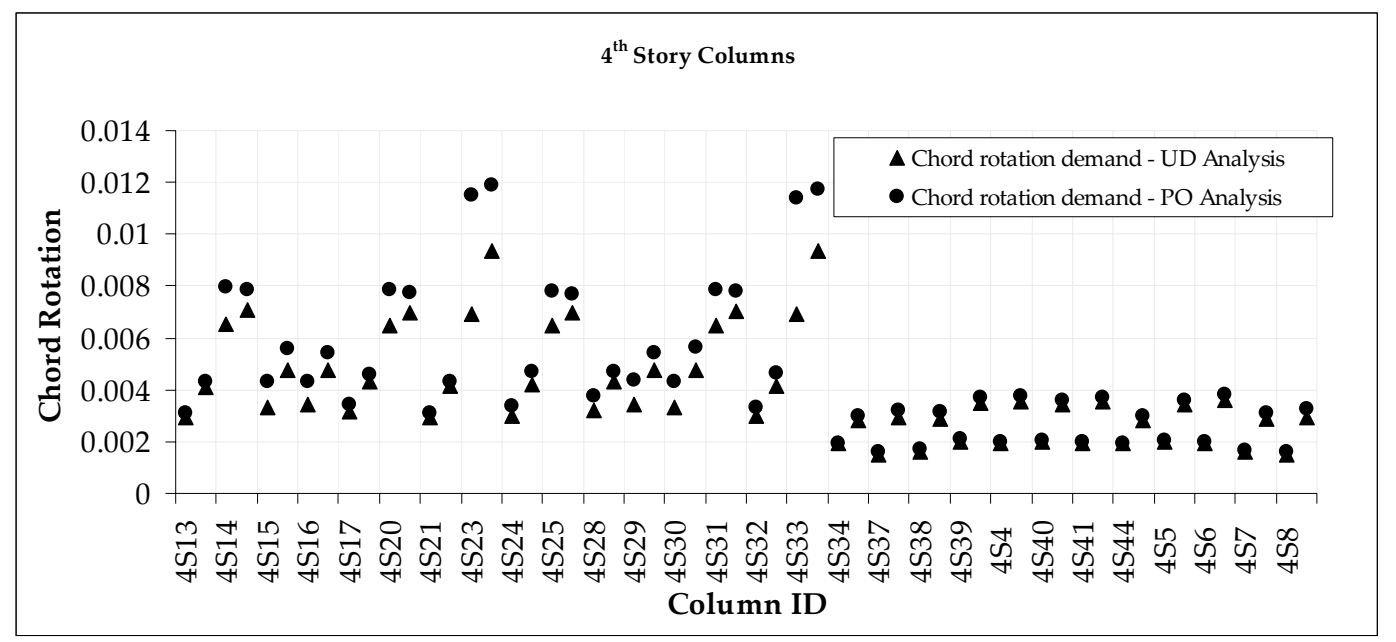

Figure 5.22 Chord rotation demands of the columns in the $Y$ direction loading (continued)

As a verification of retrofit design, nonlinear assessment results of the retrofitted building is given for the $X$ and $Y$ directions in Figure 5.23, 5.24, 5.25, 5.26, 5.27, and 5.28. Global performance of the retrofitted building is summarized in Table 5.2. According to Table 5.2 four story dormitory building satisfies Life Safety performance level defined in TEC 2007 for an earthquake having a return period of 2475 years.

Table 5.2 Global performance of the retrofitted building

\begin{tabular}{|c|c|c|c|c|c|c|c|c|c|}
\hline \multicolumn{5}{|c|}{ X Direction } & \multicolumn{5}{|c|}{ Y Direction } \\
\hline $\begin{array}{l}\text { Story } \\
\text { No. }\end{array}$ & $\begin{array}{l}V_{s t r} \\
(k N)\end{array}$ & $\begin{array}{l}V_{N C} \\
(k N)\end{array}$ & $\% N C$ & $\begin{array}{l}\% \text { NC } \\
\text { Beams }\end{array}$ & $\begin{array}{l}\text { Story } \\
\text { No. }\end{array}$ & $\begin{array}{c}V_{s t r} \\
(k N)\end{array}$ & $\begin{array}{l}V_{N C} \\
(k N)\end{array}$ & $\% N C$ & $\begin{array}{l}\% \text { NC } \\
\text { Beams }\end{array}$ \\
\hline 1 & 11418 & 201 & 1.76 & 0.00 & 1 & 11971 & 0 & 0.00 & 0.00 \\
\hline 2 & 9439 & 120 & 1.27 & 0.00 & 2 & 11186 & 0 & 0.00 & 0.00 \\
\hline 3 & 8675 & 0 & 0.00 & 0.00 & 3 & 8931 & 0 & 0.00 & 0.00 \\
\hline 4 & 4800 & 0 & 0.00 & 0.00 & 4 & 4888 & 0 & 0.00 & 0.00 \\
\hline
\end{tabular}




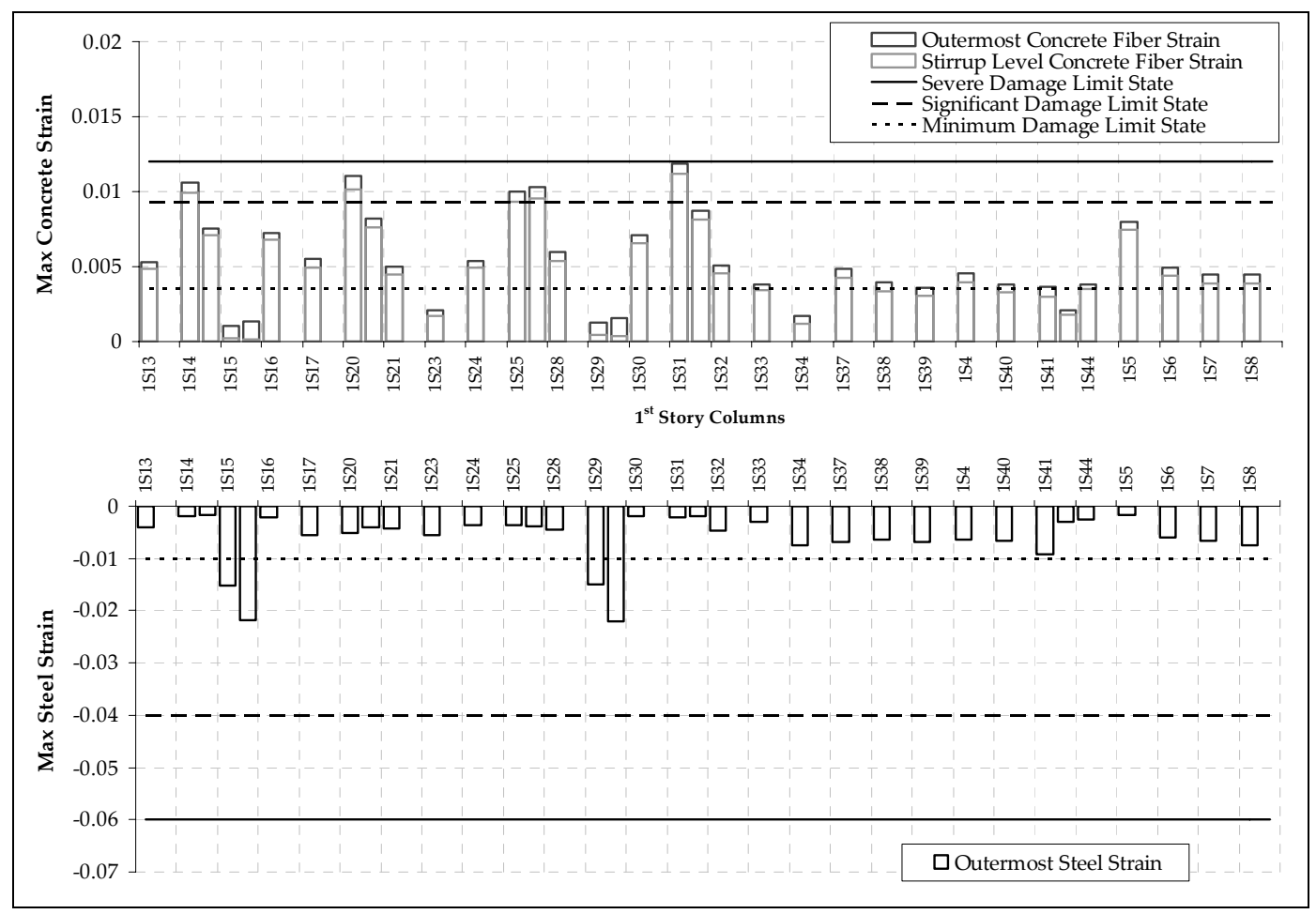

Figure 5.23 Damage levels of the columns in the $\mathrm{X}$ direction loading

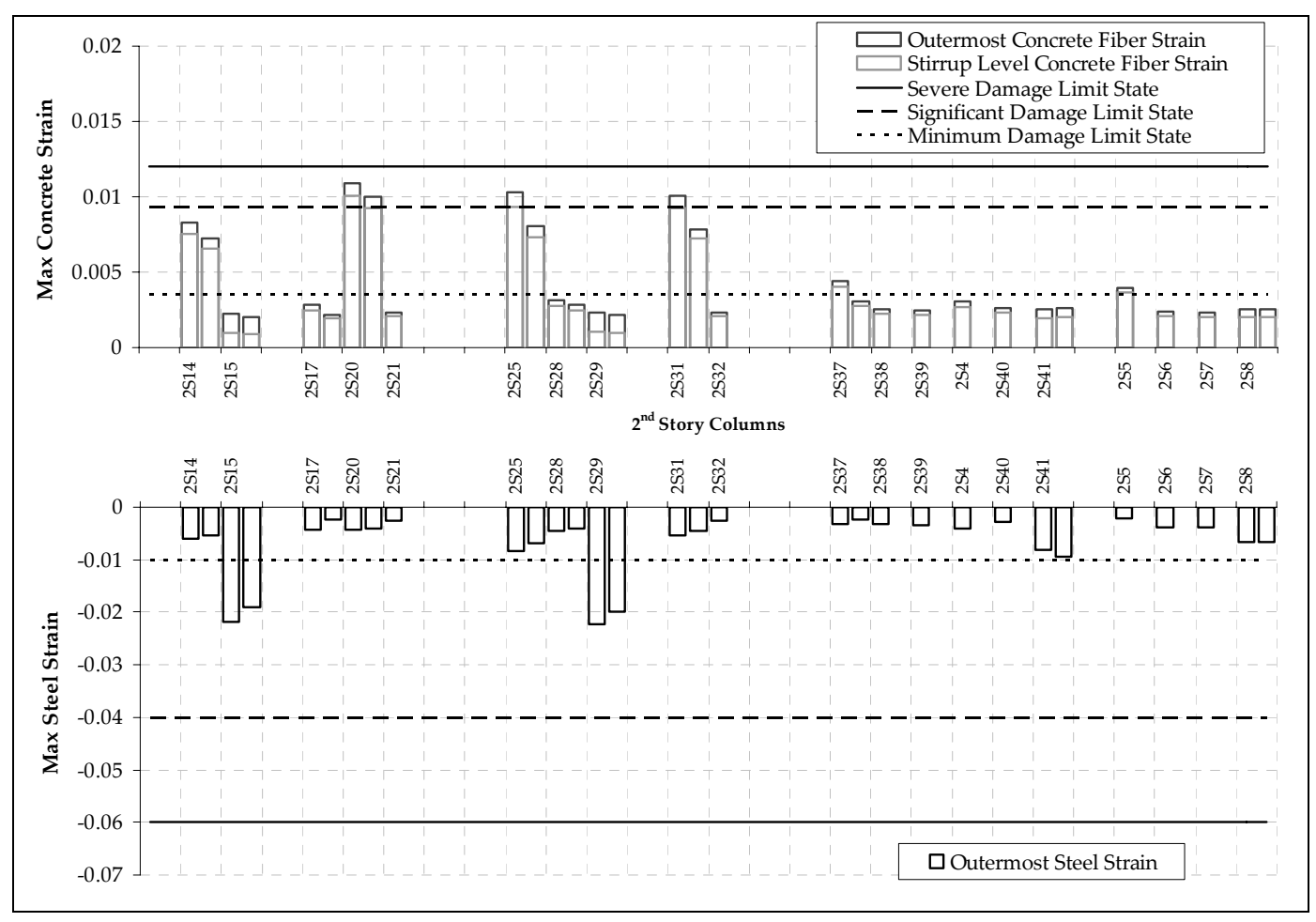

Figure 5.23 Damage levels of the columns in the $\mathrm{X}$ direction loading (continued) 


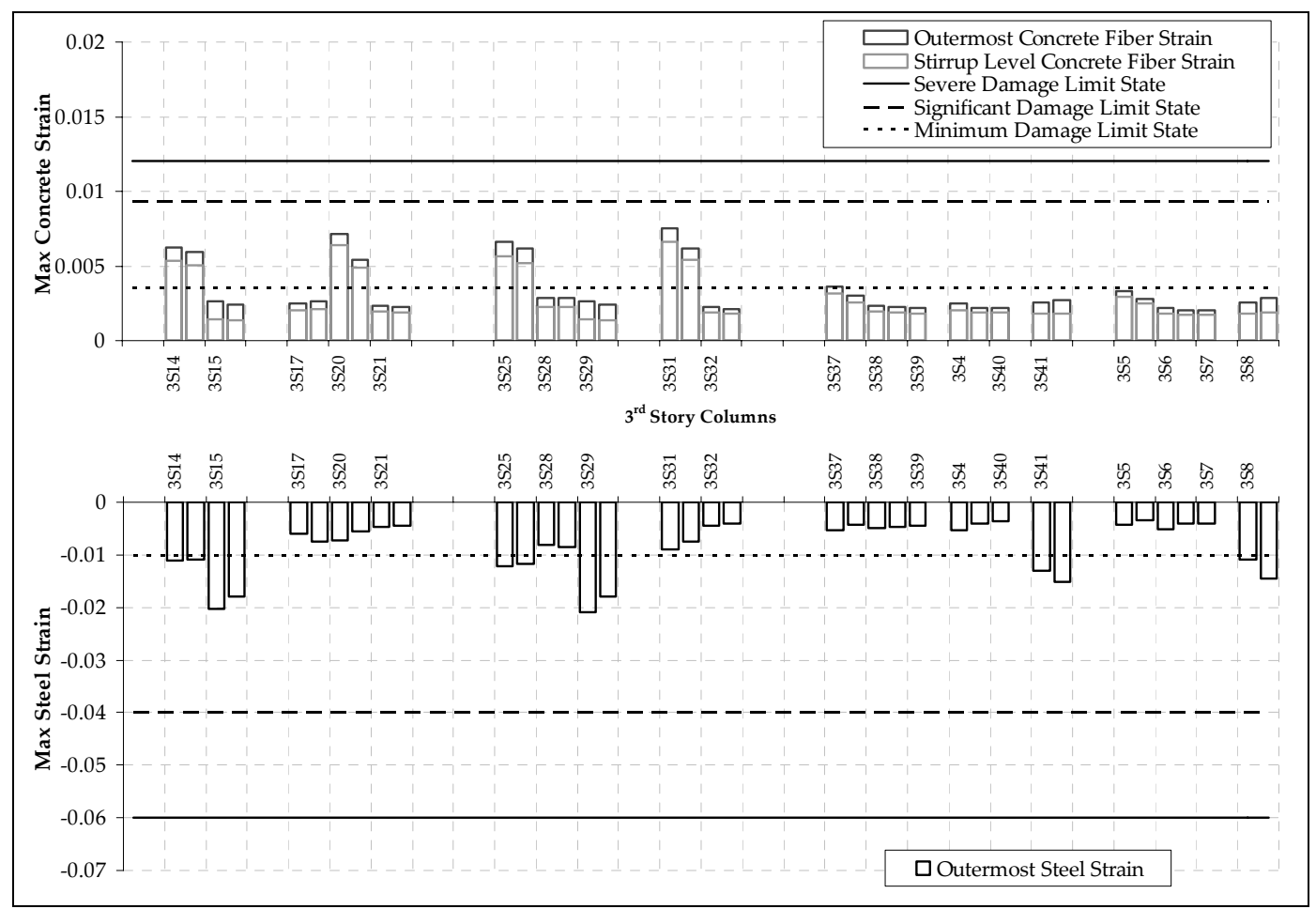

Figure 5.23 Damage levels of the columns in the X direction loading (continued)

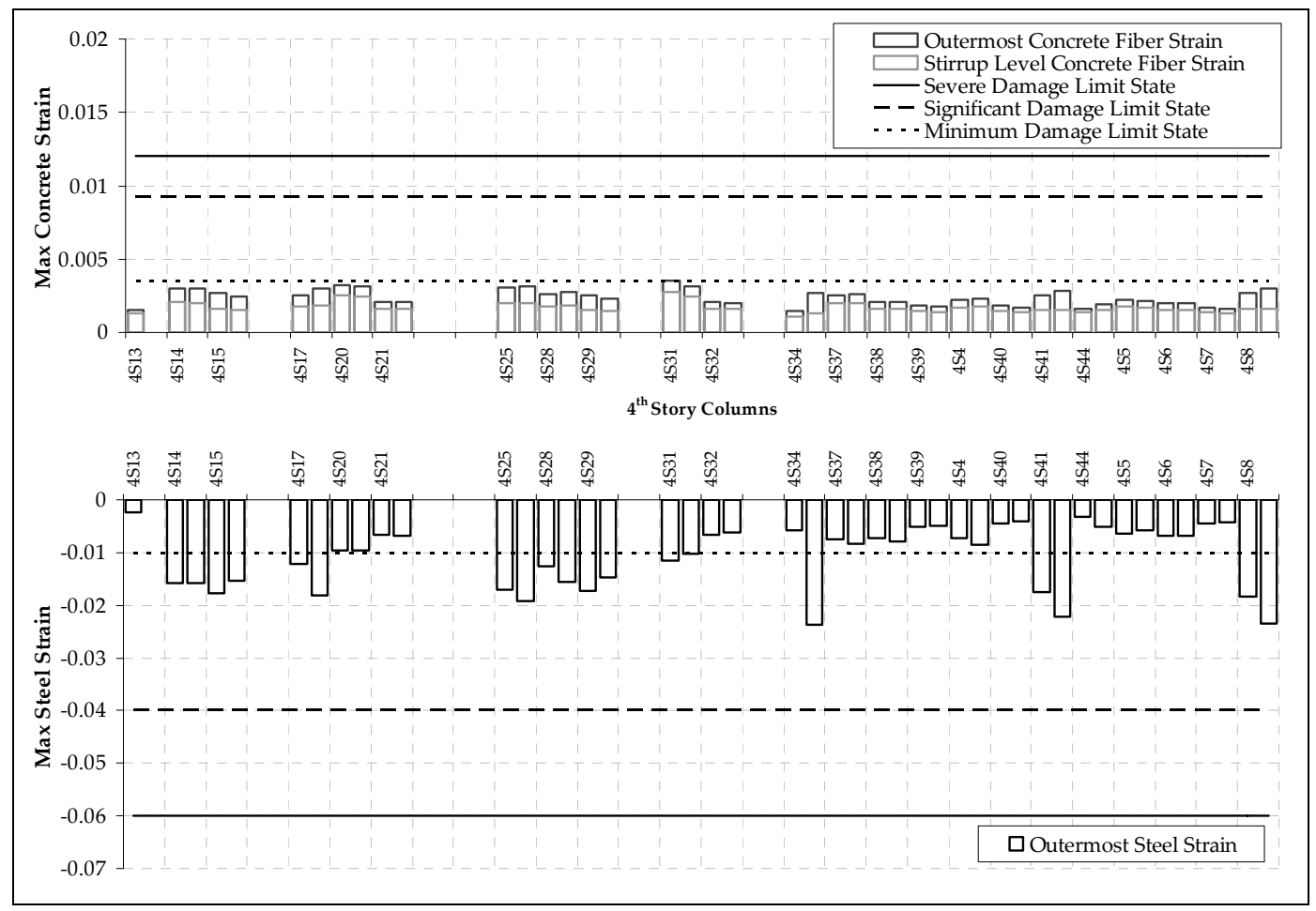

Figure 5.23 Damage levels of the columns in the $\mathrm{X}$ direction loading (continued) 


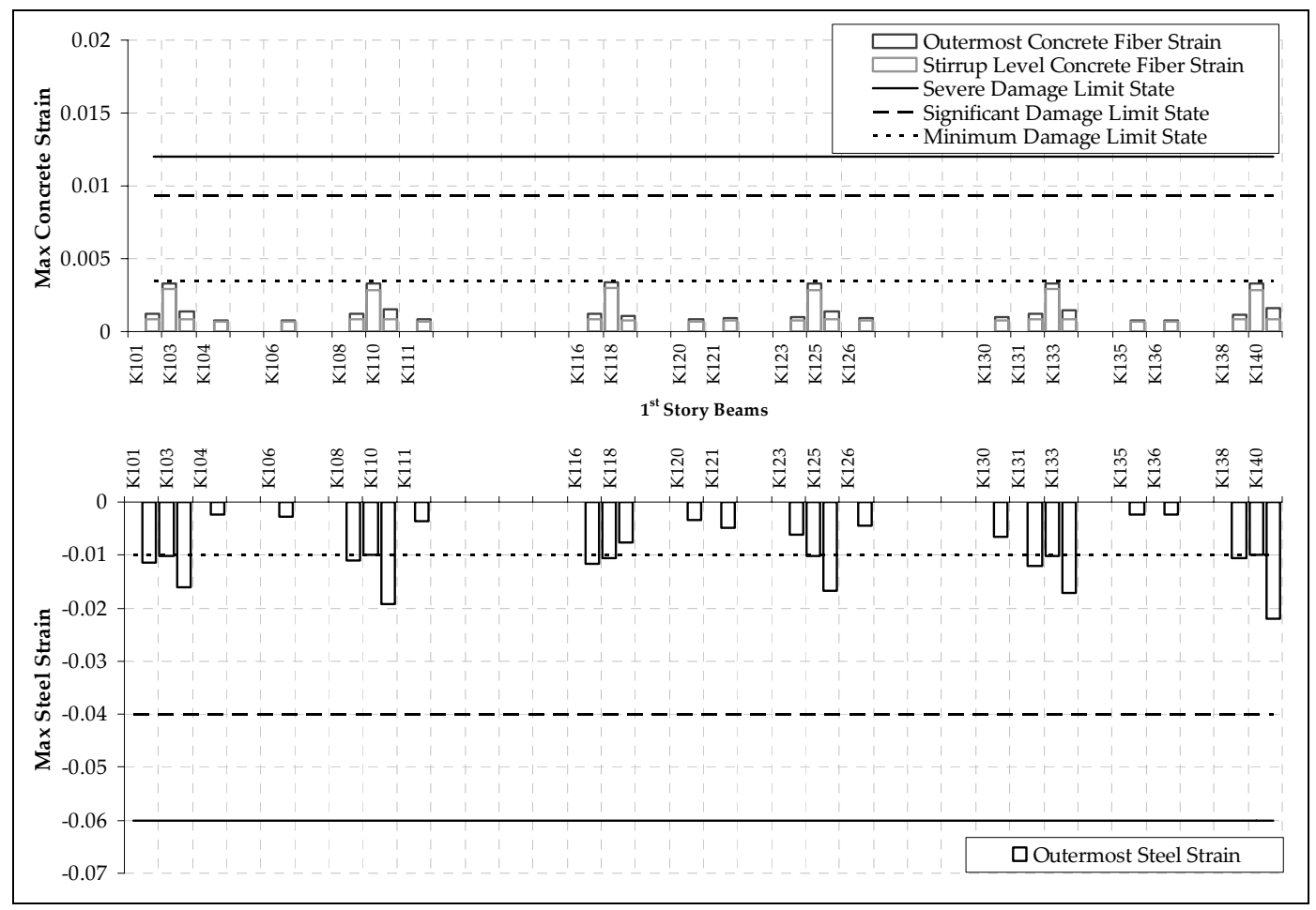

Figure 5.24 Damage levels of the beams in the $\mathrm{X}$ direction loading

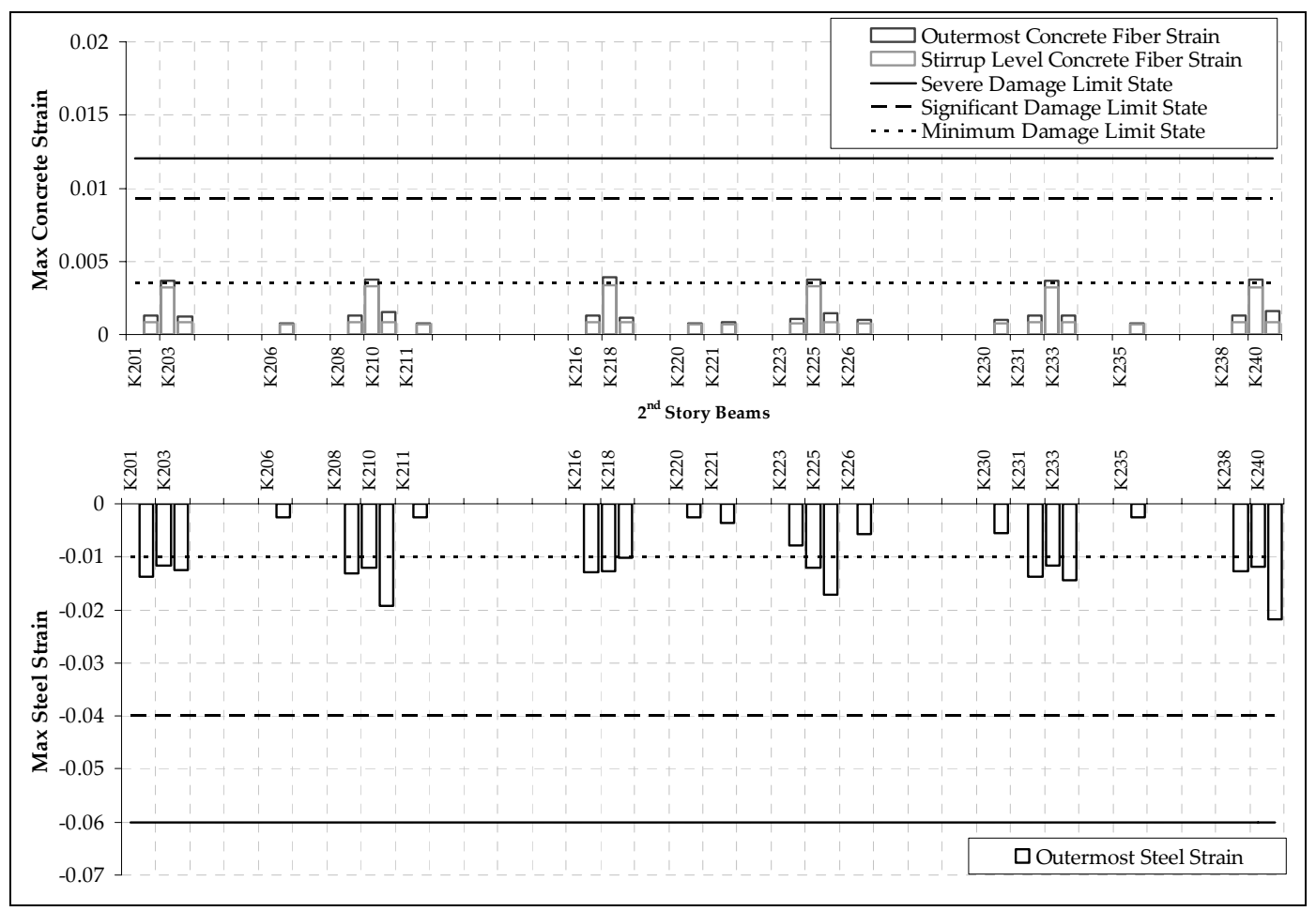

Figure 5.24 Damage levels of the beams in the $X$ direction loading (continued) 


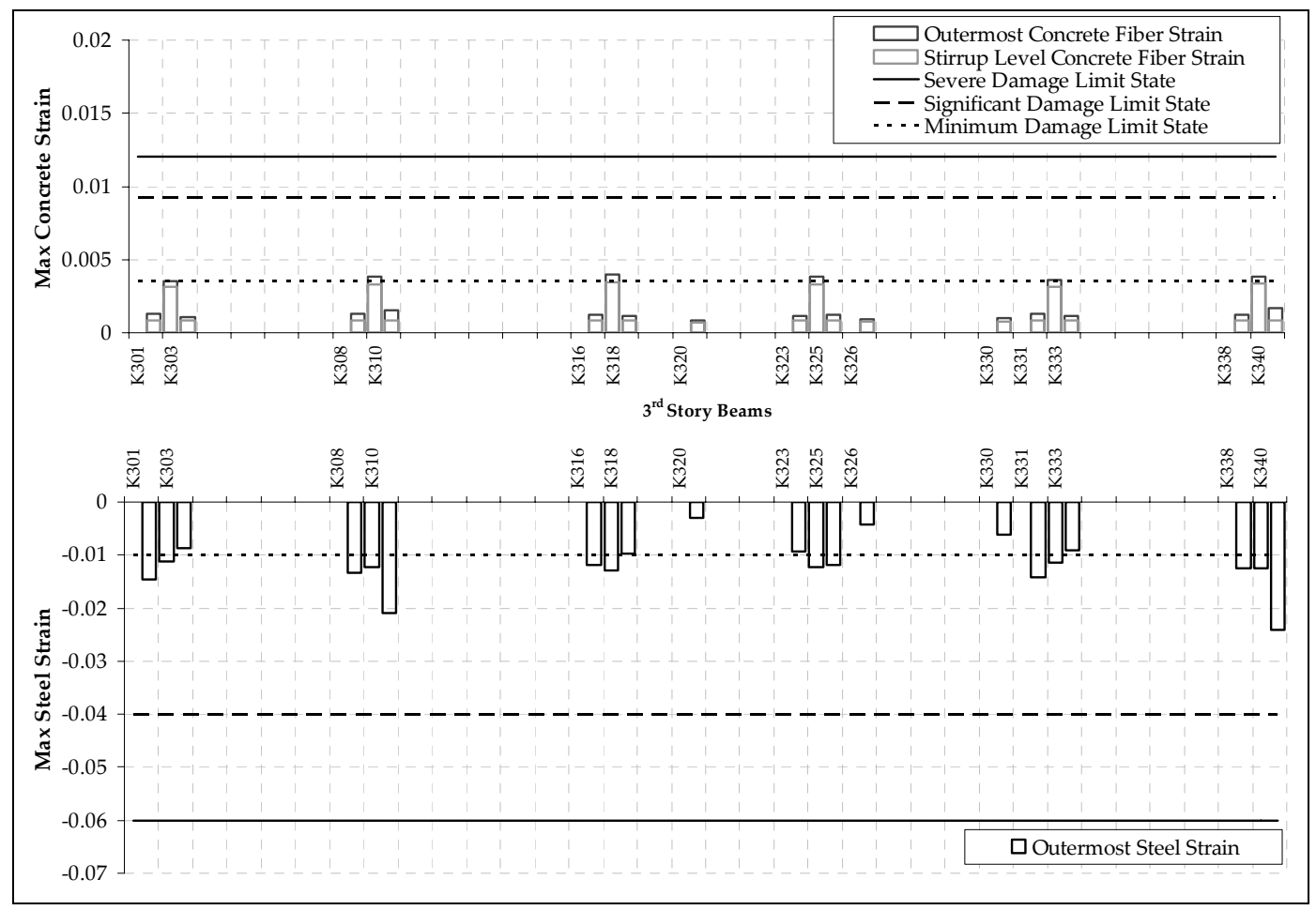

Figure 5.24 Damage levels of the beams in the $\mathrm{X}$ direction loading (continued)

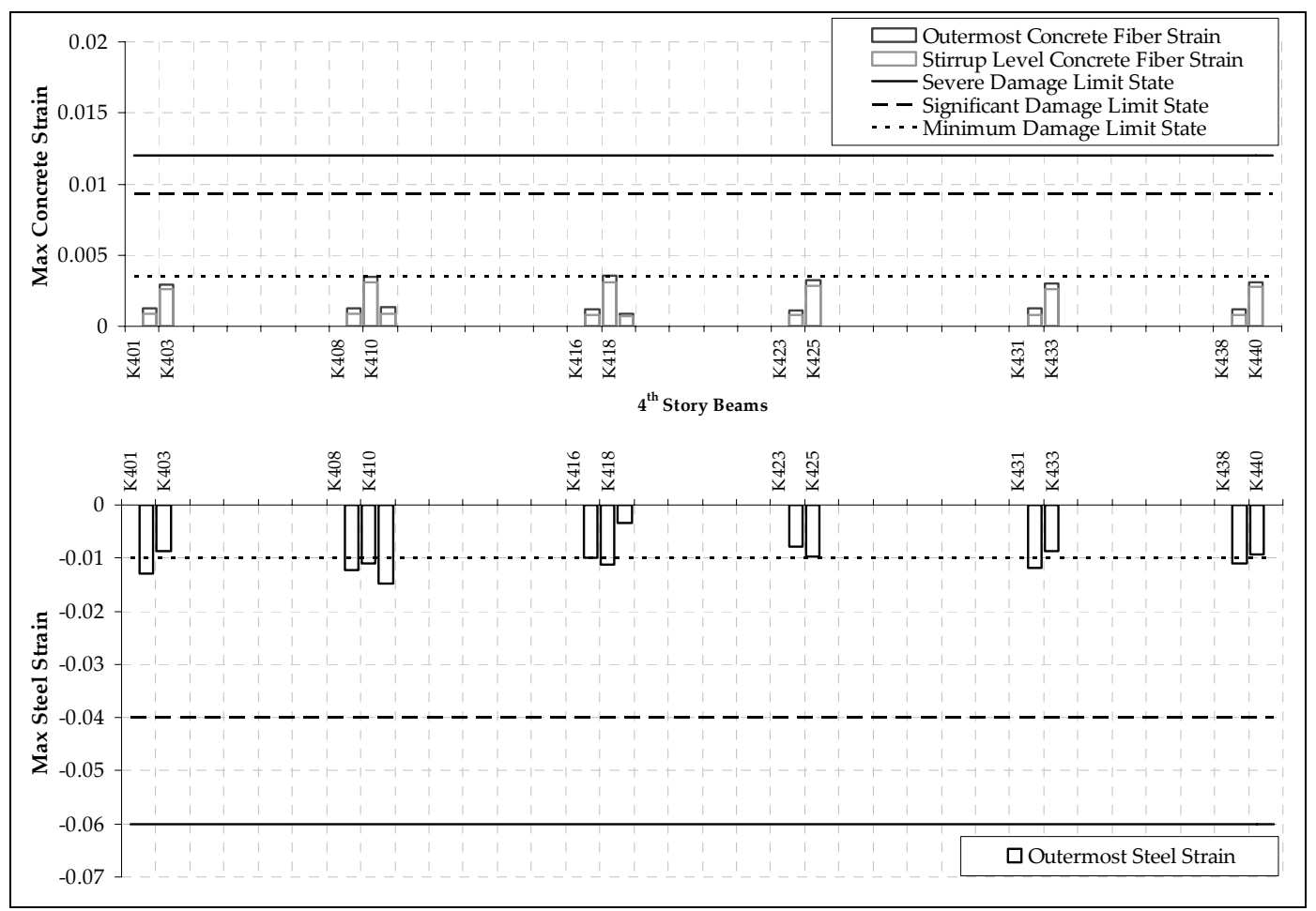

Figure 5.24 Damage levels of the beams in the $\mathrm{X}$ direction loading (continued) 


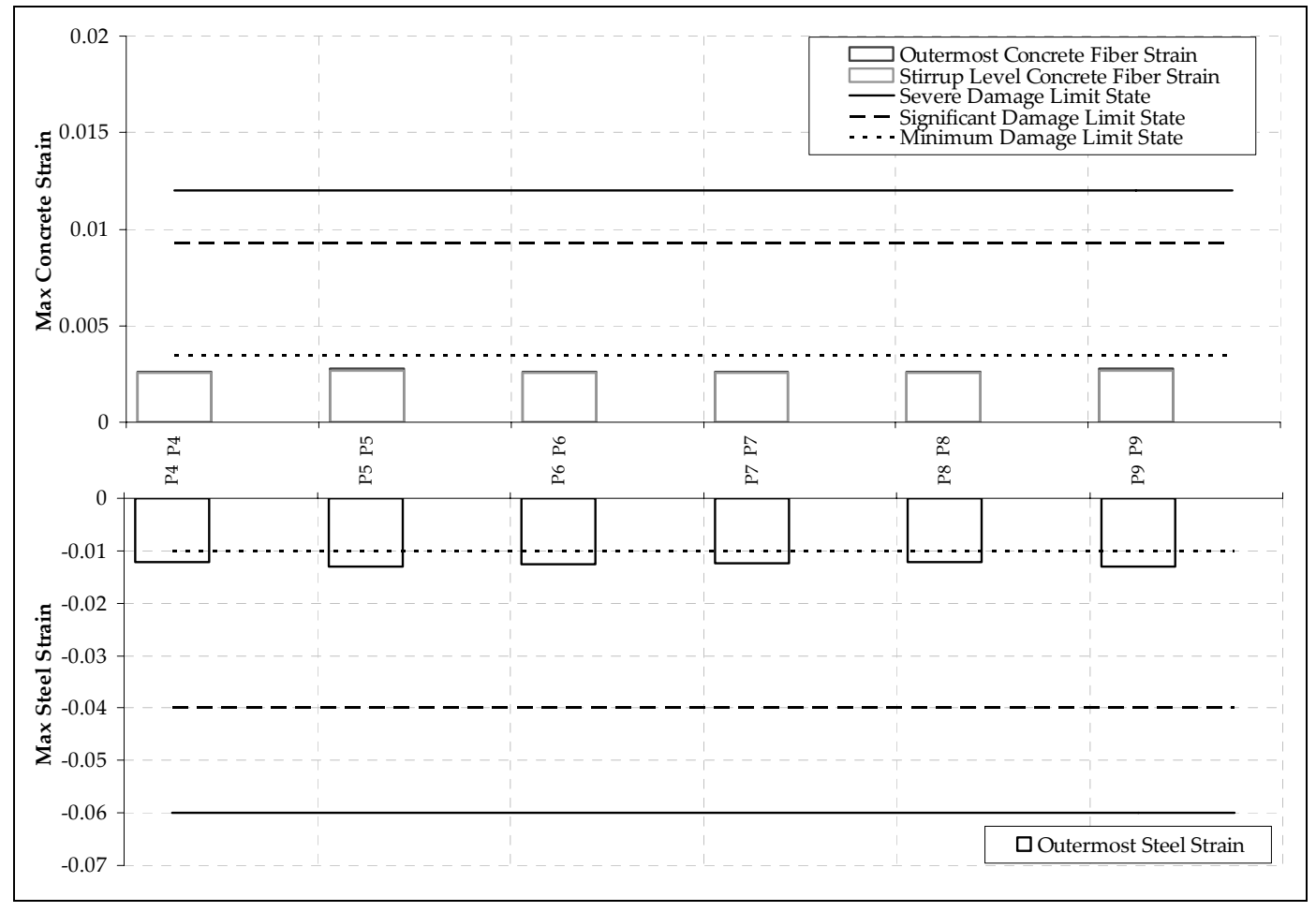

Figure 5.25 Damage levels of the shear walls in the X direction loading

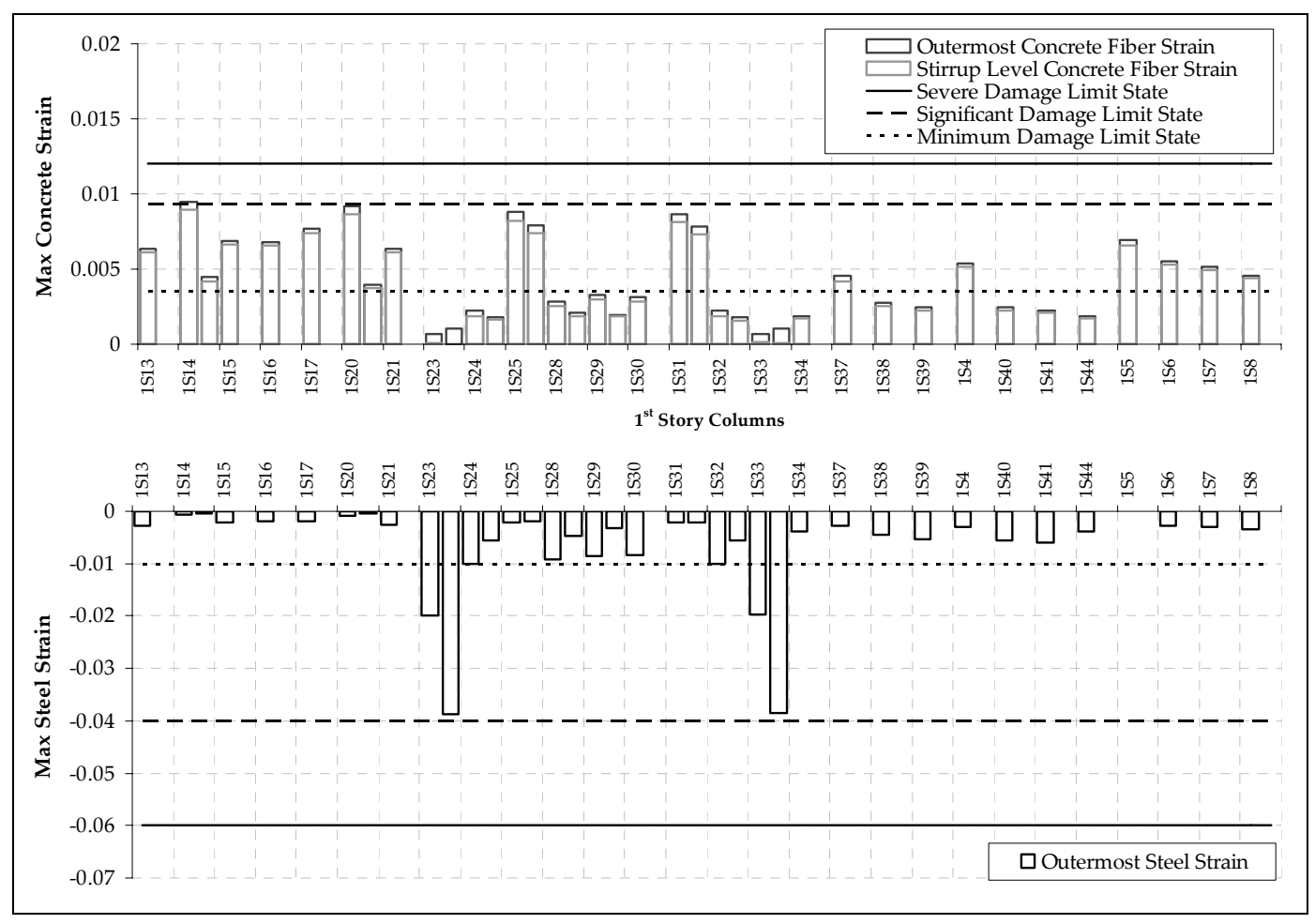

Figure 5.26 Damage levels of the columns in the $Y$ direction loading 


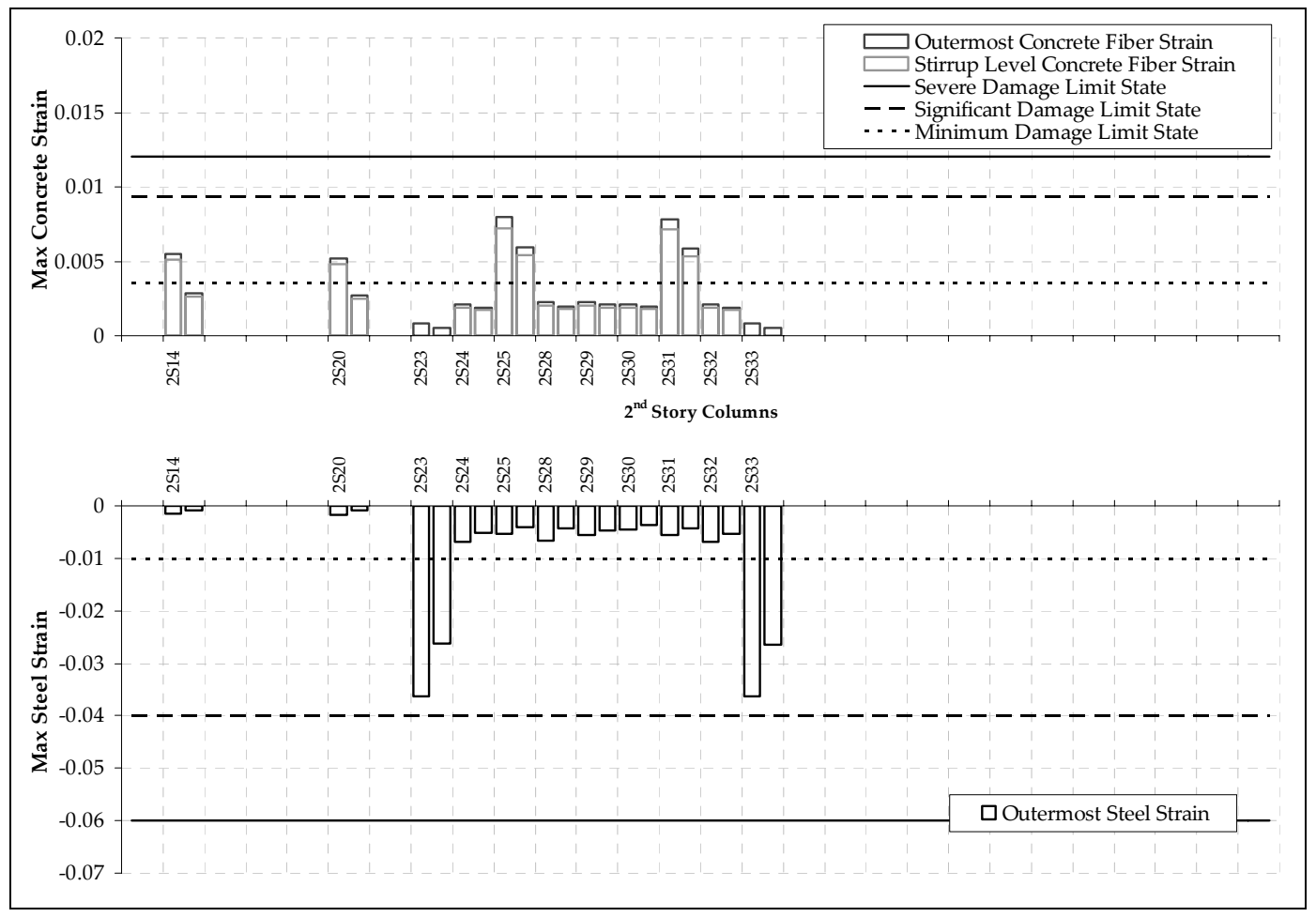

Figure 5.26 Damage levels of the columns in the $\mathrm{Y}$ direction loading (continued)

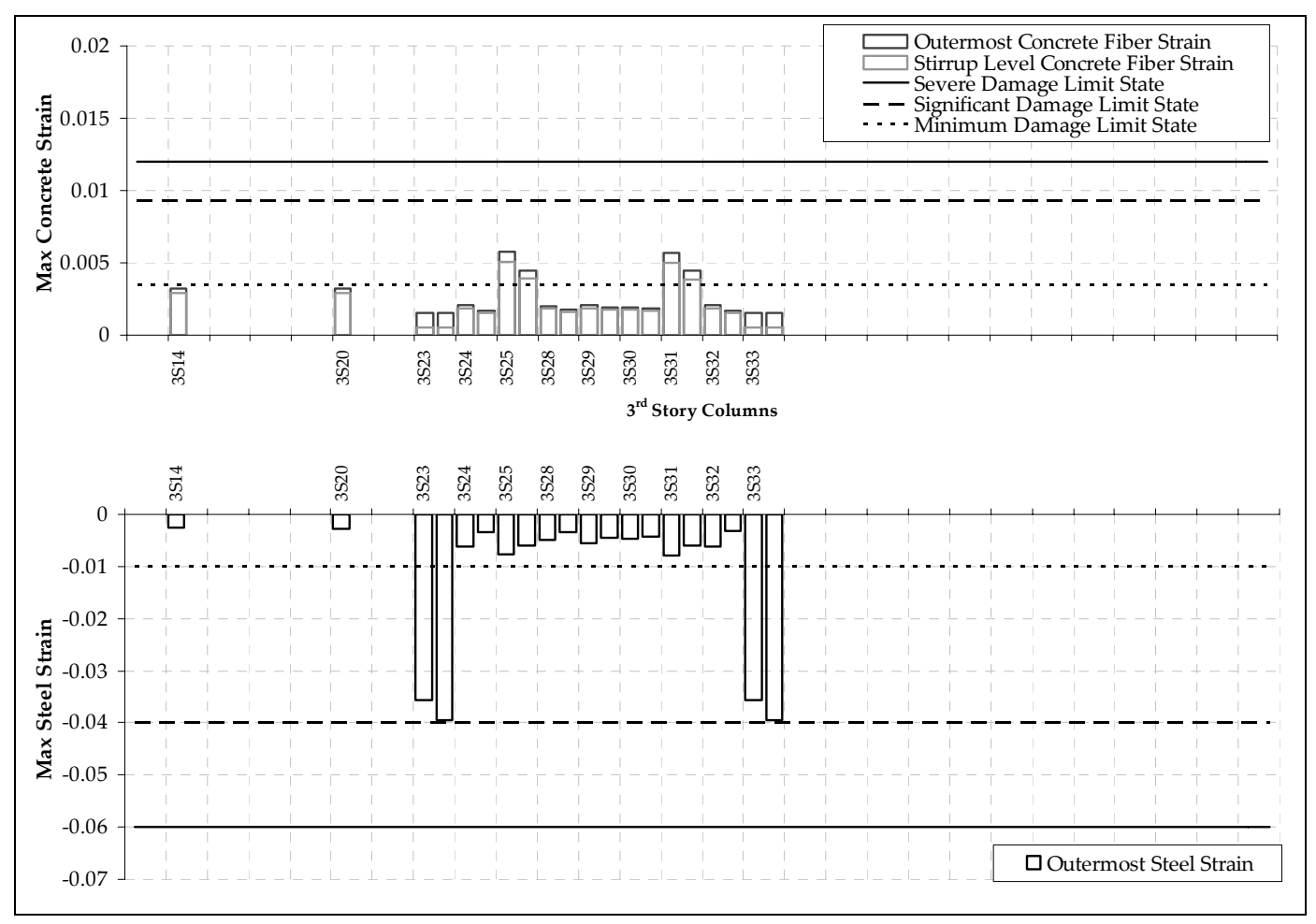

Figure 5.26 Damage levels of the columns in the $Y$ direction loading (continued) 


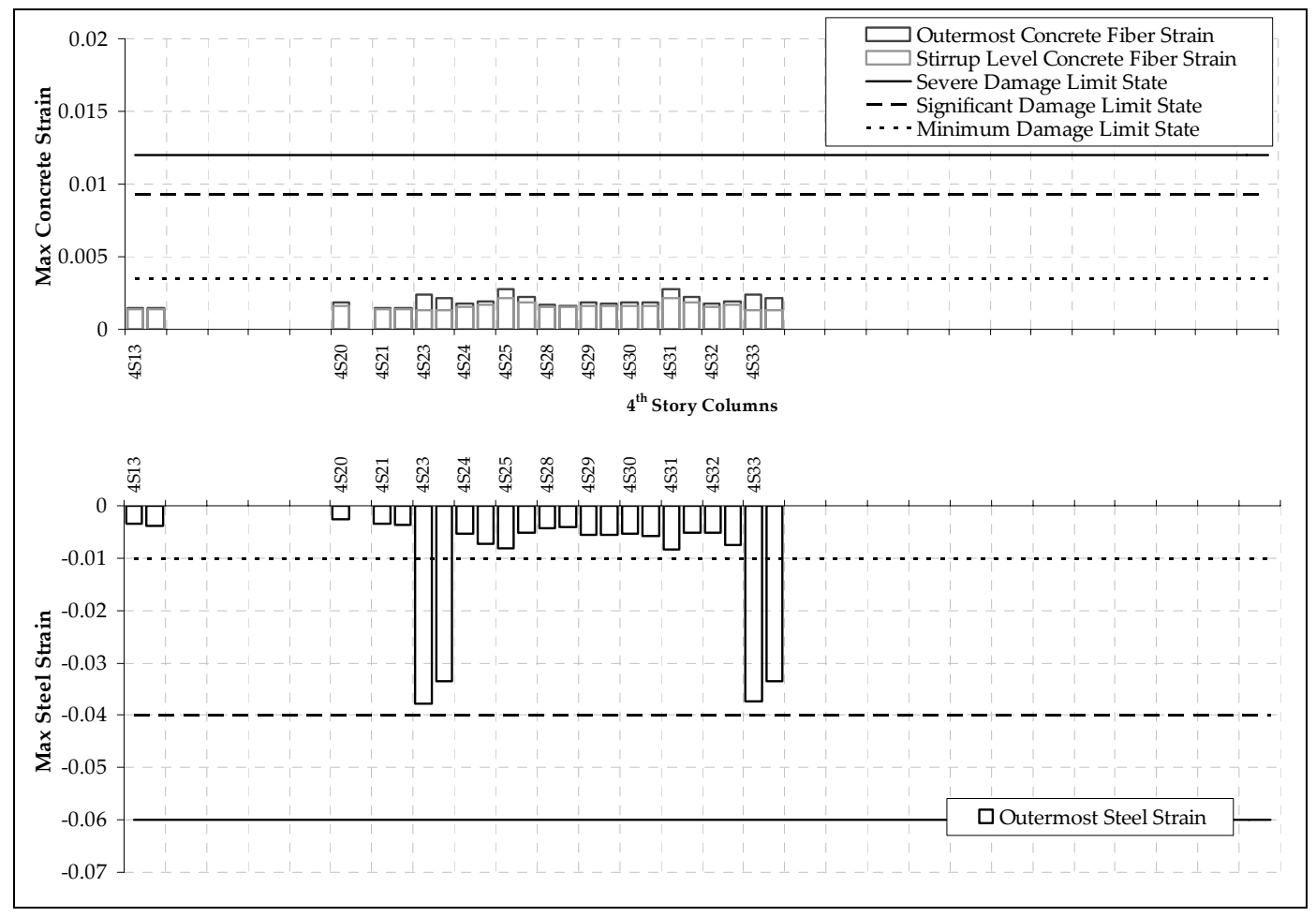

Figure 5.26 Damage levels of the columns in the $\mathrm{Y}$ direction loading (continued)

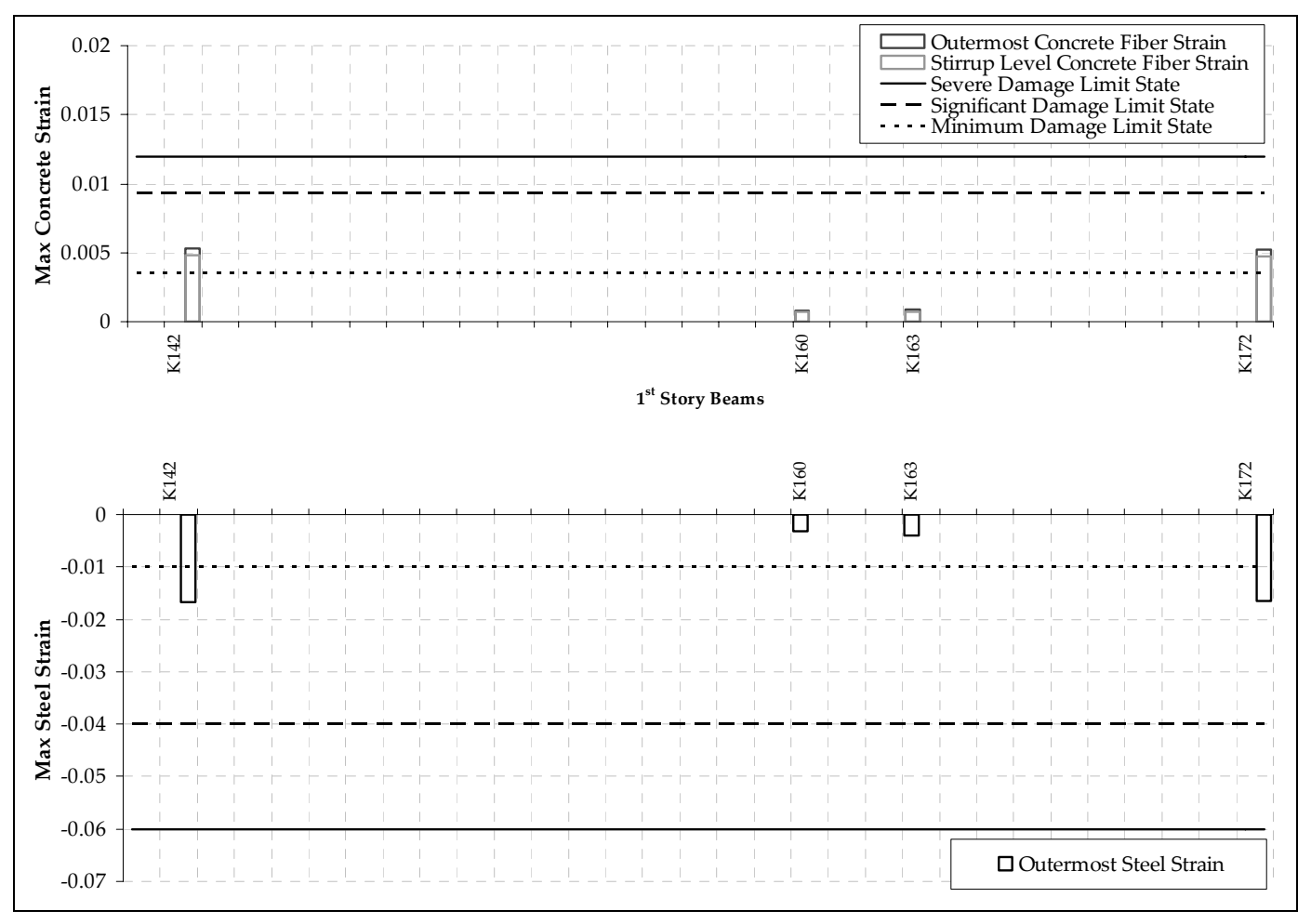

Figure 5.27 Damage levels of the beams in the $\mathrm{Y}$ direction loading 


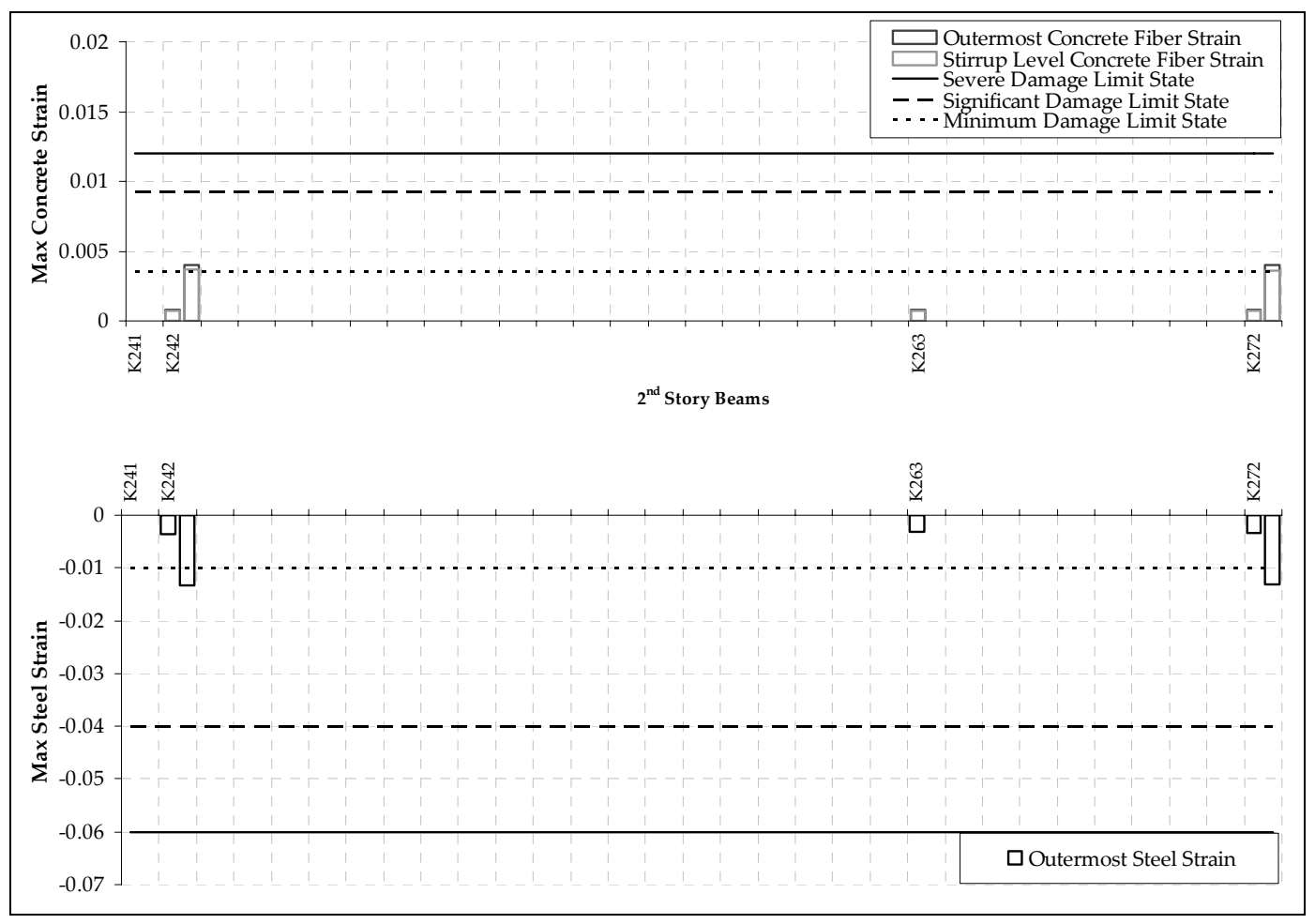

Figure 5.27 Damage levels of the beams in the $\mathrm{Y}$ direction loading (continued)

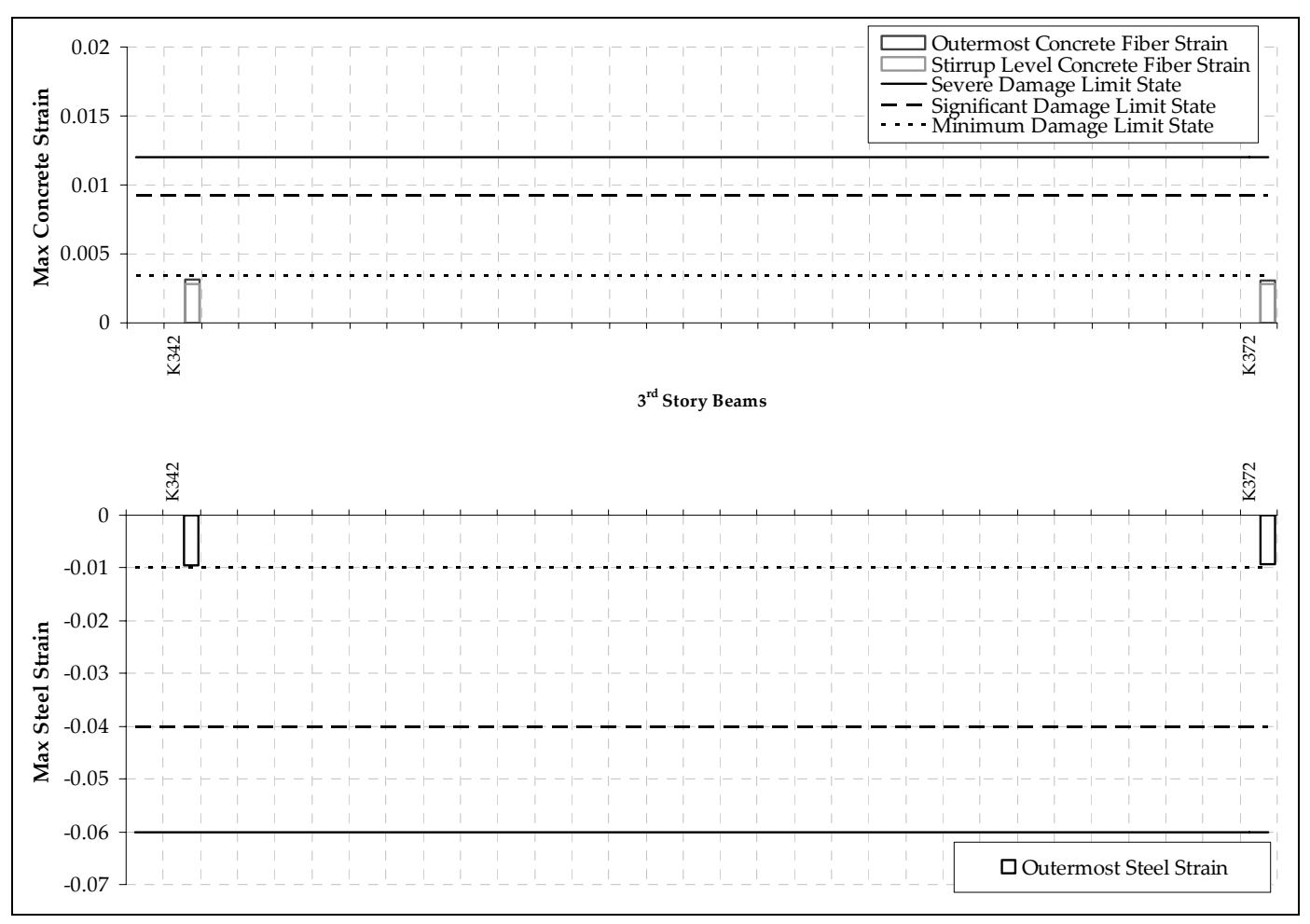

Figure 5.27 Damage levels of the beams in the $Y$ direction loading (continued) 


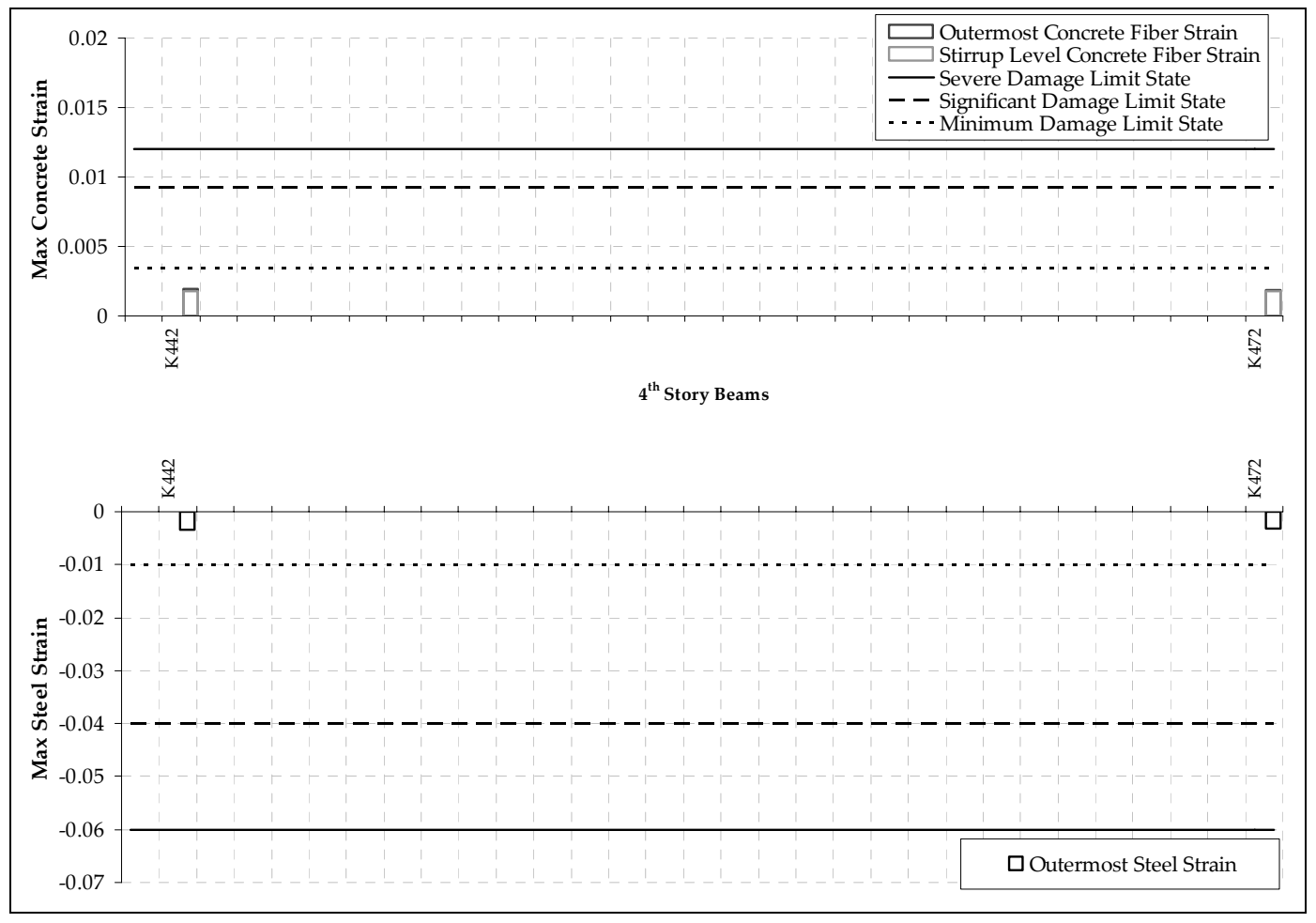

Figure 5.27 Damage levels of the beams in the $Y$ direction loading (continued)

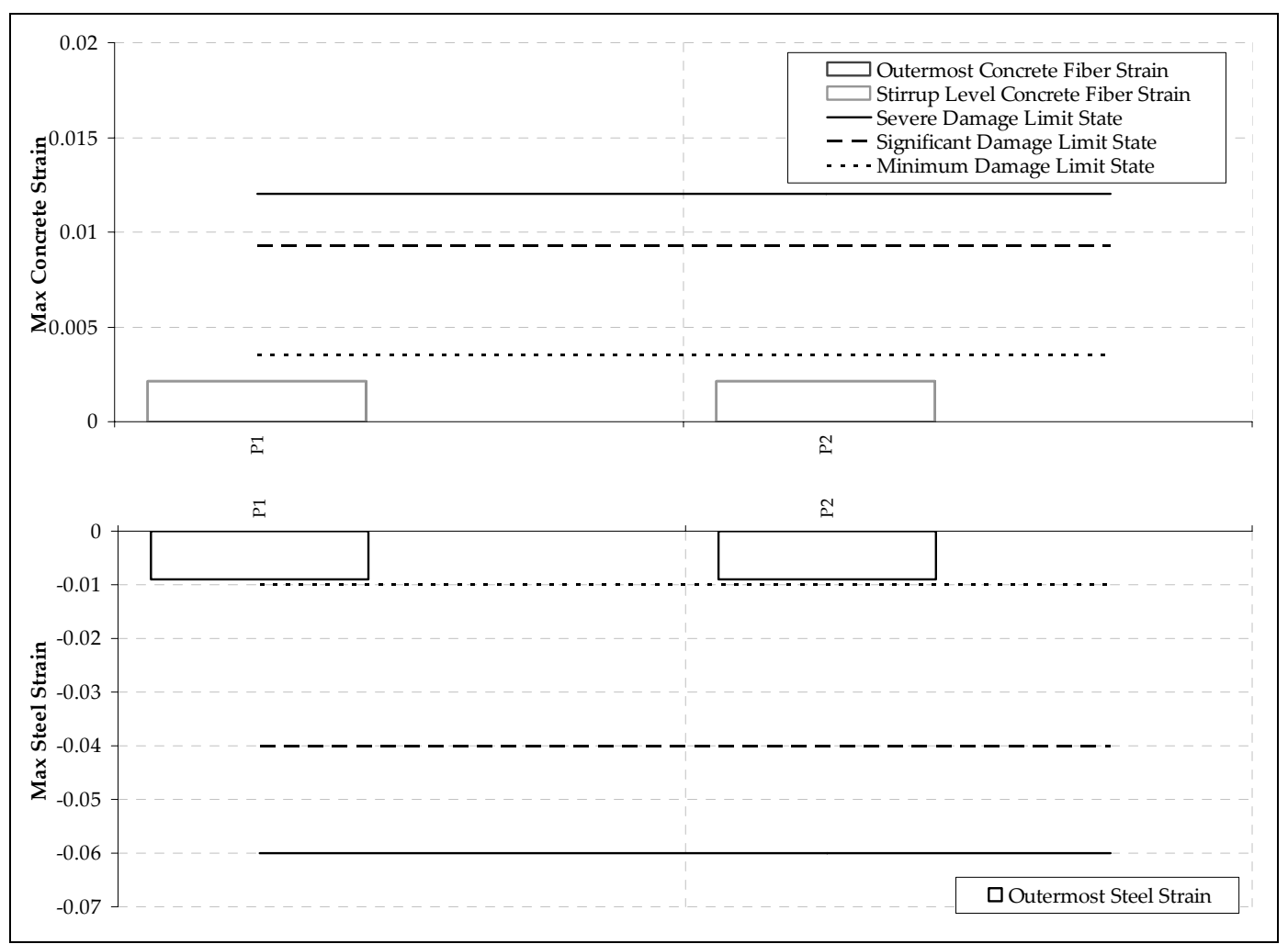

Figure 5.28 Damage levels of the shear walls in the $\mathrm{Y}$ direction loading 


\subsection{Force-Based Rehabilitation of The Building}

First story plan of the force-based retrofitted building is shown in Figure 5.29. In order to determine deficient columns in the retrofitted system linear assessment methods defined in TEC 2007 was used. Columns S13, S14, S17, S20, S21, S24, S25, S31, and S32 at the first story were not capable of meeting demand-capacity-ratio limits of significant damage level stated in TEC 2007. In this sense these columns were strengthened by wrapping with RC jackets having a thickness of $150 \mathrm{~mm}$. Additionally S15 and S30 were wrapped with FRP sheets in order to prevent brittle failure.

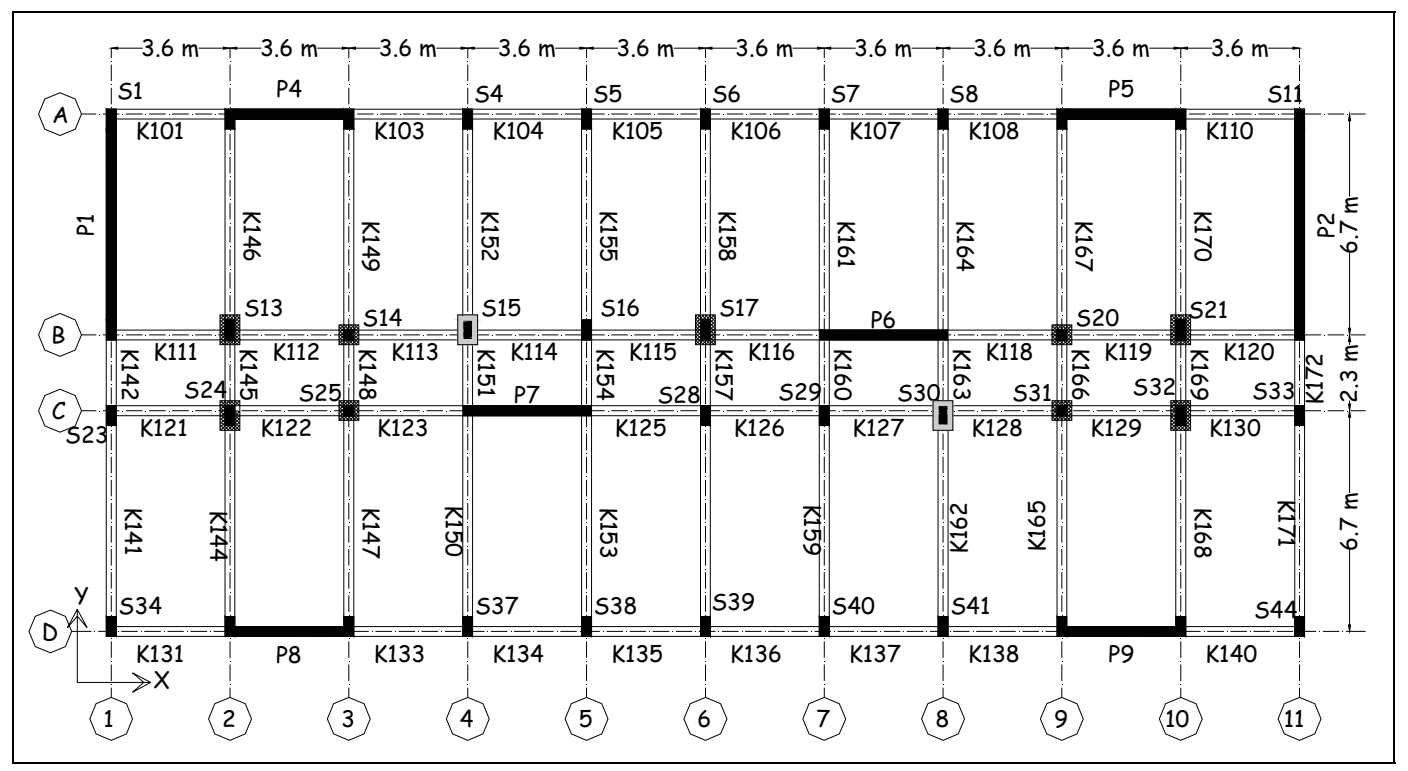

Figure 5.29 Plan view of the force-based retrofitted building

In the design of new shear walls, design spectrum was obtained by reducing the response spectrum used for seismic performance evaluation which represents an earthquake having a return period of 2475 years by $R=4.5$. According to TEC 2007, P4-9 were classified as slender walls. Thus, along the critical height which was taken as $3.5 \mathrm{~m}$, confined ends were formed at the wall boundaries. Longitudinal reinforcement ratio needed for shear walls in the $\mathrm{X}$ direction was determined as 0.01 by following the design procedures for shear walls given in TEC 2007. On the other hand, shear walls P1 and P4 were classified as squat walls and detailed accordingly. For these shear walls, no confined ends were needed according to 
TEC 2007. Longitudinal reinforcement ratio was determined as 0.012 for P1 and P4. In case of shear design, shear demand was calculated as $1427 \mathrm{kN}$ for P4 and $4421 \mathrm{kN}$ for P1. These demands yielded transverse reinforcement ratios of 0.0025 and 0.0049 for P4 and P1 respectively. Detailing and axial force-moment capacity interaction diagrams for shear walls P4 and P1 are presented in Figures 5.31, 5.32, 5.33, and 5.34.

\subsection{Comparison of Displacement-Based and Force-Based Retrofit Solutions}

Displacement-based and force-based retrofit solutions for the dormitory building were compared. Considering the retrofitted columns in the displacement-based retrofitted case, FRP wrapping was determined as sufficient to increase shear strength and deformation capacity of square columns. On the other hand in the force-based design, in order to decrease axial force demands and increase both shear and deformation capacities, deficient columns were strengthened by RC jackets. However, nonlinear analysis results revealed that FRP wrapping is sufficient as a retrofit solution. According to linear elastic procedures columns S13, S15, S17, S21, and S30-31-32 at the first story and columns S14, S20, S25, and S31 at the first two stories were deficient. Except columns S15 and S30, deficient columns are strengthened with RC jackets having thickness of $15 \mathrm{~cm}$. In figure $5.30 \mathrm{RC}$ jacket detail of the column 1S17 is shown. In case of the displacement-based procedure, only square columns S14, S20, S25, and S31 at the first two stories were strengthened with FRP sheets due to lack of deformation capacity. Additionally, columns S13, S17, S21, S24, S28, and S32 were wrapped with FRP sheets only at the first story in order to increase their deformation capacities. For other columns deformation demands were computed as less than the deformation capacities.

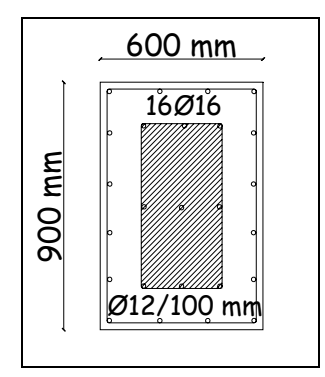

Figure 5.30 RC jacket detail of the column $1 \mathrm{~S} 17$ 
Detailing of the added shear walls in the $\mathrm{X}$ and $\mathrm{Y}$ directions according to displacementbased and force-based designs are compared in Figures 5.31, 5.32, 5.33, and 5.34 along with the corresponding P-M interaction diagrams and P-M demands for the force-based design.

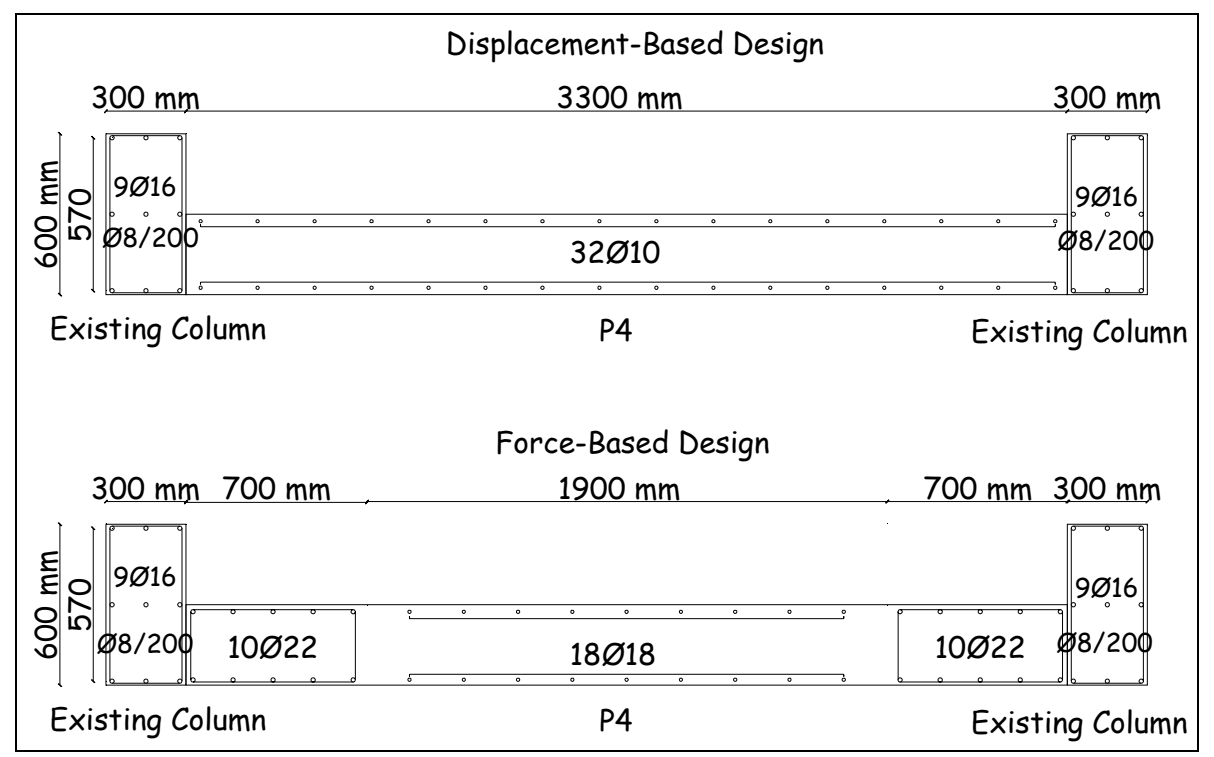

Figure 5.31 Detailing of the shear wall P4 according to the displacement-based and forcebased designs

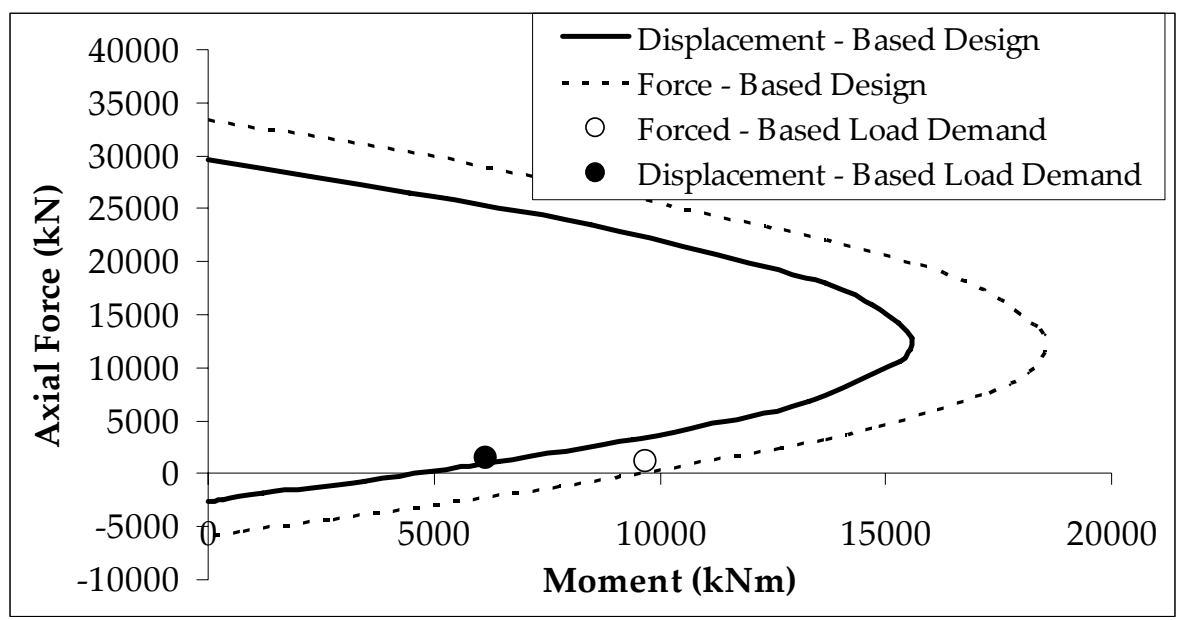

Figure 5.32 P-M Interaction diagrams of shear wall P4 according to displacement-based and forced-based designs

In force-based design, confined end regions were formed at the boundaries of slender shear walls by following TEC 2007. In displacement-based design, deformation demands were 
satisfied with the given detailing in Figures 5.31 and 5.32 without any confined ends. It can be concluded that, displacement-based design gives more economic solutions considering the longitudinal reinforcement used in the shear walls..

\begin{tabular}{|c|c|c|c|}
\hline \multicolumn{4}{|c|}{ Displacement-Based Design } \\
\hline \multirow{3}{*}{$\begin{array}{l}\text { 产 } \\
\text { Oे }\end{array}$} & $\begin{array}{c}600 \mathrm{~mm} \\
570\end{array}$ & \multirow[t]{2}{*}{$5800 \mathrm{~mm}$} & $\begin{array}{c}600 \mathrm{~mm} \\
570 \\
\end{array}$ \\
\hline & $\begin{array}{r}9816 \\
08 / 200 \\
\end{array}$ & & $\begin{array}{r}9 \varnothing 16 \\
\varnothing 8 / 200 \\
\end{array}$ \\
\hline & Existing Column & P1 & \multirow[t]{2}{*}{ Existing Column } \\
\hline \multicolumn{3}{|c|}{ Force-Based Design } & \\
\hline \multicolumn{2}{|r|}{$\begin{array}{l}600 \mathrm{~mm} \\
570\end{array}$} & $5800 \mathrm{~mm}$ & $\begin{array}{c}600 \mathrm{~mm} \\
570 \\
\end{array}$ \\
\hline $\begin{array}{l}\text { E } \\
\text { \& } \\
\text { O }\end{array}$ & $\begin{array}{c}9616 \\
\varnothing 8 / 200\end{array}$ & $56 \varnothing 22$ & 9016 \\
\hline \multicolumn{2}{|c|}{ Existing Column } & P1 & Existing Column \\
\hline
\end{tabular}

Figure 5.33 Detailing of the shear wall TP05 according to displacement-based and forcebased designs

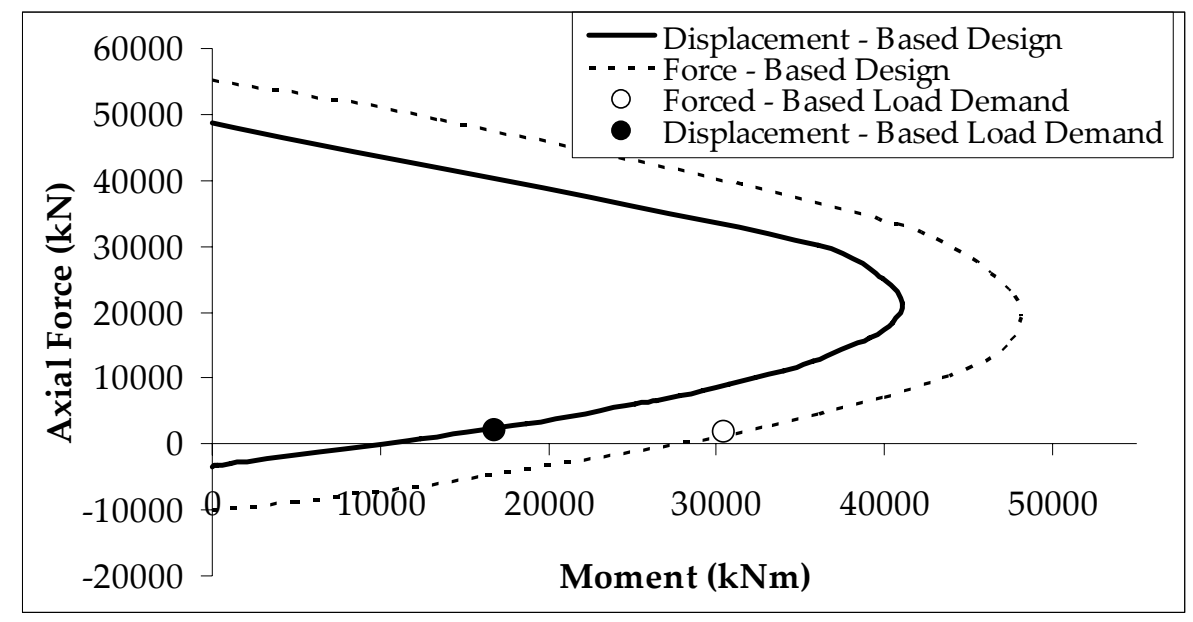

Figure 5.34 P-M Interaction diagrams of the shear wall P1 according to displacement-based and forced-based designs

In order to compare retrofit solutions in system level, nonlinear analysis was conducted for both retrofit cases of the school building. Capacity curves in the $X$ and $Y$ directions are shown in Figure 5.35 for both retrofit cases. It is apparent in the Figure 5.34 that force-based retrofit design offers more strength. However, roof displacement demands of both cases do not differ much. Target roof displacement demands of the force-based retrofitted building 
are $0.079 \mathrm{~m}$ in $\mathrm{X}$ direction and $0.057 \mathrm{~m}$ in $\mathrm{Y}$ direction for an earthquake having a return period of 2475 years. On the other hand, target roof displacement demands of the displacement-based retrofitted building were calculated as $0.090 \mathrm{~m}$ in the $\mathrm{X}$ direction and $0.065 \mathrm{~m}$ in $\mathrm{Y}$ the direction under the same design earthquake.

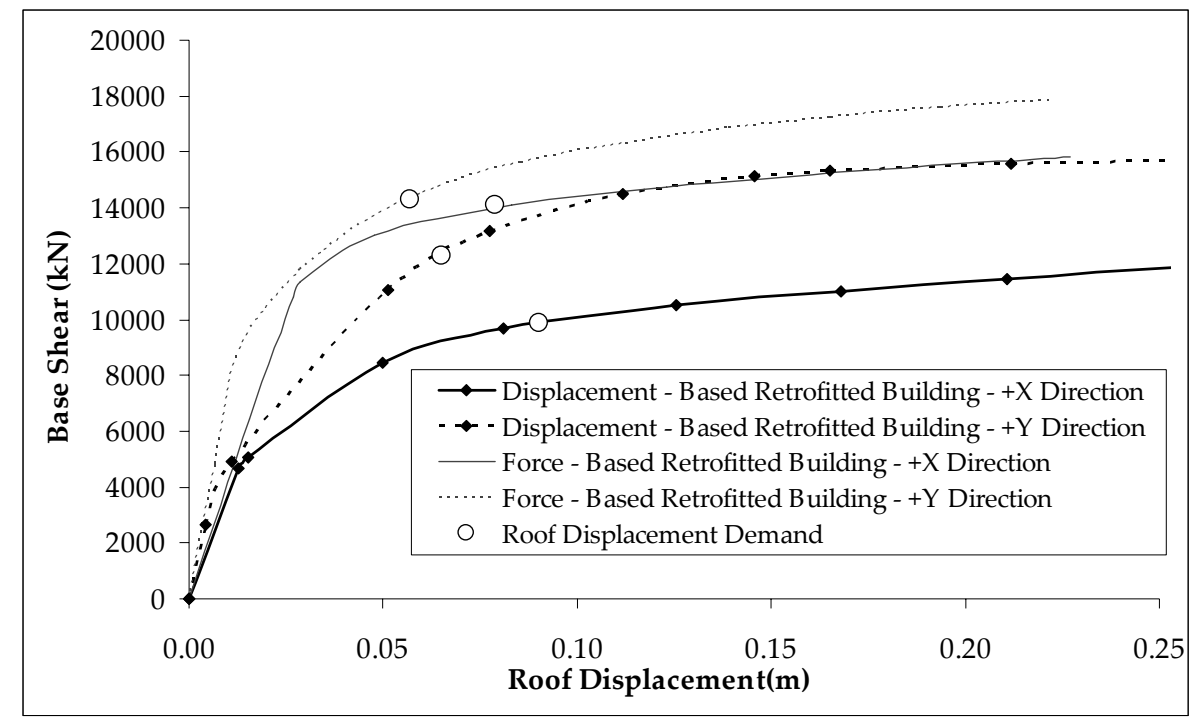

Figure 5.35 Capacity curves of the retrofitted building according to displacement-based and force-based approaches 


\section{CHAPTER 6}

\section{DISCUSSION OF RESULTS AND CONCLUSIONS}

A displacement-based retrofit design methodology is proposed in this study for seismic rehabilitation of medium rise reinforced concrete buildings. Throughout this study implementation and validity of the procedure are investigated and results of several comparative studies are presented. Results obtained from the examples and case studies are evaluated in this chapter.

\subsection{Discussion of Results}

\subsubsection{Uniform Drift Analysis vs. Pushover Analysis}

The proposed methodology relies on estimation of inelastic chord rotation demands by a linear elastic analysis in which a pre-assumed deformation pattern is imposed to the building for a target seismic performance level. This deformation pattern is chosen as a uniform drift profile along the building height since drift profiles of non-ductile medium height RC frame buildings retrofitted with new shear walls are approximately uniform. A uniform drift distribution calculated for a target roof displacement is imposed to the building elastically together with gravity loading. Then chord rotation demands are calculated at member ends. Figure 6.1 compares chord rotation demands calculated from the uniform drift and pushover analyses for lower ends of the first story columns at the retrofitted building. It can be concluded by following Figure 6.1 that uniform drift 
assumption is successful in estimating the inelastic chord rotation demand at basement level.

In the case of shear wall design, the objective is to satisfy the calculated rotation demand at the basement at a given performance level. A significant observation is that confined boundaries are not necessary in most cases in order to satisfy the deformation demands. Moreover existing columns are taken into account as boundary elements for both practical and analytical points of view.

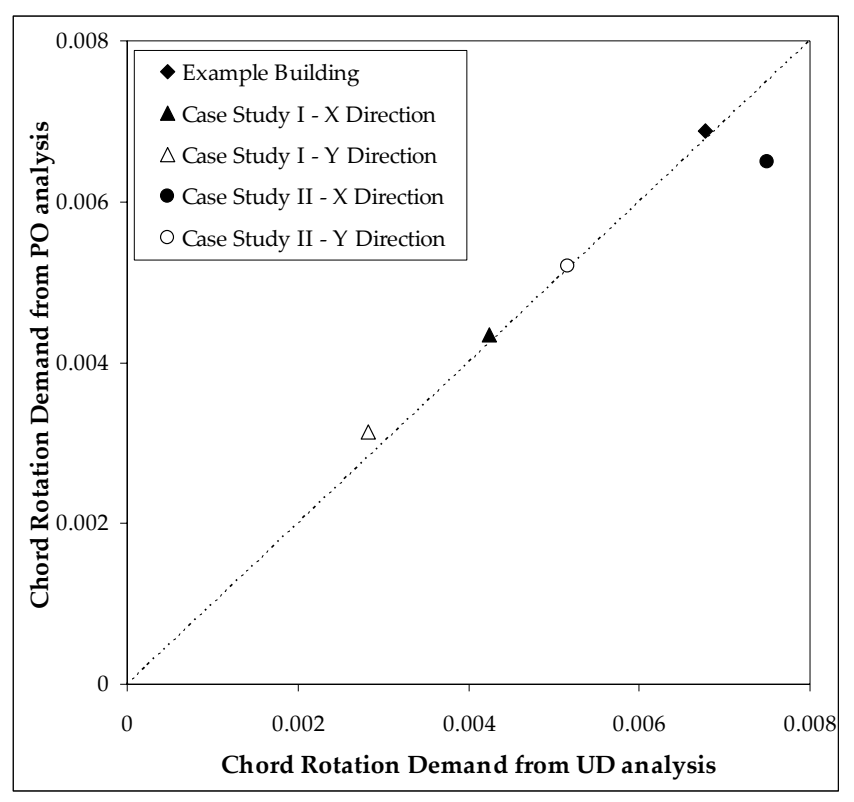

Figure 6.1 Chord rotation demands at the shear wall bases calculated from uniform drift and pushover analyses

Thus they are included in calculations by forming a composite wall section of new wall between the existing boundary columns. Initial stresses due to gravity loading on existing columns are taken into account as well. Limit states are calculated in terms of strain value at the onset of bar buckling.

Additionally, existing columns in the retrofitted systems are examined by comparing chord rotation demands calculated from uniform drift analysis with chord rotation capacities at limit states for particular damage levels. Interventions like FRP wrapping or RC jacketing 
are applied to columns having lower capacities than demands in order to increase their deformation capacities. Chord rotation demands calculated from the uniform drift and pushover analyses were compared at the performance points. It is concluded from the results for the case study buildings and example building that uniform drift analysis is successful in capturing the inelastic chord rotation demands calculated from pushover analysis. However, as nonlinearity increases along the building, uniform drift assumption loses proximity to estimate deformation demands. Variation between chord rotation demands calculated from the uniform drift and pushover analyses is more apparent for upper stories. Additionally uniform drift analysis underestimates chord rotation demands for columns in tension at the performance point. These columns are adjacent columns to shear walls in most of the cases. Although story drifts are well estimated by the uniform drift analysis, variations occur in joint rotations resulting different chord rotation demands. Nevertheless it is observed that true chord rotation demands calculated from pushover analysis are less than the calculated capacities at significant damage level for most of such columns. Ignorance of variation in axial load levels of the columns due to earthquake loading can be stated as another short coming. For chord rotation capacity calculations, axial loads due to gravity loading are taken into account. However, in the case of earthquake loading axial load levels of the columns can change. This situation may be critical for the exterior columns which can be loaded excessively in compression or tension.

\subsubsection{Displacement-Based Retrofit Solutions vs. Force-Based Retrofit Solutions}

Another comparative study on the alternative solutions of retrofit design methodologies is presented for the case study and example buildings. Force-based retrofit design basically employs linear elastic methods and reduced elastic forces calculated for particular performance levels. However, nonlinear assessment results revealed that more economical and efficient retrofit design is achievable in case of a displacement-based approach. Difference between the retrofit design solutions in terms of economy is mainly caused by the methodology employed in design. In forced-based procedure, capacity design is conducted and reduced elastic forces are employed causing need of more load carrying capacity. 
In order to evaluate differences between retrofit solutions, force-based and displacementbased retrofitted buildings are compared in both member and system levels. In member level, longitudinal and transverse reinforcement ratios of wall sections including existing columns are compared in Table 6.1 for case study and example buildings.

Obviously using different amount of reinforcement causes different member capacities and lateral load carrying capacities of entire systems. Following the comparison of capacity curves presented throughout this study, moment capacities of new shear walls directly affect the lateral load carrying capacities of the buildings. On the other hand design of footings under the new shear walls are controlled by the moment capacities of the walls. In practical design, footings under the shear walls are continued to the adjacent columns as illustrated in Figure 6.2 for the example building examined in Chapter 2.

In order to make the wall work efficiently under lateral loading, footings should have more moment capacity since they should stay elastic when yielding occurs at the wall base. Thus in case of footing design, capacity design is employed and sufficient moment capacity is supplied to the footing. As moment capacity of the added shear wall increases, design moment capacity of the footing increases as well. Table 6.2 compares moment capacities of shear walls at the performance points designed by employing displacement and forcebased approaches.

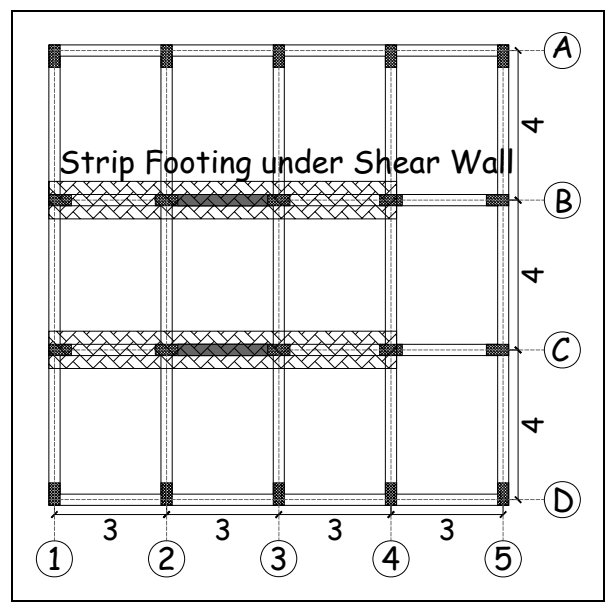

Figure 6.2 Footing under the new shear walls in plan 
Table 6.1 Comparison of reinforcement ratios according to displacement and force-based designs

\begin{tabular}{|c|c|c|c|c|}
\hline \multirow{2}{*}{ Wall } & \multicolumn{4}{|c|}{ Example Building } \\
\cline { 2 - 5 } & \multicolumn{2}{|c|}{ Displacement-Based } & \multicolumn{2}{c|}{ Force-Based } \\
\cline { 2 - 5 } P1 & Longitudinal & Transverse & Longitudinal & Transverse \\
\hline \hline \multirow{3}{*}{ Wall } & 0.0047 & 0.0025 & 0.0111 & 0.0045 \\
\cline { 2 - 5 } & \multicolumn{4}{|c|}{ Case Study I } \\
\cline { 2 - 5 } & Displacement-Based & \multicolumn{2}{c|}{ Force-Based } \\
\hline TP01 & 0.0065 & 0.0025 & 0.0118 & 0.0072 \\
\hline TP02 & 0.0065 & 0.0025 & 0.0118 & 0.0072 \\
\hline TP03 & 0.0065 & 0.0025 & 0.0118 & 0.0072 \\
\hline TP04 & 0.0065 & 0.0025 & 0.0118 & 0.0072 \\
\hline TP05 & 0.0048 & 0.0025 & 0.0083 & 0.0078 \\
\hline TP08 & 0.0048 & 0.0025 & 0.0083 & 0.0078 \\
\hline \hline & \multicolumn{4}{|c|}{ Case Study II } \\
\cline { 2 - 5 } Wall & Displacement-Based & Force-Based \\
\cline { 2 - 5 } & Longitudinal & Transverse & Longitudinal & Transverse \\
\hline P1 & 0.0038 & 0.0030 & 0.0119 & 0.0049 \\
\hline P2 & 0.0038 & 0.0030 & 0.0119 & 0.0049 \\
\hline P4 & 0.0052 & 0.0030 & 0.0135 & 0.0025 \\
\hline P5 & 0.0052 & 0.0030 & 0.0135 & 0.0025 \\
\hline P6 & 0.0052 & 0.0030 & 0.0135 & 0.0025 \\
\hline P7 & 0.0052 & 0.0030 & 0.0135 & 0.0025 \\
\hline P8 & 0.0052 & 0.0030 & 0.0135 & 0.0025 \\
\hline P9 & 0.0052 & 0.0030 & 0.0135 & 0.0025 \\
\hline
\end{tabular}

In addition to the observations made by comparing displacement and force-based retrofit design approaches, it can be added that since deformation demands are employed as design parameters, the relation between target and obtained performance is more transparent in displacement-based retrofit design. Utilizing deformation demands and deformation capacities at particular limit states gives advantage of examining behavior and performance of members individually in a performance-based understanding. 
Table 6.2 Comparison of moment capacities of the walls designed according to displacement-based and force-based approaches

\begin{tabular}{|c|c|c|}
\hline \multirow{2}{*}{ Wall } & \multicolumn{2}{|c|}{ Example Building } \\
\cline { 2 - 3 } & Displacement-Based & Force-Based \\
\cline { 2 - 3 } P1 & Moment Capacity (kNm) & Moment Capacity (kNm) \\
\hline \hline \multirow{3}{*}{ Wall } & \multicolumn{2}{|c|}{ Case Study I } \\
\cline { 2 - 3 } & Displacement-Based & Force-Based \\
\cline { 2 - 3 } & Moment Capacity (kNm) & Moment Capacity (kNm) \\
\hline TP01 & 6401 & 11085 \\
\hline TP02 & 6401 & 11085 \\
\hline TP03 & 6401 & 11085 \\
\hline TP04 & 6401 & 11085 \\
\hline TP05 & 15501 & 24860 \\
\hline TP08 & 15501 & 24860 \\
\hline \hline \multirow{3}{*}{ Wall } & \multicolumn{2}{|c|}{ Case Study II } \\
\cline { 2 - 3 } & Displacement-Based & Force-Based \\
\cline { 2 - 3 } & Moment Capacity (kNm) & Moment Capacity (kNm) \\
\hline P1 & 20332 & 31927 \\
\hline P2 & 20332 & 31927 \\
\hline P4 & 8587 & 9457 \\
\hline P5 & 8587 & 9457 \\
\hline P6 & 8587 & 9457 \\
\hline P7 & 8587 & 9457 \\
\hline P8 & 8587 & 9457 \\
\hline P9 & 8587 & 9457 \\
\hline
\end{tabular}

\subsubsection{Modeling of the Shear Walls as Fixed-Base and Flexible-Base}

For a better estimation of inelastic chord rotation demands, a more realistic approach in which the effect of soil and footing flexibility under the shear wall is modeled with a rotational spring was analyzed as well. Retrofitted case of the example building examined in Chapter 2 was solved in this sense. Paragraph 4.4.2.1.2 of FEMA 356 was followed in order to calculate spring stiffness holding properties of stiff soil and footing stiffness 
parameters of the building. Target roof displacement demand of the retrofitted building was calculated as $0.126 \mathrm{~m}$ corresponding to an effective fundamental period of 0.56 seconds. Uniform drift profile compatible with this demand was calculated and imposed to the building. Besides, pushover analysis was conducted for the computed target roof displacement demand. In Figure 6.3 chord rotation demands calculated from the uniform and the pushover analyses are compared for the retrofitted building which was modeled with rotational spring.

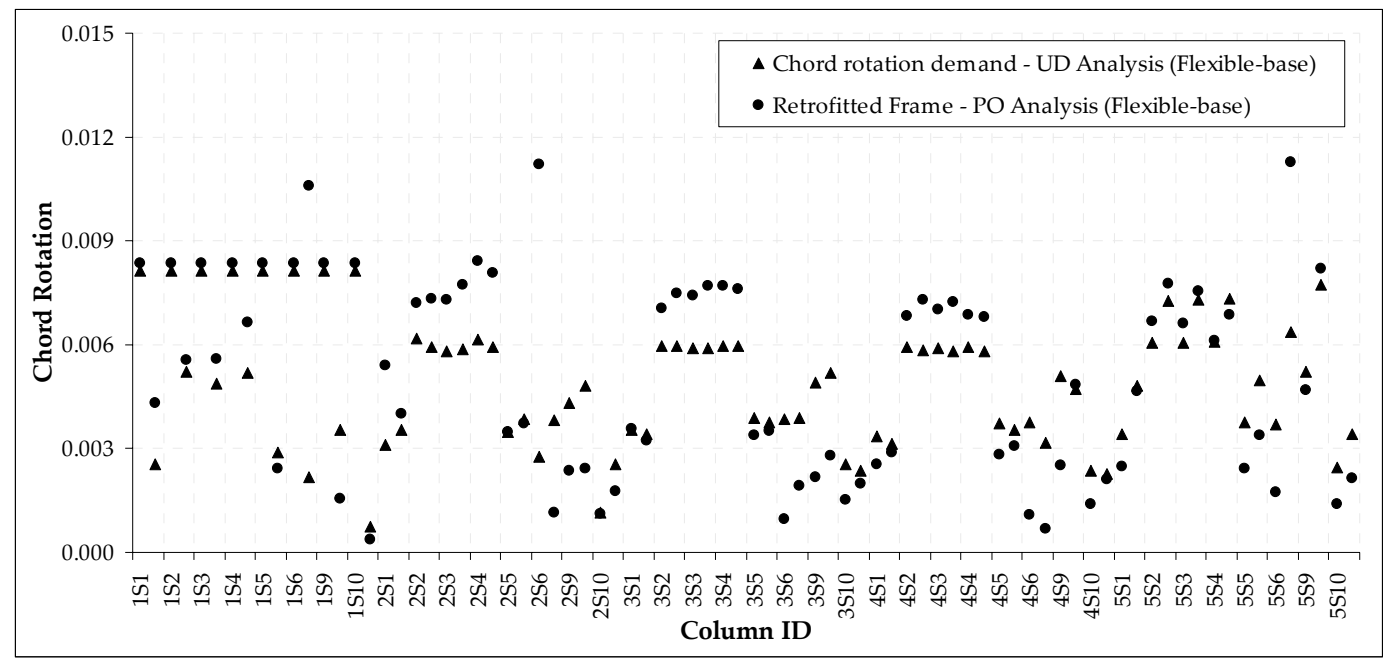

Figure 6.3 Chord rotation demands calculated from the uniform drift and the pushover analyses for the retrofitted case of the example building with spring

In Figure 6.4 chord rotation demands calculated from models with and without rotational springs together with chord rotation capacities calculated for significant damage level are given. From Figures 6.3 and 6.4, the model with spring gives greater chord rotation demands than the model having no spring. This is basically due to increased drift ratio and target displacement demands. On the other hand level of proximity between the uniform drift and pushover analyses is not affected significantly by including the rotational springs. Moreover weakness in estimation of chord rotation demands of the columns in tension, namely $1 \mathrm{~S} 6$ and 2S6, is not improved in the model with springs. 


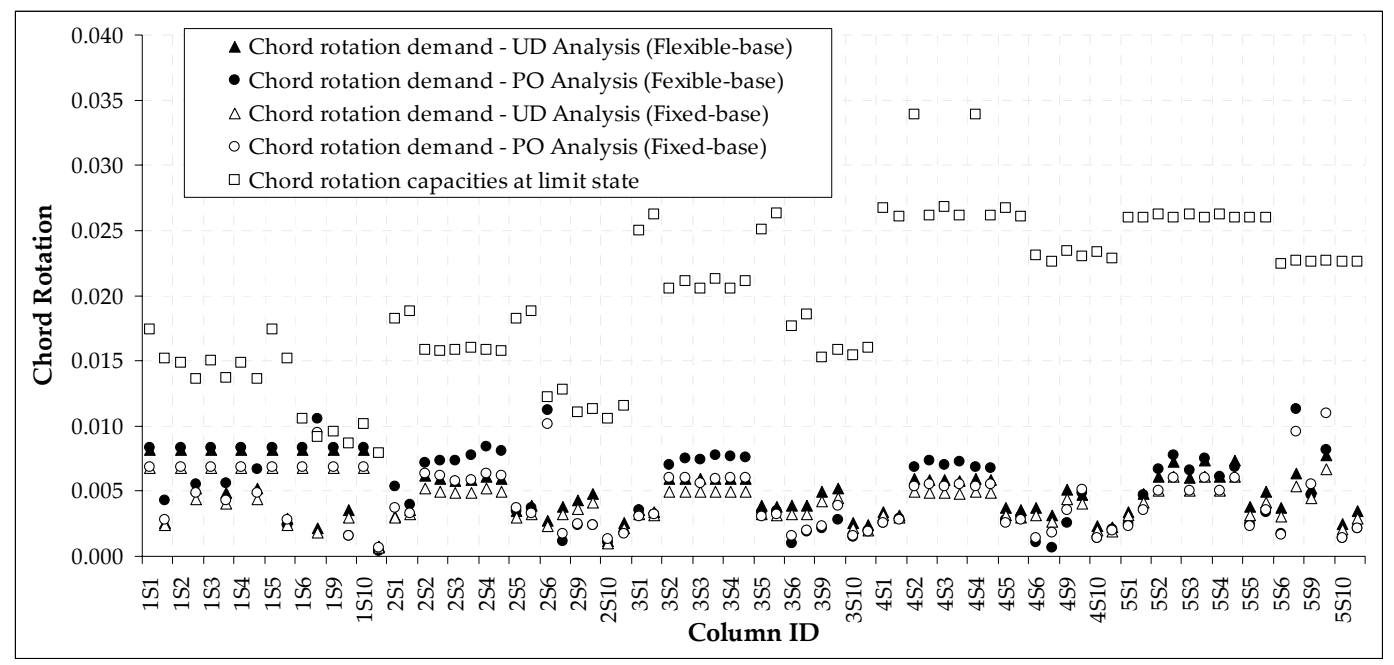

Figure 6.4 Chord rotation demands and capacities calculated from the uniform drift and the pushover analyses for the retrofitted case of the example building with spring

\subsection{Conclusions}

A displacement-based seismic retrofit design methodology is proposed in this study for medium height concrete buildings. The main feature of retrofit design is adding new shear walls to the deficient system. Although this is a well known retrofitting method, displacement-based approach brings new insight in developing a sound design solution. The basic differences obtained by following a displacement-based approach as compared to a force-based approach are the following.

1. Added shear walls reduce deformation demands on the deficient members of the existing system significantly. The existing flexural deformation capacities of critical members mostly become sufficient in meeting the reduced demands, although their flexural strengths are insufficient to carry the internal forces calculated from force-based evaluation of the retrofitted system.

2. Those members which remain insufficient in the retrofitted system in terms of flexural deformation capacities require intervention only for increasing their deformation capacities. This is usually achieved by external confinement, preferably by FRP wrapping, which is practical. 
3. Strength capacity increase in the retrofitted system is only required for members and components failing in shear.

4. Added shear walls in a medium height concrete building are subjected to quite low deformation demands. Hence, they may not require special seismic detailing for enhanced ductility. Minimum web reinforcement is usually sufficient for the new shear walls, without a need for the confined end regions.

5. Accordingly, lower capacity design forces are obtained for the foundations of the added walls compared to the force-based capacity design.

6. The relationship between the target performance level and the obtained performance is more transparent in displacement-based retrofitting. 


\section{REFERENCES}

American Society of Civil Engineers (2000). Prestandard and Commentary for the Seismic Rehabilitation of Buildings, Report No. FEMA-356, Washington, D.C.

Applied Technology Council, ATC 40 1996, " Seismic Evaluation and Retrofit of Concrete Buildings", Volume 1-2 Redwood City, California.

Berry, M., Eberhard, M., "Performance Models for Flexural Damage in Reinforced Concrete Columns", Pacific Earthquake Engineering Research Center, PEER 2003/18.

Calvi G.M. and Sullivan. T.J. Editors (2009) "A model code for the Displacement-Based Seismic Design of Structures, DBD09 - Draft Issued for Public Enquiry ", IUSS Press, 80 pages.

Computers and Structures Inc. (CSI), 1998, SAP2000 Three Dimensional Static and Dynamic Finite Element Analysis and Design of Structures V7.40N, Berkeley, California.

European Committee for Standardization (2005) "Eurocode 8: Design of structures for earthquake resistance Part 3: Strengthening and repair of buildings - Final" Eurocode 8, Brussels.

Federal Emergency Management Agency (FEMA), 2000, “Prestandard and Commentary for the Seismic Rehabilitation of Buildings, FEMA 356.

Federal Emergency Management Agency (FEMA), 2005, “Improvement of Nonlinear Static Seismic Analysis Procedures, FEMA 440.

Kongoli, X., Minami, T., Sakai, Y., "Effects of Structural Walls on The Elastic-Plastic Earthquake Responses of Frame-Wall Buildings", Earthquake Engineering and Structural Dynamics, 28, No 4, 1999, Pages 479-500. 
Kowalsky, M. J., "RC Structural Walls Designed According to UBC and DisplacementBased Methods", Journal of Structural Engineering, Volume 127, No. 5, May, 2001.

Ministry of Public Works and Settlement (2007). Turkish Earthquake Code: Specifications for Buildings to be Constructed in Earthquake Zones, Ankara, Turkey.

Moehle, J. P., "Displacement-Based Design of RC Structures Subjected to Earthquakes", Earthquake Spectra, Vol. 8, No. 3, 1992, Pages 403-428.

Moyer, M. J., Kowalsky, M. J., "Influence of Tension Strain on Buckling of Reinforcement in Concrete Columns", ACI Structural Journal, January-February 2003, Pages 75-85.

Panagiotakos, T. B., Fardis, M. N., “Deformation-Controlled Earthquake-Resistant Design of RC Buildings", Earthquake Engineering and Structural Dynamics, 28, No 4, 1999, Pages 501-528.

Panagiotakos, T. B., Fardis, M. N., "Estimation of Inelastic Deformation Demands In Multistorey RC Frame Buildings", Journal of Earthquake Engineering, Vol. 3, No 4, 1999, Pages 495-518.

Paulay, T., "Seismic response of structural walls: recent developments", Canada Journal of Civil Engineering, Volume 28, 2001, Pages 922-937.

Priestley, M. J. N., “Displacement-Based Seismic Assessment of Reinforced Concrete Buildings", Journal of Earthquake Engineering, Vol. 1, No. 1, 1997, Pages 157-192.

Priestley, M.J.N., Calvi, G.M. and Kowalsky, M.J. (2007). Displacement-Based Seismic Design of Structures, IUSS Press, Pavia, Italy.

Sucuoğlu,H., “2007 Deprem Yönetmeliği Performans Esaslı Hesap Yöntemlerinin Karşılıklı Değerlendirilmesi", İnşaat Mühendileri Odası (IMO) Türkiye Mühendislik Haberleri, Sayı: 444-445 - 2006/4-5.

Şengöz Ali, "Quantitative Evaluation of Assessment Methods in The 2007 Turkish Earthquake Code", MSc. Thesis, Department of Civil Engineering, Middle East Technical University, Ankara, 2007. 
Thermou,G.E., Pantazopoulou, S. J., Elnashai, A. S., " Design Methodology for Seismic Upgrading of Substandard Reinforced Concrete Structures", Journal of Earthquake Engineering, Volume 11, Issue 4 July 2007 , pages 582 - 606.

Thomsen, J. H., Wallace, J. W., “Displacement-Based Design of Slender Reinforced Concrete Structural Walls - Experimental Verification", Journal of Structural Engineering, Vol. 130, No. 4, 2004, 618-630.

Tjhin, T. N., Ascheim, M. A., Wallace, J. W., "Yield displacement-based seismic design of RC wall buildings", Engineering Structures, 29, 2007, 2946-2959. 